University of Louisville

ThinkIR: The University of Louisville's Institutional Repository

Electronic Theses and Dissertations

$12-2011$

\title{
FEM modeling of a concrete arch bridge.
}

Christina Allgeier Perez

University of Louisville

Follow this and additional works at: https://ir.library.louisville.edu/etd

\section{Recommended Citation}

Perez, Christina Allgeier, "FEM modeling of a concrete arch bridge." (2011). Electronic Theses and Dissertations. Paper 1114.

https://doi.org/10.18297/etd/1114

This Master's Thesis is brought to you for free and open access by ThinkIR: The University of Louisville's Institutional Repository. It has been accepted for inclusion in Electronic Theses and Dissertations by an authorized administrator of ThinkIR: The University of Louisville's Institutional Repository. This title appears here courtesy of the author, who has retained all other copyrights. For more information, please contact thinkir@louisville.edu. 


\title{
FEM MODELING OF A CONCRETE ARCH BRIDGE
}

\author{
By
}

Christina Allgeier Perez

B.S., University of Louisville, 2010

\author{
A Thesis \\ Submitted to the Faculty of the \\ University of Louisville \\ J. B. Speed School of Engineering \\ as Partial Fulfillment of the Requirements \\ for the Professional Degree
}

MASTER OF ENGINEERING

Department of Civil and Environmental Engineering

December 2011 



\section{FEM MODELING OF A CONCRETE ARCH BRIDGE}

Submitted by:

Christina Allgeier Perez

A Thesis Approved on

(Date)

By the Following Reading and Examination Committee:

\begin{tabular}{c}
\hline Dr. J. P. Mohsen, Thesis Director \\
\hline Dr. Terence Weigel \\
\hline Dean Michael Day
\end{tabular}




\section{ACKNOWLEDGEMENTS}

I'd like to thank Dr. J.P. Mohsen for introducing me to this project and guiding me through every step of the thesis process.

I'd also like to thank Dr. John Kielkopf and Jeffery Hay for accepting me into their project and being patient with me as I learned to use ANSYS and produce the results they needed to support and continue their research.

Thanks to Dr. Terence Weigel and Dean Michael Day at the University of Louisville and Dr. Tom Baber and Dr. Kirk Martini at the University of Virginia for taking the time to answer my questions and offer all the advice and assistance I needed for this project.

A special thanks to the Cowan family for choosing me as the Cowan Fellowship recipient and providing me with the financial aid necessary to make this thesis a possibility.

Finally, a heartfelt thank you to my husband, Alan, for all the reassurance and support I needed to continue after every setback or complication. I wouldn't have made it this far without him at my side. 


\section{ABSTRACT}

A Physics doctoral project seeks to reduce the uncertainty of inaccurate visual bridge inspections by producing a remote sensor program to determine and monitor the changes in health of a specified bridge. The Eastern Parkway Bridge was determined as the first bridge to test. As part of this project, a computer-aided analysis of the studied bridge was created using the simulation program ANSYS to assist in documenting the areas requiring the most attention. The model also offered supporting evidence to back the frequencies registered by the optical sensors to ensure proper functioning of the device. Furthermore, the model provided a baseline of the health of the bridge to be used to

determine if and where investigation is required after the bridge has suffered a large impact or deterioration. 
TABLE OF CONTENTS

\begin{tabular}{|c|c|c|}
\hline & & lage \\
\hline ROVAL PAGE & ......... & \\
\hline SE & SEMENTS.. & \\
\hline 1 & & \\
\hline VCLATUR & & \\
\hline OF TABLES & ....... & vii \\
\hline DF FIGURE & & \\
\hline IN & INTRODUCTION & \\
\hline II. & ITERATURE REVIEW. & \\
\hline III. & DEVELOPING THE COMPUTER MODEL & 6 \\
\hline IV. & CALCULATIONS & 15 \\
\hline & s to Calculations & 18 \\
\hline V. & RESULTS AND DISCUSSION ........ & 22 \\
\hline VI. & CONCLU & 25 \\
\hline & a. & 26 \\
\hline VII. & RECOMMENDATIONS AND FUTURE WORK ... & 30 \\
\hline BLIOGRAPHY. & & \\
\hline PPENDIX I. & PICTURES OF EASTERN PARKWAY AND CONSTRUCTION . & 33 \\
\hline APPENDIX II. & PREPARATION AND INITIAL PROPERTIES IN ANSYS ......... & 48 \\
\hline APPENDIX III. & SCREEN CAPTURES OF MODELING PROCESS .. & 2 \\
\hline APPENDIX IV. & STEEL REINFORCEMENT CALCULATIONS....... & 62 \\
\hline APPENDIX V. & SCREEN CAPTURES OF LOAD CONFIGURATIONS ............. & 63 \\
\hline APPENDIX VI. & SCREEN CAPTURES OF DEFORMED SHAPES........................ & 76 \\
\hline APPENDIX VII. & PONENTS OF DISPLACEMEN & \\
\hline APPENDIX VIII. & [. SCREEN CAPTURES OF Y-COMPONENTS OF STRESSES..... & 102 \\
\hline APPENDIX IX. & SCREEN CAPTURES OF FIRST PRINCIPAL STRESSES . & 12 \\
\hline APPENDIX $\mathrm{X}$. & SCREEN CAPTURES OF VON MISES STRESSES ................ & 154 \\
\hline APPENDIX XI. & SCREEN CAPTURES OF Y-COMPONENTS OF STRAIN ......... & 180 \\
\hline APPENDIX XII. & SCREEN CAPTURES OF FIRST PRINCIPAL STRAINS ........... & 20 \\
\hline APPENDIX XIII. & I. OTHER MODAL ANALYSIS METHODS... & 23 \\
\hline APPENDIX XIV. & SCREEN CAPTURES OF MODAL ANALYSIS & \\
\hline & & \\
\hline
\end{tabular}




\section{NOMENCLATURE}

$$
\begin{aligned}
\mathrm{ft} & =\text { foot } \\
\mathrm{ft}^{2} & =\text { square foot } \\
\mathrm{ft}^{3} & =\text { cubic foot } \\
\mathrm{Ibf} & =\text { pound-force } \\
\mathrm{Ibm} & =\text { pound-mass } \\
\mathrm{s} & =\text { second }
\end{aligned}
$$




\section{LIST OF TABLES}

TABLE I. PROPERTIES AND CORRESPONDING UNITS USED IN ANSYS

$\underline{\text { Page }}$ CALCULATIONS .............................................................. 8

TABLE II. SUPPORT TYPE FOR EACH PIER OR ABUTMENT LOCATION....... 13

TABLE III. PERCENT CHANGE CALCULATIONS USED TO DETERMINE MESHING SIZE ......................................................... 16

TABLE IV. LOAD CONFIGURATION DETAILS ..................................... 19

TABLE V. KEY SOLUTIONS FOR EACH ITERATION AND LOAD CONFIGURATION 


\section{LIST OF FIGURES}

FIGURE 1. Representations of ANSYS SOLID65 Element

FIGURE 2. Finished ANSYS Computer Model Without Support Conditions.. 10

FIGURE 3. Steel Reinforcement Properties as Entered in ANSYS .............. 12

FIGURE 4. Support Conditions as Modeled in ANSYS ............................ 14

FIGURE 5. Finished ANSYS Model With Meshing Applied ........................ 17

FIGURE 6. First Page of Settings for Block Lanczos Modal Analysis .......... 20

FIGURE 7. Second Page of Settings for Block Lanczos Modal Analysis....... 20

FIGURE 8. West End of Eastern Parkway Bridge As Viewed From South

During Construction ........................................................ 33

FIGURE 9. West End of Eastern Parkway Bridge As Viewed From South Brook Street During Construction ......................................... 34

FIGURE 10. Eastern Parkway Bridge As Viewed From Southwest Corner During Construction ..................................................... 35

FIGURE 11. Piers One Through Four of Eastern Parkway Bridge As Viewed From Northwest Corner During Construction.......................... 37

FIGURE 12. Abutment One and Pier One of Eastern Parkway Bridge As Viewed From South Side During Construction ....................... 38

FIGURE 13. Piers One and Two of Eastern Parkway Bridge As Viewed From South Side During Construction

FIGURE 14. Piers Three Through Seven of Eastern Parkway Bridge As Viewed From North Side During Construction........................ 40

FIGURE 15. Piers Three Through End of Eastern Parkway Bridge As Viewed From West Side During Construction ................................... 41

FIGURE 16. Pier Four of Eastern Parkway Bridge As Viewed From North Side During Construction ...................................................

FIGURE 17. Accelerometer Placed Between Piers Five and Six As Viewed From South Side During Construction ....................................

FIGURE 18. Surface of Eastern Parkway Bridge As Viewed From Northwest Corner During Construction ...

FIGURE 19. Surface of Eastern Parkway Bridge As Viewed From Southwest Corner During Construction

FIGURE 20. Piers One Through Three of Eastern Parkway Bridge As Viewed From South Side After Construction.

FIGURE 21. Piers One Through Six of Eastern Parkway Bridge As Viewed From South Side After Construction......................................

FIGURE 22. Surface of Eastern Parkway Bridge As Viewed From West Side After Construction

FIGURE 23. Pier Layout With Abutment One At The West End And Abutment Two At The East End Of The Bridge 
FIGURE 24. Screen Captures of Concrete Properties Used in ANSYS

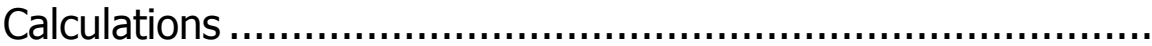

FIGURE 25. Screen Capture of Steel Properties Used in ANSYS

Calculations ................................................................ 50

FIGURE 26. Screen Capture of All Material Properties Used in ANSYS

Calculations .............................................................. 50

FIGURE 27. Screen Capture of Gravitational Acceleration Used in ANSYS

Calculations ............................................................... 51

FIGURE 28. Screen Capture of All Inertia Load Options Used in ANSYS

Calculations .................................................................. 51

FIGURE 29. First Step of Modeling Showing Half Cross-Section of Model

Without Beams ............................................................ 52

FIGURE 30. Second Step of Modeling Showing Extrusion of Half Cross-

Section From Beneath the Bridge Model .............................. 53

FIGURE 31. Third Step of Modeling Showing Addition of Beams From South Side of Bridge Model ...................................................... 54

FIGURE 32. Third Step of Modeling Showing Addition of Beams From Beneath The Bridge Model....................................................... 55

FIGURE 33. Isometric View of Third Step of Modeling Showing Half the Bridge With the Addition of Beams.................................... 56

FIGURE 34. Isometric View of Fourth Step of Modeling Showing Bridge With Full Cross-Section ........................................................ 57

FIGURE 35. Final Step of Modeling Showing Full Cross-Section of Model With Additional Supports Between Beams

FIGURE 36. Isometric View of Final Step of Modeling Showing Completed Bridge Model .............................................................. 59

FIGURE 37. Meshing Applied to Model in ANSYS ................................. 60

FIGURE 38. Support Conditions As Modeled in ANSYS ........................... 61

FIGURE 39. Load Configuration for Iteration One ................................. 63

FIGURE 40. Load Configuration for Iteration Two................................. 64

FIGURE 41. Load Configuration for Iteration Three ................................ 65

FIGURE 42. Load Configuration for Iteration Four ............................... 66

FIGURE 43. Load Configuration for Iteration Five ................................ 67

FIGURE 44. Load Configuration for Iteration Six................................ 68

FIGURE 45. Load Configuration for Iteration Seven ............................... 69

FIGURE 46. Load Configuration for Iteration Eight ................................ 70

FIGURE 47. Load Configuration for Iteration Nine ............................... 71

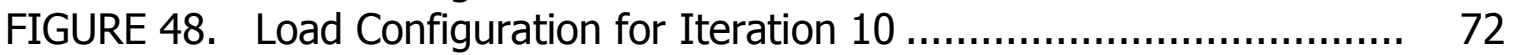

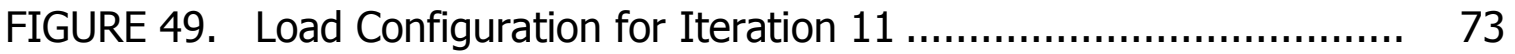

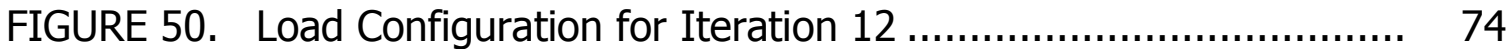

FIGURE 51. Load Configuration for Iteration 13 .................................. 75

FIGURE 52. Deformed Shape for Iteration One .................................... 76 
FIGURE 53. Deformed Shape for Iteration Two ...................................... 77

FIGURE 54. Deformed Shape for Iteration Three................................. 78

FIGURE 55. Deformed Shape for Iteration Four.................................... 79

FIGURE 56. Deformed Shape for Iteration Five .................................. 80

FIGURE 57. Deformed Shape for Iteration Six .................................. 81

FIGURE 58. Deformed Shape for Iteration Seven ................................ 82

FIGURE 59. Deformed Shape for Iteration Eight.................................... 83

FIGURE 60. Deformed Shape for Iteration Nine.................................. 84

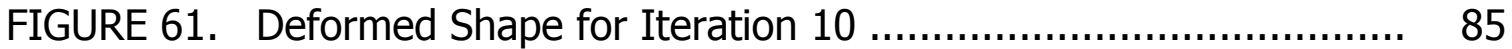

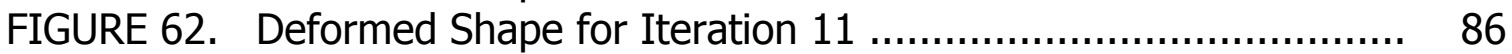

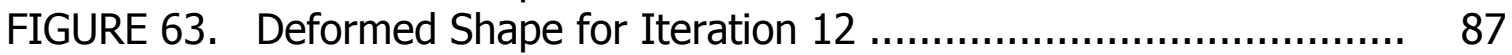

FIGURE 64. Deformed Shape for Iteration 13 ................................... 88

FIGURE 65. Y-Component of Displacement for Iteration One ................... 89

FIGURE 66. Y-Component of Displacement for Iteration Two ................... 90

FIGURE 67. Y-Component of Displacement for Iteration Three.................. 91

FIGURE 68. Y-Component of Displacement for Iteration Four ................. 92

FIGURE 69. Y-Component of Displacement for Iteration Five ................... 93

FIGURE 70. Y-Component of Displacement for Iteration Six.................... 94

FIGURE 71. Y-Component of Displacement for Iteration Seven ................. 95

FIGURE 72. Y-Component of Displacement for Iteration Eight................... 96

FIGURE 73. Y-Component of Displacement for Iteration Nine................... 97

FIGURE 74. Y-Component of Displacement for Iteration $10 \ldots \ldots \ldots \ldots \ldots \ldots \ldots . . . . . . . . . .68$

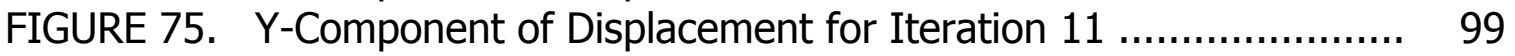

FIGURE 76. Y-Component of Displacement for Iteration $12 \ldots \ldots \ldots \ldots \ldots \ldots . . . . . . . .100$

FIGURE 77. Y-Component of Displacement for Iteration $13 \ldots \ldots \ldots \ldots \ldots \ldots \ldots . \ldots 1$

FIGURE 78. Y-Component of Stress for Iteration One ............................. 102

FIGURE 79. Y-Component of Stress for Iteration One As Viewed From

Below....................................................................... 103

FIGURE 80. Y-Component of Stress for Iteration Two............................. 104

FIGURE 81. Y-Component of Stress for Iteration Two As Viewed From

Below.......................................................................... 105

FIGURE 82. Y-Component of Stress for Iteration Three ......................... 106

FIGURE 83. Y-Component of Stress for Iteration Three As Viewed From

Below..................................................................... 107

FIGURE 84. Y-Component of Stress for Iteration Four ........................... 108

FIGURE 85. Y-Component of Stress for Iteration Four As Viewed From

Below..................................................................... 109

FIGURE 86. Y-Component of Stress for Iteration Five .............................. 110

FIGURE 87. Y-Component of Stress for Iteration Five As Viewed From

Below........................................................................ 111

FIGURE 88. Y-Component of Stress for Iteration Six............................. 112

FIGURE 89. Y-Component of Stress for Iteration Six As Viewed From Below 113 
FIGURE 90. Y-Component of Stress for Iteration Seven .......................... 114

FIGURE 91. Y-Component of Stress for Iteration Seven As Viewed From Below......................................................................... 115

FIGURE 92. Y-Component of Stress for Iteration Eight .......................... 116

FIGURE 93. Y-Component of Stress for Iteration Eight As Viewed From Below.......................................................................... 117

FIGURE 94. Y-Component of Stress for Iteration Nine ........................... 118

FIGURE 95. Y-Component of Stress for Iteration Nine As Viewed From Below...................................................................... 119

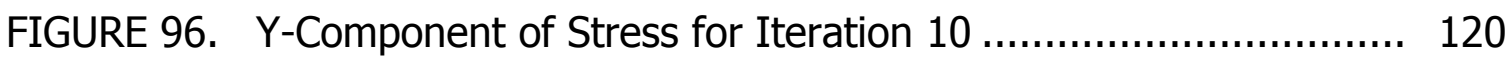

FIGURE 97. Y-Component of Stress for Iteration 10 As Viewed From Below 121

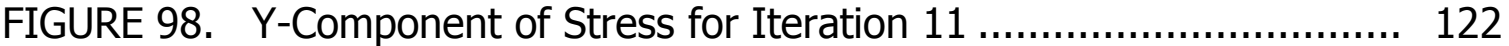

FIGURE 99. Y-Component of Stress for Iteration 11 As Viewed From Below 123

FIGURE 100. Y-Component of Stress for Iteration 12 ............................. 124

FIGURE 101. Y-Component of Stress for Iteration 12 As Viewed From Below 125

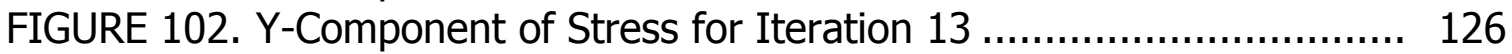

FIGURE 103. Y-Component of Stress for Iteration 13 As Viewed From Below 127

FIGURE 104. First Principal Stress for Iteration One ............................... 128

FIGURE 105. First Principal Stress for Iteration One As Viewed From Below.. 129

FIGURE 106. First Principal Stress for Iteration Two ............................... 130

FIGURE 107. First Principal Stress for Iteration Two As Viewed From Below . 131

FIGURE 108. First Principal Stress for Iteration Three............................... 132

FIGURE 109. First Principal Stress for Iteration Three As Viewed From Below 133

FIGURE 110. First Principal Stress for Iteration Four ................................ 134

FIGURE 111. First Principal Stress for Iteration Four As Viewed From Below. 135

FIGURE 112. First Principal Stress for Iteration Five ................................ 136

FIGURE 113. First Principal Stress for Iteration Five As Viewed From Below.. 137

FIGURE 114. First Principal Stress for Iteration Six................................. 138

FIGURE 115. First Principal Stress for Iteration Six As Viewed From Below ... 139

FIGURE 116. First Principal Stress for Iteration Seven .............................. 140

FIGURE 117. First Principal Stress for Iteration Seven As Viewed From Below 141

FIGURE 118. First Principal Stress for Iteration Eight............................... 142

FIGURE 119. First Principal Stress for Iteration Eight As Viewed From Below 143

FIGURE 120. First Principal Stress for Iteration Nine ............................... 144

FIGURE 121. First Principal Stress for Iteration Nine As Viewed From Below. 145

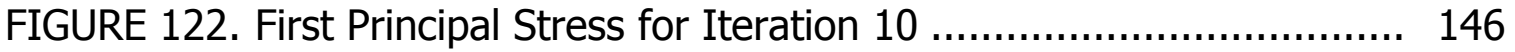

FIGURE 123. First Principal Stress for Iteration 10 As Viewed From Below .... 147

FIGURE 124. First Principal Stress for Iteration 11 ................................. 148

FIGURE 125. First Principal Stress for Iteration 11 As Viewed From Below .... 149

FIGURE 126. First Principal Stress for Iteration 12 ................................. 150

FIGURE 127. First Principal Stress for Iteration 12 As Viewed From Below .... 151

FIGURE 128. First Principal Stress for Iteration 13 ................................. 152 
FIGURE 129. First Principal Stress for Iteration 13 As Viewed From Below .... 153

FIGURE 130. Von Mises Stress for Iteration One ................................... 154

FIGURE 131. Von Mises Stress for Iteration One As Viewed From Below ...... 155

FIGURE 132. Von Mises Stress for Iteration Two.................................... 156

FIGURE 133. Von Mises Stress for Iteration Two As Viewed From Below ...... 157

FIGURE 134. Von Mises Stress for Iteration Three .................................. 158

FIGURE 135. Von Mises Stress for Iteration Three As Viewed From Below .... 159

FIGURE 136. Von Mises Stress for Iteration Four .................................... 160

FIGURE 137. Von Mises Stress for Iteration Four As Viewed From Below ...... 161

FIGURE 138. Von Mises Stress for Iteration Five .................................... 162

FIGURE 139. Von Mises Stress for Iteration Five As Viewed From Below....... 163

FIGURE 140. Von Mises Stress for Iteration Six..................................... 164

FIGURE 141. Von Mises Stress for Iteration Six As Viewed From Below ........ 165

FIGURE 142. Von Mises Stress for Iteration Seven ................................. 166

FIGURE 143. Von Mises Stress for Iteration Seven As Viewed From Below.... 167

FIGURE 144. Von Mises Stress for Iteration Eight.................................... 168

FIGURE 145. Von Mises Stress for Iteration Eight As Viewed From Below ..... 169

FIGURE 146. Von Mises Stress for Iteration Nine .................................... 170

FIGURE 147. Von Mises Stress for Iteration Nine As Viewed From Below...... 171

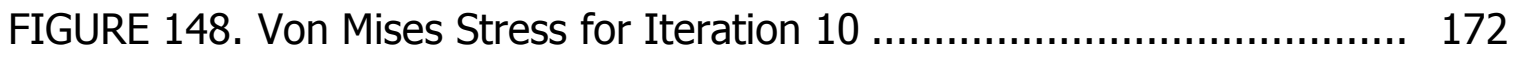

FIGURE 149. Von Mises Stress for Iteration 10 As Viewed From Below........ 173

FIGURE 150. Von Mises Stress for Iteration 11 ...................................... 174

FIGURE 151. Von Mises Stress for Iteration 11 As Viewed From Below......... 175

FIGURE 152. Von Mises Stress for Iteration 12 ....................................... 176

FIGURE 153. Von Mises Stress for Iteration 12 As Viewed From Below......... 177

FIGURE 154. Von Mises Stress for Iteration 13 ..................................... 178

FIGURE 155. Von Mises Stress for Iteration 13 As Viewed From Below......... 179

FIGURE 156. Y-Component of Strain for Iteration One ............................. 180

FIGURE 157. Y-Component of Strain for Iteration One As Viewed From

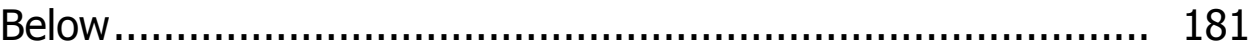

FIGURE 158. Y-Component of Strain for Iteration Two ............................. 182

FIGURE 159. Y-Component of Strain for Iteration Two As Viewed From

Below........................................................................... 183

FIGURE 160. Y-Component of Strain for Iteration Three.......................... 184

FIGURE 161. Y-Component of Strain for Iteration Three As Viewed From

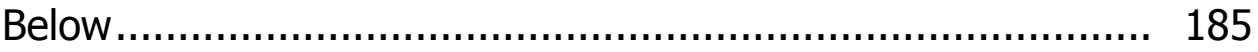

FIGURE 162. Y-Component of Strain for Iteration Four........................... 186

FIGURE 163. Y-Component of Strain for Iteration Four As Viewed From

Below......................................................................... 187

FIGURE 164. Y-Component of Strain for Iteration Five ............................. 188

FIGURE 165. Y-Component of Strain for Iteration Five As Viewed From

Below............................................................................... 
FIGURE 166. Y-Component of Strain for Iteration Six

FIGURE 167. Y-Component of Strain for Iteration Six As Viewed From

Below.....

FIGURE 168. Y-Component of Strain for Iteration Seven

192

FIGURE 169. Y-Component of Strain for Iteration Seven As Viewed From Below....

FIGURE 170. Y-Component of Strain for Iteration Eight

FIGURE 171. Y-Component of Strain for Iteration Eight As Viewed From Below

FIGURE 172. Y-Component of Strain for Iteration Nine.

FIGURE 172. Y-Component of Strain for Iteration Nine As Viewed From Below

FIGURE 174. Y-Component of Strain for Iteration 10................................

FIGURE 175. Y-Component of Strain for Iteration 10 As Viewed From Below

FIGURE 176. Y-Component of Strain for Iteration 11.

FIGURE 177. Y-Component of Strain for Iteration 11 As Viewed From Below

FIGURE 178. Y-Component of Strain for Iteration 12.

200

FIGURE 179. Y-Component of Strain for Iteration 12 As Viewed From Below

FIGURE 180. Y-Component of Strain for Iteration 13.

201

202

203

FIGURE 181. Y-Component of Strain for Iteration 13 As Viewed From Below

FIGURE 182. First Principal Strain for Iteration One 204

FIGURE 183. First Principal Strain for Iteration One As Viewed From Below..

FIGURE 184. First Principal Strain for Iteration Two ....

205

206

FIGURE 185. First Principal Strain for Iteration Two As Viewed From Below..

FIGURE 186. First Principal Strain for Iteration Three.

207

208

FIGURE 187. First Principal Strain for Iteration Three As Viewed From Below

FIGURE 188. First Principal Strain for Iteration Four...

209

210

211

FIGURE 189. First Principal Strain for Iteration Four As Viewed From Below .

FIGURE 190. First Principal Strain for Iteration Five...

212

FIGURE 191. First Principal Strain for Iteration Five As Viewed From Below ..

FIGURE 192. First Principal Strain for Iteration Six

213

214

FIGURE 193. First Principal Strain for Iteration Six As Viewed From Below....

FIGURE 194. First Principal Strain for Iteration Seven...............................

FIGURE 196. First Principal Strain for Iteration Eight.

215 216

FIGURE 197. First Principal Strain for Iteration Eight As Viewed From Below

FIGURE 198. First Principal Strain for Iteration Nine

FIGURE 199. First Principal Strain for Iteration Nine As Viewed From Below . 223

FIGURE 200. First Principal Strain for Iteration 10 ................................ 224

FIGURE 201. First Principal Strain for Iteration 10 As Viewed From Below .... 225

FIGURE 202. First Principal Strain for Iteration 11 ................................ 226

FIGURE 203. First Principal Strain for Iteration 11 As Viewed From Below .... 227 
FIGURE 204. First Principal Strain for Iteration 12 ................................. 228

FIGURE 205. First Principal Strain for Iteration 12 As Viewed From Below .... 229

FIGURE 206. First Principal Strain for Iteration 13 .................................. 230

FIGURE 207. First Principal Strain for Iteration 13 As Viewed From Below .... 231

FIGURE 208. First Page of Settings for PCG Lanczos Modal Analysis As Entered in ANSYS.

FIGURE 209. Second Page of Settings for PCG Lanczos Modal Analysis As Entered in ANSYS.

FIGURE 210. First Page of Settings for Supernode Modal Analysis As Entered in ANSYS

FIGURE 211. Second Page of Settings for Supernode Modal Analysis As Entered in ANSYS.

FIGURE 212. First Mode Shape As Calculated by the Block Lanczos and PCG Lanczos Modal Analysis Methods

FIGURE 213. Second Mode Shape As Calculated by the Block Lanczos and PCG Lanczos Modal Analysis Methods

FIGURE 214. First Mode Shape As Calculated by the Supernode Modal Analysis Method

FIGURE 215. Second Mode Shape As Calculated by the Supernode Modal Analysis Method 


\section{INTRODUCTION}

The regular inspection of bridges is an important part of maintaining its safety. However, this is often completed as a visual inspection only, presenting the chance for a minor weakness to go unnoticed until a failure is inevitable.

A Physics doctoral project seeks to reduce this uncertainty by producing a remote sensor program for determining the health of a specified bridge. The optical sensor will be used from a distance to measure frequencies developed in the span of the bridge under the carrying loads moving across it. The program then uses these frequencies to analyze the bridge and determine possible weaknesses and indicate any threat of failure.

As part of this project, a computer-aided analysis of the studied bridge was desired. The main goals of the model included documenting the areas requiring the most attention and offering supporting evidence to back the frequencies registered by the optical sensors to ensure proper functioning of the device. Furthermore, the model provided a baseline of the health of the bridge. This can be used for comparison later, after the bridge has suffered a large impact or deterioration, to determine if and where investigation is required. These components of the project constitute the material of this thesis. 
To satisfy the above objectives, certain outputs were determined to be necessary. These included static deflections and local stresses, as well as the frequencies seen in the bridge, especially the resonant frequencies. It was also important to determine how these properties changed under specific loads and where the properties were at the maximum values to determine the locations of potential failure points.

The bridge being analyzed is a reinforced concrete arch bridge located on the campus of the University of Louisville. It allows Eastern Parkway to pass over two small roads and a railroad track. It was built in 1954 to help ease the traffic in and around the campus ("October 8" 1954). In 2009, a project was begun to repair the rapidly deteriorating concrete structure and to renovate the decking to again ease traffic conditions (Starks 2011). Pictures of the bridge and the construction can be seen in Appendix I. Because of this construction, an opportunity was presented that allowed for the attachment an accelerometer so that frequencies generated by the construction could be calculated. These frequencies allowed for another means of verifying the readings of the optical sensor. 


\section{LITERATURE REVIEW}

To complete the analysis, the simulation program ANSYS was utilized. The ANSYS program uses a finite element analysis (FEA) approach to solve for various engineering properties; for this paper, the desired properties include deflection, stress, and mode shapes under given load conditions.

Past bridge analysis projects have also utilized ANSYS or another form of the finite element analysis. A research project completed at the Université de Sherbrooke in Sherbrooke, Québec, Canada, used an FEA program, ANACAP, to compare the behavior of continuous or simply supported bridges constructed with traditional steel reinforcement and newer fiber reinforced polymers (FRP) composite reinforcement. The concrete component was modeled by a 20 -node iso-parametric brick element. Rebar sub-elements were used for the reinforcements. The bridge was divided into three longitudinal sections. A finer mesh was applied to the center section, where the load was being applied, so that calculations would be accurate; the outer sections were given larger elements to avoid slowing the program. Truck loads were incremental applied as pressures on the bridge, and only those configurations returning the maximum strains were used. When the results of the FEA were compared to field test 
findings, it was concluded that the FEA was an acceptable method to predict FRP composite reinforced bridge behavior (El-Ragaby et al. 2005).

A study sponsored by the Virginia Transportation Research Council in 1997 sought to determine an appropriate strategy for studying static and dynamic bridge responses. The project included developing a software package that utilized standard ANSYS 5.0 features in an interactive setting specifically for bridge analysis. Through this package, bridges could be modeled as one of three situations: as layers of plate and beam elements representing deck and girder components respectively, as a one-layer composite beam with beam elements only, or as a single-node layer made of both beam and shell elements. For connections, all internal supports were assumed to be pins while the end supports were defined by the user. Other properties of the bridge were chosen from several predetermined options. For loading conditions, user had the choice between transient, modal, harmonic and static. To ensure proper calculations, two bridges were modeled and field tested. The results showed that the ANSYS models provided accurate representation of bridge responses (Barefoot 1997).

Although the research described above used an older version of ANSYS, the modal application and results discussed in the Virginia Transportation paper were similar to the analysis necessary in the Eastern Parkway model and provided some insight for the analysis described below. Furthermore, the paper demonstrated the fact that there are programs more specific to bridge applications. For this thesis project, a student edition of ANSYS was already 
provided, but in future bridge studies in which an FEA program is not readily available, a program designed for more specific application should perhaps be considered.

A more recent ANSYS application was completed at the University of South Carolina and involved studying bridge superstructures to determine the effect of relative rigidity between the deck and other components through the manipulation of three areas: composite action, slenderness ratio and presence of diaphragms. Research was completed on a $1 / 6.6$-scale simply supported, reinforced concrete deck with support from four steel girders from a previous experimental study. To model the bridge, a SOLID65 element was used for the deck, SHELL63 for the girders and LINK8 for the steel diaphragms. The model was also designed to allow for nonlinear behavior and the presence of cracking and crushing. To be certain of the accuracy of the model, results from the ANSYS calculations were compared to the experimental data collected from the previous study of the bridge. This project provided an example of modeling the nonlinear behavior of reinforced concrete in ANSYS applications (Zhou et al. 2004). Although beyond the scope of this thesis, the method may prove valuable if future detailed studies of the Eastern Parkway bridge behavior are necessary. 


\section{DEVELOPING THE COMPUTER MODEL}

To begin analyzing the bridge in question, a computer model had to be created in ANSYS. Because the highest priority in this project was identifying frequency and deflection in the spans, only the superstructure of the bridge was modeled.

First, the type of geometric element had to be defined. ANSYS has almost 150 element options ranging from two-dimensional links and beams to model structures that have lengths that are significantly larger than its width to threedimensional solid and shell elements to model structures with lengths and widths that are much closer in size. These are further classified by element shape, makeup and type of analysis (Moaveni 2003, 391-396). For this project, the element SOLID65 was selected because it was specifically designed to model reinforced concrete. It consisted of a brick, or cubic, shape with 8 nodes, one at each corner of the element (Moaveni 2003, 701-702). It allows for nodal movement in all three dimensions as well as options for cracking, crushing, creep, and other concrete and steel properties (Moaveni 2003, 701-702).

The bridge was divided into three sections based on the location of four expansion joints at Piers One, Four and Nine and Abutment Two; Appendix II includes an illustration of this layout. It was assumed that these expansion joints 
would absorb any movement between individual bridge sections. Therefore, the bridge would act as three separate deck units and could be modeled as such. For the purpose of this paper, only the section from Piers One to Four will be examined.

\section{Reinforced Solid}

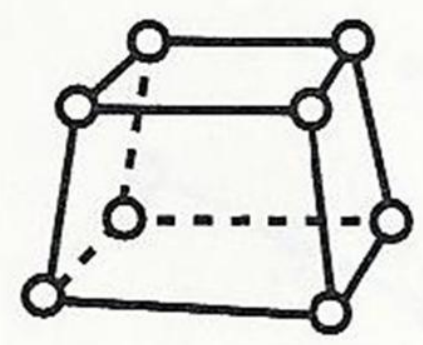

\section{SOLID65}

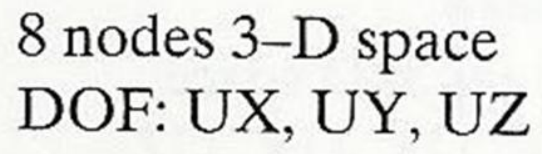

Figure 65.1: SOLID65 Geometry

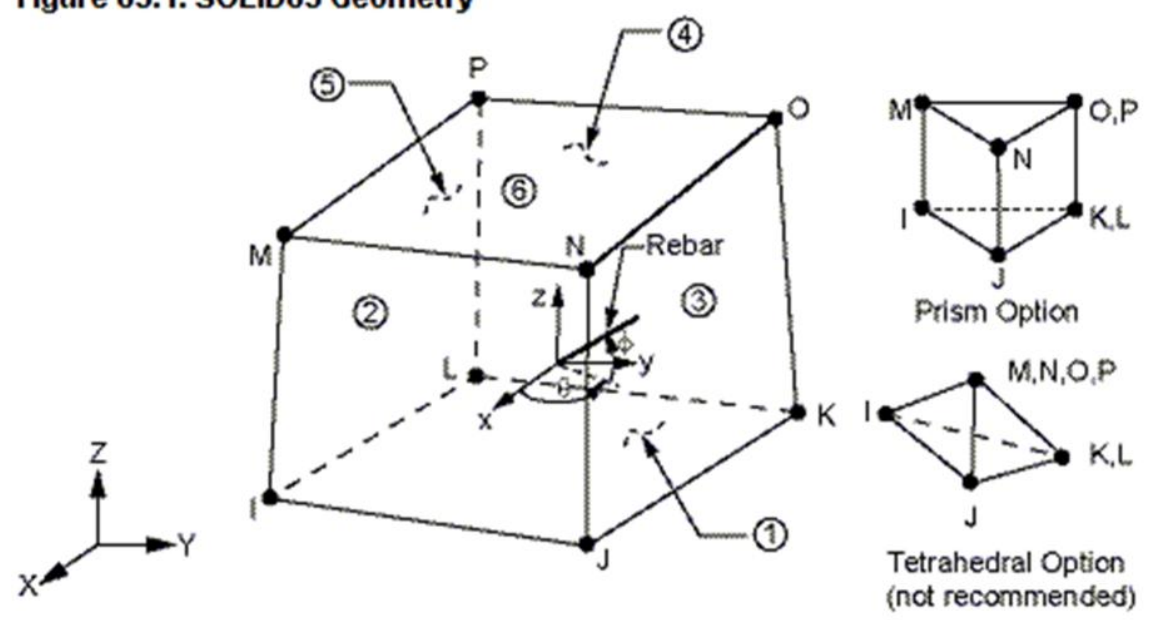

FIGURE 1 - Representations of ANSYS SOLID65 Element (Moaveni 2003, 394; ANSYS Release 12.1). 
The ANSYS programming is written in such a way that measuring units must be uniform throughout the process. It was determined that for this project, length would be measured in the unit of feet, force in kips, or 1,000 pounds, and time in seconds. Because ANSYS applied a gravitational acceleration to calculate the weight of the bridge, density units, originally given in kips or lbf, had to be adjusted to mass units, typically measured in masspounds or lbm, by means of Equation 1, seen below ("Effect" 2011).

$$
1 \mathrm{lbm}=\frac{1 \mathrm{lbf}}{32.2 \mathrm{ft} / \mathrm{s}^{2}}
$$

Table I documents the units used ("Conversion" 2011). These can also be seen as they were entered into ANSYS in Appendix II.

TABLE I

\begin{tabular}{|c|c|}
\hline Property & Unit \\
\hline Length & $\mathrm{ft}$ \\
\hline Force & $\mathrm{kip}$ \\
\hline Mass & $\mathrm{kip}^{*} \mathrm{~s}^{2} / \mathrm{ft}$ \\
\hline Time & $\mathrm{s}$ \\
\hline Density & $\mathrm{kip}^{*} \mathrm{~s}^{2} / \mathrm{ft}^{4}$ \\
\hline Young's Modulus & $\mathrm{kip} / \mathrm{ft}^{2}$ \\
\hline Poisson's Ratio & unitless \\
\hline Stress & $\mathrm{kip} / \mathrm{ft}^{2}$ \\
\hline Acceleration & $\mathrm{ft} / \mathrm{s}^{2}$ \\
\hline
\end{tabular}

PROPERTIES AND CORRESPONDING UNITS USED IN ANSYS CALCULATIONS 
Using a set of plans from the bridge reconstruction project, a crosssection of half of the bridge was developed first. Only half was needed as the bridge was symmetrical and could later be mirrored to create the full bridge deck. The cross section was then extruded to a given length and height to create the volume and slope of the bridge deck. Appendix III includes screen shots of this process.

After the deck was finished, the beams were added. These had to be finished in a process apart from the process above due to the arched nature. Because each arch had a unique radius and no information on the exact values of these radii were known, the arch was approximated. To do this, elevations were estimated for the top of each pier as well as at the highest point of each arch. Connecting these points with a straight line produced an inverted "V" shape and thus represented important components of the arches. When all of these features of the model were designed, the model was mirrored around the centerline, on the z-axis, to create the full cross-section of the bridge.

Upon closer examination of the bridge itself, it was seen to have additional elements not noted in the construction plans. These elements ran perpendicular to the beams at each pier location. Because these supports offered a greater rigidity to the decking and therefore influenced the deformation of the deck under load, they were added to the model. Figure 2 shows the completed model without the support conditions and meshing applied. 


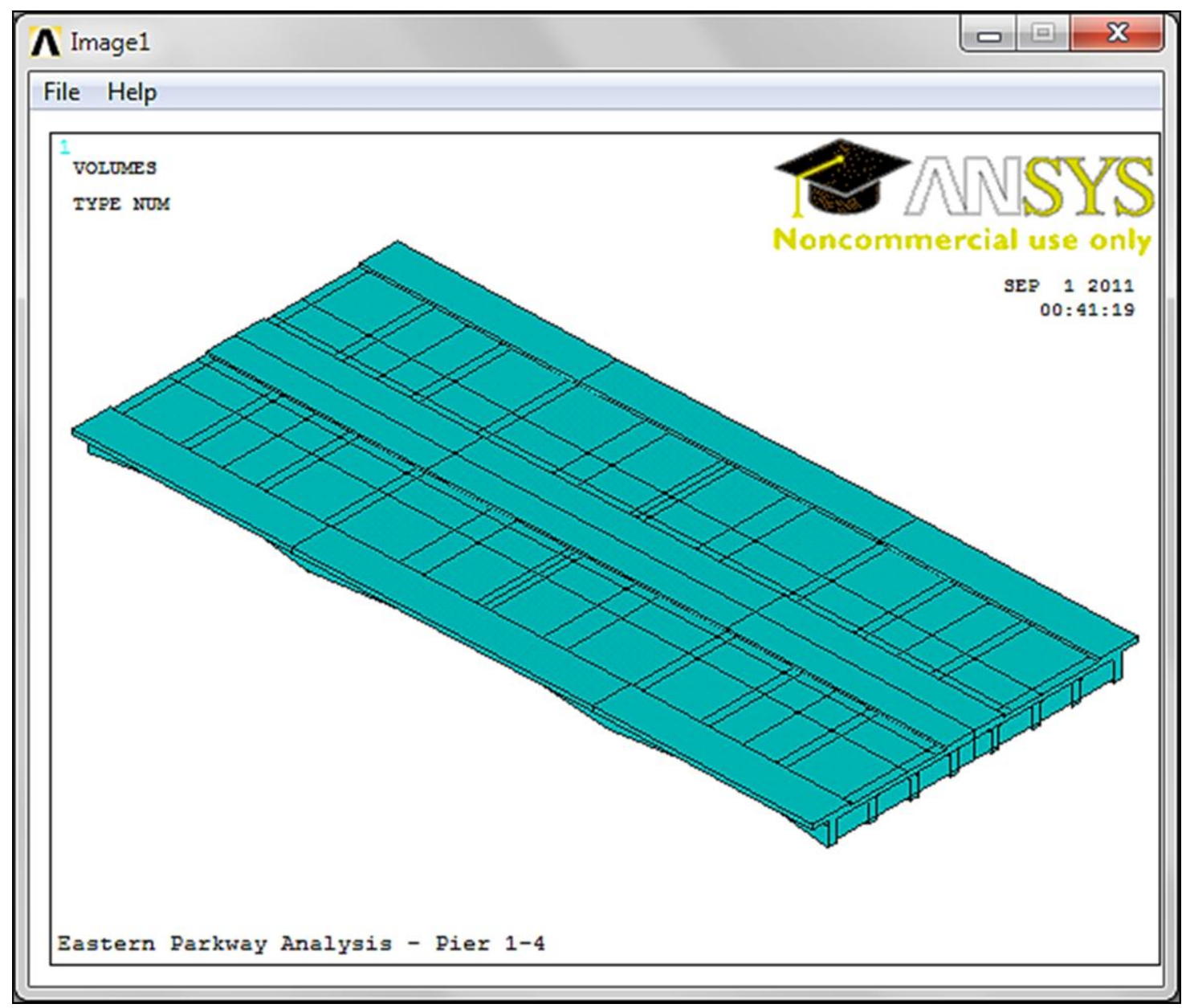

FIGURE 2 - Finished ANSYS Computer Model Without Support Conditions

The steel reinforcement of the bridge decking was added next. ANSYS applies a "smearing" technique to represent the steel, which results in the volume ratio - the ratio of the volume of steel to the volume of the entire element -to be evenly distributed across the entire volume instead of grouped into individual bars at specific locations (Moaveni 2003, 702). This superstructure had three distinct steel elements: the cross-sectional and longitudinal steel reinforcements in the decking and the steel reinforcement in 
the beams below the decking. There was also existing steel reinforcement that was noted in the reconstruction plans, but not specified further; therefore, it was assumed that this steel matched the new steel being placed and was included in the corresponding ratios. The volume of steel of each of these elements per linear foot of the superstructure was calculated first, followed by the total volume. See Appendix IV for these calculations. These ratios, as well as the angles necessary to define the orientation of the bars, were entered in the program, as seen in Figure 3.

Support configuration was determined by visual inspection of the bridge; no data was available on the construction and connection of the superstructure to the pier supports, so estimations had to be used. Table II shows the connections for each pier; those in bold are the supports for the section discussed in this thesis.

For a fixed connection, all degrees of freedom were held at zero units of displacement. For a roller connection, the $y$ - and z-axes were held were held at zero units of displacement. The $y$-axis measures the vertical height of the superstructure. The z-axis represents the width of the bridge and was held due to the nature of loading in the ANSYS program. The programming in ANSYS does not allow for a user to easily apply a load perpendicular to a surface face. Because the bridge deck has a slight angle to allow for storm runoff, the truck loading was being applied to the minor angle, resulting in a displacement in the z-axis that was not natural. After several checks of the model to ensure that all 


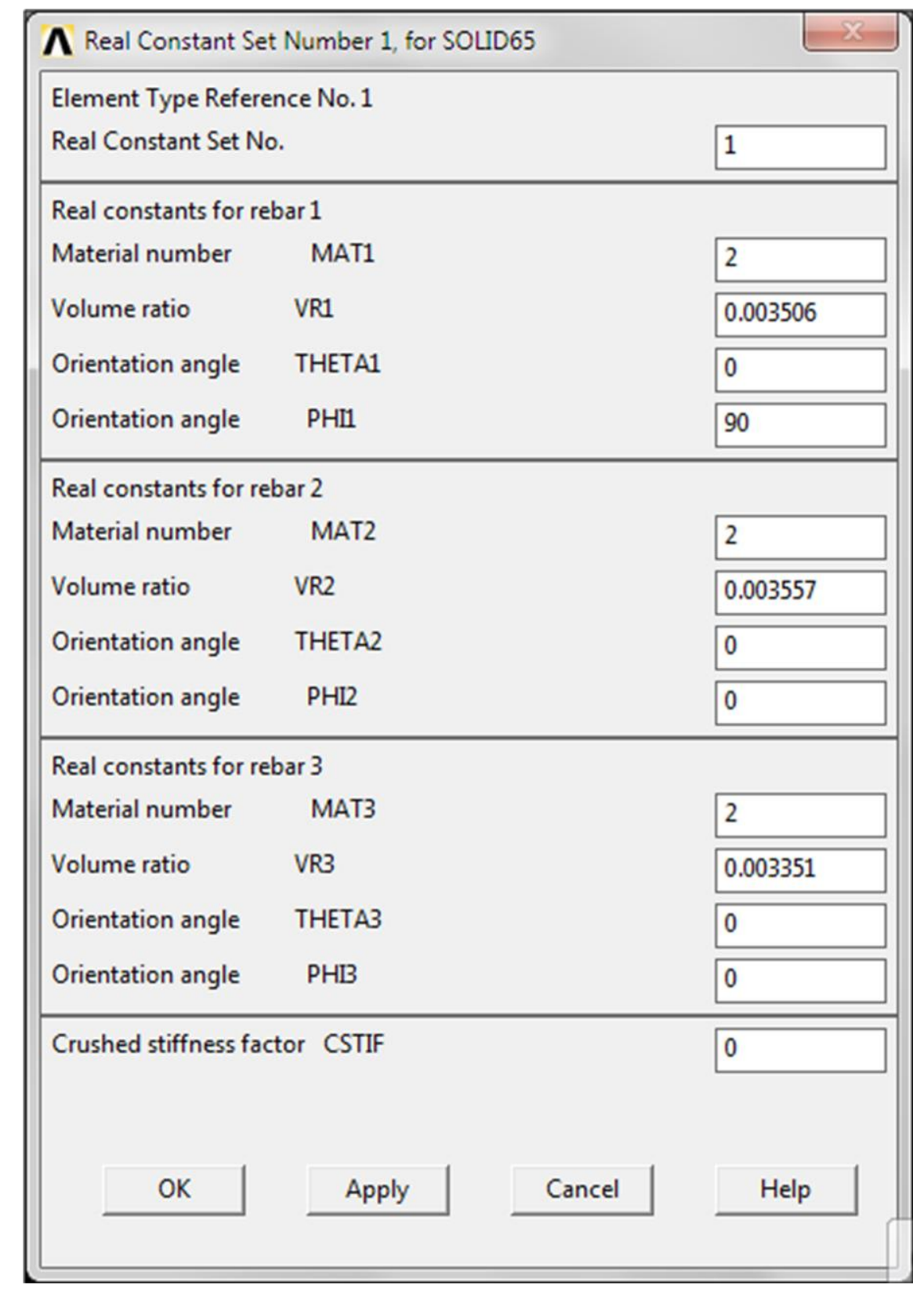

FIGURE 3 - Steel Reinforcement Properties as Entered in ANSYS

other factors were correctly entered, it was decided that holding the z-axis would cause negligible interference with the more important $y$-axis readings and was in fact a necessary alteration. Figure 4 demonstrates the support conditions as entered in ANSYS. Please note that the left edge of this model represents Pier 
One and the right edge is Pier Four. Piers Two and Three are located at the middle supports.

TABLE II

\begin{tabular}{|c|c|}
\hline $\begin{array}{c}\text { Pier } \\
\text { Number }\end{array}$ & $\begin{array}{c}\text { Connection } \\
\text { Type }\end{array}$ \\
\hline 1 & Fixed \\
\hline 2 & Fixed \\
\hline 3 & Roller \\
\hline 4 & Fixed \\
\hline 5 & Fixed \\
\hline 6 & Fixed \\
\hline 7 & Roller \\
\hline 8 & Roller \\
\hline 9 & Fixed \\
\hline 10 & Fixed \\
\hline 11 & Fixed \\
\hline 12 & Fixed \\
\hline 13 & Roller \\
\hline 14 & Roller \\
\hline Abutment 2 & Fixed \\
\hline
\end{tabular}

SUPPORT TYPE FOR EACH PIER OR ABUTMENT LOCATION 


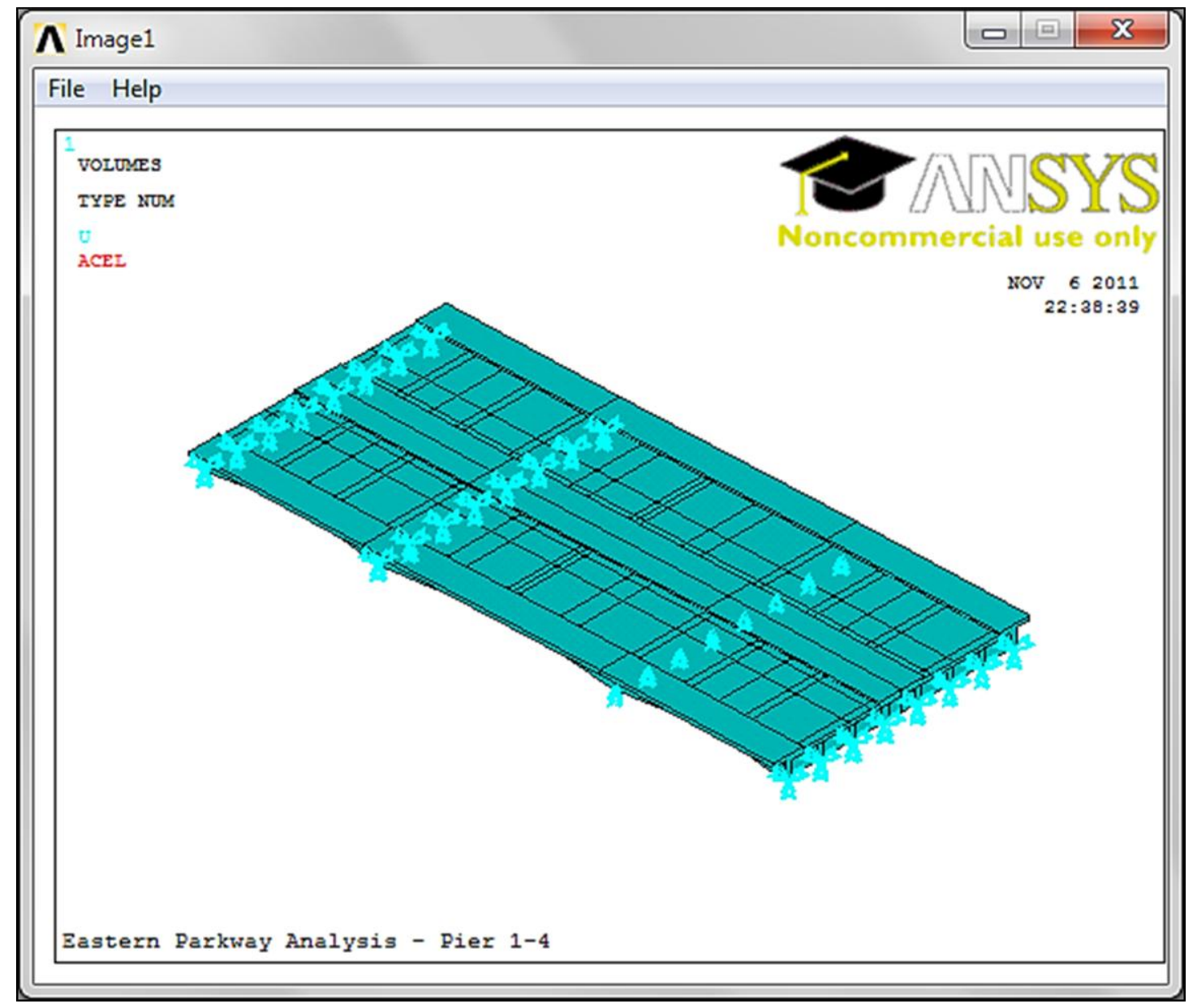

FIGURE 4 - Support Conditions as Modeled in ANSYS. 


\section{CALCULATIONS}

As described above, ANSYS uses a mesh, or system of nodes and elements, to complete the calculations on the model. The size of the mesh needed to be determined. Meshing that was too large did not capture the small variations in the model and returned false values. To find the correct sizing, multiple calculations were completed with each subsequent analysis using a slightly smaller size. When the newest results became consistent with the values of the previous analysis, the correct size has been reached. Using the sizing of the next to the last test analysis produced accurate results without slowing the program through an excessive use of nodes and elements. Table III shows the percent change calculations used to make this decision. Values were calculated using the "Iteration 4" load configuration, discussed later.

For this model, the smart-sizing option in ANSYS was also utilized. This applied preset mesh sizes to the model, simplifying the meshing process and eliminating much of the guess-and-check involved. For this model, a smart-size mesh of six was applied to the structure.

The loading used to simulate traffic crossing the bridge was based on the largest vehicle to cross the bridge: an 18-wheel semi-truck modeled by the AASHTO HS20-44 loading configuration. The configuration included two four-kip 
loads followed by two 16-kip loads at a distance of 14 feet and 44 feet from the first set of loads. Each pair of loads was separated by a width of 6 feet (Tonias 97-100).

\section{TABLE III}

\begin{tabular}{|c|c|c|c|}
\hline & $\begin{array}{c}\text { Y-Component of } \\
\text { Displacement } \\
\text { (ft) }\end{array}$ & $\begin{array}{c}\text { Y-Component } \\
\text { of Stress } \\
\left(\mathrm{kip} / \mathrm{ft}^{2}\right)\end{array}$ & $\begin{array}{c}\text { Von Mises } \\
\text { Stress } \\
\left(\mathrm{kip} / \mathrm{ft}^{2}\right)\end{array}$ \\
\hline $\begin{array}{c}\text { Smart Size } 8 \\
\text { Values }\end{array}$ & -0.001173 & 7.018 & 146.232 \\
\hline $\begin{array}{c}\text { Smart Size } 7 \\
\text { Values }\end{array}$ & -0.001216 & 5.309 & 141.252 \\
\hline $\begin{array}{c}\% \text { Change } \\
\text { between } 7 \& 8\end{array}$ & $3.67 \%$ & $-24.35 \%$ & $-3.41 \%$ \\
\hline $\begin{array}{c}\text { Smart Size } 6 \\
\text { Values }\end{array}$ & -0.001216 & 5.888 & 146.399 \\
\hline $\begin{array}{c}\% \text { Change } \\
\text { between } 6 \text { \& } 7\end{array}$ & $0.00 \%$ & $10.91 \%$ & $3.64 \%$ \\
\hline $\begin{array}{c}\text { \% Change } \\
\text { between } 6 \& 8\end{array}$ & $3.67 \%$ & $-16.10 \%$ & $0.11 \%$ \\
\hline $\begin{array}{c}\text { Smart Size } 5 \\
\text { Values }\end{array}$ & -0.001217 & 5.886 & 146.254 \\
\hline $\begin{array}{c}\text { \% Change } \\
\text { between } 5 \& 6\end{array}$ & $0.08 \%$ & $-0.03 \%$ & $-0.10 \%$ \\
\hline $\begin{array}{c}\% \text { Change } \\
\text { between } 5 \text { \& } 7\end{array}$ & $0.08 \%$ & $10.87 \%$ & $3.54 \%$ \\
\hline $\begin{array}{c}\% \text { Change } \\
\text { between } 5 \& 8\end{array}$ & $3.75 \%$ & $-16.13 \%$ & $0.02 \%$ \\
\hline
\end{tabular}

PERCENT CHANGE CALCULATIONS USED TO DETERMINE MESHING SIZE 


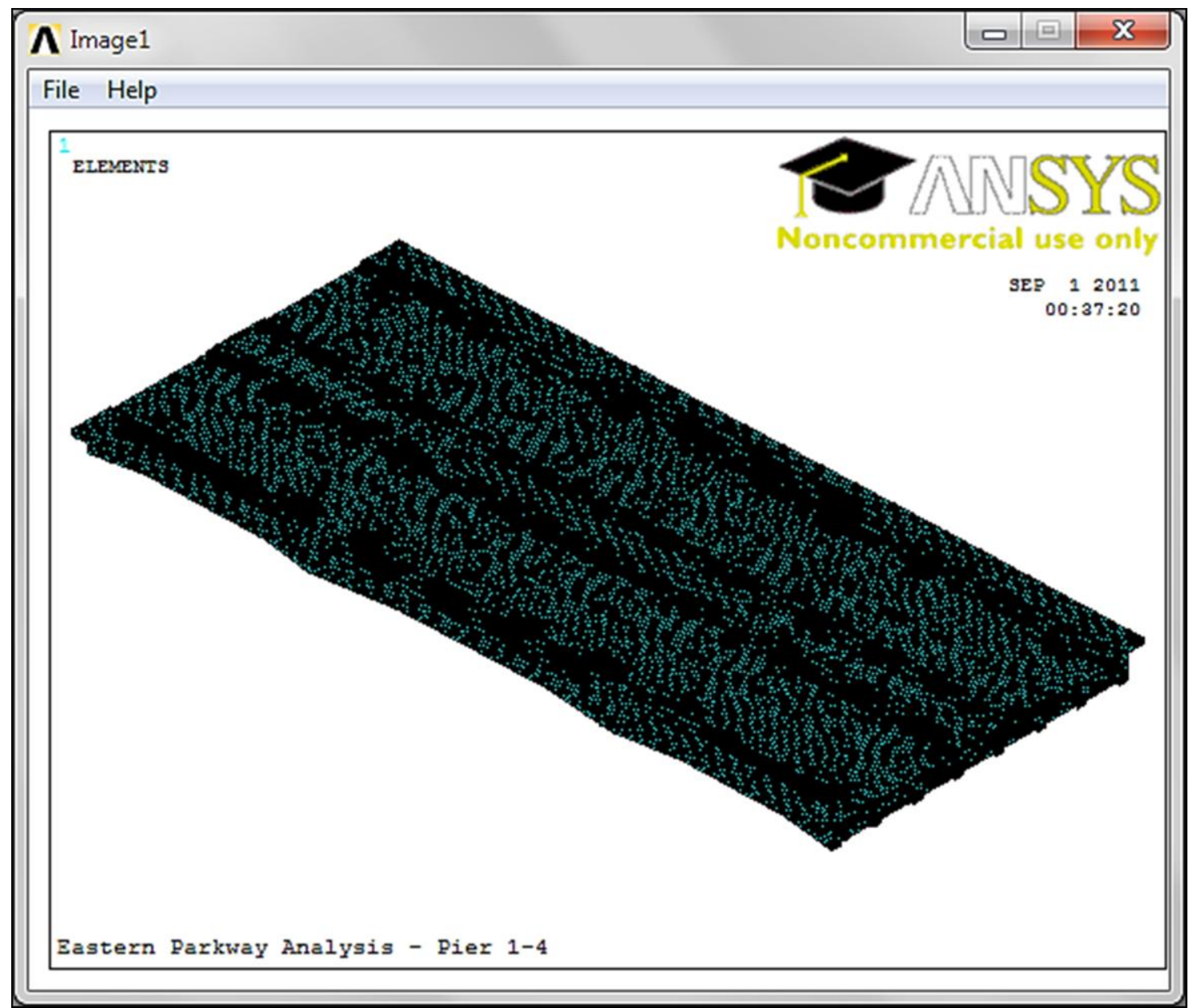

FIGURE 5 - Finished ANSYS Model With Meshing Applied

These loads were placed at strategic points along the bridge deck to mimic the movement of a truck across the bridge. Because the maximum stress was a critical property to be identified and the maximum stress occurs with at least one of the truck loads at a support, loads were placed so that one pair of loads was always over a pier location. Detailed maximum deflections were not needed, so no other loading configurations were solved. Table IV details the iterations completed and the corresponding load configurations and Appendix V shows screen captures of these load configurations. Please note that these 
configurations are simulating a truck moving east along the bridge, with Pier One located on the extreme left and Pier Four on the extreme right of the bridge section when viewing the bridge from the south side. To obtain a resonant frequency value, a Block Lanczos method was used within the ANSYS program. Figures 6 and 7 show the settings used. To confirm these results, several other methods were also applied: the PCG Lanczos and supernode methods. These can be seen in Appendix XIII. Both returned similar results, shown in screen captures in Appendix XIV.

\section{A. Obstacles to Calculations}

Multiple obstacles were encountered with the first attempts to calculate deflections and stress values. As mentioned in the previous section, the roller supports had to be adjusted to remove unrealistically high horizontal displacement.

One of the first setbacks during this process was determining how much of the superstructure had to be modeled for accurate calculations. Originally, it was decided that only half the superstructure was needed because of its symmetry. However, this method was rejected after speaking with Dr. Tom Baber and Dr. Kirk Martini at the University of Virginia; both professors expressed reservations, stating that it would be easier to model the entire superstructure. Using only half the structure would require additional work in applying support and symmetrical conditions at the cut to accurately model reactions to the loading. In addition, the symmetrical conditions would also 
reflect the loads applied, resulting in reactions that included a truck moving upside down in the opposite lane. Obviously this is an impossible situation and would necessitate even more work to reverse such conditions.

TABLE IV

\begin{tabular}{|c|c|c|c|}
\hline \multirow[b]{2}{*}{$\begin{array}{c}\text { Iteration } \\
\text { Number }\end{array}$} & \multicolumn{3}{|c|}{ Load Configuration } \\
\hline & $\begin{array}{c}2 \text { - } 4 \text { kip } \\
\text { loads (front) }\end{array}$ & $\begin{array}{c}2 \text { - } 16 \text { kip } \\
\text { loads (mid) }\end{array}$ & $\begin{array}{c}\text { 2- } 16 \text { kip } \\
\text { loads (back) }\end{array}$ \\
\hline 1 & \multicolumn{3}{|c|}{ No loading - reaction under self-weight } \\
\hline 2 & Pier 1 & $\mathrm{~N} / \mathrm{A}$ & $\mathrm{N} / \mathrm{A}$ \\
\hline 3 & $\begin{array}{l}14 \mathrm{ft} \text { right of } \\
\text { Pier } 1\end{array}$ & Pier 1 & $\mathrm{~N} / \mathrm{A}$ \\
\hline 4 & $\begin{array}{l}44 \mathrm{ft} \text { right of } \\
\text { Pier } 1\end{array}$ & $\begin{array}{l}30 \mathrm{ft} \text { right of } \\
\text { Pier } 1\end{array}$ & Pier 1 \\
\hline 5 & Pier 2 & $\begin{array}{l}14 \mathrm{ft} \text { left of } \\
\text { Pier } 2\end{array}$ & $\begin{array}{l}44 \mathrm{ft} \mathrm{left} \mathrm{of} \\
\text { Pier } 2\end{array}$ \\
\hline 6 & $\begin{array}{l}14 \mathrm{ft} \text { right of } \\
\text { Pier } 2\end{array}$ & Pier 2 & $\begin{array}{l}30 \mathrm{ft} \mathrm{left} \mathrm{of} \\
\text { Pier } 2\end{array}$ \\
\hline 7 & $\begin{array}{l}44 \mathrm{ft} \text { right of } \\
\text { Pier } 2\end{array}$ & $\begin{array}{c}30 \mathrm{ft} \text { right of } \\
\text { Pier } 2\end{array}$ & Pier 2 \\
\hline 8 & Pier 3 & $\begin{array}{c}14 \mathrm{ft} \mathrm{left} \mathrm{of} \\
\text { Pier } 3\end{array}$ & $\begin{array}{c}44 \mathrm{ft} \text { left of } \\
\text { Pier } 3\end{array}$ \\
\hline 9 & $\begin{array}{l}14 \mathrm{ft} \text { right of } \\
\text { Pier } 3\end{array}$ & Pier 3 & $\begin{array}{l}30 \mathrm{ft} \text { left of } \\
\text { Pier } 3\end{array}$ \\
\hline 10 & $\begin{array}{l}44 \mathrm{ft} \text { right of } \\
\text { Pier } 3\end{array}$ & $\begin{array}{c}30 \mathrm{ft} \text { right of } \\
\text { Pier } 3\end{array}$ & Pier 3 \\
\hline 11 & Pier 4 & $\begin{array}{l}14 \mathrm{ft} \text { left of } \\
\text { Pier } 4\end{array}$ & $\begin{array}{l}44 \mathrm{ft} \text { left of } \\
\text { Pier } 4\end{array}$ \\
\hline 12 & N/A & Pier 4 & $\begin{array}{l}30 \mathrm{ft} \text { left of } \\
\text { Pier } 4\end{array}$ \\
\hline 13 & N/A & N/A & Pier 4 \\
\hline
\end{tabular}

LOAD CONFIGURATION DETAILS 


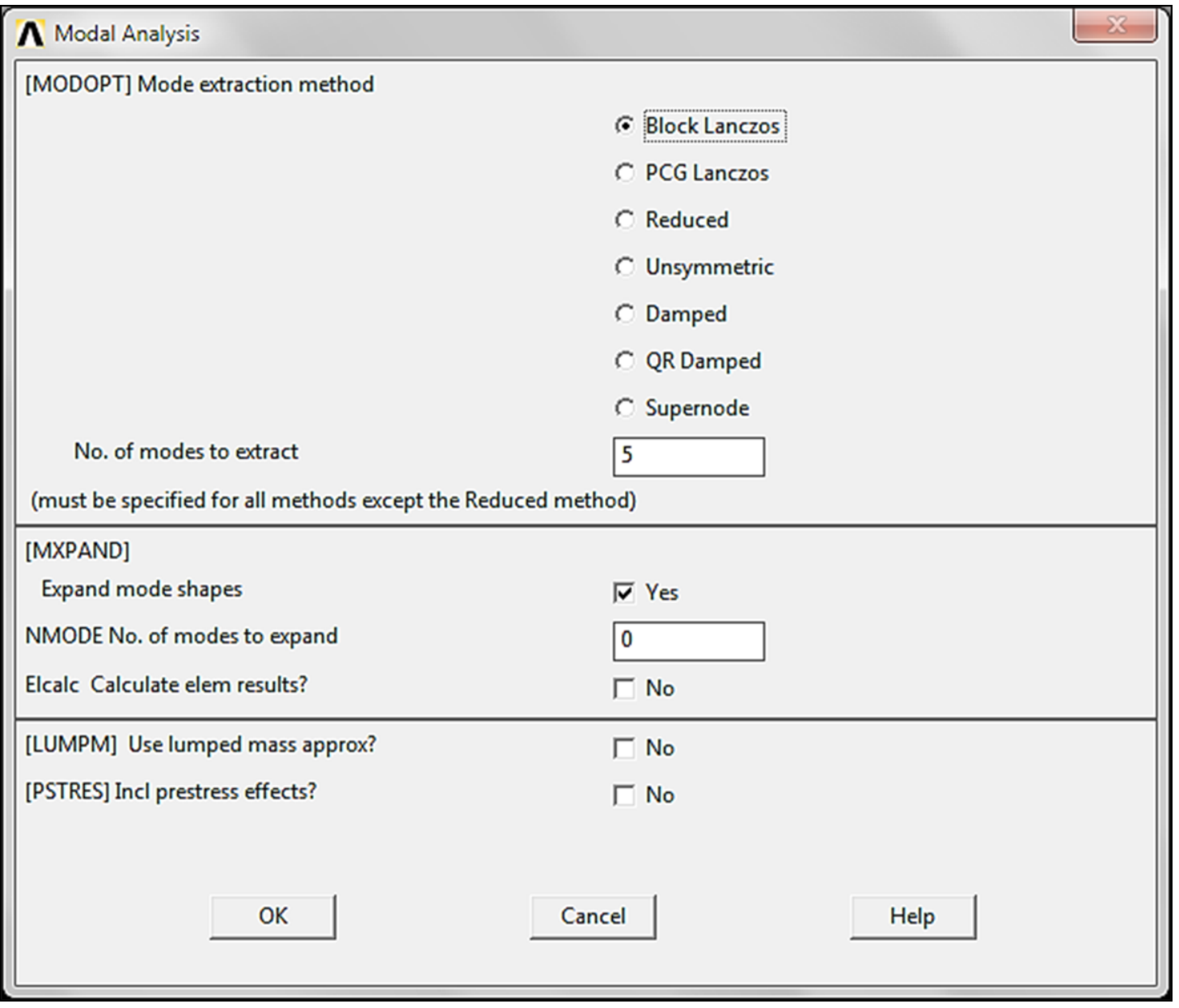

FIGURE 6 - First Page of Settings for Block Lanczos Modal Analysis

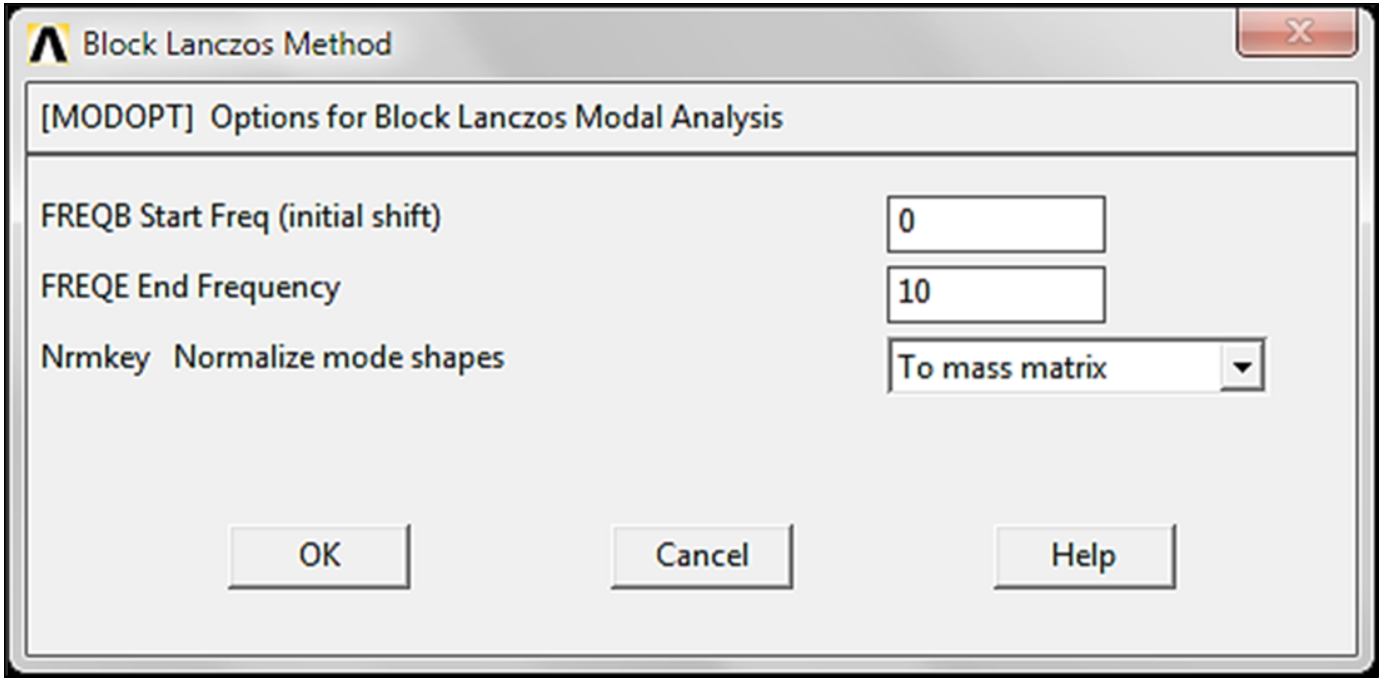

FIGURE 7 - Second Page of Settings for Block Lanczos Modal Analysis 
By modeling the entire superstructure of the bridge, additional nodes and elements were required to run the calculations. The ANSYS program utilized during this project was a student edition utilizing the "Academic Teaching Advanced" license and therefore limited the number of nodes applied to 256,000 per model. For the purposes of this thesis, this limitation was not a problem. However, for modeling of the second and third bridge sections, the number of nodes required for accurate results was exceeded. A larger version of the program was purchased, but the research could not continue due to restrictions in access. 


\section{RESULTS \& DISCUSSION}

Because it was unknown exactly what data would be needed for the baseline health of the bridge and for other analyses, a range of results were taken. Completing a calculation in ANSYS was a time-consuming process and saving multiple complete calculations required a significant amount of available storage space. For this reason, as much data as was determined necessary was saved in visual models and numerical lists for analysis at a later time; the actual ANSYS calculations were overwritten with the subsequent iteration or lost with the close of the program and therefore not available for later viewing.

As indicated above, 13 calculations were completed. For each load configuration, models were created to represent the following results:

- Deformed Shape

- Y-Component of Displacement (DOF Solution)

- Y-Component of Stress

- First Principal Stresses

- Von Mises Stresses

- Y-Component of Strain

- First Principal Strains 
Numerical lists were also saved for more detail. These included displacement values at every node and the reaction solution at each support node. These lists are not included in the thesis due to the sheer size of documenting such information and the corresponding detail.

Table $\mathrm{V}$ lists some of the important solutions collected from the calculations. Screen captures for every solution can be found in Appendices VI through XII.

The frequency under no loading was determined by the Block Lanczos method was 6.193 hertz. Again, screen captures of the results can be found in Appendix XIV. 
TABLE V

\begin{tabular}{|c|c|c|c|}
\hline $\begin{array}{l}\text { Iteration } \\
\text { Number }\end{array}$ & $\begin{array}{l}\text { Deflection - } \\
\text { Maximum (ft) } \\
\text { \& Location }\end{array}$ & $\begin{array}{l}\text { Maximum } \\
\text { Deflection at } \\
\text { Location of } \\
\text { Loading }\end{array}$ & $\begin{array}{l}\text { Local Stress - } \\
\text { Maximum (ksf) } \\
\text { \& Location }\end{array}$ \\
\hline 1 & $\begin{array}{c}-0.012939 \\
\text { Between } 2 \& 3\end{array}$ & $\mathrm{~N} / \mathrm{A}$ & $\begin{array}{c}51.336 \\
\text { Beams b/w } 2 \& 3\end{array}$ \\
\hline 2 & $\begin{array}{c}-0.012942 \\
\text { Between } 2 \& 3\end{array}$ & 0 & $\begin{array}{c}51.345 \\
\text { Beams b/w } 2 \& 3\end{array}$ \\
\hline 3 & $\begin{array}{c}-0.012953 \\
\text { Between } 2 \& 3\end{array}$ & -0.003722 & $\begin{array}{c}51.39 \\
\text { Beams b/w } 2 \& 3\end{array}$ \\
\hline 4 & $\begin{array}{c}-0.012804 \\
\text { Between } 2 \& 3\end{array}$ & -0.005222 & $\begin{array}{c}51.031 \\
\text { Beams b/w } 2 \& 3\end{array}$ \\
\hline 5 & $\begin{array}{c}-0.012819 \\
\text { Between } 2 \text { \& } 3\end{array}$ & -0.003707 & $\begin{array}{c}51.054 \\
\text { Beams b/w } 2 \& 3\end{array}$ \\
\hline 6 & $\begin{array}{c}-0.013143 \\
\text { Between } 2 \& 3\end{array}$ & -0.005325 & $\begin{array}{c}51.633 \\
\text { Beams b/w } 2 \& 3\end{array}$ \\
\hline 7 & $\begin{array}{l}-0.015675 \\
\text { Under loads }\end{array}$ & -0.015675 & $\begin{array}{c}59.488 \\
\text { Beams under loads }\end{array}$ \\
\hline 8 & $\begin{array}{l}-0.015376 \\
\text { Under loads }\end{array}$ & -0.015376 & $\begin{array}{c}57.597 \\
\text { Beams under loads }\end{array}$ \\
\hline 9 & $\begin{array}{l}-0.015258 \\
\text { Under loads }\end{array}$ & -0.015258 & $\begin{array}{c}60.581 \\
\text { Beams under loads }\end{array}$ \\
\hline 10 & $\begin{array}{c}-0.012479 \\
\text { Between } 2 \& 3\end{array}$ & -0.002175 & $\begin{array}{c}49.679 \\
\text { Beams b/w } 2 \& 3\end{array}$ \\
\hline 11 & $\begin{array}{c}-0.012494 \\
\text { Between } 2 \& 3\end{array}$ & -0.002176 & $\begin{array}{c}49.758 \\
\text { Beams b/w } 2 \& 3\end{array}$ \\
\hline 12 & $\begin{array}{c}-0.012514 \\
\text { Between } 2 \& 3\end{array}$ & -0.002163 & $\begin{array}{c}50.047 \\
\text { Beams b/w } 2 \& 3\end{array}$ \\
\hline 13 & $\begin{array}{c}-0.012936 \\
\text { Between } 2 \text { \& } 3\end{array}$ & 0 & $\begin{array}{c}51.324 \\
\text { Beams b/w } 2 \& 3\end{array}$ \\
\hline
\end{tabular}

KEY SOLUTIONS FOR EACH ITERATION AND LOAD CONFIGURATION 


\section{CONCLUSIONS}

Based on the data collected, the area requiring the most attention for the first section of the bridge was the span between Piers Two and Three. At this location, the deflections were consistently the highest values seen in the entire section. This was understandable as it was also the longest span of the section. This specific span also deserves attention because of the stresses seen in the beams supporting the span. Again, this area had the highest stress values under any of the loading conditions.

As far as providing evidence to confirm the accuracy of the sensor readings, the model produced a frequency of $6.19 \mathrm{~Hz}$, which was very similar to the $6 \mathrm{~Hz}$ measured by the optical sensor. However, this section of the bridge cannot be used as the only evidence to support the sensor readings. The remaining two sections will also need to be modeled and compared, especially since the frequencies calculated used the accelerometer readings produced in the second bridge section.

Furthermore, the frequencies were generated by construction vehicles moving across the bridge. ANSYS, however, calculated frequencies using an impact loading model, which may have produced a different frequency type. The 
fact that the frequencies are similar could be coincidental and need to be further studied before a definitive answer can be given.

The data collected from the model also helped to provide a baseline for health of bridge. Due to the scope of this thesis, further confirmation of the success of this goal cannot be given as there was no available data from the time of completion to before the start of this project. Therefore, there was no method to confirm the accuracy of the model for the given condition of the bridge as compared to other stages of its life.

\section{A. Drawbacks of design}

This model is very limited in scope and should not be used for very specific, precise documentation. Furthermore, some properties and dimensions remained unknown through the course of this project and therefore had to be estimated or assumed. This creates a certain error in the calculations that prevents a truly precise and accurate representation of the behavior of the bridge.

Errors can be traced to the following:

- Distortion in the drawing scales on the construction plans as a result of multiple copying and reprinting of the plan set.

- Estimations and approximations of arch radii, steel ratios, and other measurements of the bridge due to missing or unknown information, especially in those existing areas of the bridge that were not altered during construction. 
- Approximations of concrete properties, such as density and Young's modulus, due to lack of information.

- Assumptions of the healthy and age of the bridge structure and the disregard of cracking and other possible weaknesses present in the bridge.

- Assumptions of support conditions because of missing information relating to construction and connections of bridge superstructure to pier supports.

- Assumptions of free support end conditions between the multiple segments of the bridge due to the presence of expansion gaps.

- Use of "smearing" technique by ANSYS to model steel reinforcement rather than directly modeling each steel rebar within the structure.

- Use of an elastic model to represent bridge behavior.

- Use of a static load configuration rather than a moving mass to represent truck loads.

- Round-off and human errors.

These errors have the potential to significantly alter the results of the model. By assuming free connections between the bridge sections, the possibility of influence of the neighboring sections was removed. This limits the accuracy of the reported frequency values. If the neighboring sections do in fact 
have some effect on the studied section, the real frequencies seen in the desired section could be higher or lower because of the distortion created by the adding or canceling effects of the overlapping neighboring frequencies. A very similar situation resulted from the use of static rather than dynamic loading.

The age of the bridge also influences the real reactions of the bridge that may not be seen in the model. The computer model used properties that are more relevant to newly constructed bridges and do not reflect the wear over time that reduces such properties. Furthermore, some properties of the concrete and steel reinforcement were assumed. All of these assumptions have the potential to increase the strength of the bridge and falsely improve its health, leading to reactions and results that may be lower in deflection and stress and higher in frequency than what is actually being seen in the bridge today. It also distorts the baseline health and may result in overlooking a bridge failure because of misjudging the health of the bridge. For more accurate results, the Young's modulus could have been reduced to help account for the presence of cracking.

Finally, the assumption of support conditions at each pier has the possibility to be problematic. These support conditions significantly influence the movement of the bridge, and in consequence, the deflections and frequencies. It is also possible that the design of the bridge could be restricting moments at the supports, a condition not accounted for in the assumed support conditions. 
If the moments are restricted in the actual bridge, the model would be demonstrating frequencies lower than the real values.

The above possibilities for error provide evidence for the restricted use of the model. If specific values or reactions are required, a much more detailed model will be needed. 


\section{RECOMMENDATIONS \& FUTURE WORK}

Future work on this project will include similar studies on the two remaining bridge sections. The longest span of the bridge, located between Piers Seven and Eight, will be especially important in this study because it will theoretically produce the largest deflections and stresses. This is also the location of the accelerometer and will provide important data for comparison.

If additional precision is needed from the models, cracks and other weaknesses should be introduced into the model. A dynamic load configuration will also be necessary. These additions will allow researchers to begin modeling deterioration of the health of the bridge over time. It will also present evidence of how the properties and behavior of the structure will change under such common conditions.

For research beyond this particular bridge, other modeling and simulation programs should be considered. Suggestions include STAAD and SAP, which are more user-friendly and more specialized to this type of analysis. These programs were not used this time due to lack of comfort and the particular construction of bridge. Other programs may be much more appropriate for a simple steel bridge such as the one proposed for the next set of testing and analysis of the optical sensor. 


\section{BIBLIOGRAPHY}

1954. "October 8 set as Opening of Eastern Parkway". Courier Journal (Louisville, Kentucky). September 30.

ANSYS Release 12.1. ANSYS, Inc. Canonsburg, Pennsylvania.

Aparicio, J., Maia, I. and Salete, E. ANSYS Customization for Bridges and Prestressed Concrete Structures Analysis and Design. Ingeciber, S.A.

Baber, T. 2010. Private communication.

Barefoot, John B. 1997. Development of Finite Element Models to Predict Dynamic Bridge Response. Charlottesville, VA: Virginia Transportation Research Council.

"Conversion Factors, Material Properties and Physical Constants," Internet Source, available from http://edboyden.org/constants.html; accessed 29 July 2011.

Day, M. 2011. Private communication.

"Effect of Self Weight on a Cantilever Beam," Internet Source, available from http://www.mece.ualberta.ca/tutorials/ansys/IT/Density/Density.html; accessed 29 July 2011.

El-Ragaby, A., El-Salakawy, E.F., and Benmokrane, B. 2005. Finite Element Modeling of Concrete Bridge Deck Slabs Reinforced with FRP Bars. ACI SP230 915-934.

Geisler, C D. 1934. Analysis of a Rigid Frame Concrete Arch Analysis. Washington, D.C.: U.S. Dept. of Agriculture.

Hay, J. 2010. Private communication.

Kelsey Starks, "Eastern Parkway Road Project Complete," Internet Source, 22 June 2010, available from http://www.whas11.com/news/local/Section-ofEastern-Pkwy-set-to-reopen-Tuesday-morning-96871129.html; accessed 29 July 2011.

Kielkopf, J. 2010. Private communication. 
Lui, Yang. 2011. Bridge Health Monitoring, Maintenance and Safety. Enfield, NH: Trans Tech Publications.

Martini, K. 2011. Private communication.

Moaveni, Saeed. 2003. Finite Element Analysis: Theory and Applications with ANSYS. Upper Saddle River, New Jersey: Pearson Education, Inc.

Mohsen, J.P. 2010. Private communication.

Mondi, Andrew R. 2004. Tutorial for ANSYS. Champaign, IL: Department of General Engineering, University of Illinois at Urbana-Champaign.

Tonias, Demetrios E. and Zhao, Jim J. 2007. Bridge Engineering. New York: McGraw-Hill Companies, Inc.

Weigel, T. 2010. Private communication.

Zhou, S., Rizos, D.C., and Petrou, M.F. 2004. Effects of Superstructure Flexibility on Strength of Reinforced Concrete Bridge Decks. Computers \& Structures 82:13-23. 
APPENDIX I

PICTURES OF BRIDGE AND CONSTRUCTION

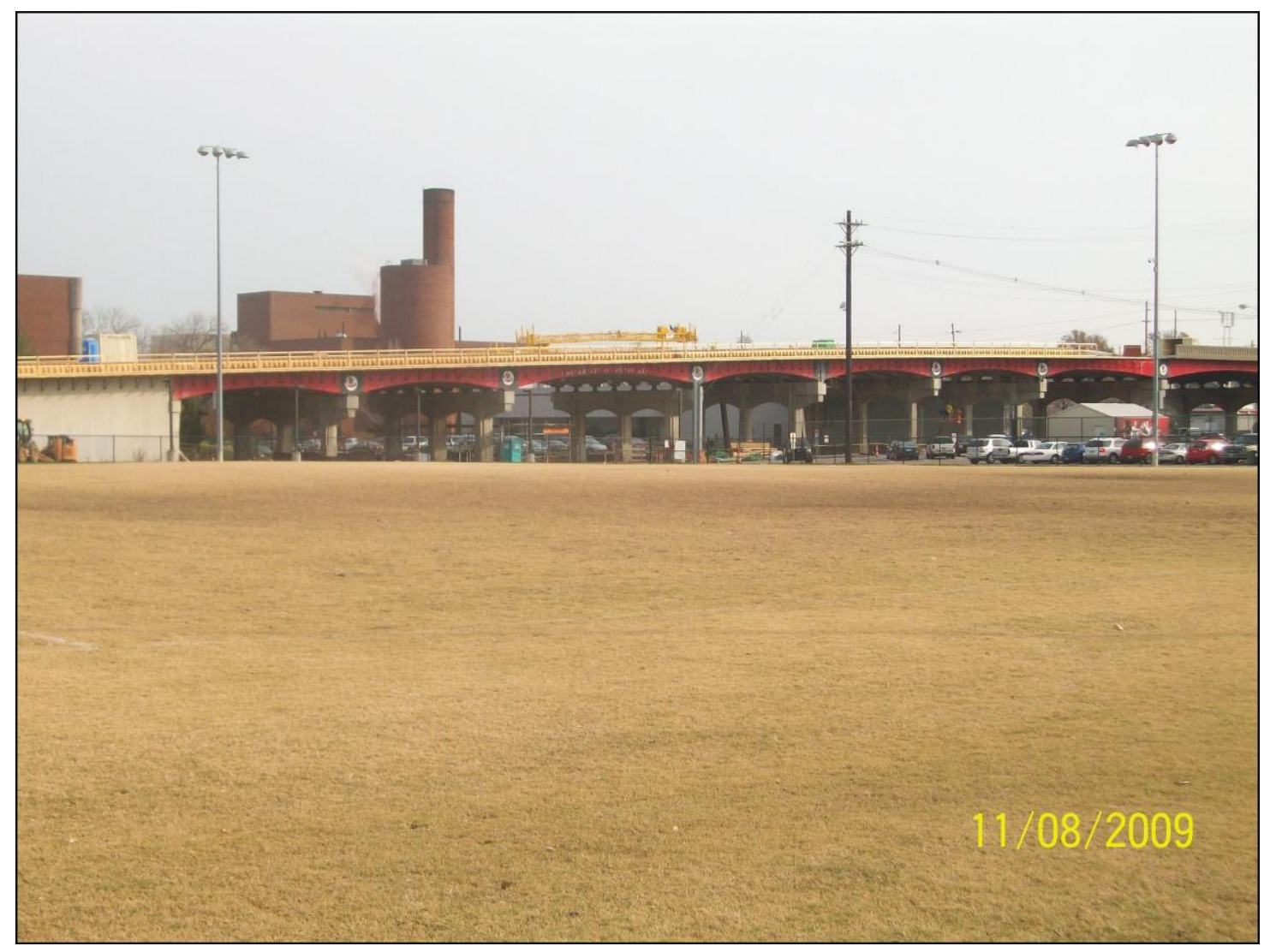

FIGURE 8 - West End of Eastern Parkway Bridge As Viewed From South During Construction 


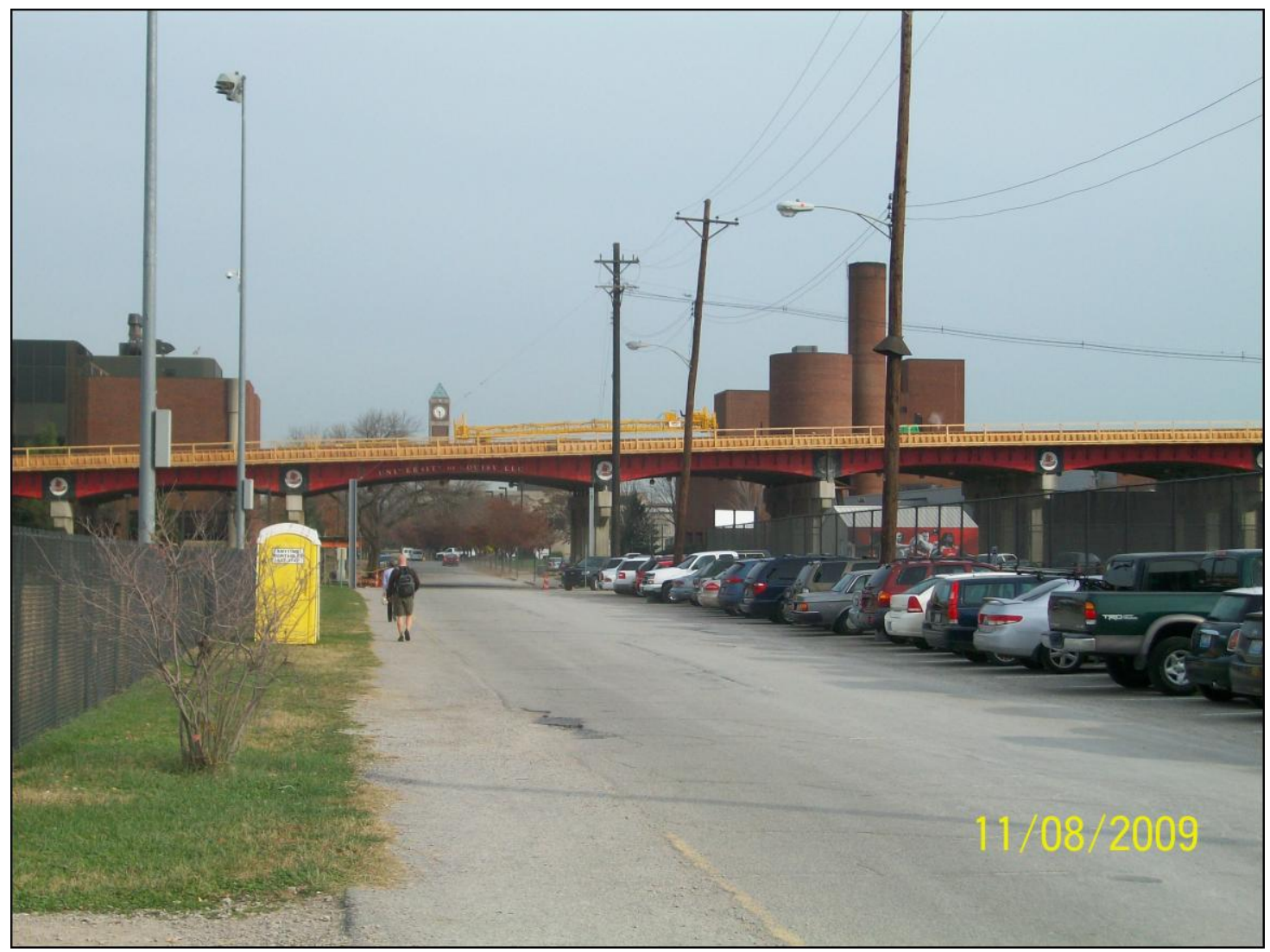

FIGURE 9 - West End of Eastern Parkway Bridge As Viewed From South Brook Street During Construction 


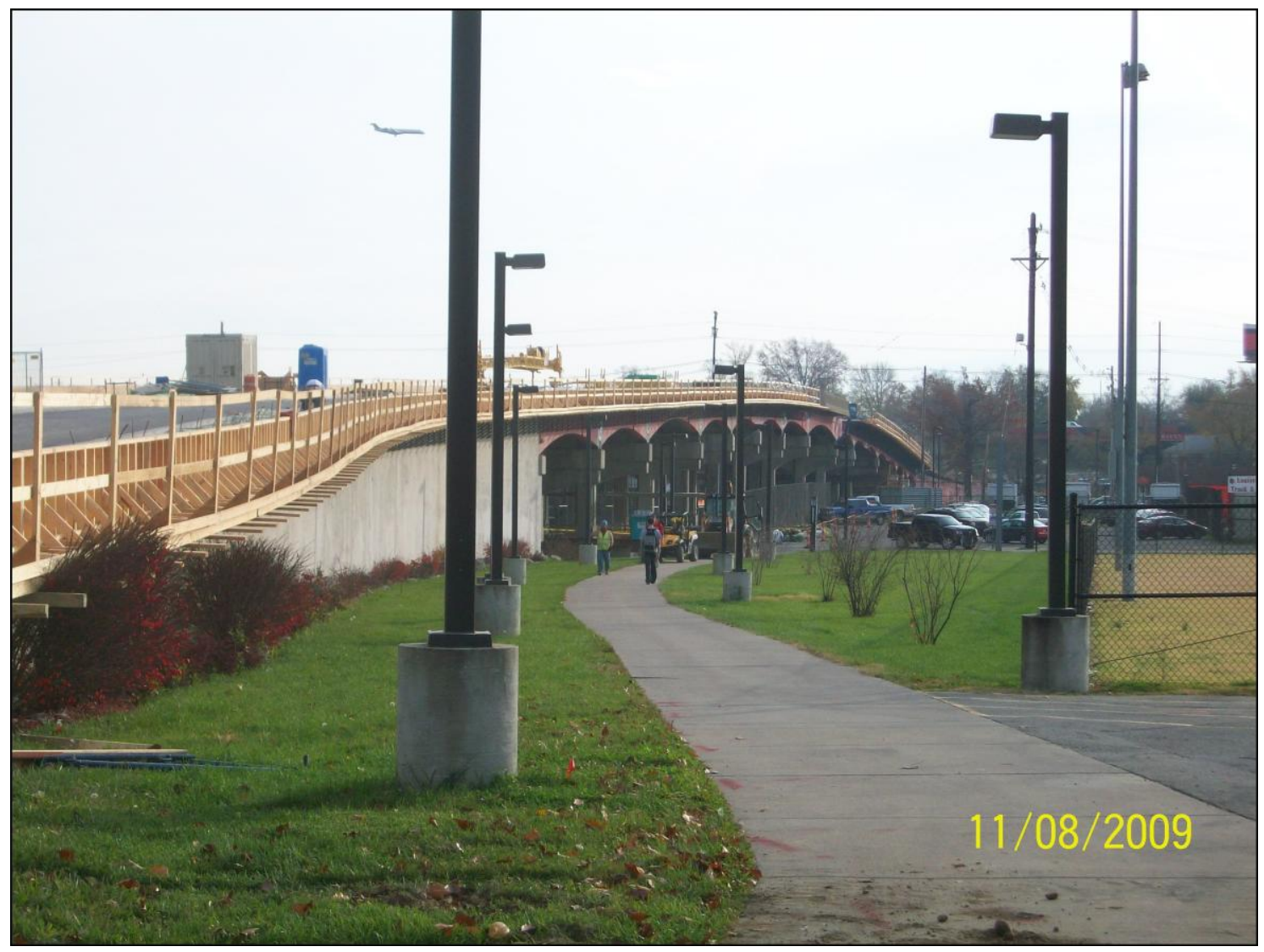

FIGURE 10 - Eastern Parkway Bridge As Viewed From Southwest Corner During Construction 


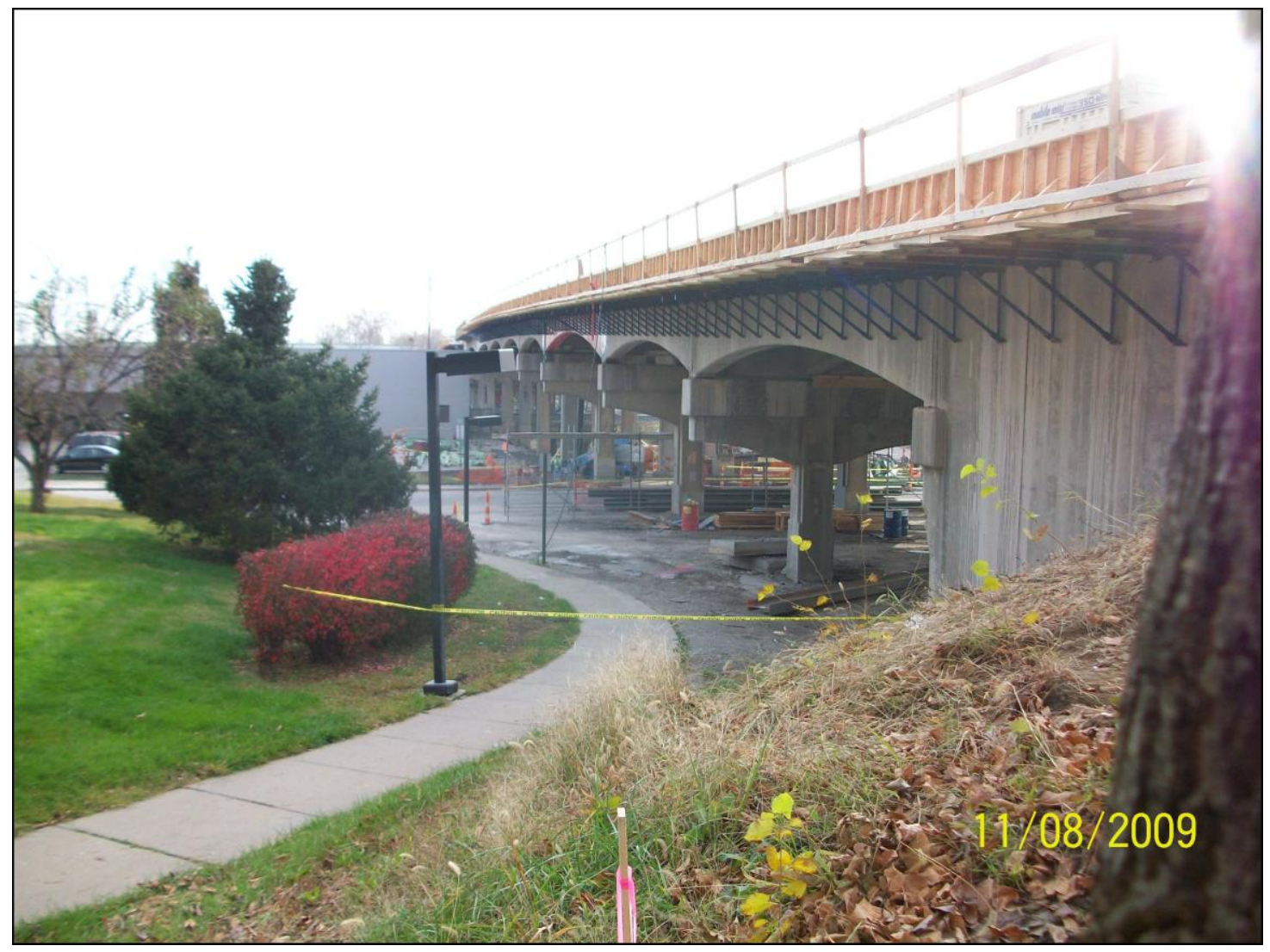

FIGURE 11 - Piers One Through Four of Eastern Parkway Bridge As Viewed From Northwest Corner During Construction 


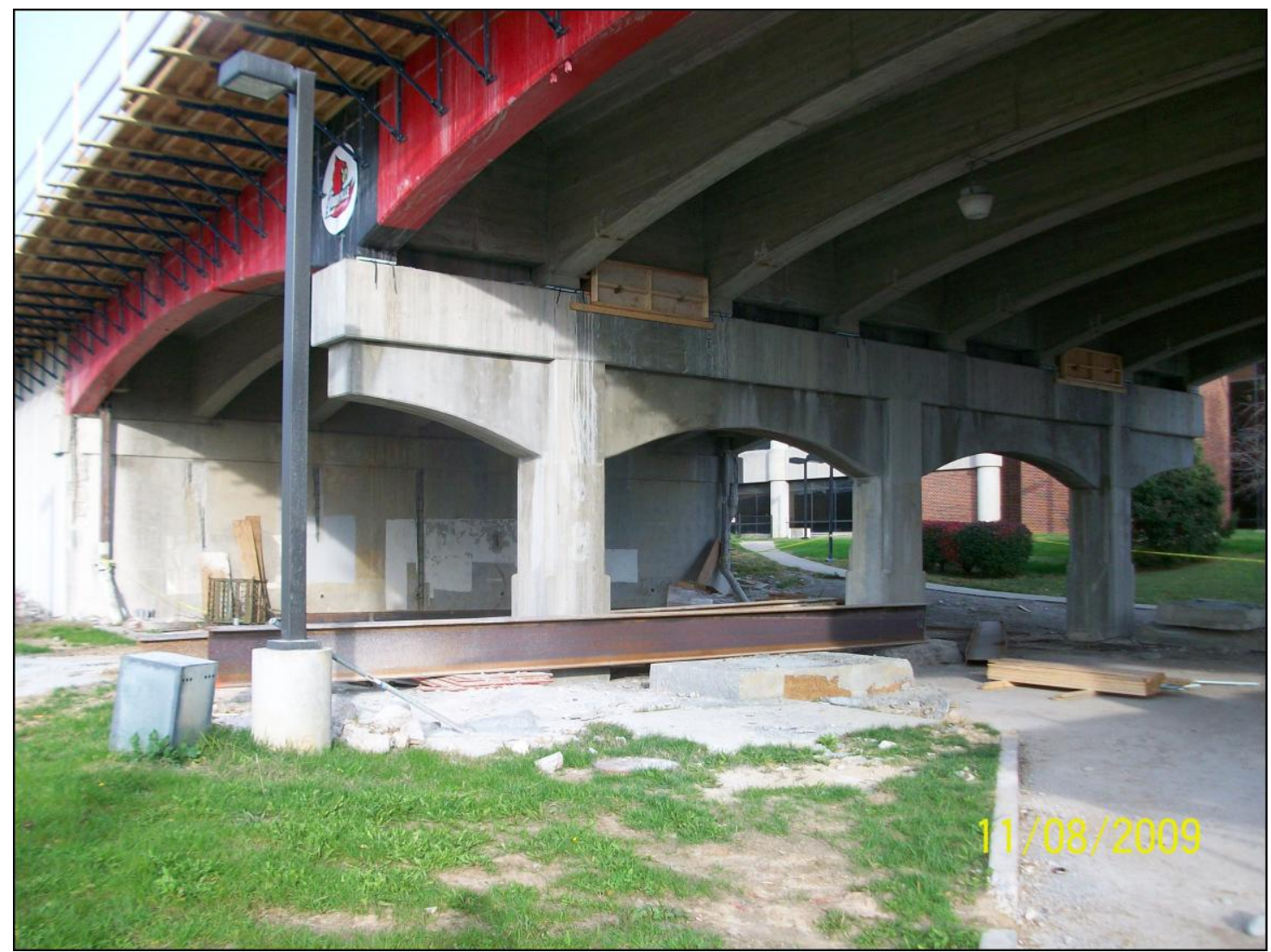

FIGURE 12 - Abutment One and Pier One of Eastern Parkway Bridge As Viewed From South Side During Construction 


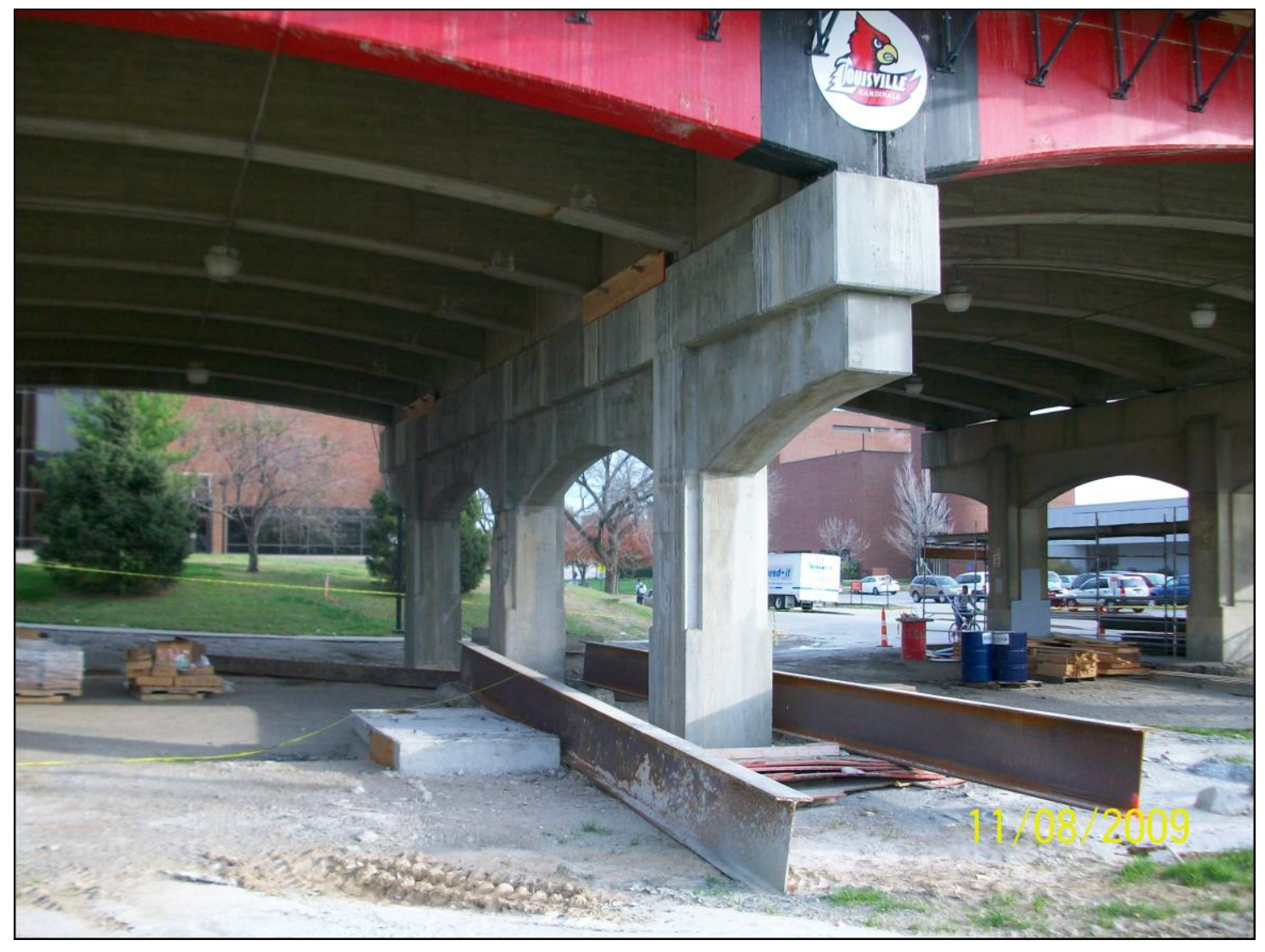

FIGURE 13 - Piers One and Two of Eastern Parkway Bridge As Viewed From South Side During Construction 


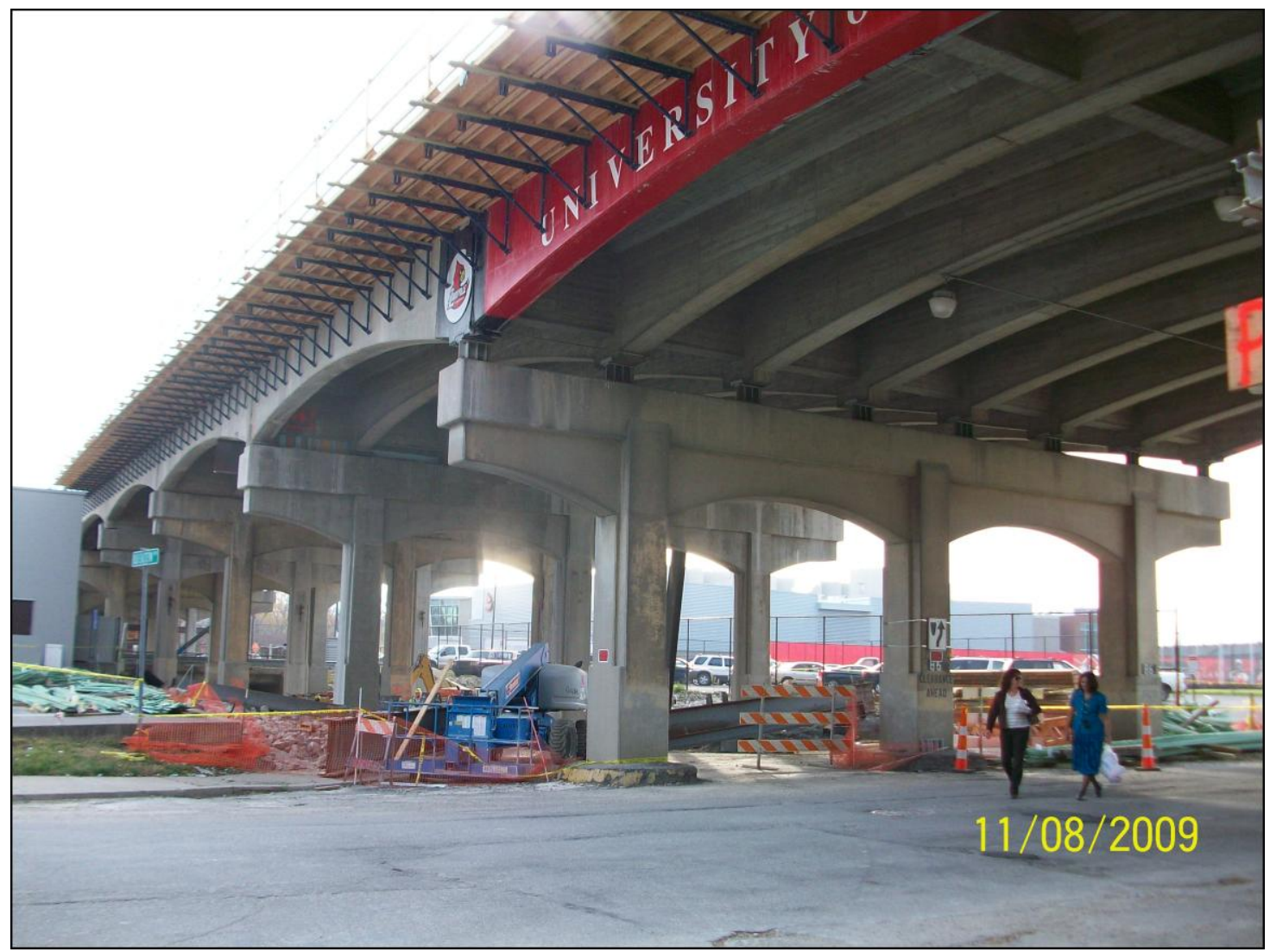

FIGURE 14 - Piers Three Through Seven of Eastern Parkway Bridge As Viewed From North Side During Construction 


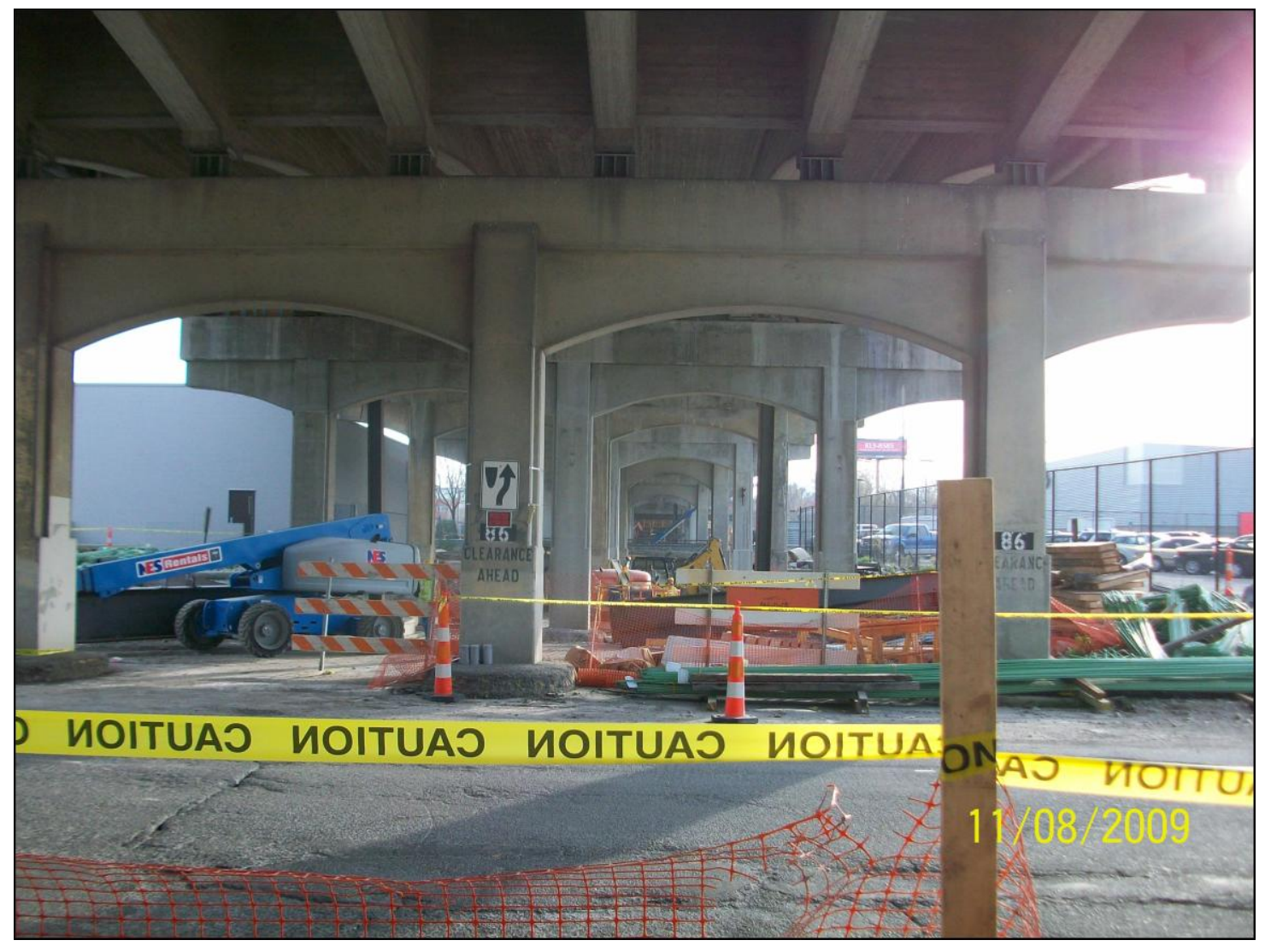

FIGURE 15 - Piers Three Through End of Eastern Parkway Bridge As Viewed From West Side During Construction 

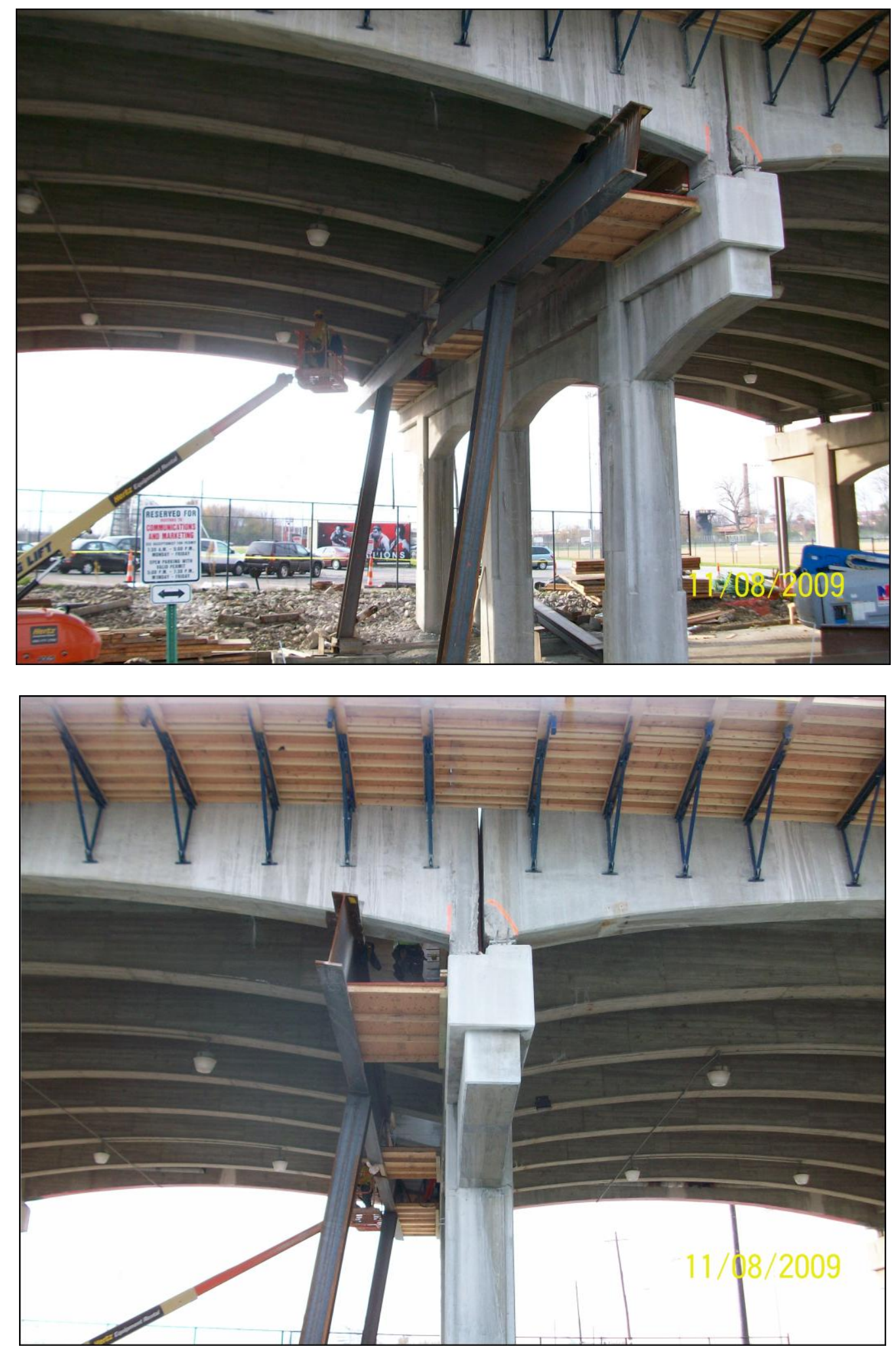

FIGURE 16 - Pier Four of Eastern Parkway Bridge As Viewed From North Side During Construction 

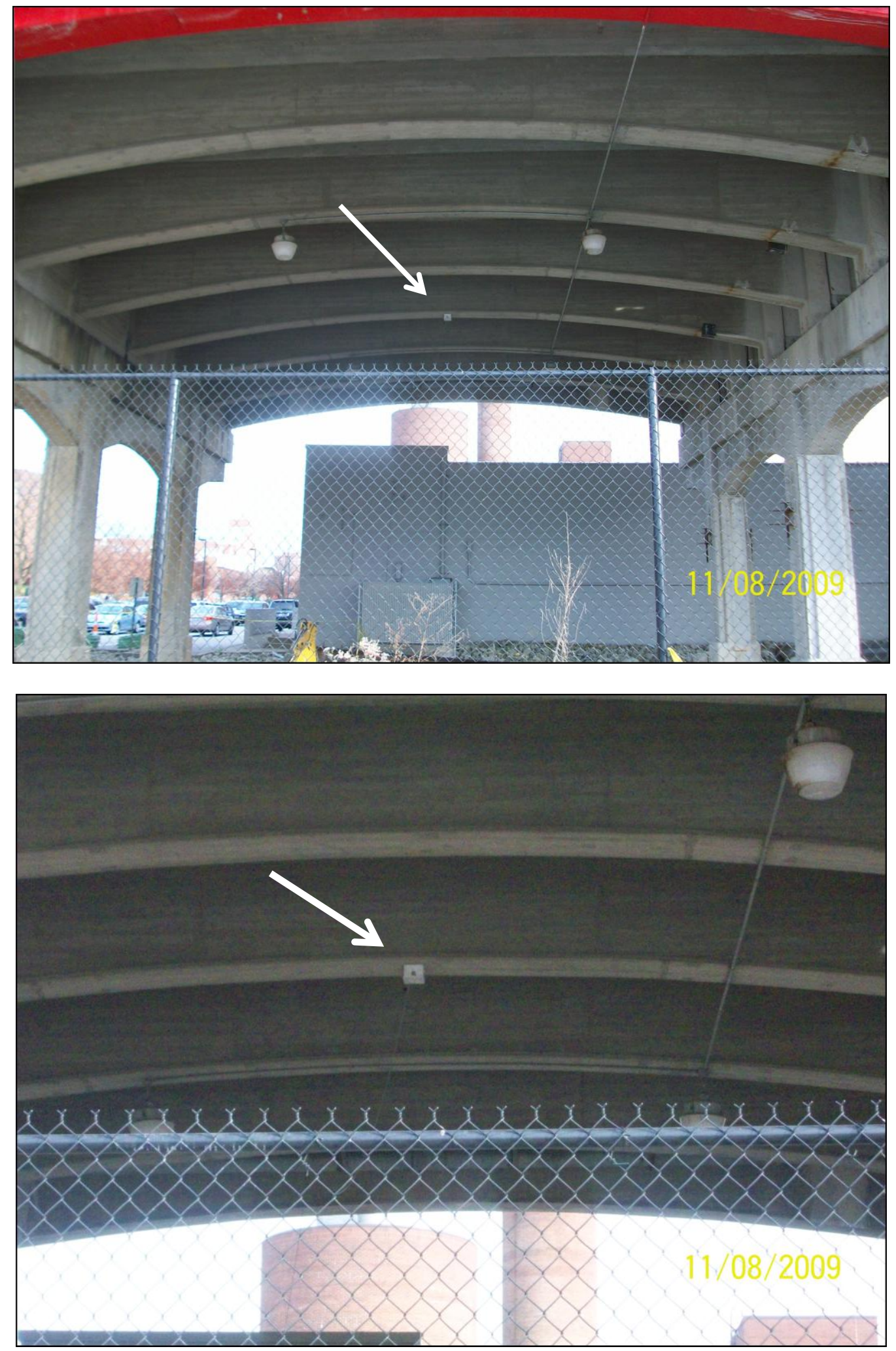

FIGURE 17 - Accelerometer Placed Between Piers Five And Six As Viewed From South Side During Construction 


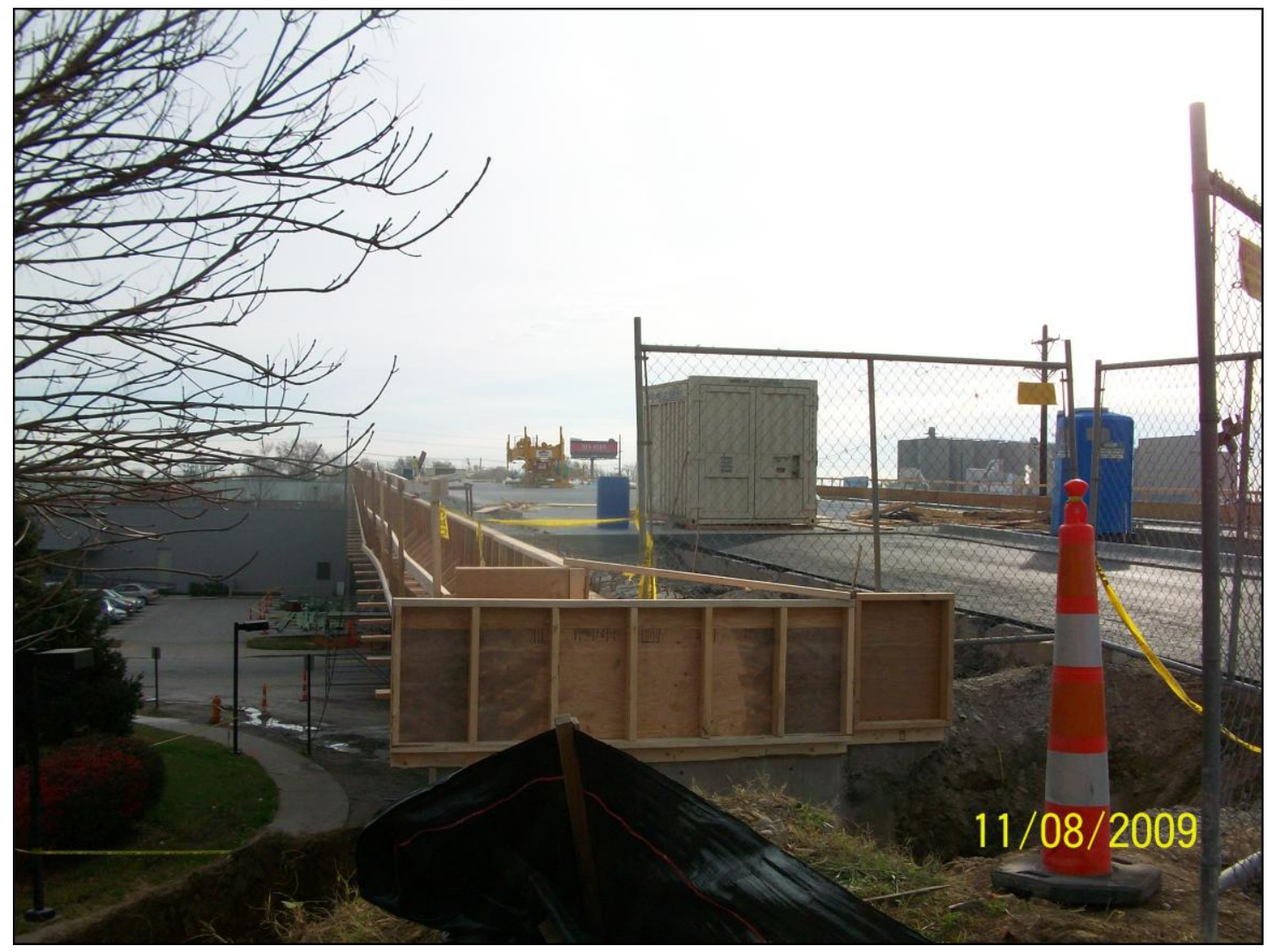

FIGURE 18 - Surface of Eastern Parkway Bridge As Viewed From Northwest Corner During Construction 


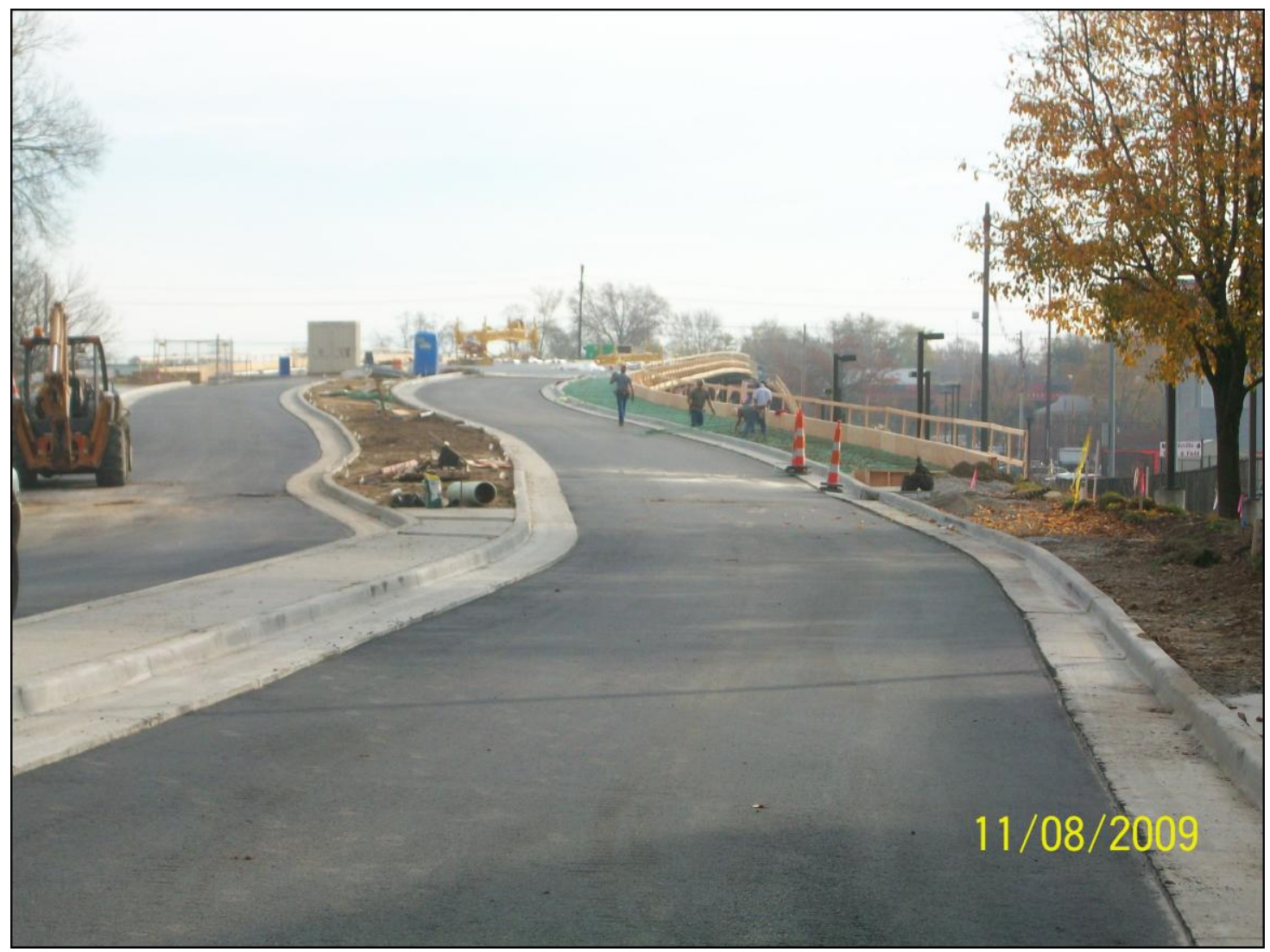

FIGURE 19 - Surface of Eastern Parkway Bridge As Viewed From Southwest Corner During Construction 


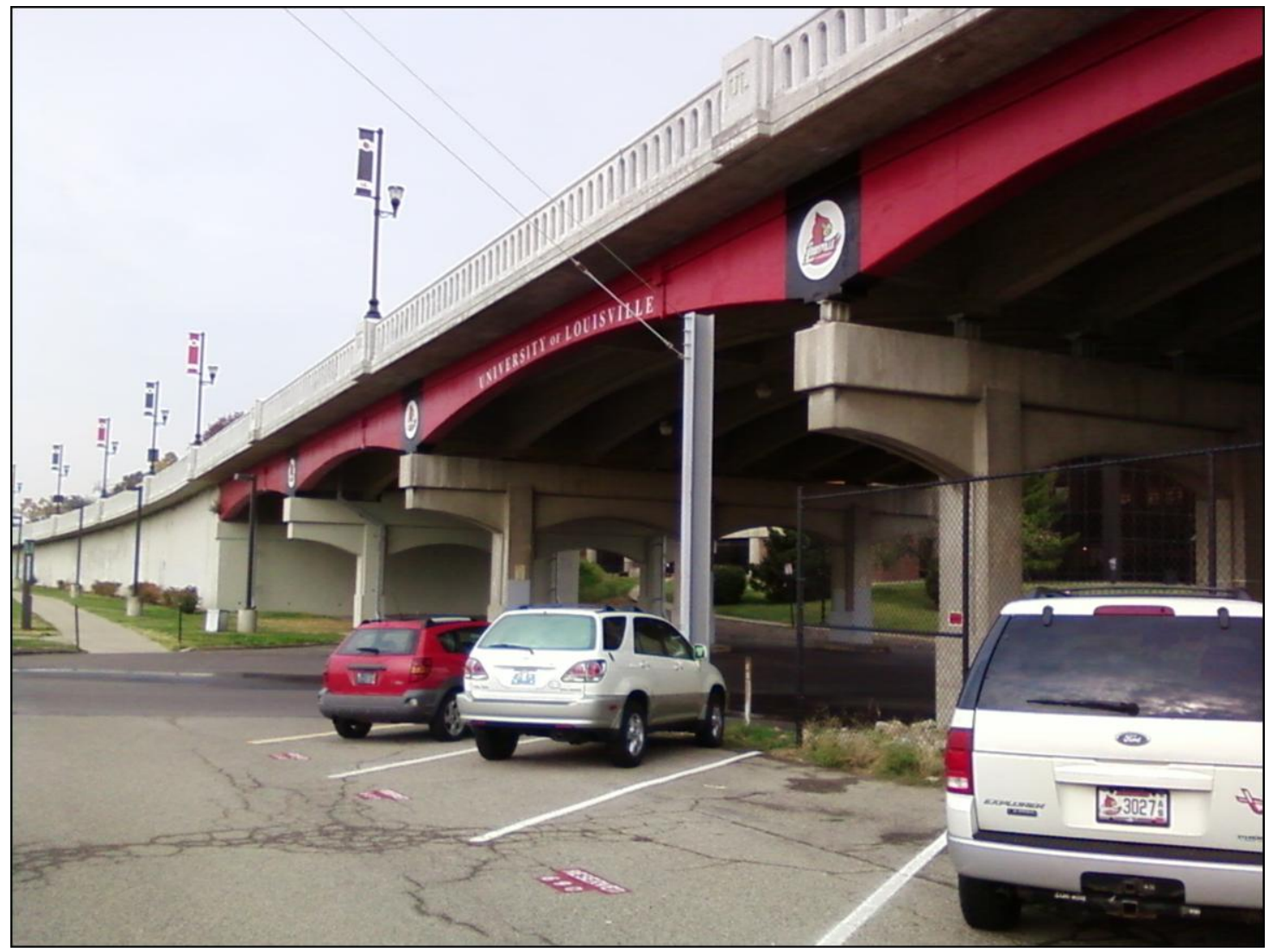

FIGURE 20 - Piers One Through Three of Eastern Parkway Bridge As Viewed From South Side After Construction 


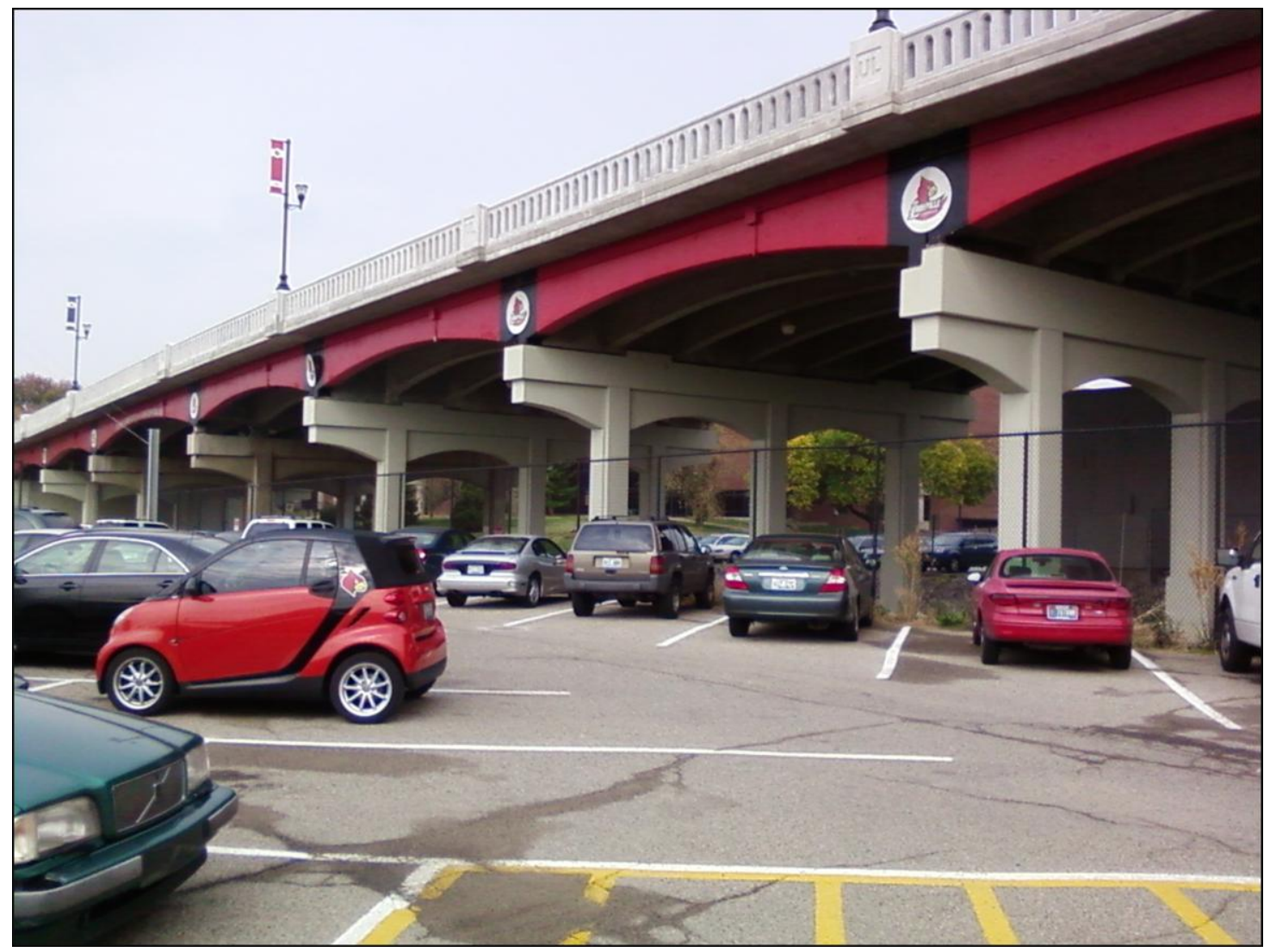

FIGURE 21 - Piers One Through Six of Eastern Parkway Bridge As Viewed From South Side After Construction 


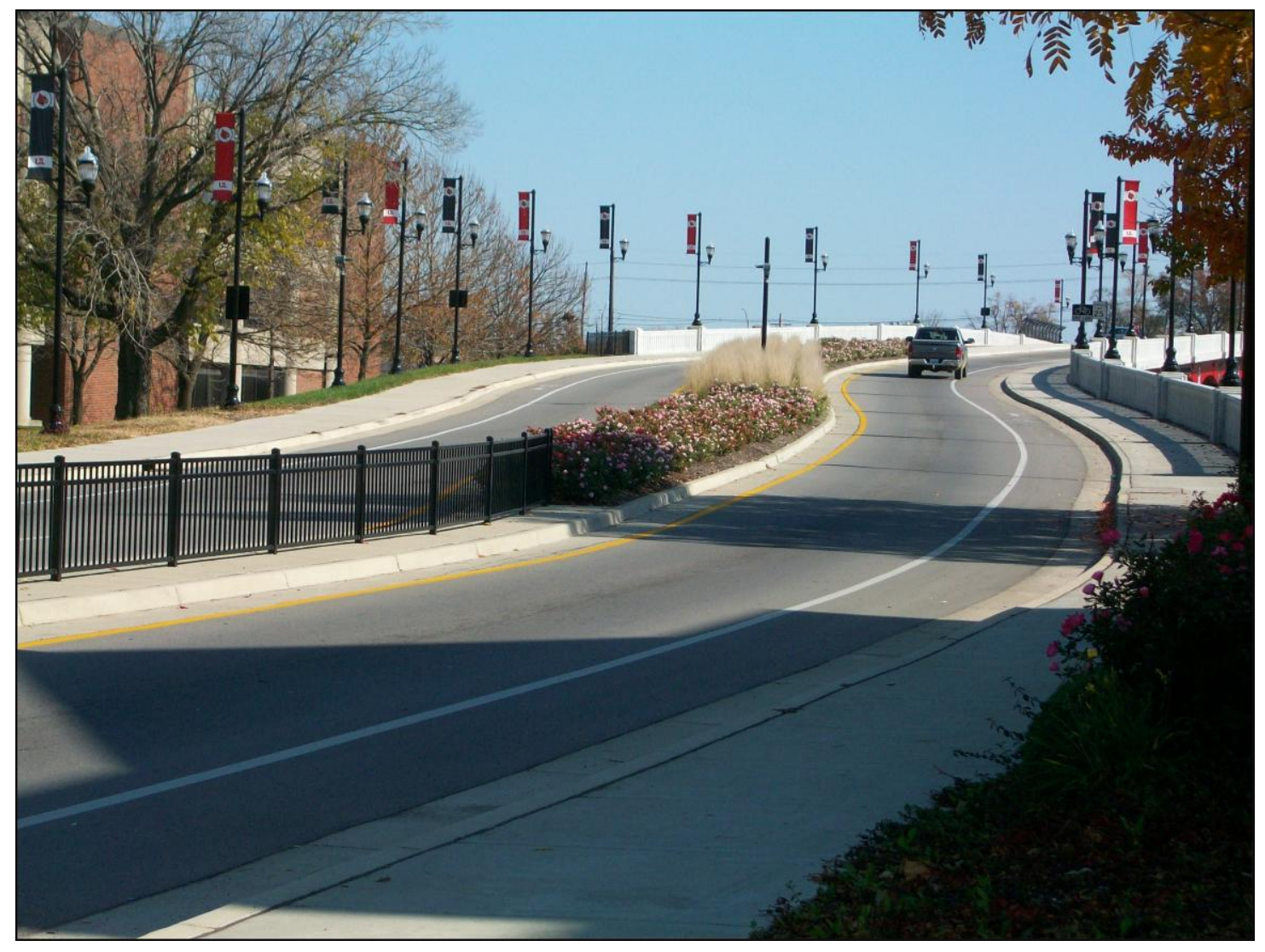

FIGURE 22 - Surface of Eastern Parkway Bridge As Viewed From West Side After Construction 


\section{APPENDIX II}

\section{PREPARATION AND INITIAL PROPERTIES IN ANSYS}

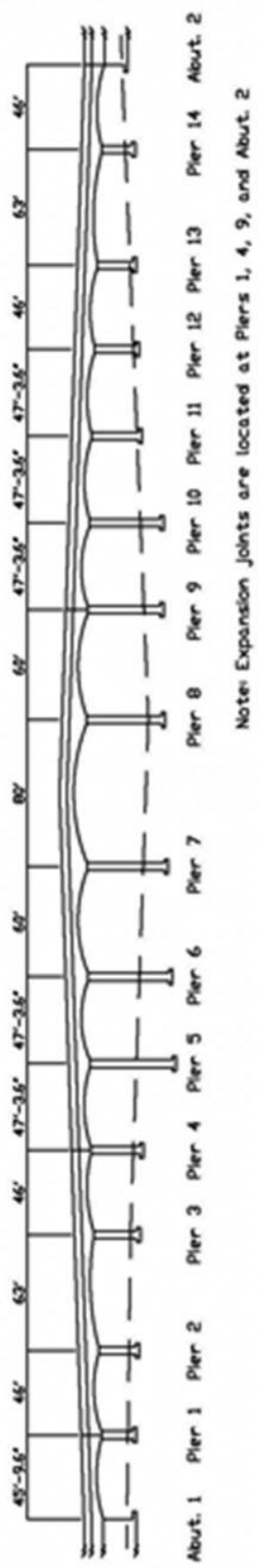

FIGURE 23 - Pier Layout With Abutment One At The West End And Abutment Two At The East End Of The Bridge 


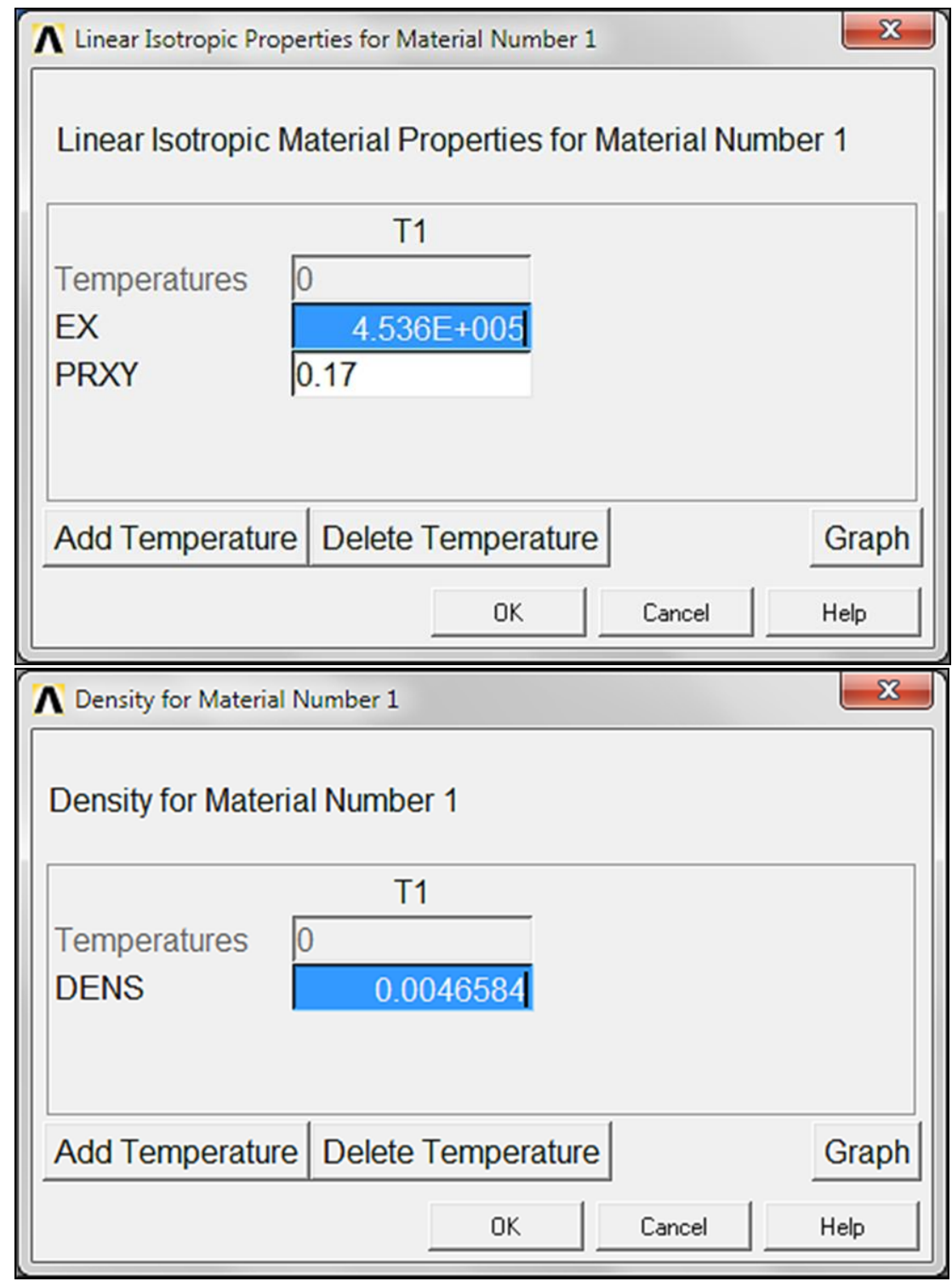

FIGURE 24 - Screen Captures of Concrete Properties Used in ANSYS Calculations 


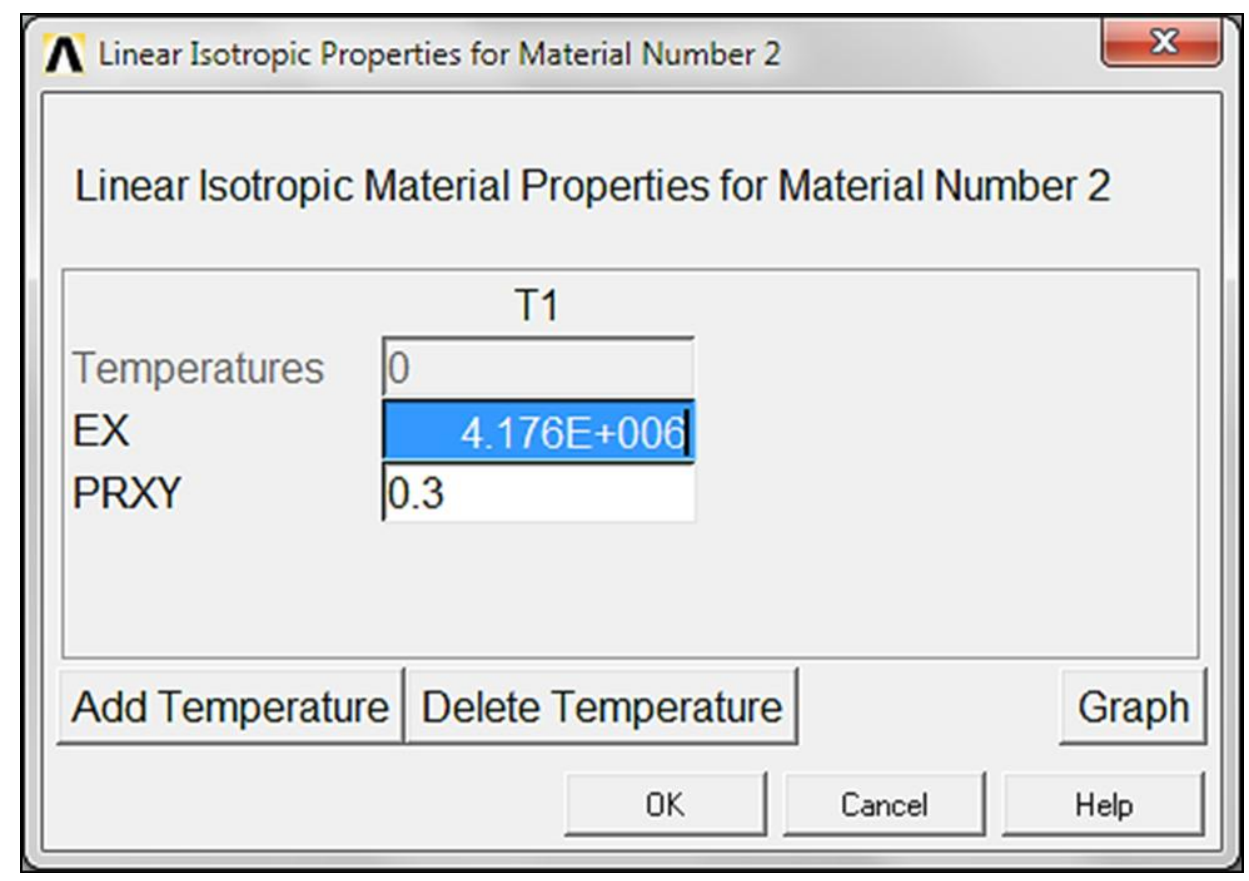

FIGURE 25 - Screen Capture of Steel Properties Used in ANSYS Calculations

\begin{tabular}{|c|c|c|c|c|}
\hline \multicolumn{3}{|c|}{ 凡 MPLIST Command } & & \multirow[t]{2}{*}{$x$} \\
\hline File & & & & \\
\hline $\begin{array}{c}\text { EUALUATE } \\
\text { MATERIAL } \\
\text { EX }= \\
\text { NUXY }= \\
\text { DENS }= \\
\text { PRXY }=\end{array}$ & $\begin{array}{l}\text { MATERIAL PROP } \\
\text { NUMBER = } \\
0.45360 \mathrm{E}+06 \\
\text { Q.1790日 } \\
0.46584 \mathrm{E}-02 \\
\text { 0.17096 }\end{array}$ & $\begin{array}{l}\text { ERTIES FOR MATERIALS } 1 \text { TO } \\
1 \text { EUALUATED AT TEMPERATURE OF }\end{array}$ & $\begin{array}{l}2 \text { IN INCREMENTS OF } \\
0.0000\end{array}$ & 1 \\
\hline $\begin{array}{l}\text { MATERIAL } \\
\text { EX }= \\
\text { NUXY }= \\
\text { PRXY }=\end{array}$ & 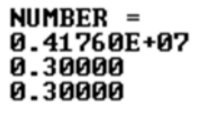 & 2 EUALUATED AT TEMPERATURE OF & 0.0000 & \\
\hline
\end{tabular}

FIGURE 26 - Screen Capture of All Material Properties Used in ANSYS Calculations 


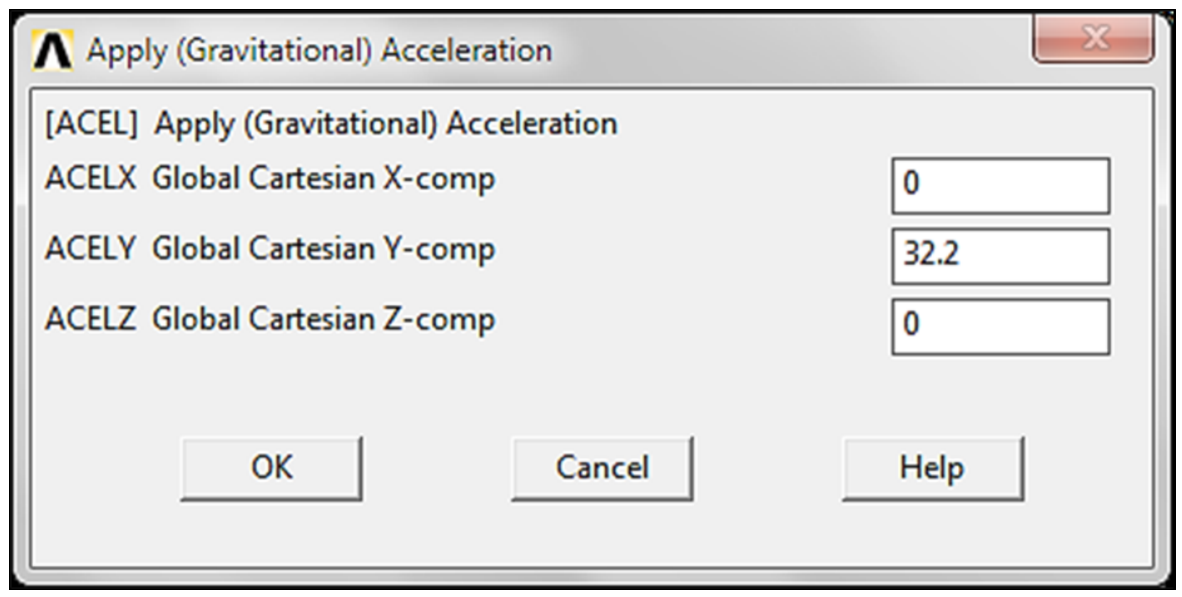

FIGURE 27 - Screen Capture of Gravitational Acceleration Used in ANSYS Calculations

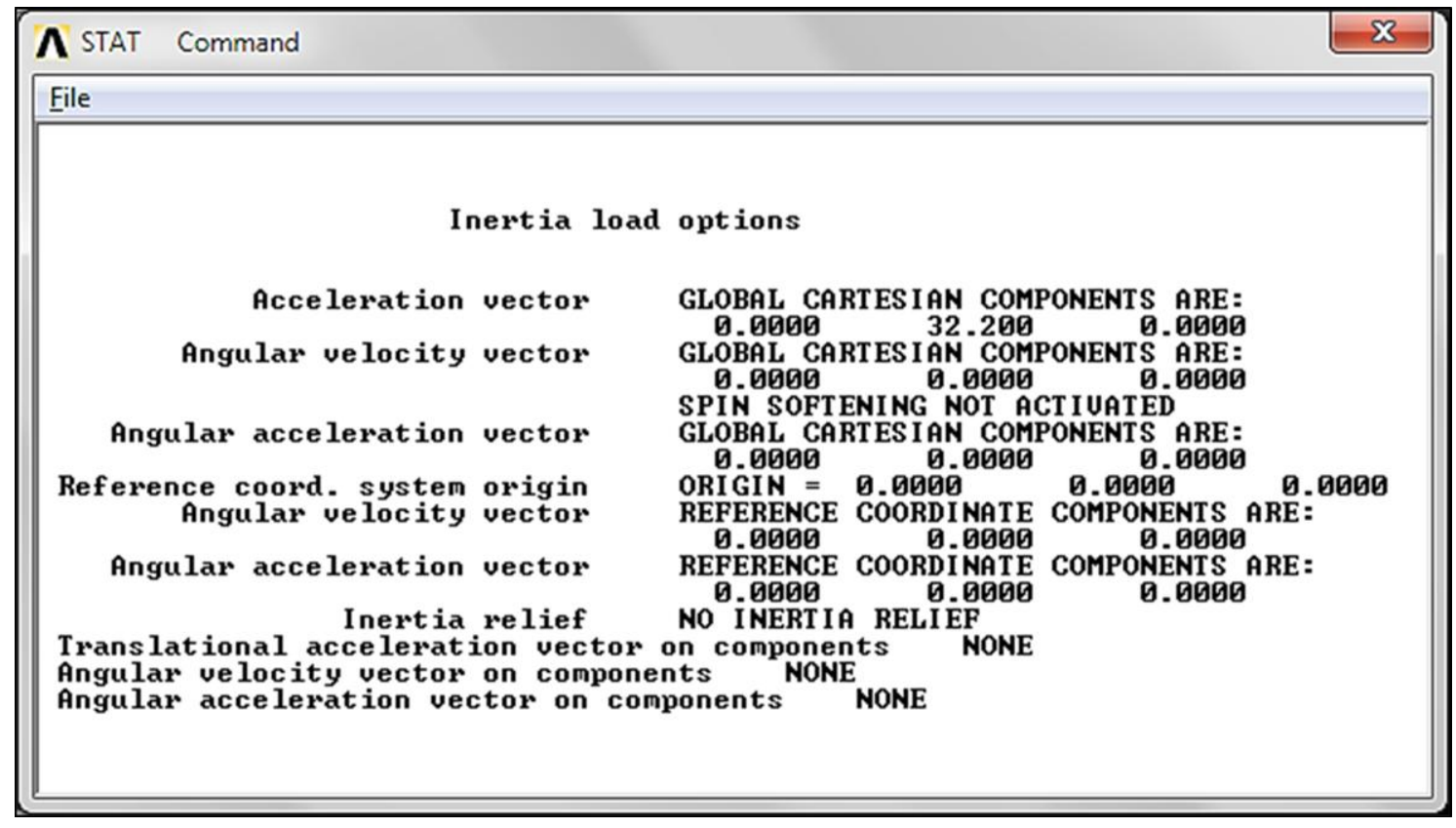

FIGURE 28 - Screen Capture of All Inertia Load Options Used in ANSYS Calculations 
APPENDIX III

SCREEN CAPTURES OF MODELING PROCESS

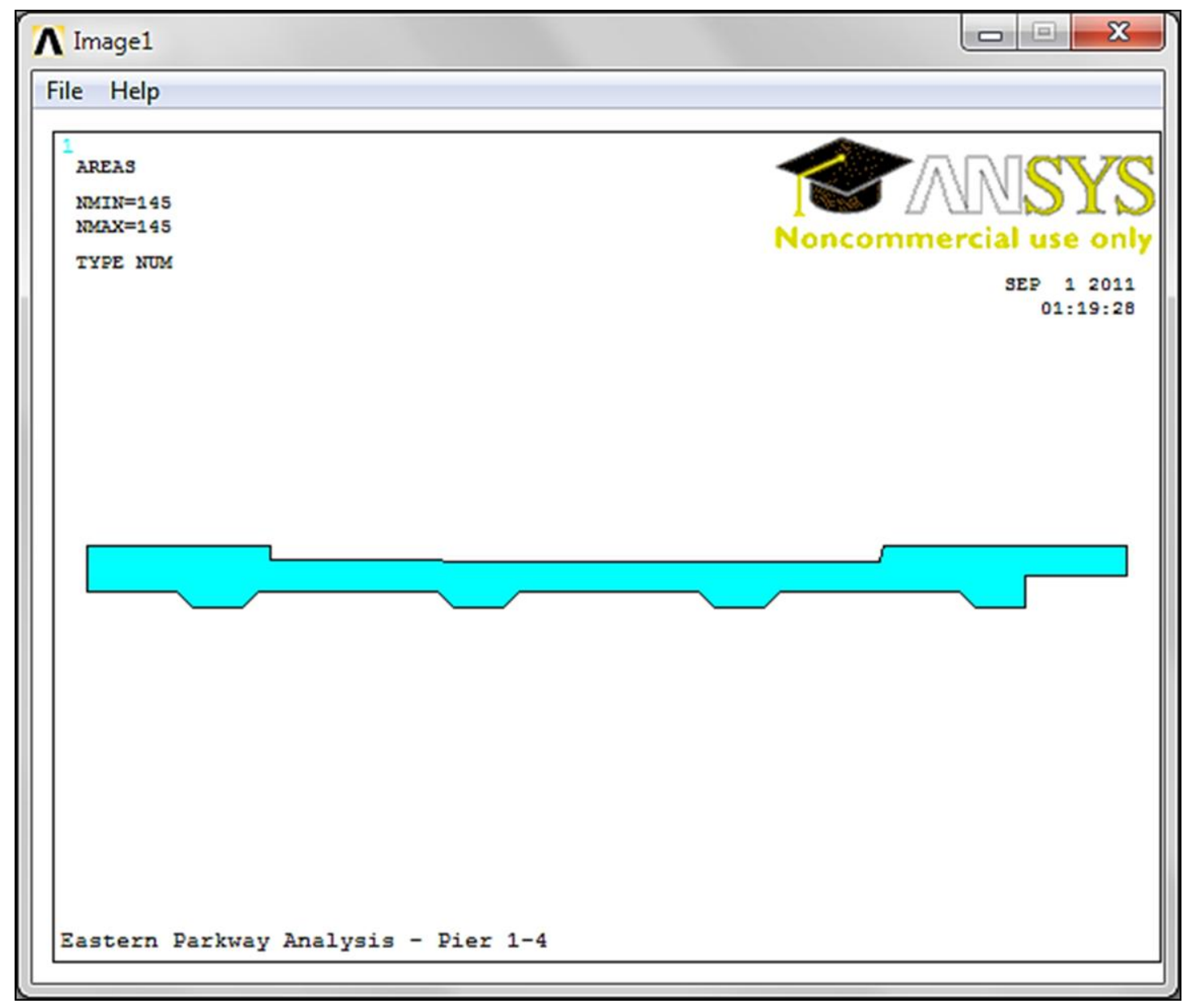

FIGURE 29 - First Step of Modeling Showing Half Cross-Section of Model Without Beams 


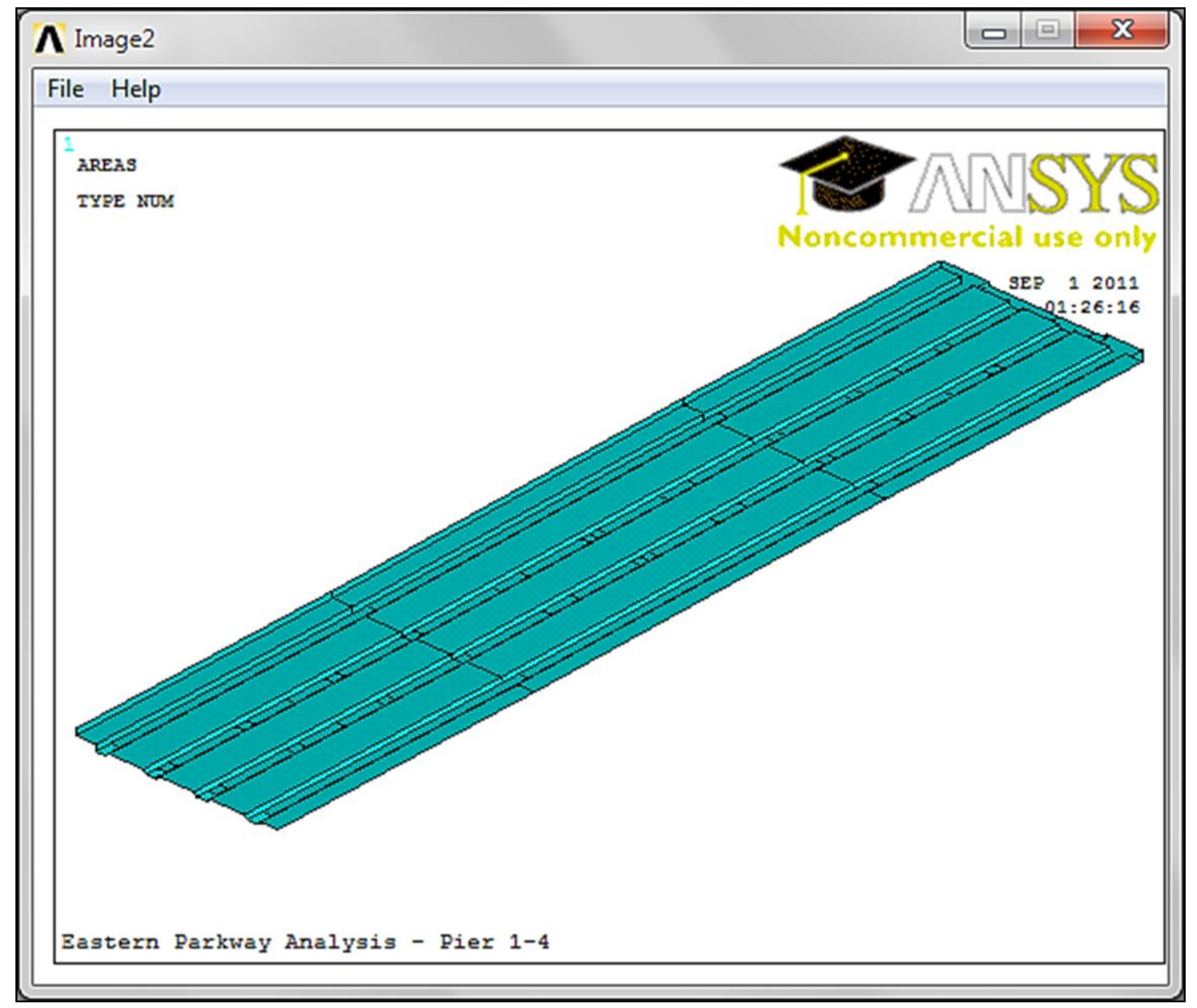

FIGURE 30 - Second Step of Modeling Showing Extrusion of Half CrossSection From Beneath the Bridge Model 


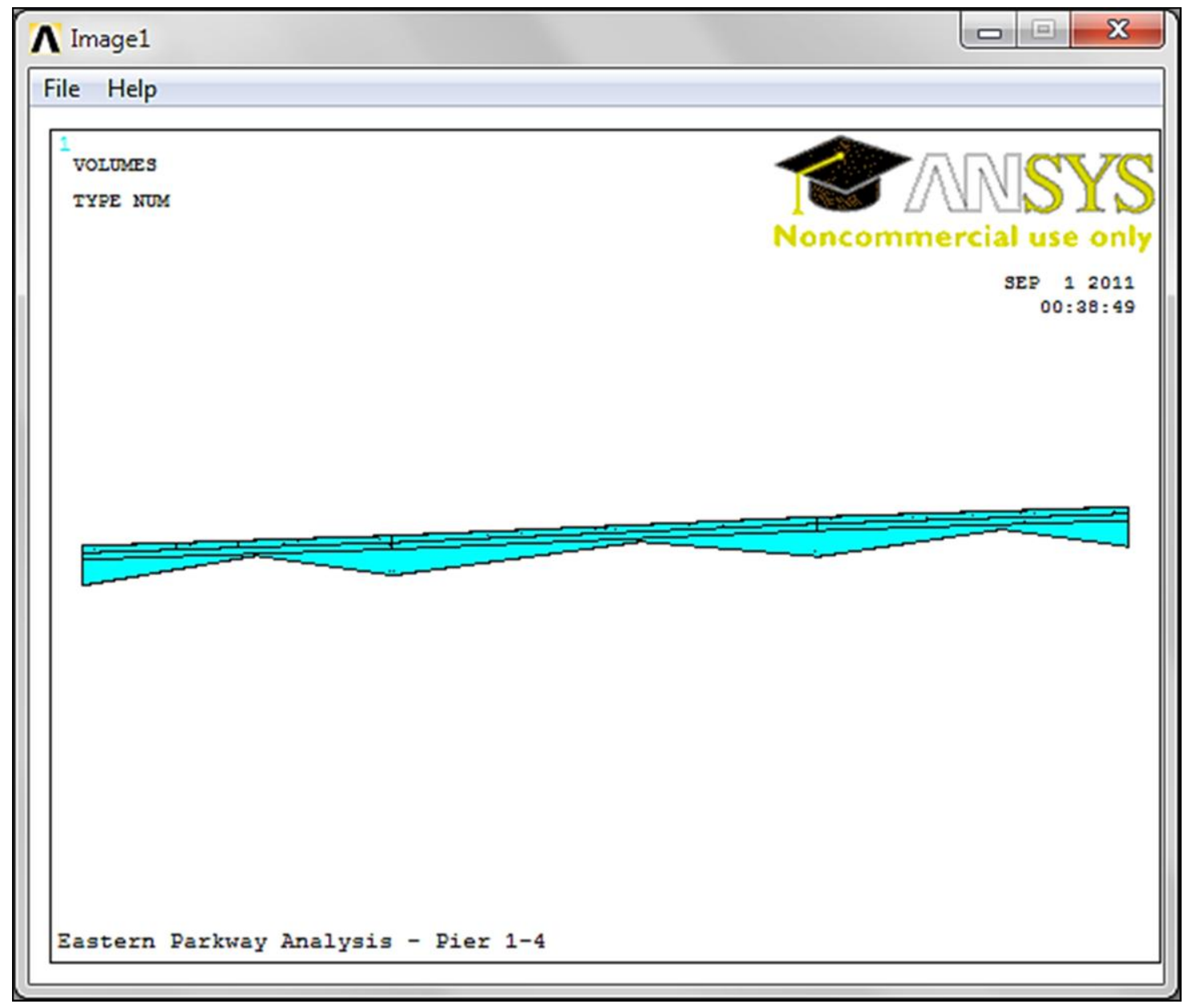

FIGURE 31 - Third Step of Modeling Showing Addition of Beams From South Side of Bridge Model 


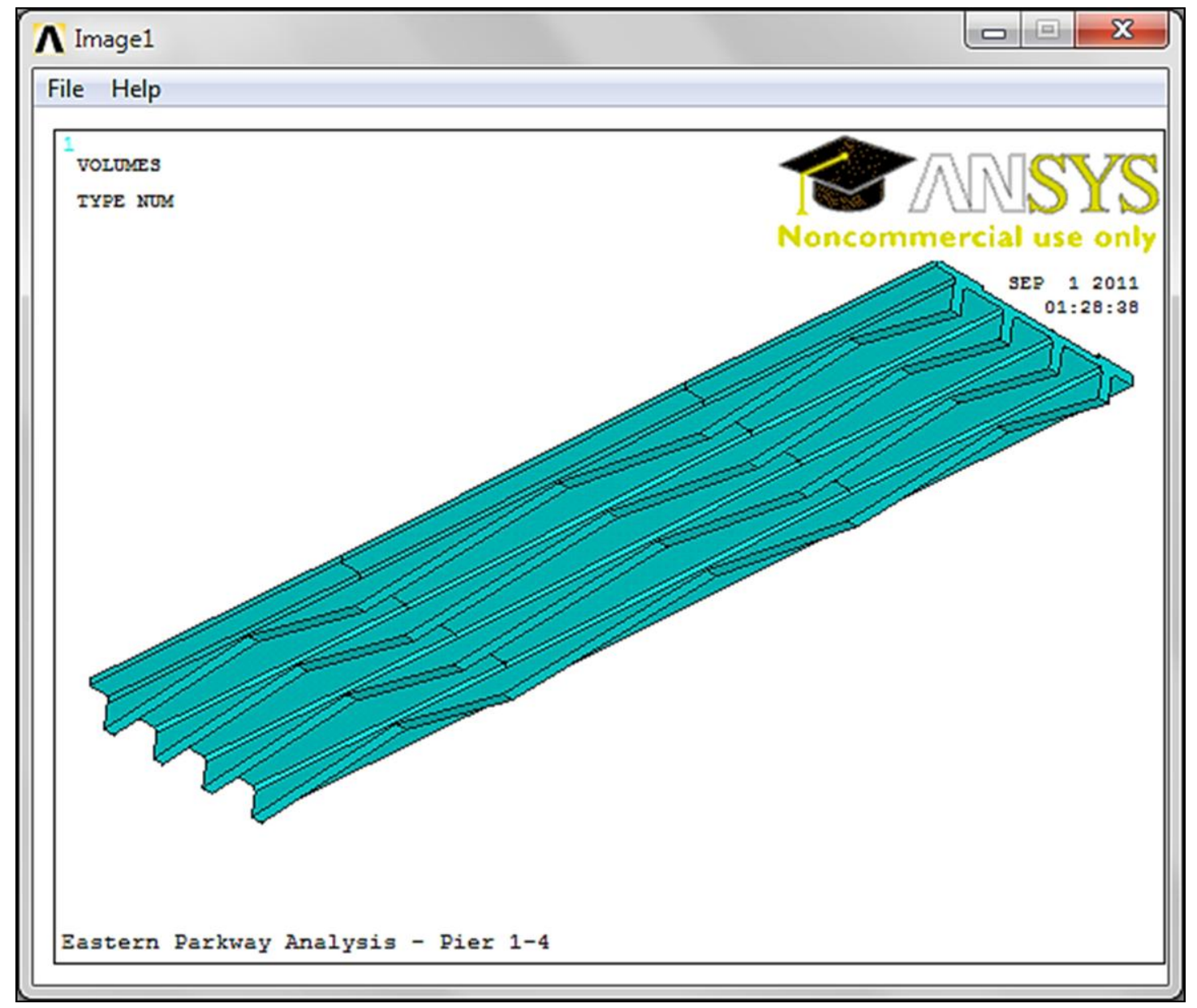

FIGURE 32 - Third Step of Modeling Showing Addition of Beams From Beneath the Bridge Model 


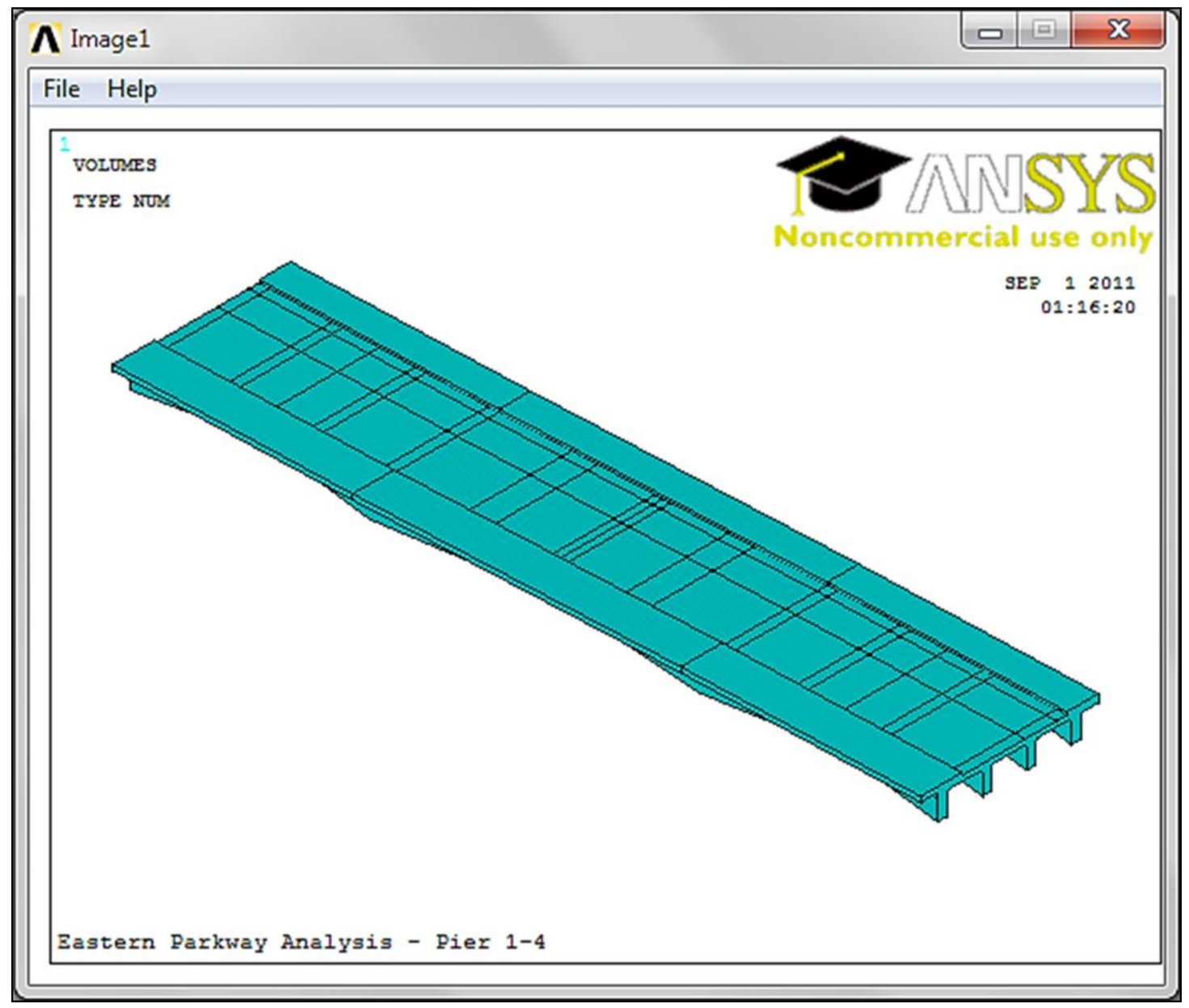

FIGURE 33 - Isometric View of Third Step of Modeling Showing Half the Bridge With the Addition of Beams 


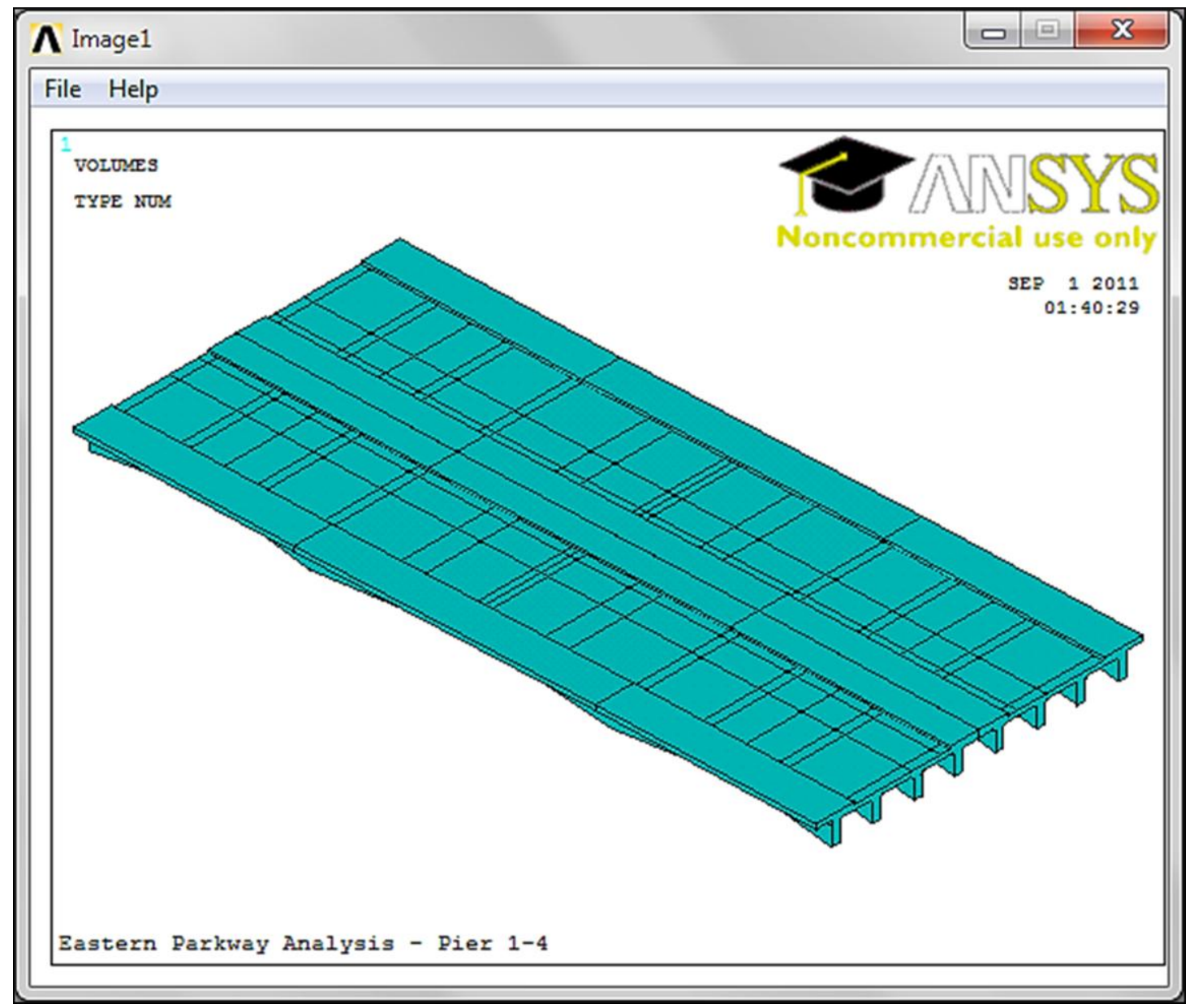

FIGURE 34 - Isometric View of Fourth Step of Modeling Showing Bridge With Full Cross-Section 


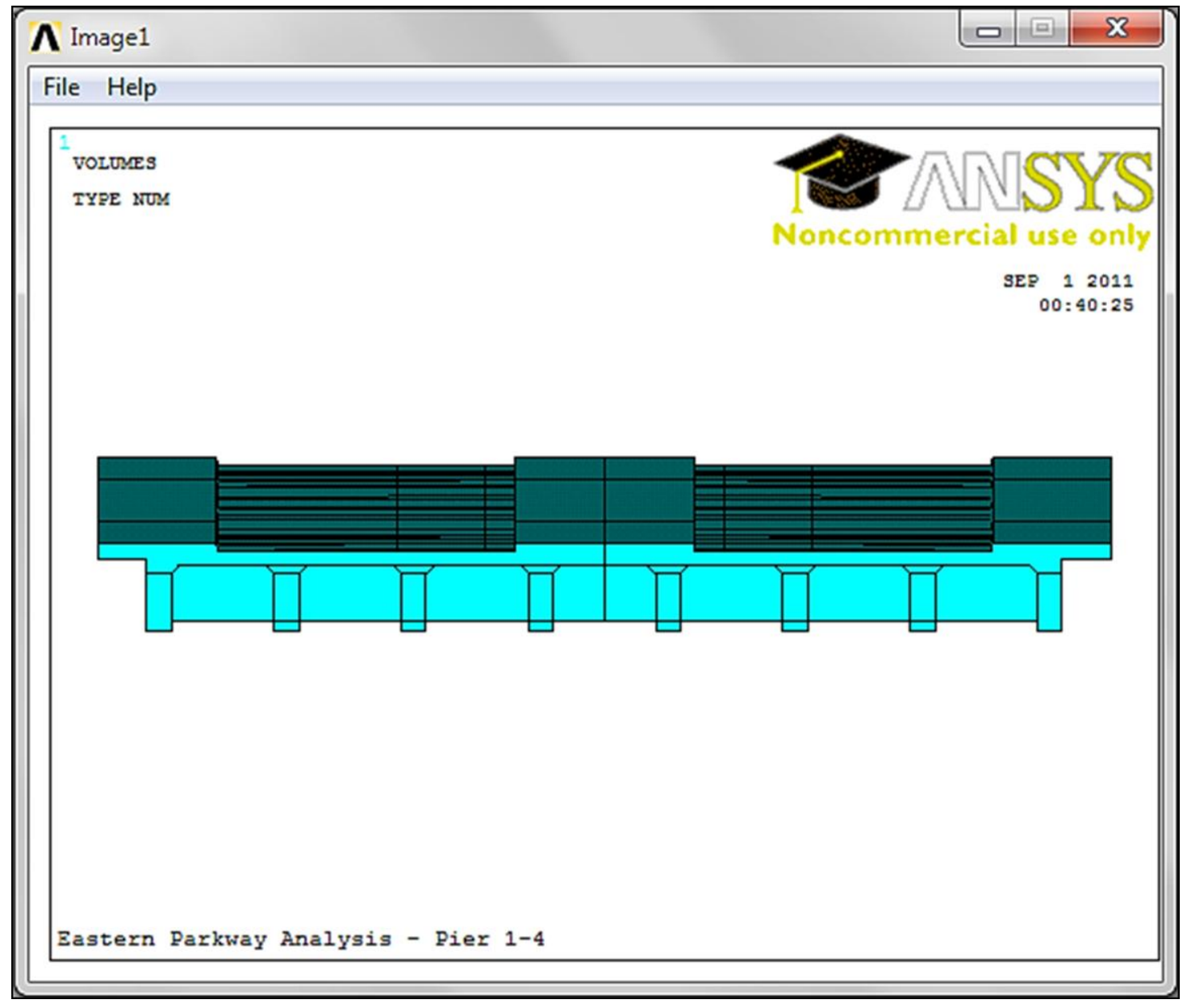

FIGURE 35 - Final Step of Modeling Showing Full Cross-Section of Model with Additional Supports Between Beams 


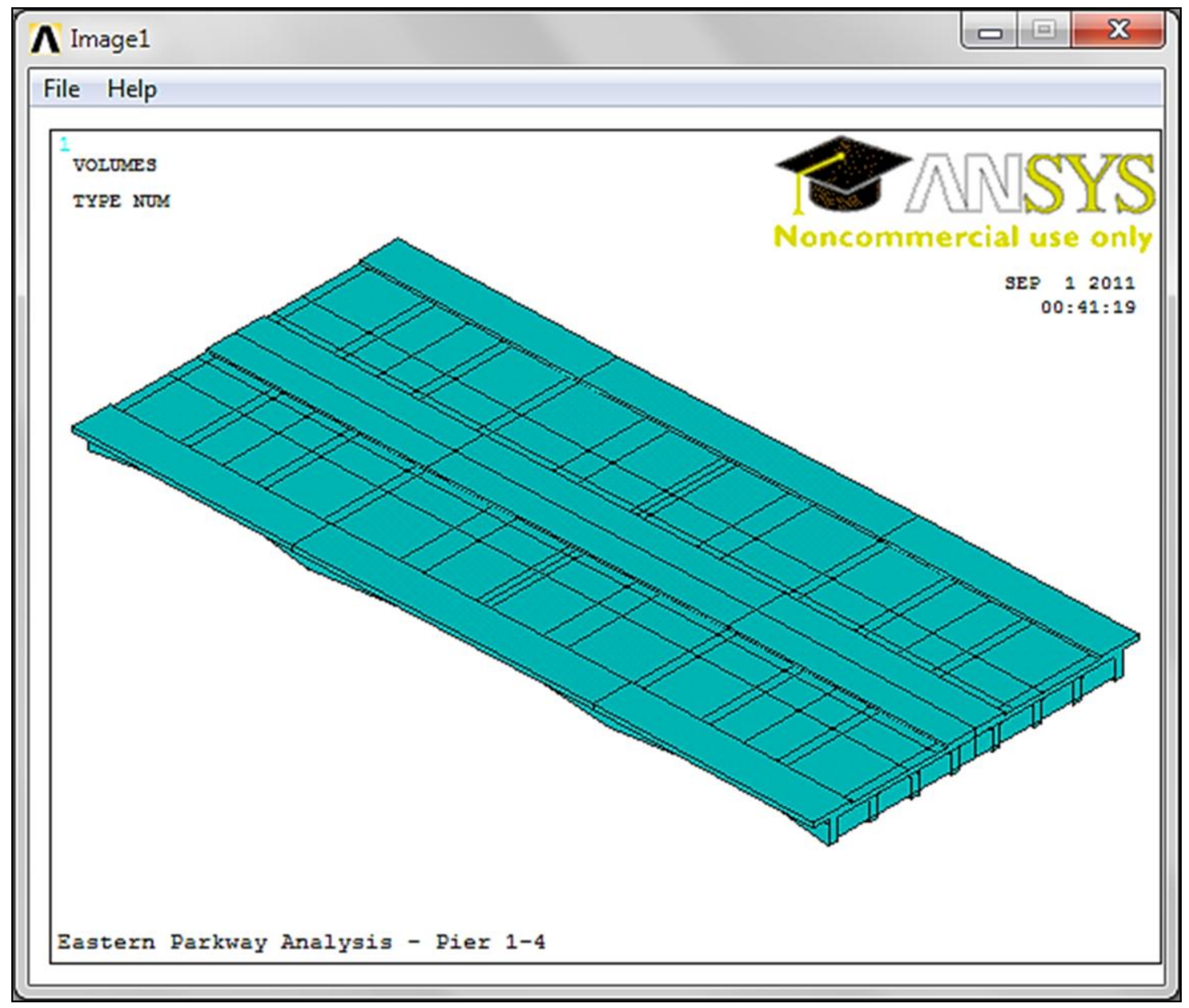

FIGURE 36 - Isometric View of Final Step of Modeling Showing Completed Bridge Model 


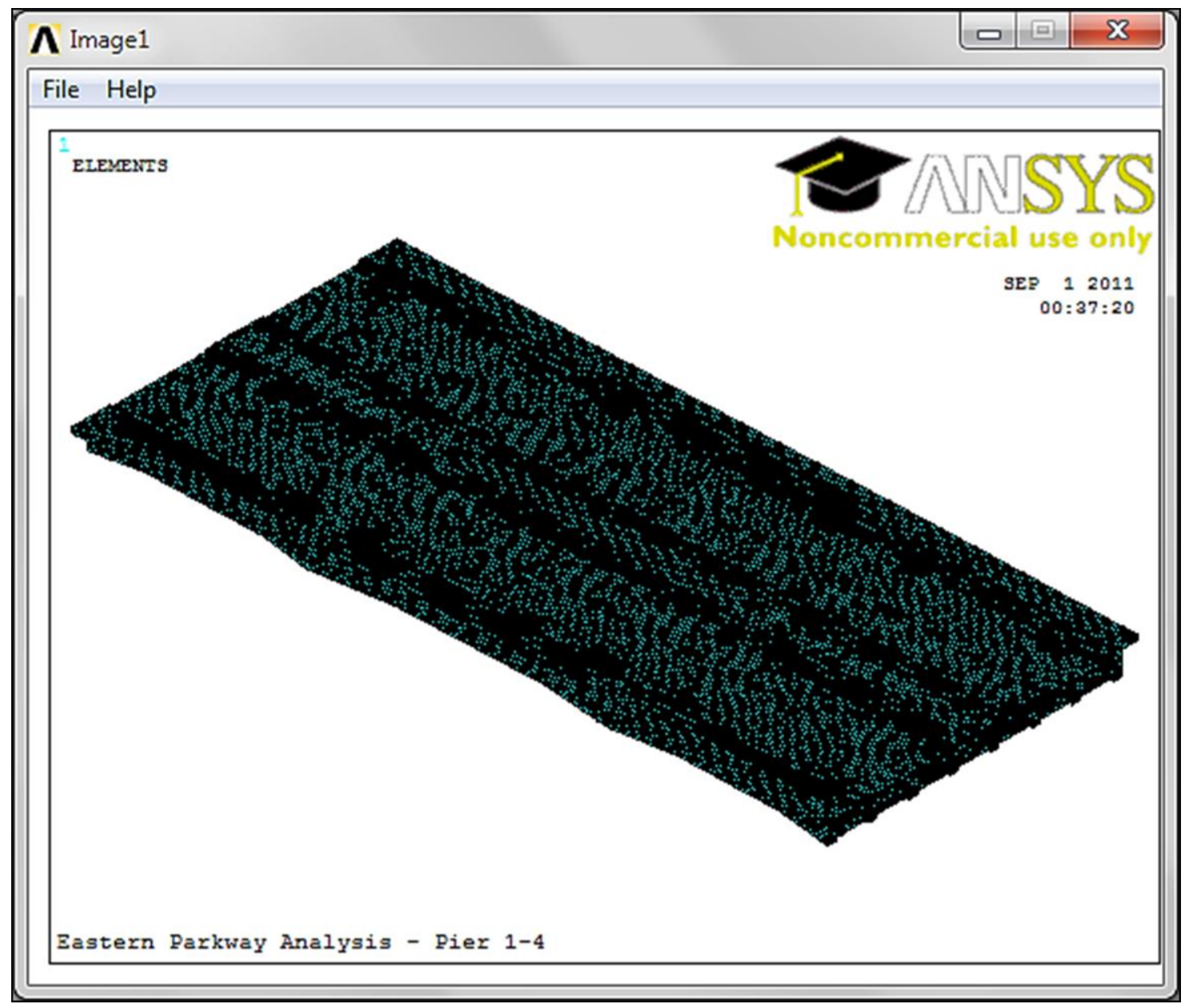

FIGURE 37 - Meshing Applied to Model in ANSYS 


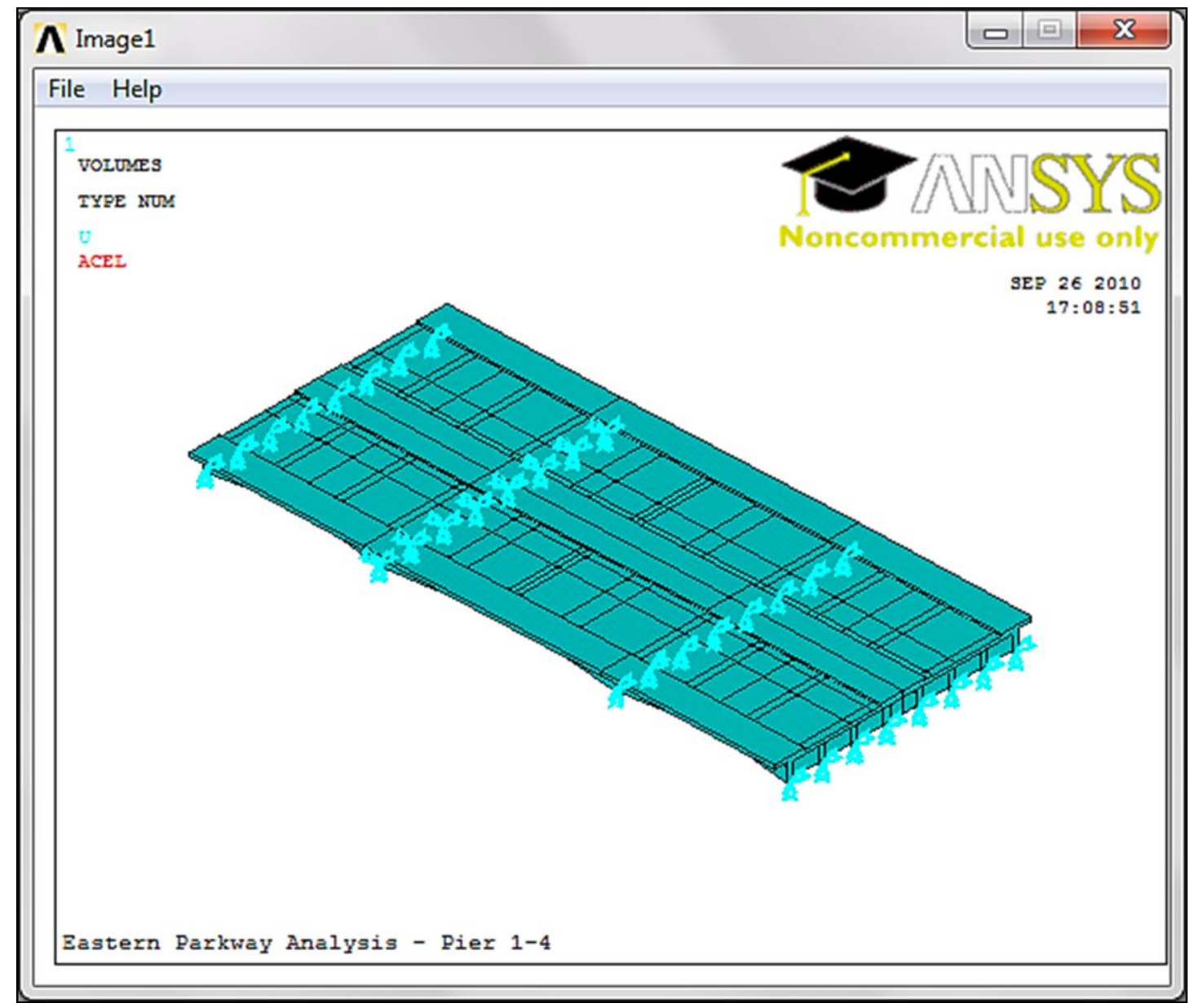

FIGURE 38 - Support Conditions As Modeled in ANSYS 
APPENDIX IV

\section{STEEL REINFORCEMENT CALCULATIONS}

Volume of Decking (per linear foot) $=53.3 \mathrm{ft} \wedge 3$

Volume of All Beams (per linear foot) $=25.7 \mathrm{ft} \wedge 3$

Volume of Cross-Sectional Steel (per linear foot of decking) $=0.187 \mathrm{ft} \wedge 3$

Volume of Longitudinal Steel (per linear foot of decking) $=0.189 \mathrm{ft} \wedge 3$

Volume of Steel (per linear foot of beams) $=0.0861 \mathrm{ft}^{\wedge} 3$

Calculating Volume Ratios for Cross-Sectional Steel:

$$
\frac{\text { Volume of Steel }}{\text { Volume of Decking }}=\frac{0.187 f t^{3}}{53.3 f t^{3}}=0.00351
$$

Calculating Volume Rations of Longitudinal Steel:

$$
\frac{\text { Volume of Steel }}{\text { Volume of Decking }}=\frac{0.189 f t^{3}}{53.3 f t^{3}}=0.00356
$$

Calculating Volume Ratios for Steel in Beams:

$$
\frac{\text { Volume of Steel }}{\text { Volume of Decking }}=\frac{0.0861 \mathrm{ft}^{3}}{25.7 \mathrm{ft}^{3}}=0.00335
$$


APPENDIX V

SCREEN CAPTURES OF LOAD CONFIGURATIONS

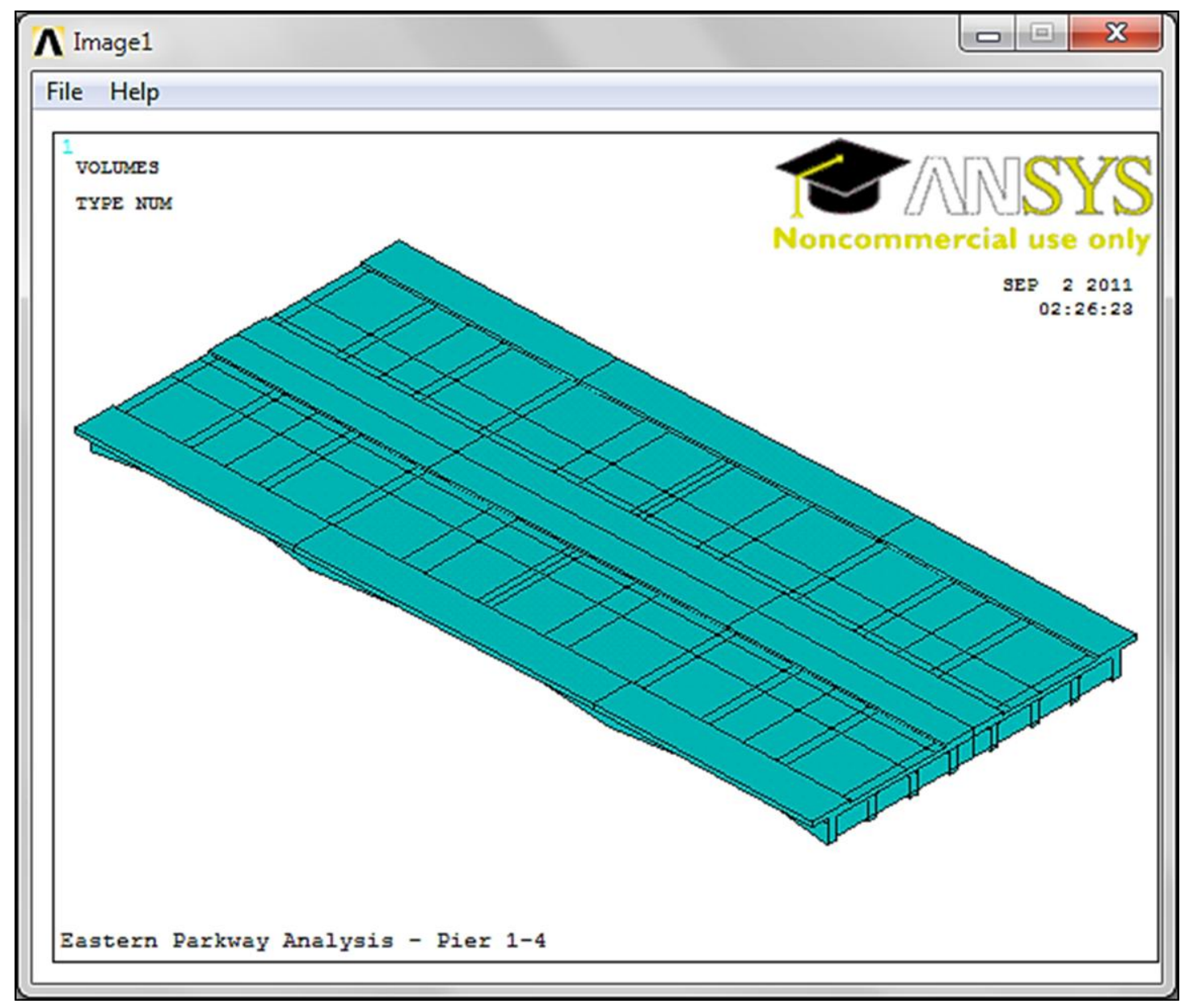

FIGURE 39 - Load Configuration for Iteration One 


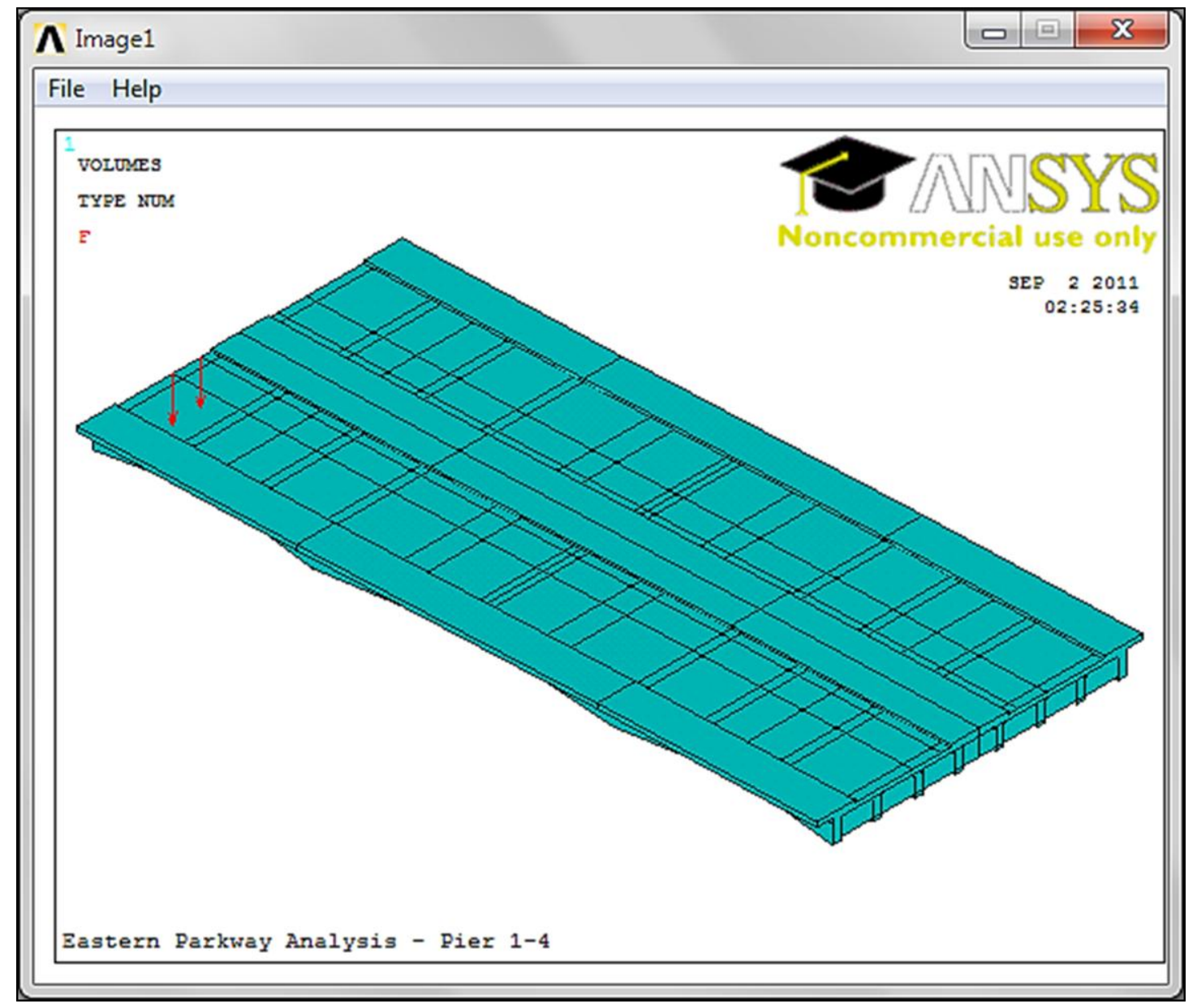

FIGURE 40 - Load Configuration for Iteration Two 


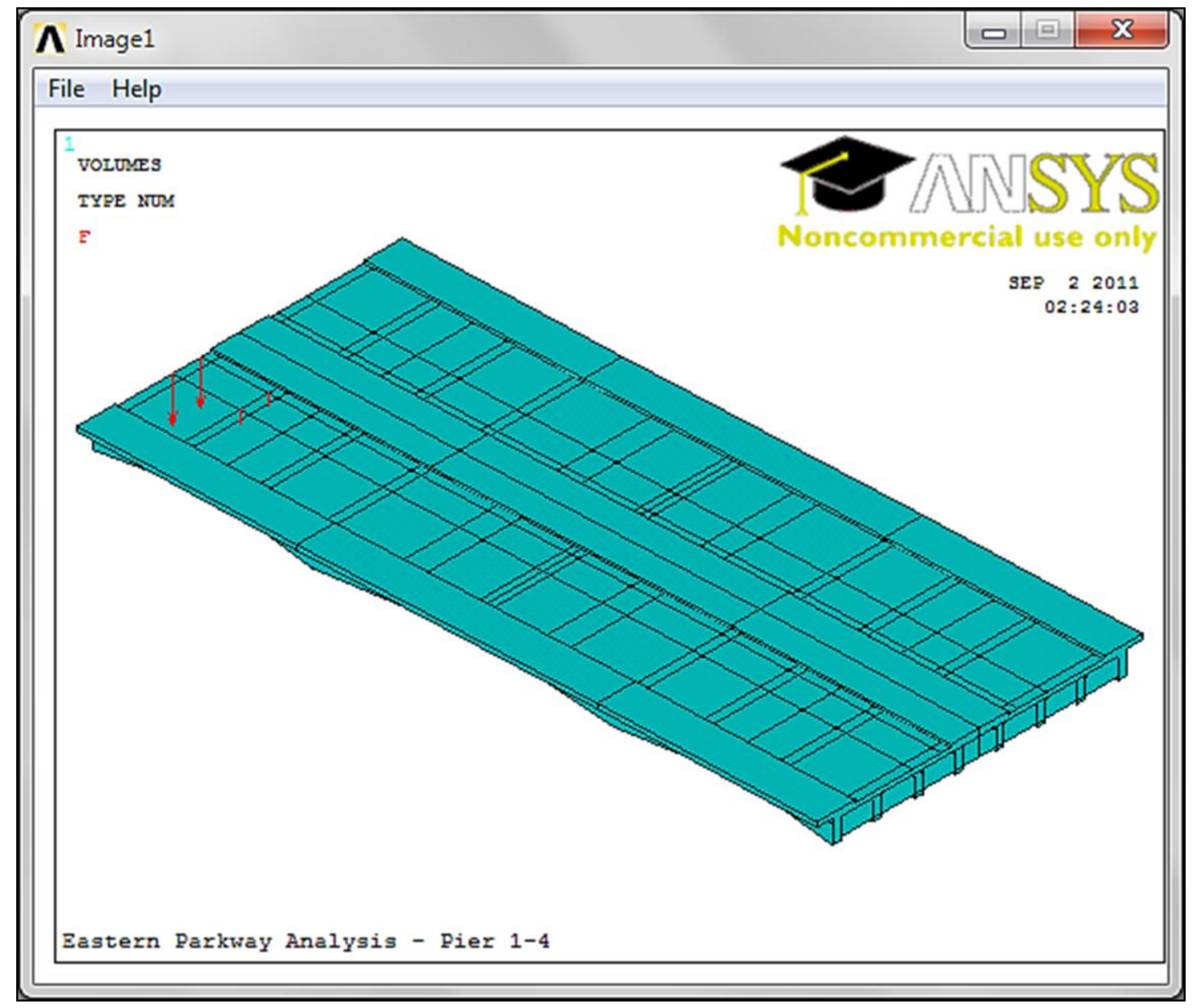

FIGURE 41 - Load Configuration for Iteration Three 


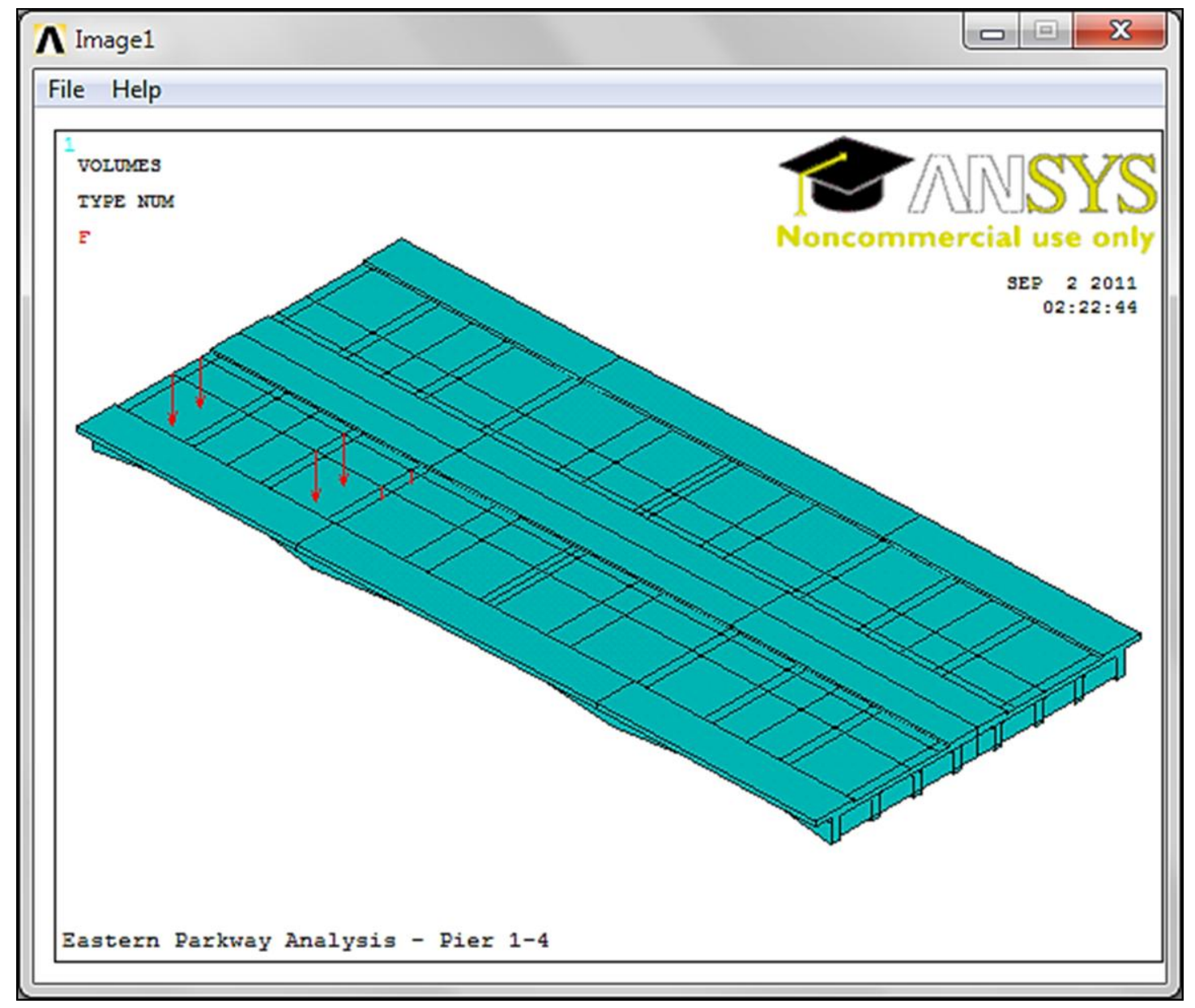

FIGURE 42 - Load Configuration for Iteration Four 


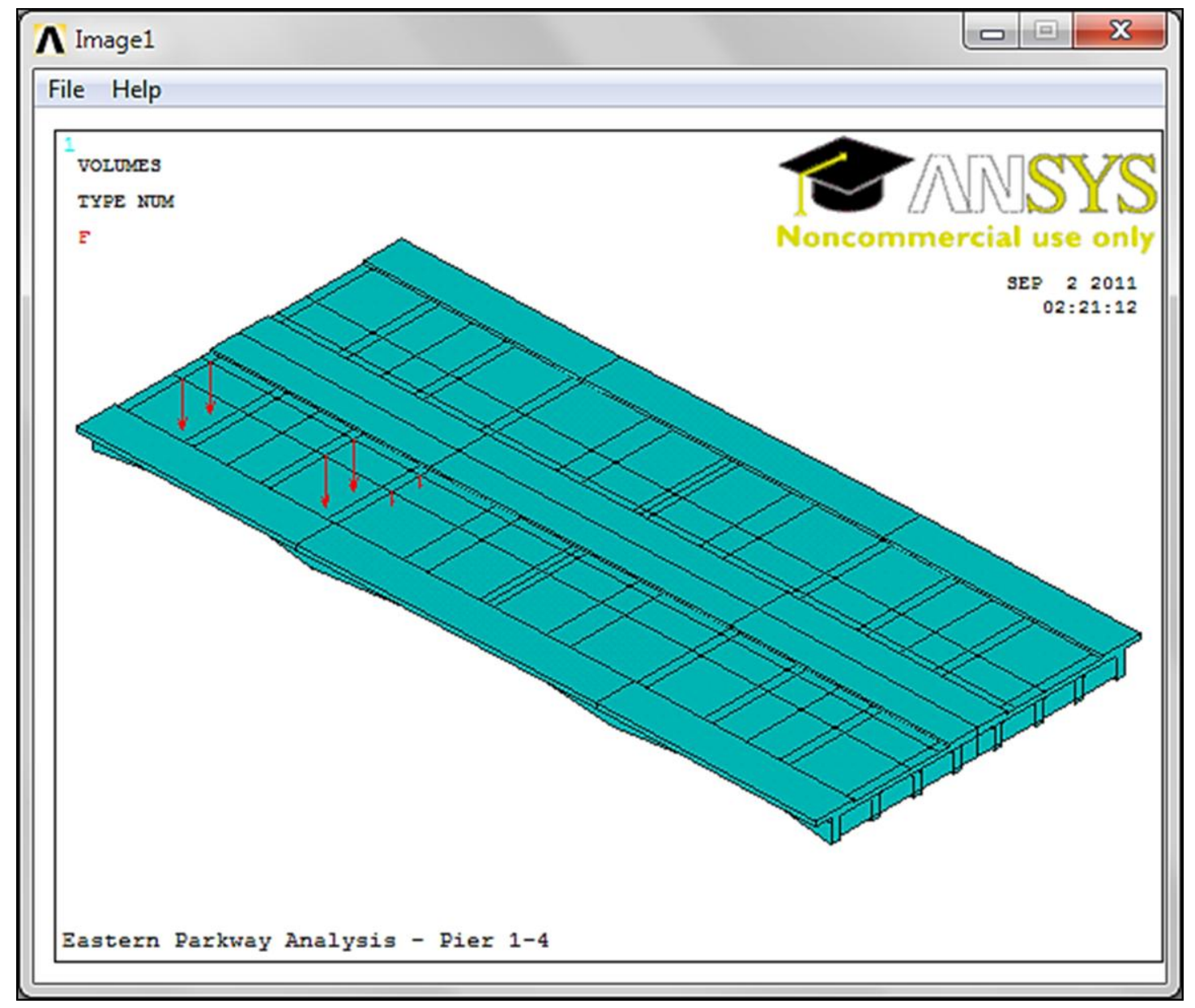

FIGURE 43 - Load Configuration for Iteration Five 


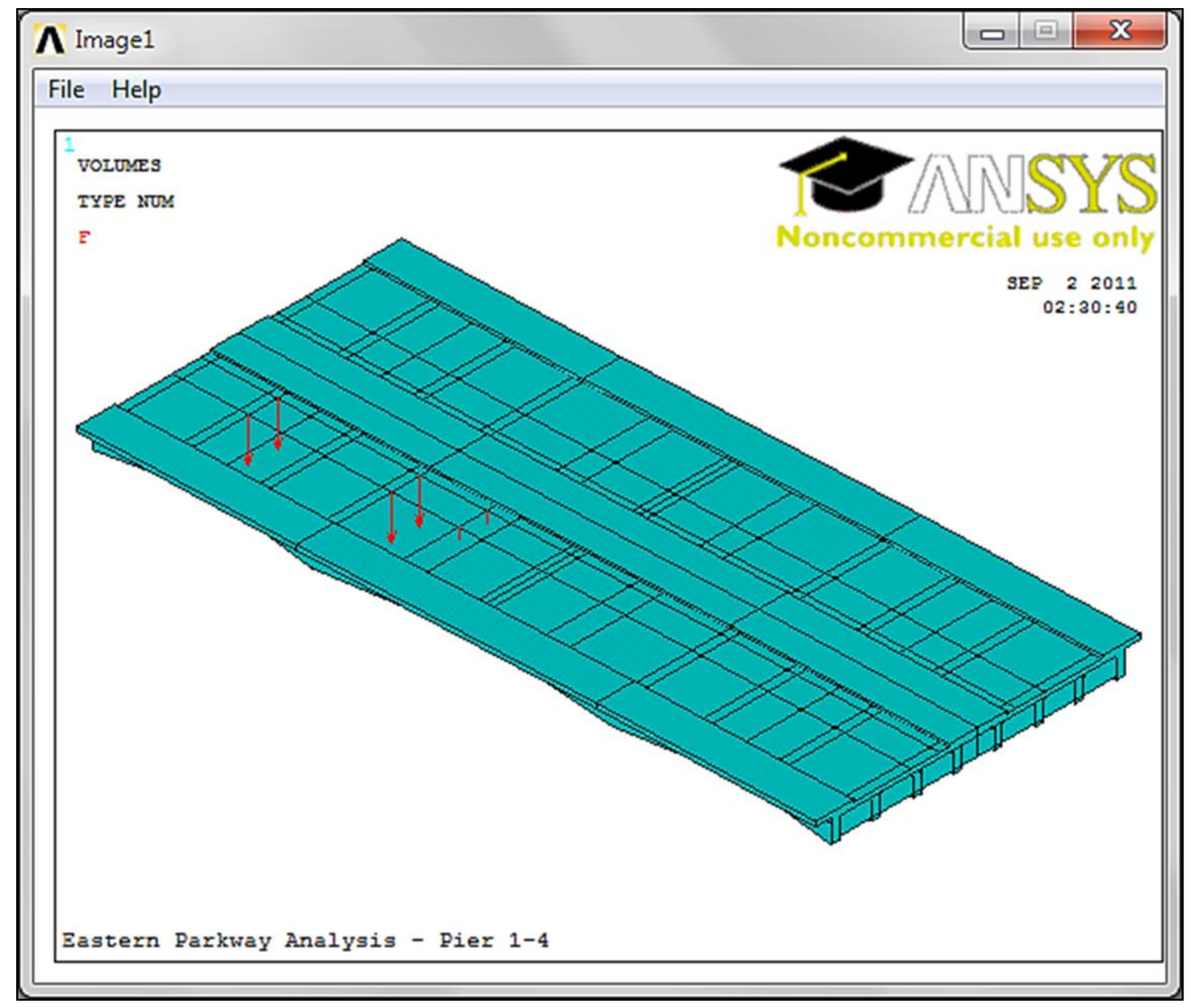

FIGURE 44 - Load Configuration for Iteration Six 


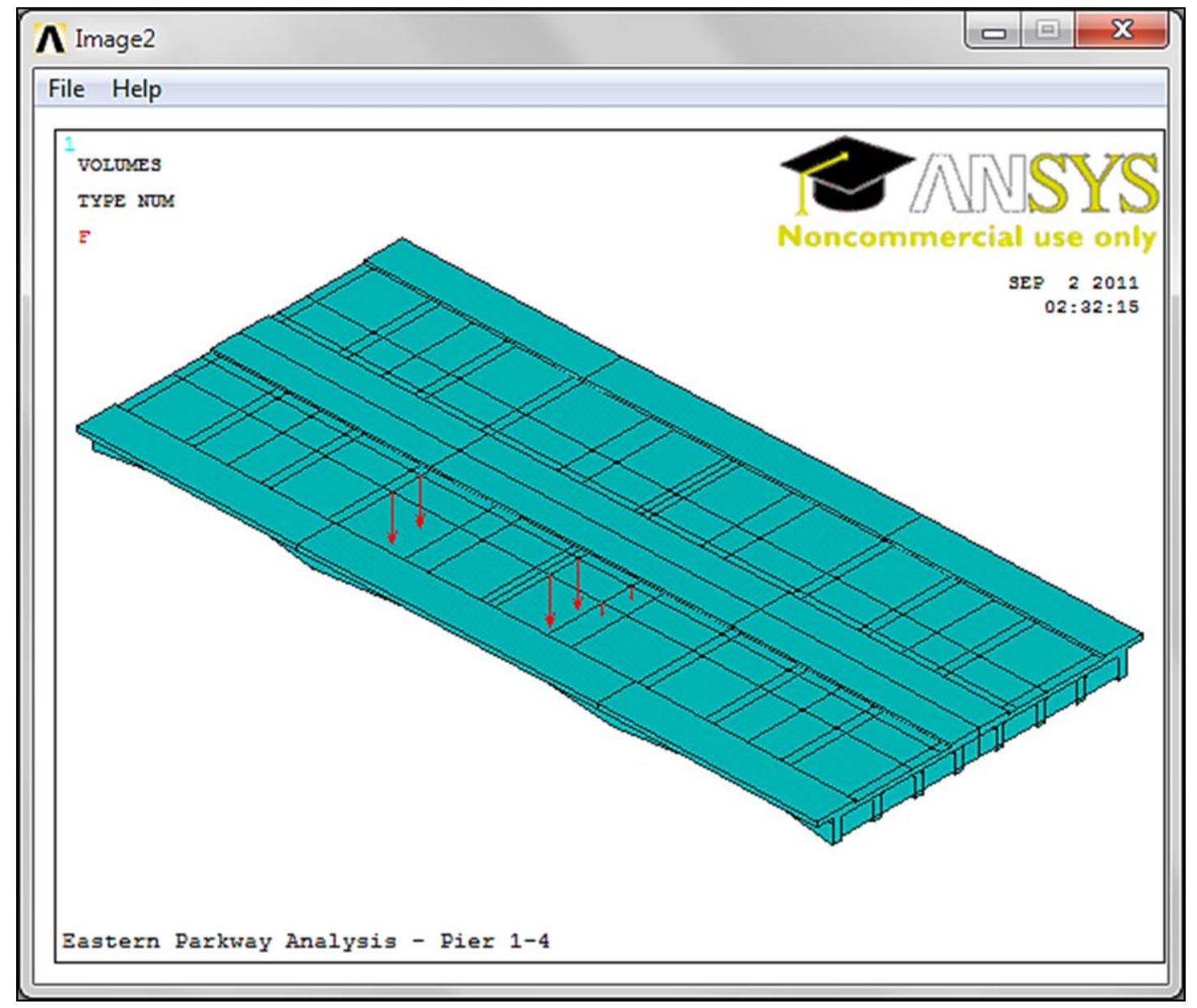

FIGURE 45 - Load Configuration for Iteration Seven 


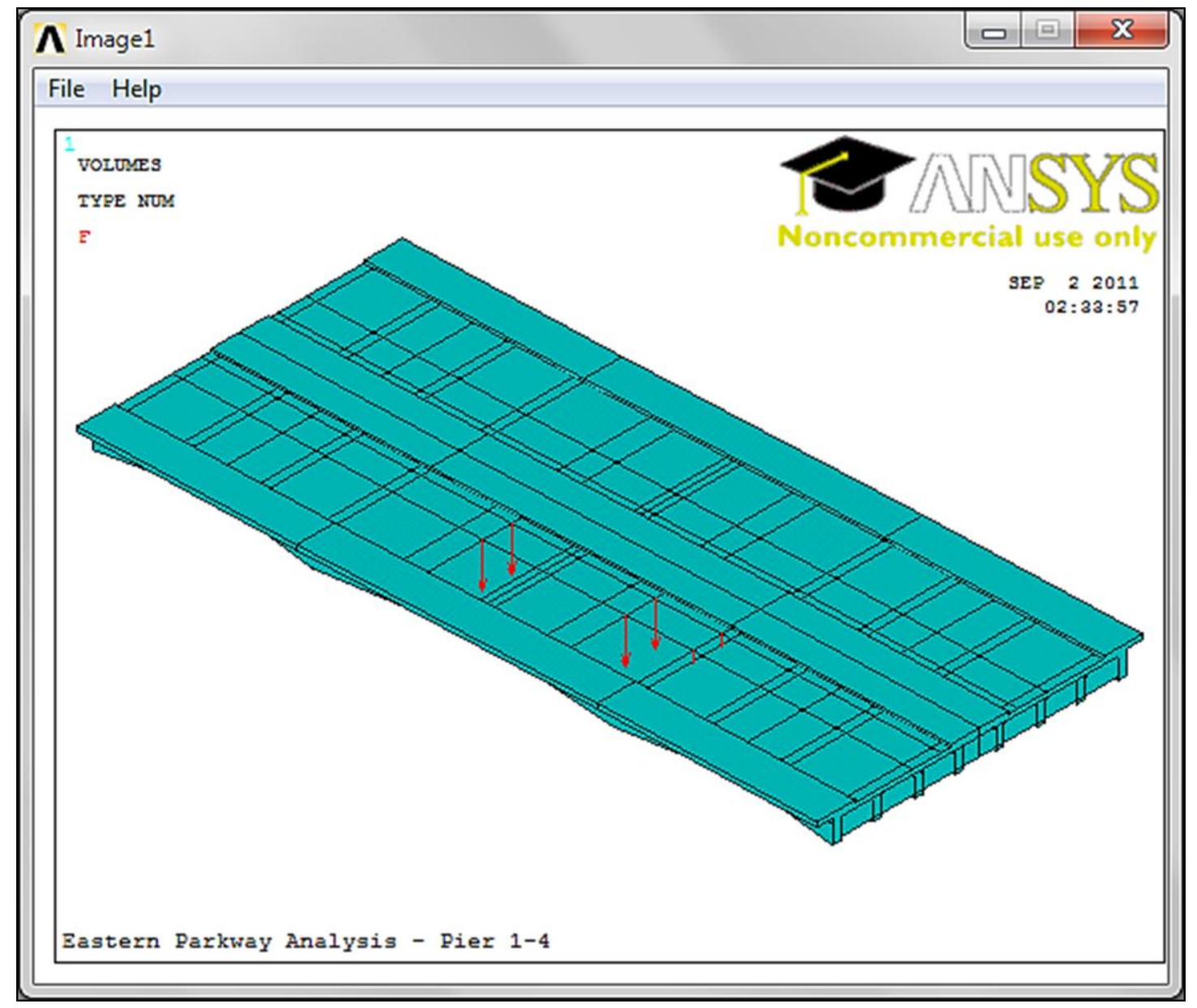

FIGURE 46 - Load Configuration for Iteration Eight 


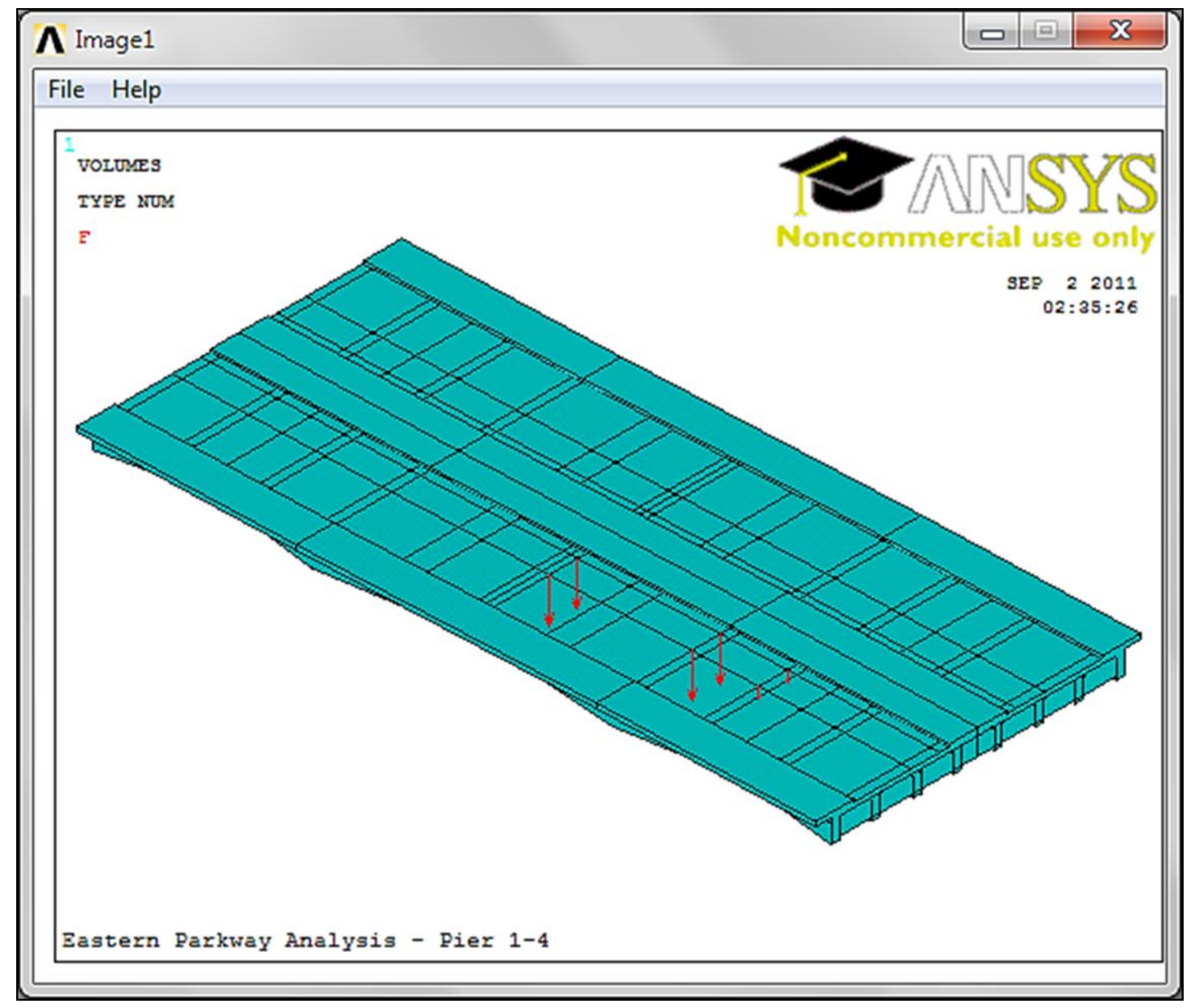

FIGURE 47 - Load Configuration for Iteration Nine 


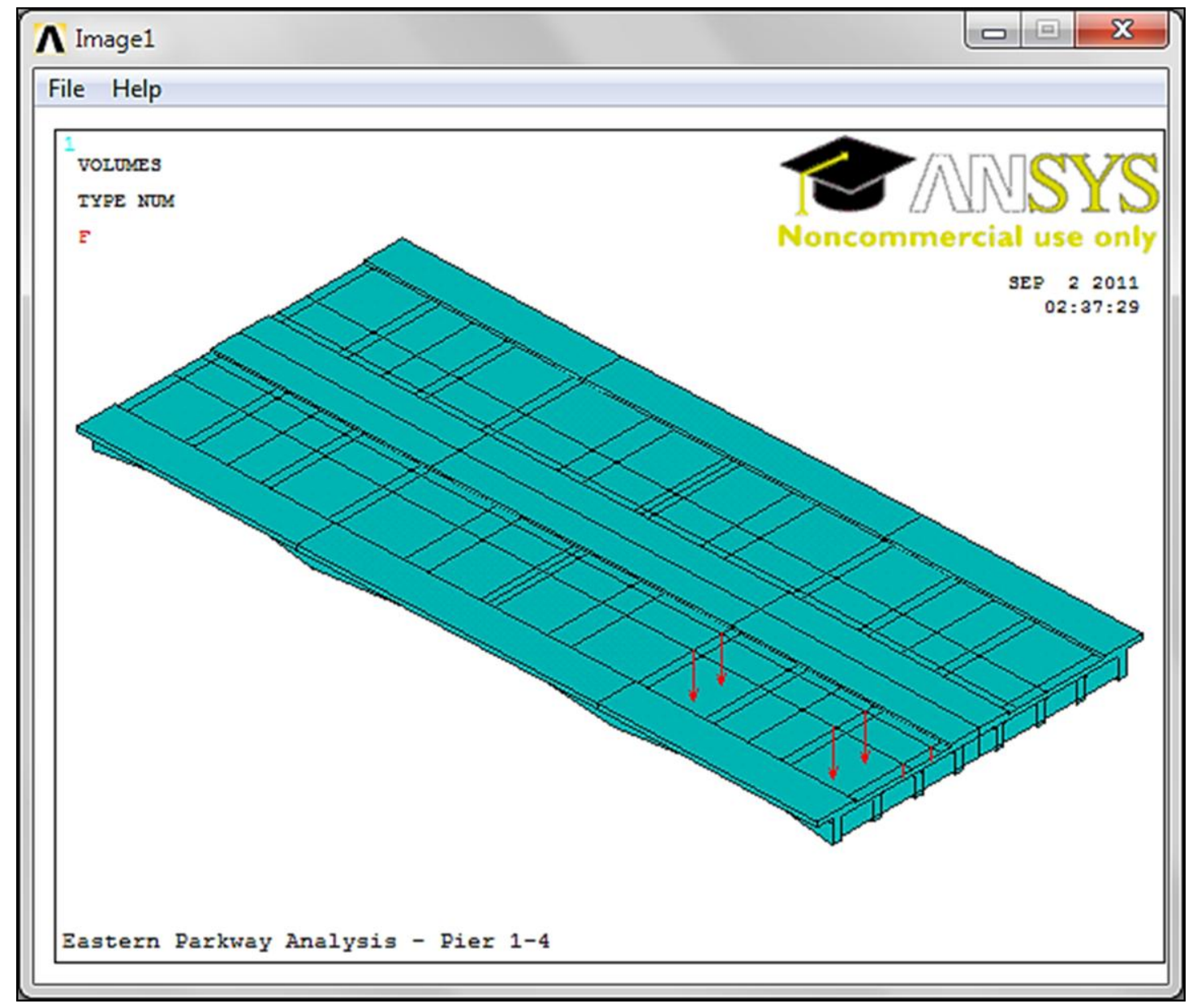

FIGURE 48 - Load Configuration for Iteration 10 


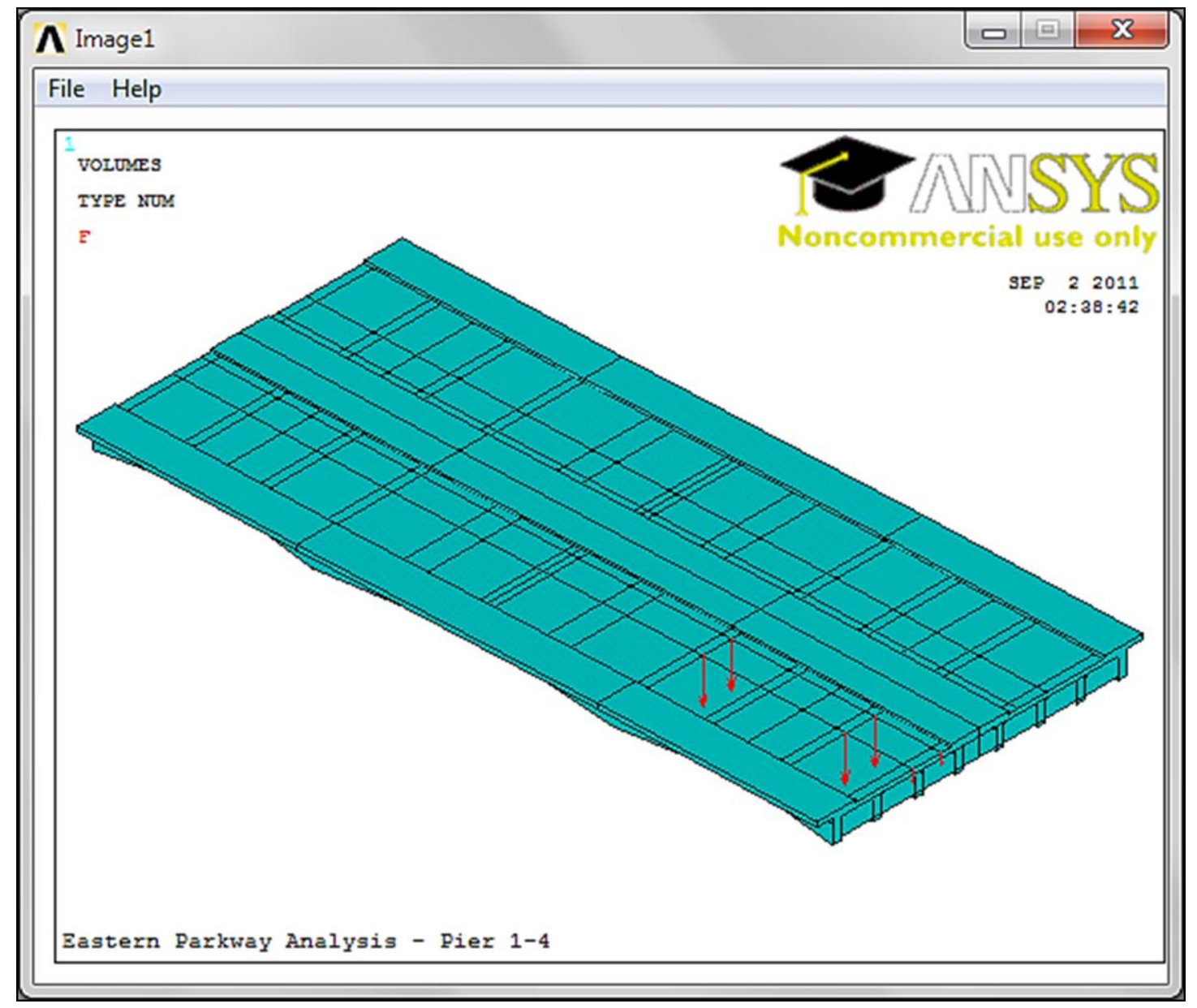

FIGURE 49 - Load Configuration for Iteration 11 


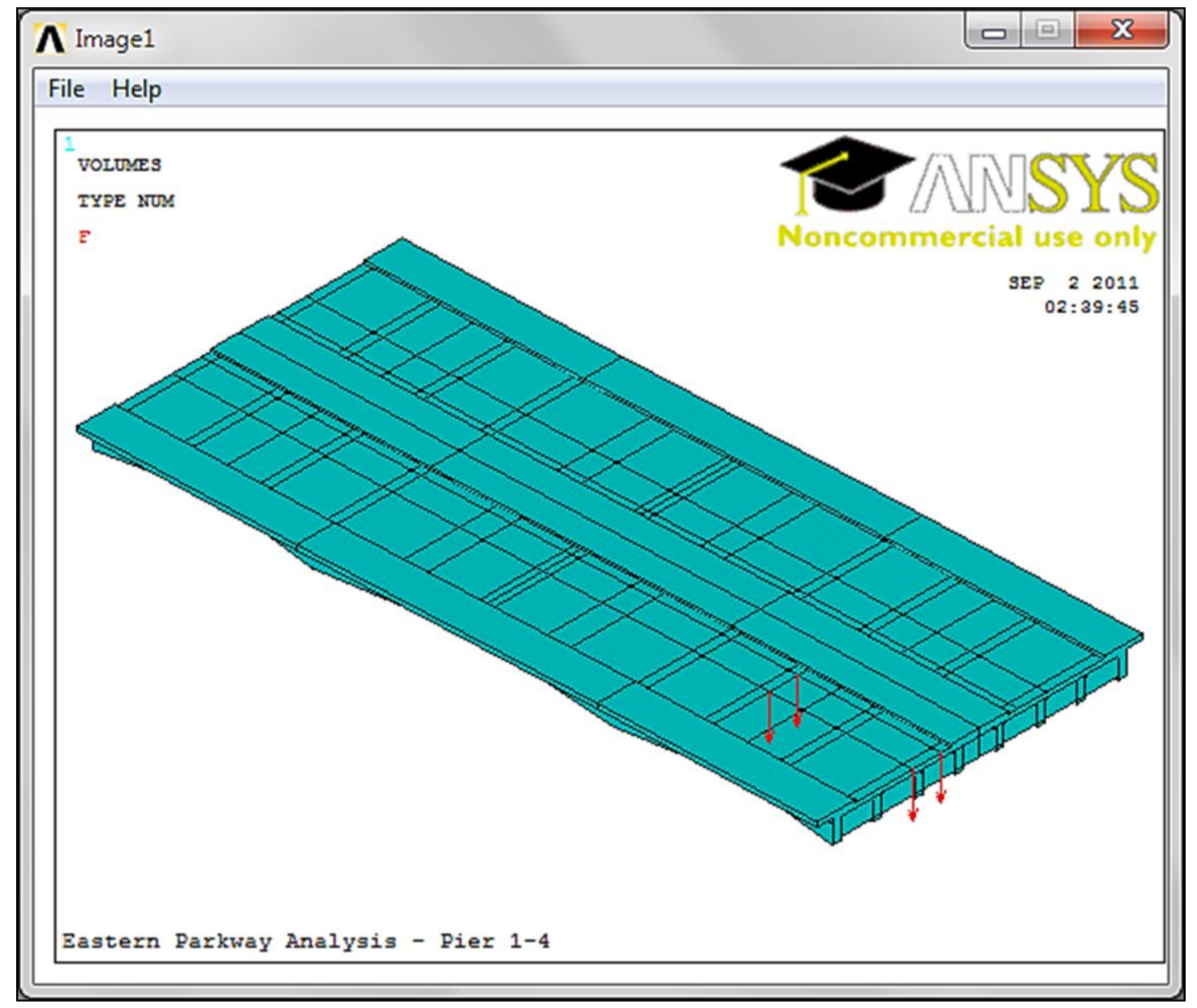

FIGURE 50 - Load Configuration for Iteration 12 


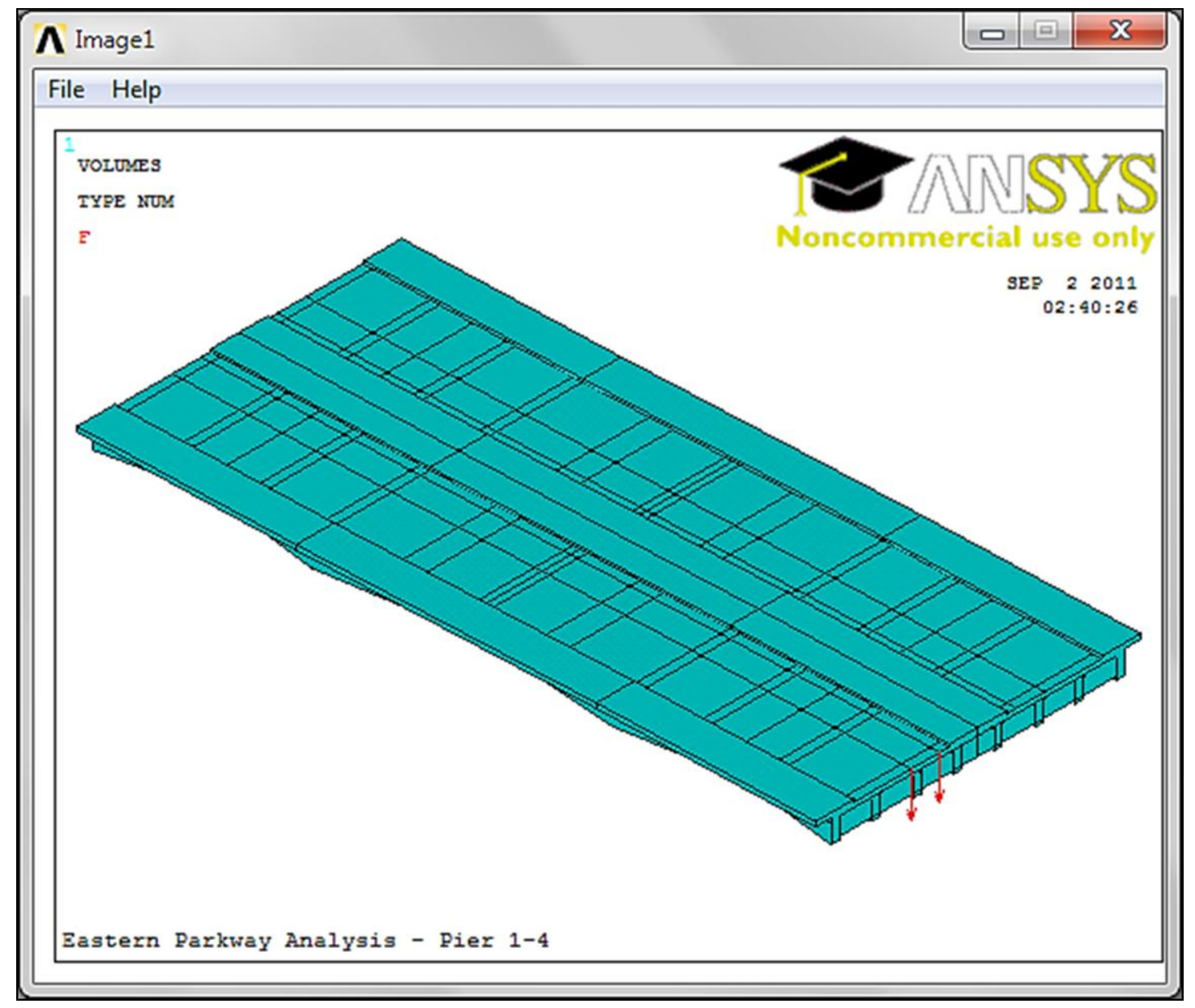

FIGURE 51 - Load Configuration for Iteration 13 
APPENDIX VI

SCREEN CAPTURES OF DEFORMED SHAPES

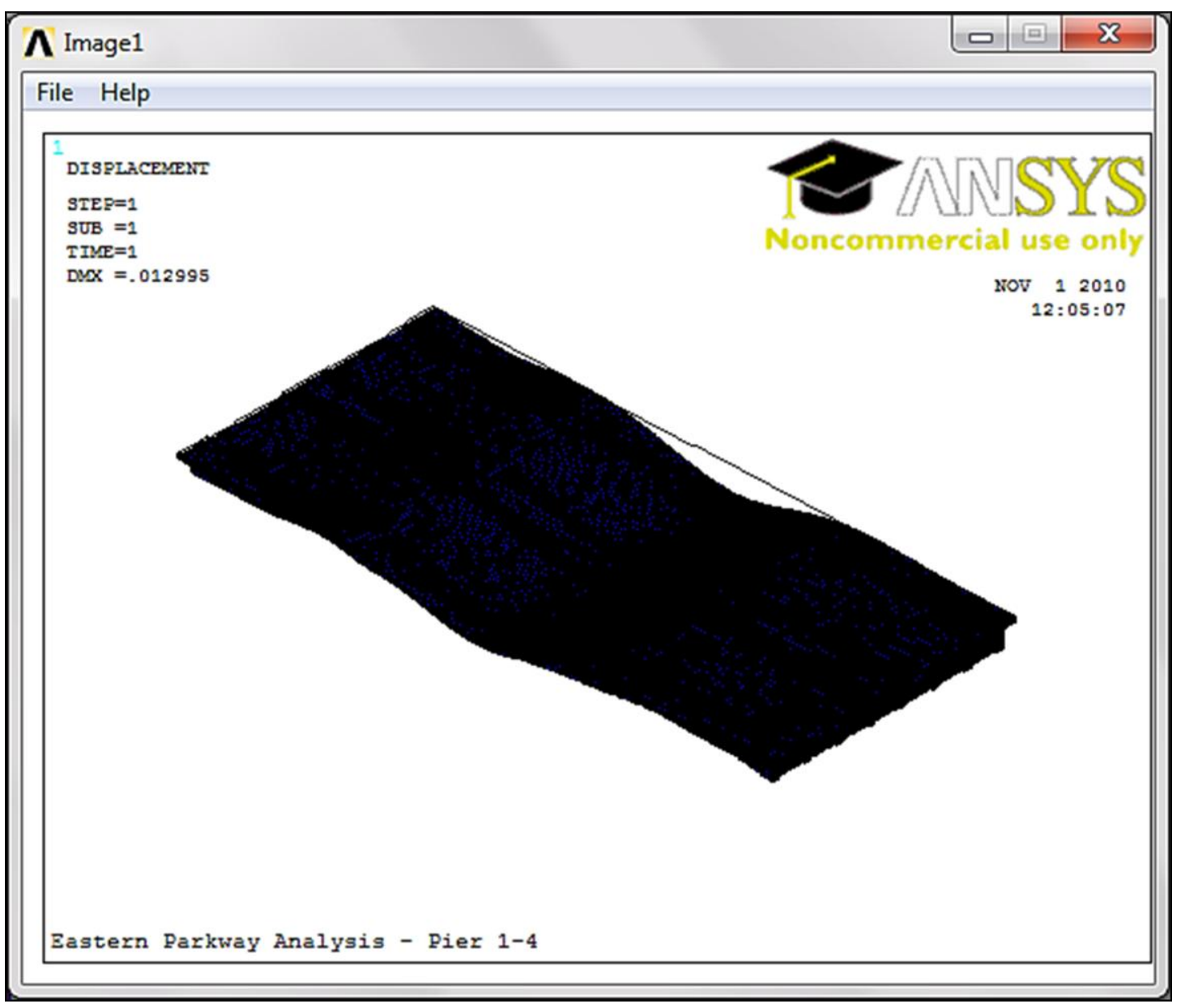

FIGURE 52 - Deformed Shape for Iteration One 


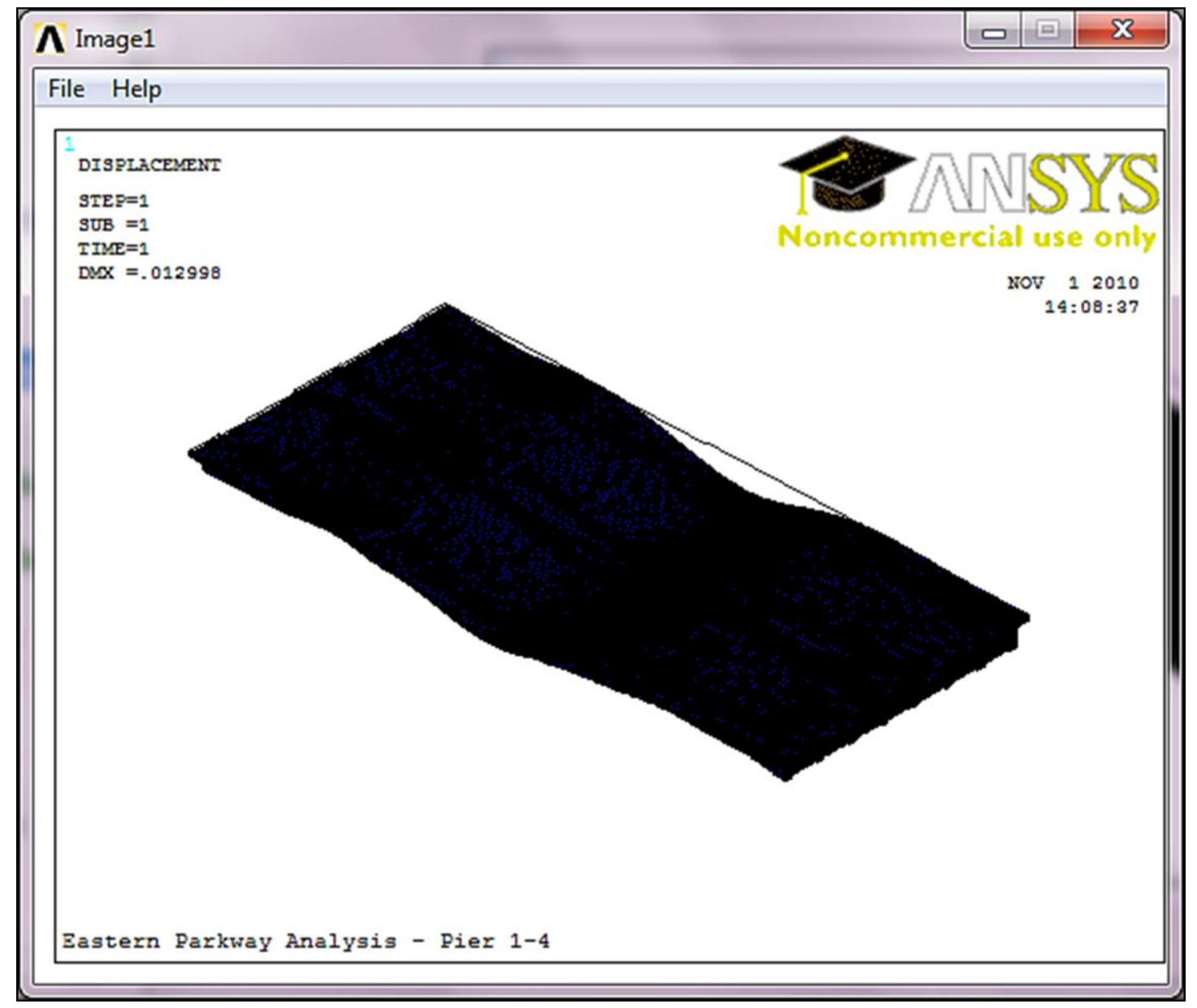

FIGURE 53 - Deformed Shape for Iteration Two 


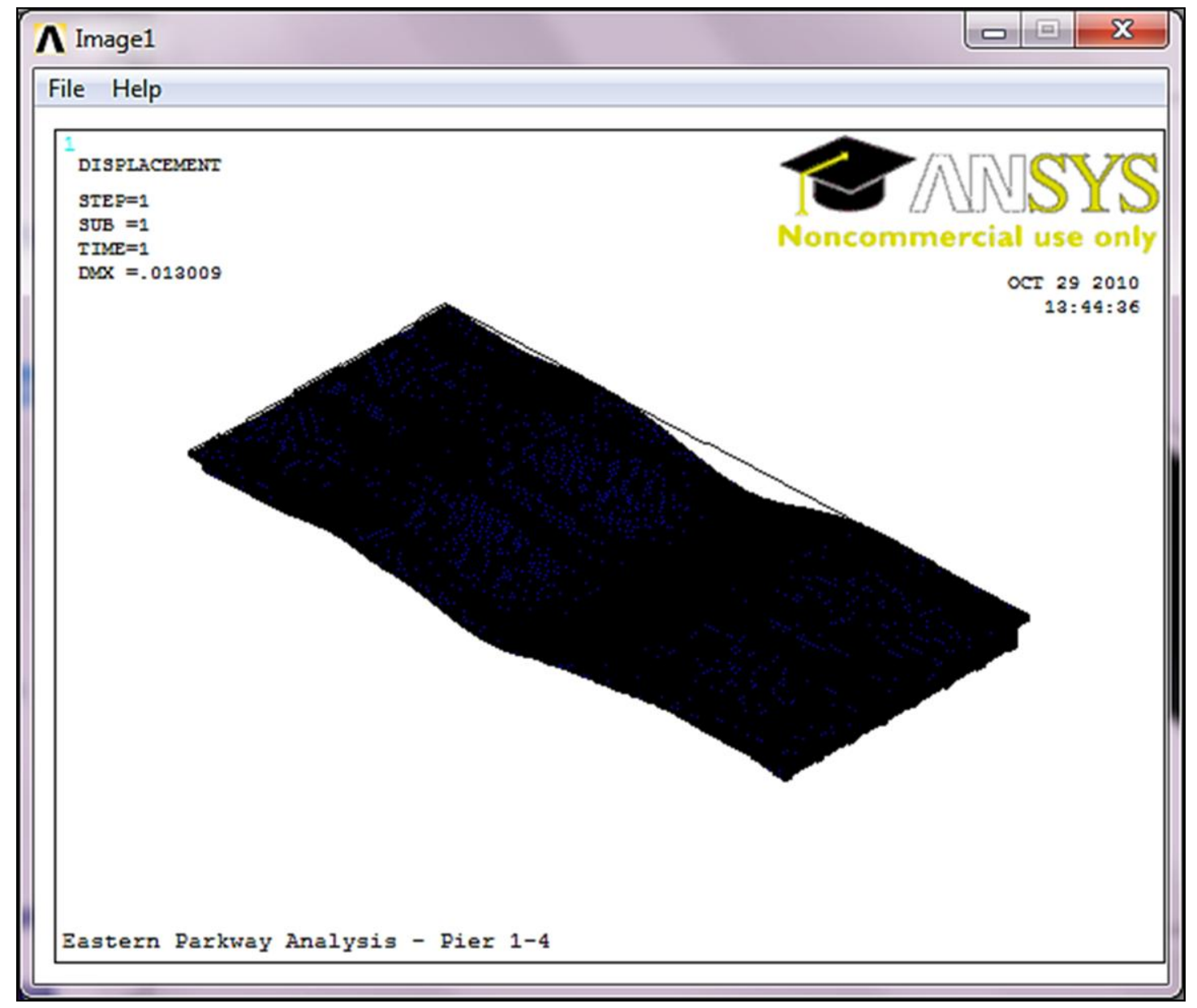

FIGURE 54 - Deformed Shape for Iteration Three 


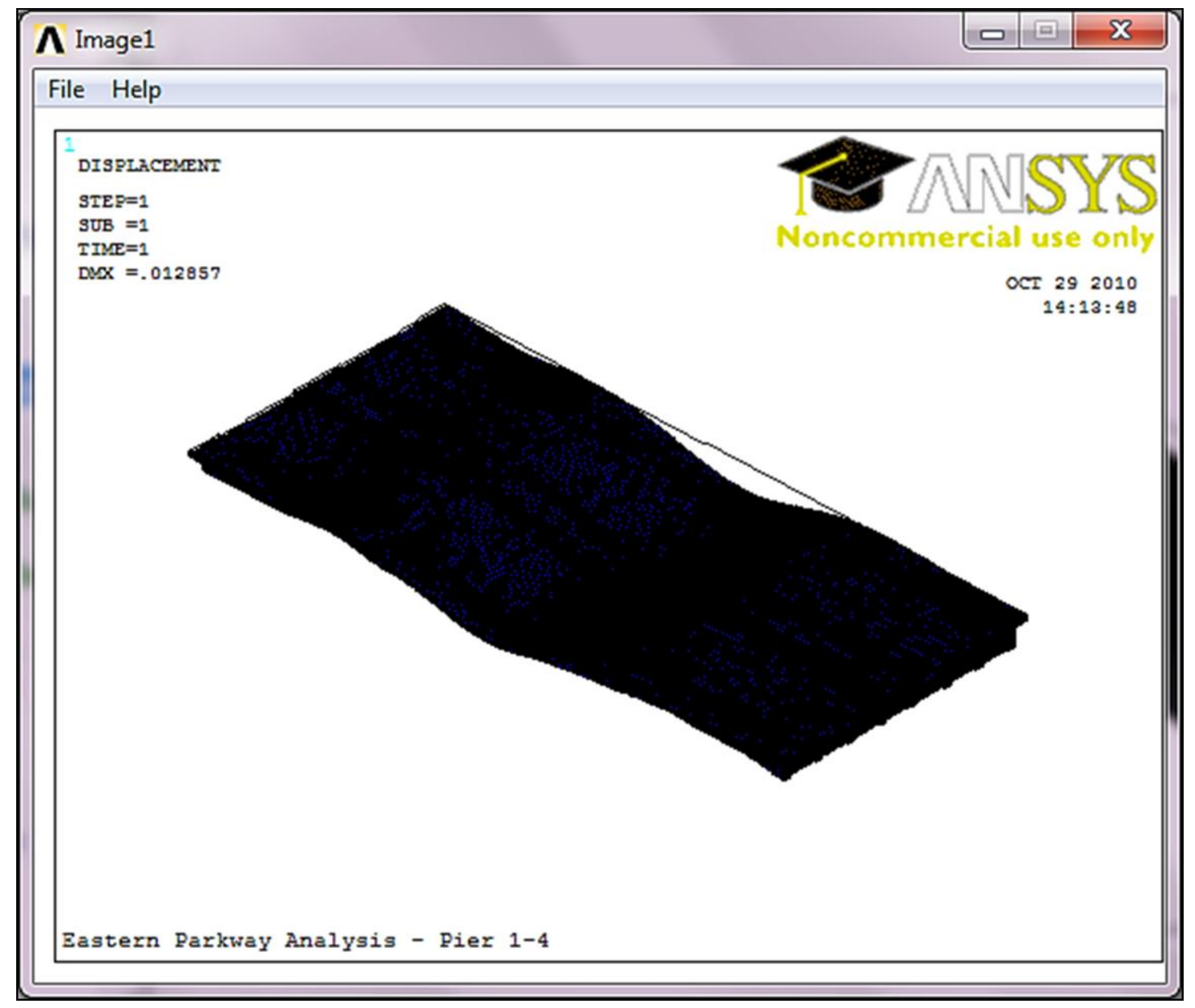

FIGURE 55 - Deformed Shape for Iteration Four 


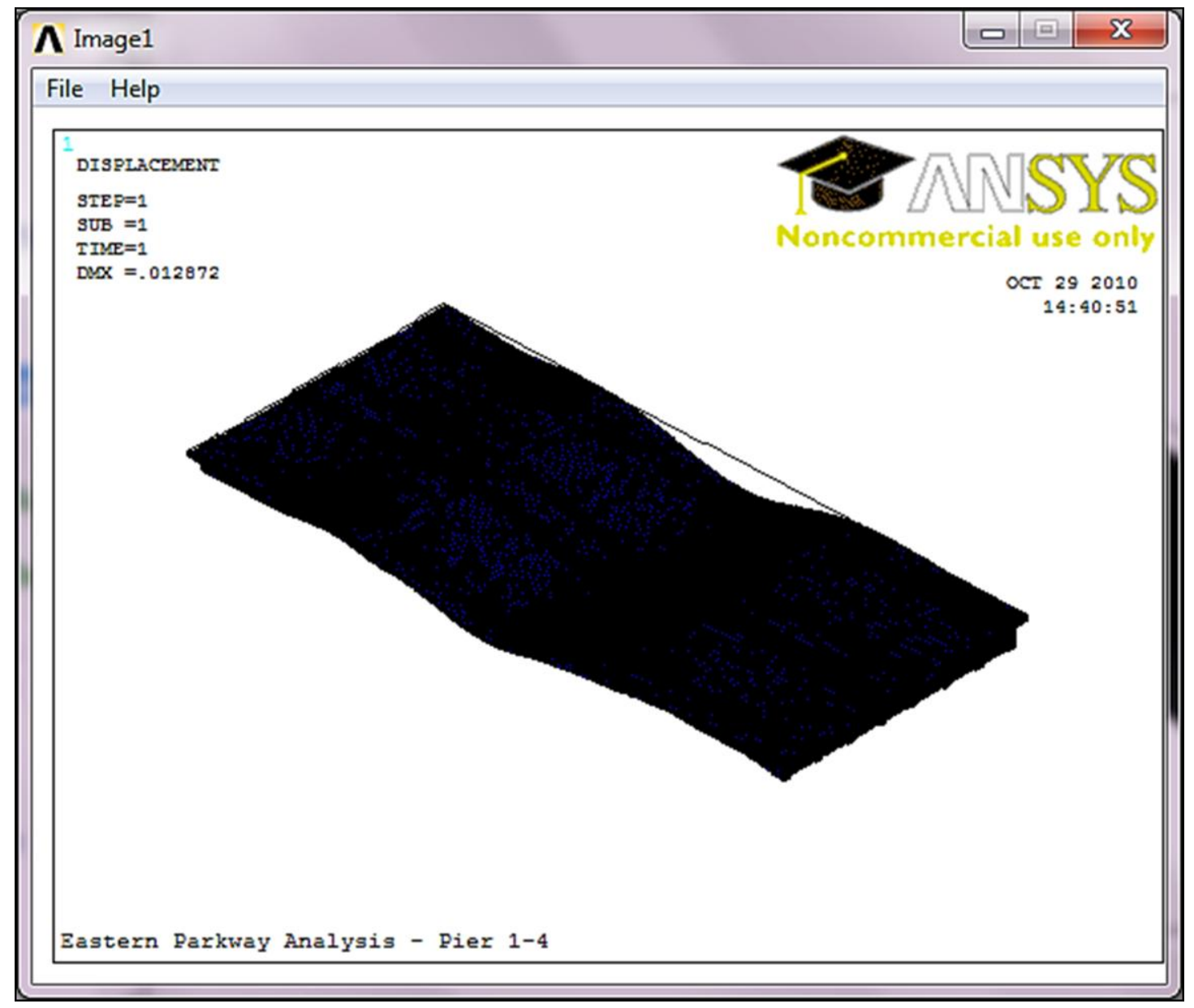

FIGURE 56 - Deformed Shape for Iteration Five 


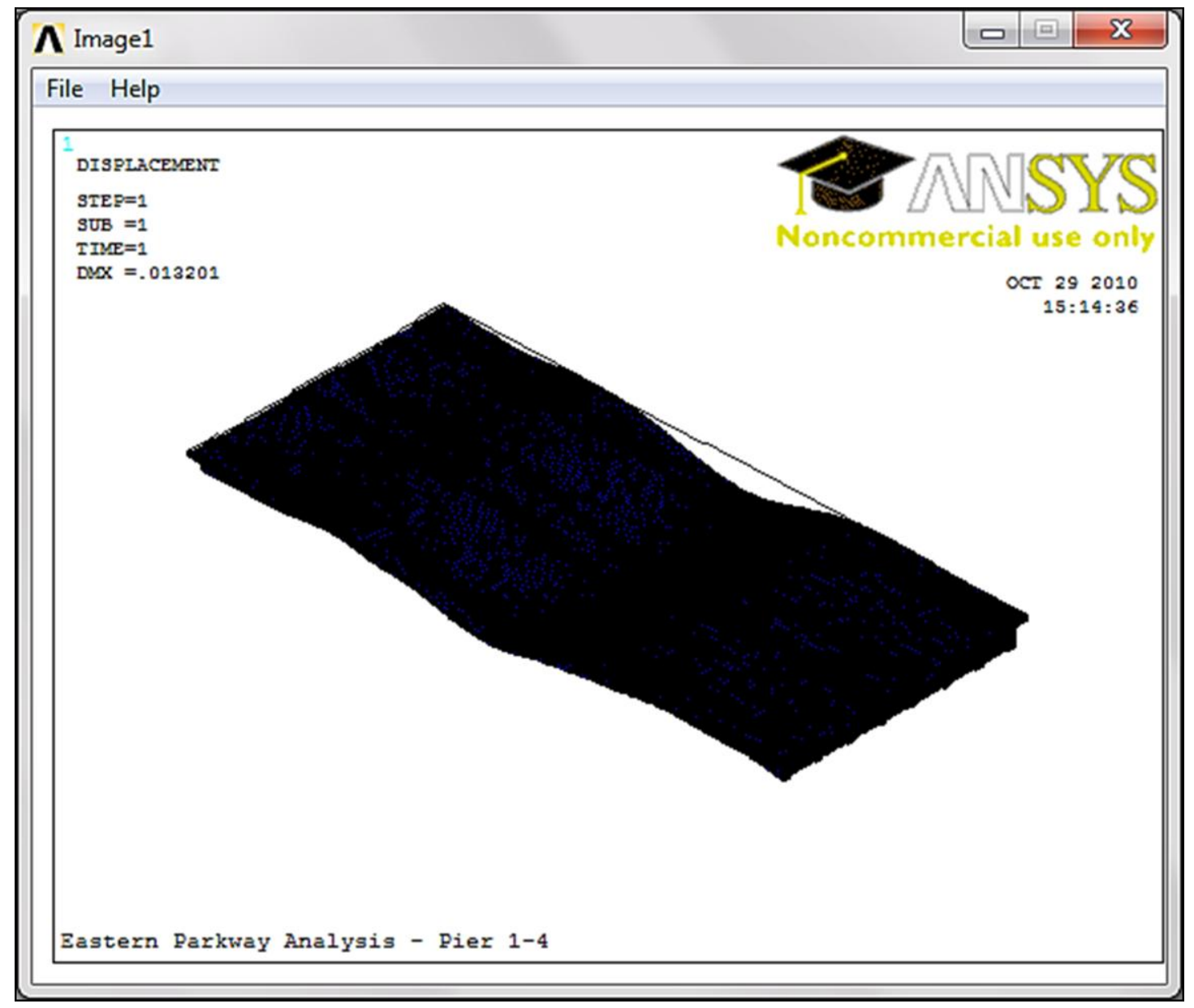

FIGURE 57 - Deformed Shape for Iteration Six 


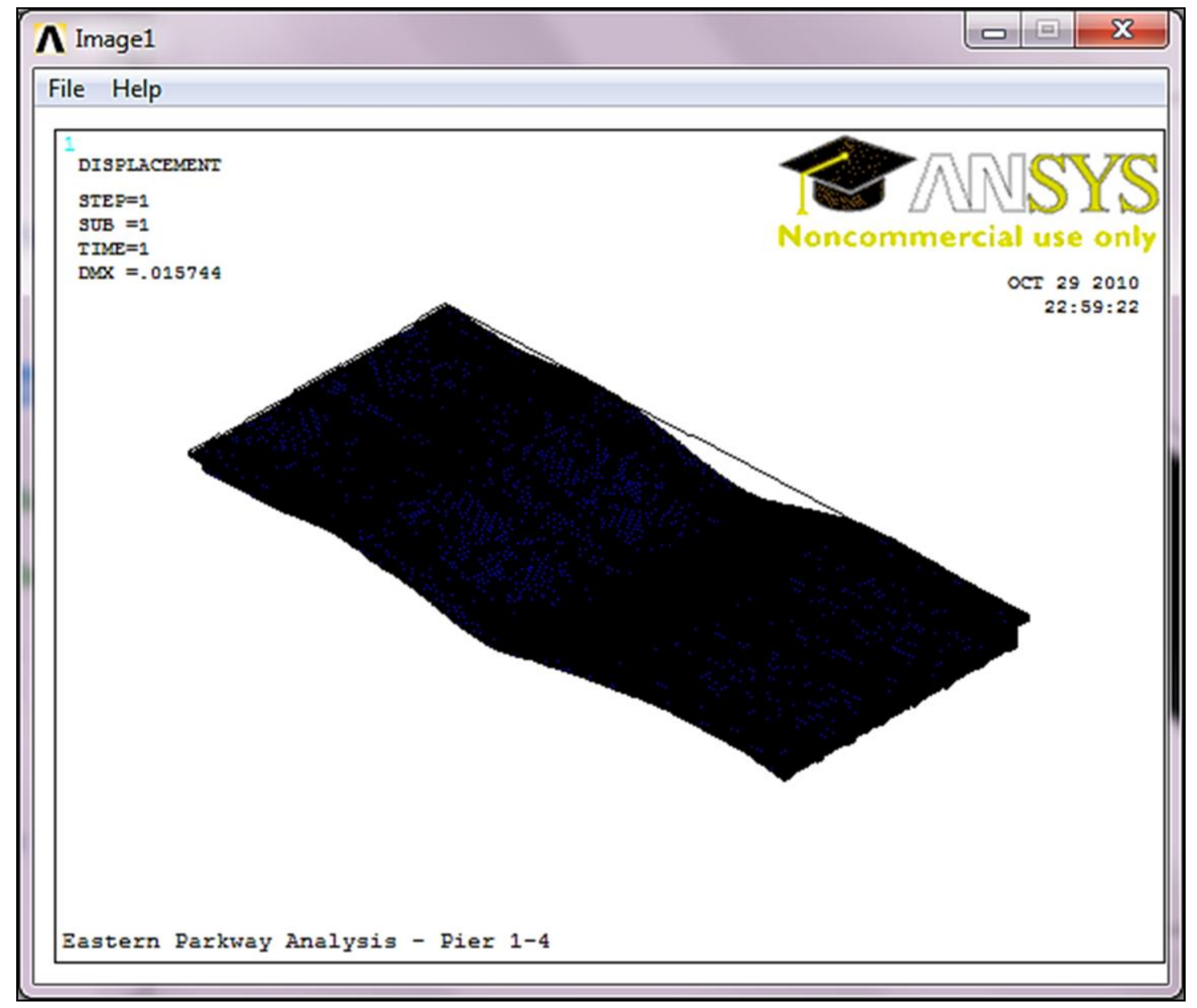

FIGURE 58 - Deformed Shape for Iteration Seven 


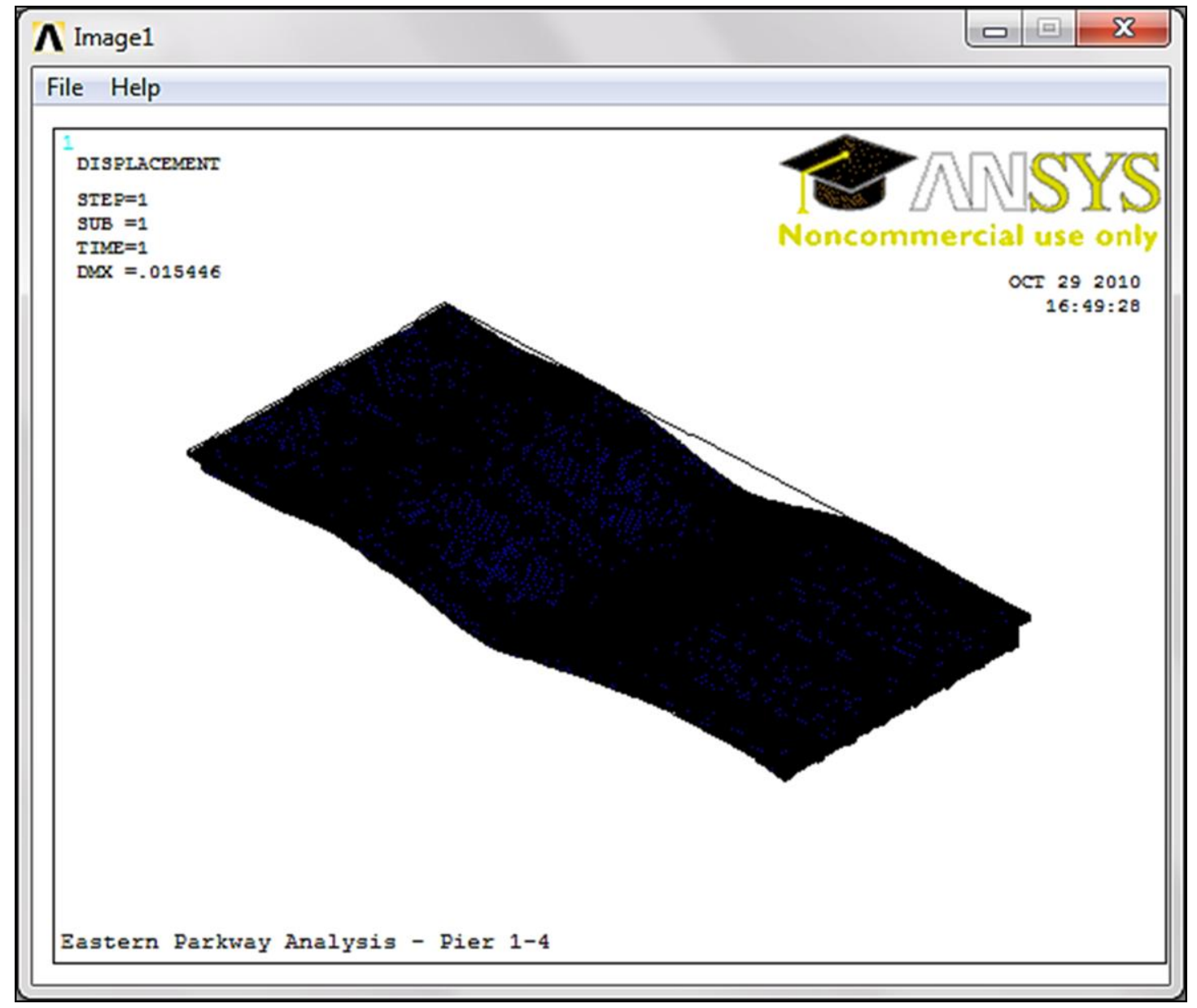

FIGURE 59 - Deformed Shape for Iteration Eight 


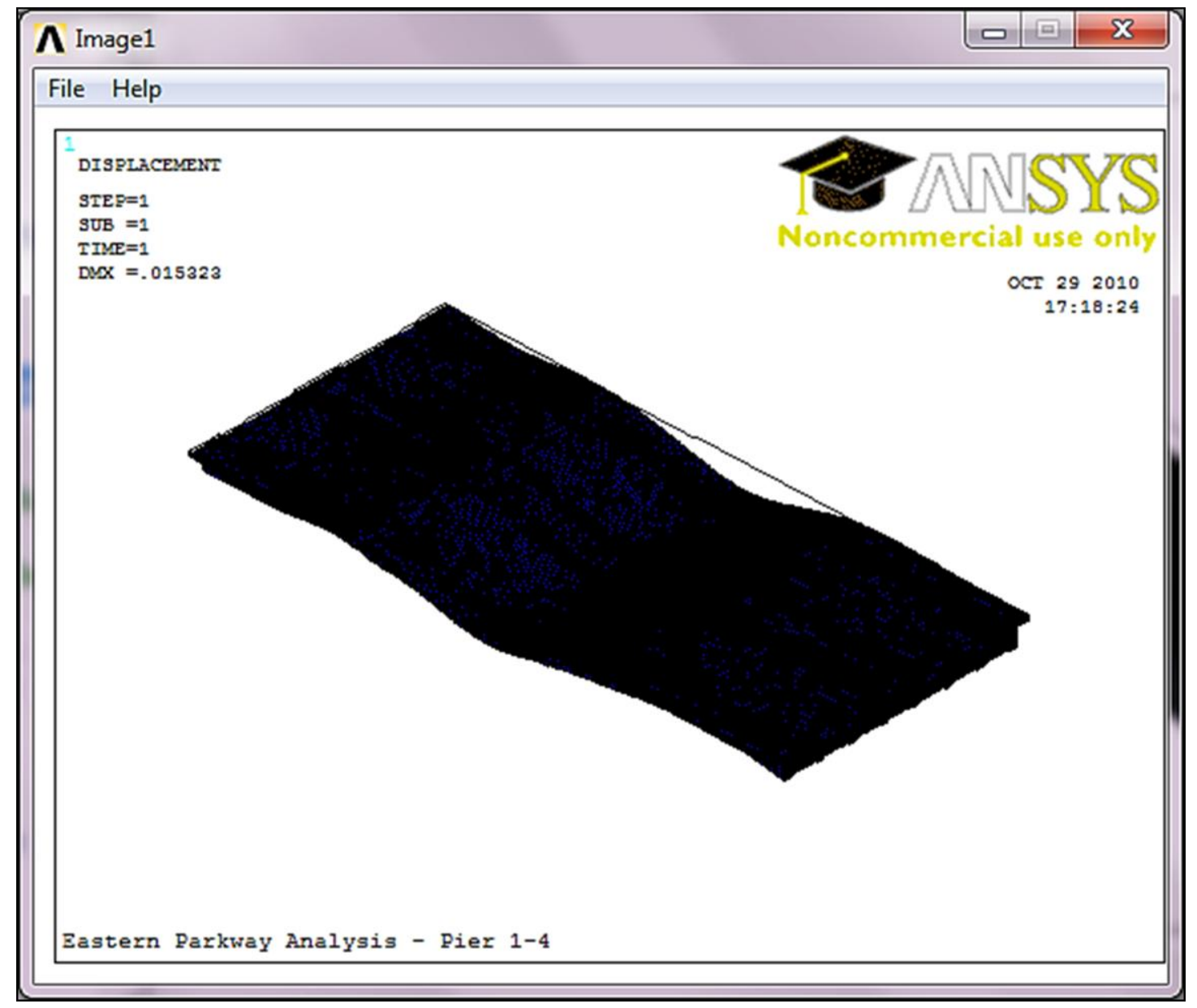

FIGURE 60 - Deformed Shape for Iteration Nine 


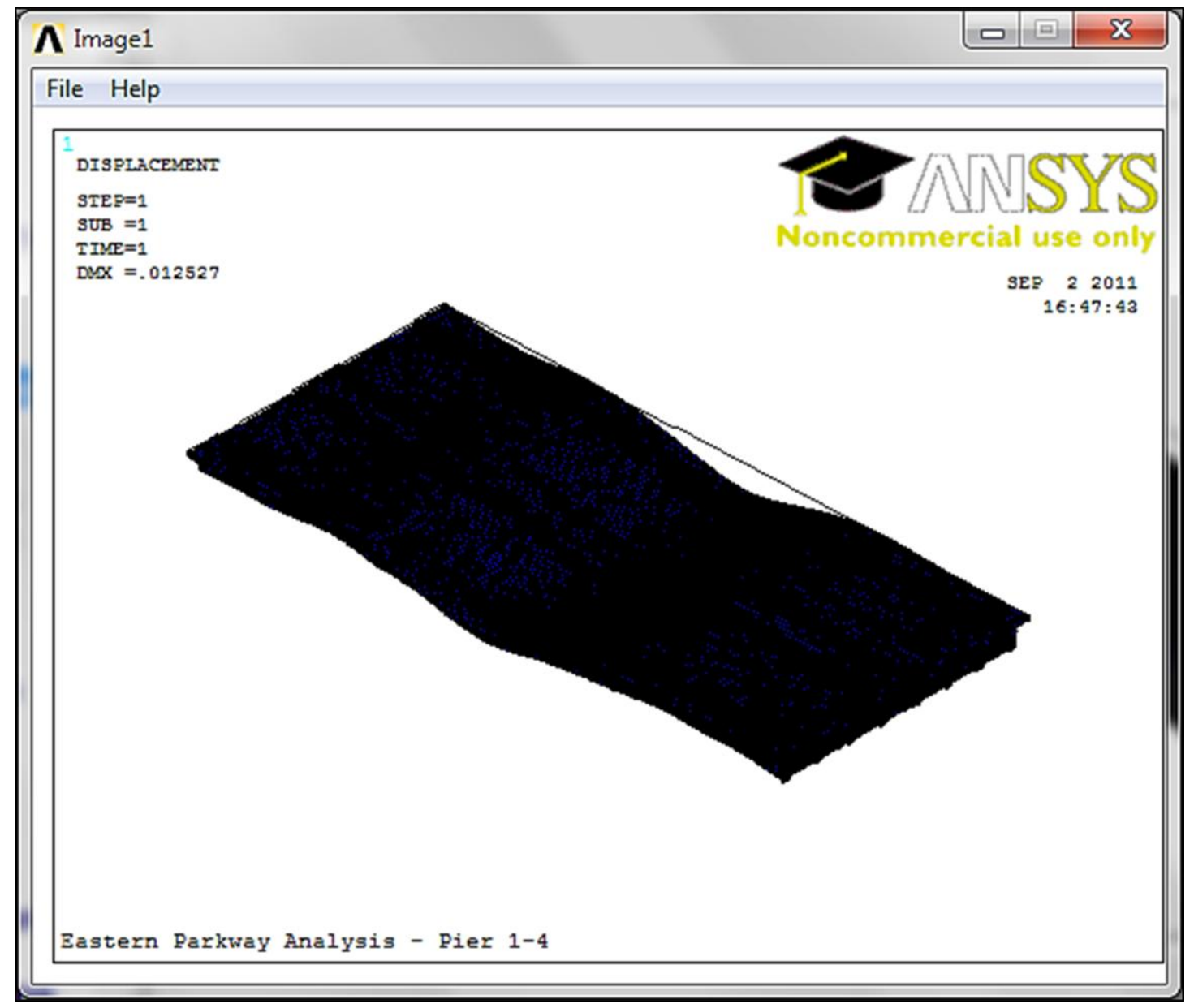

FIGURE 61 - Deformed Shape for Iteration 10 


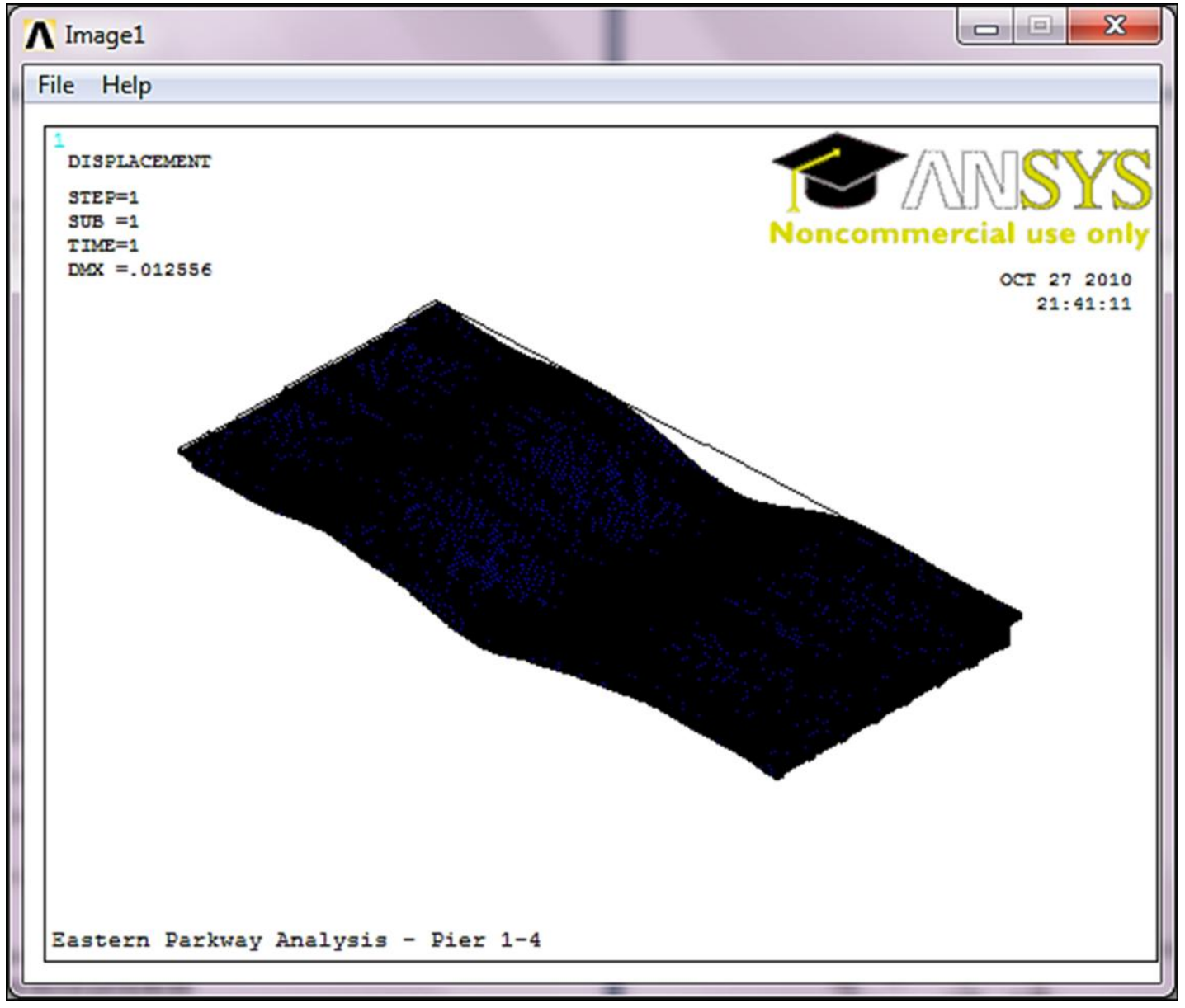

FIGURE 62 - Deformed Shape for Iteration 11 


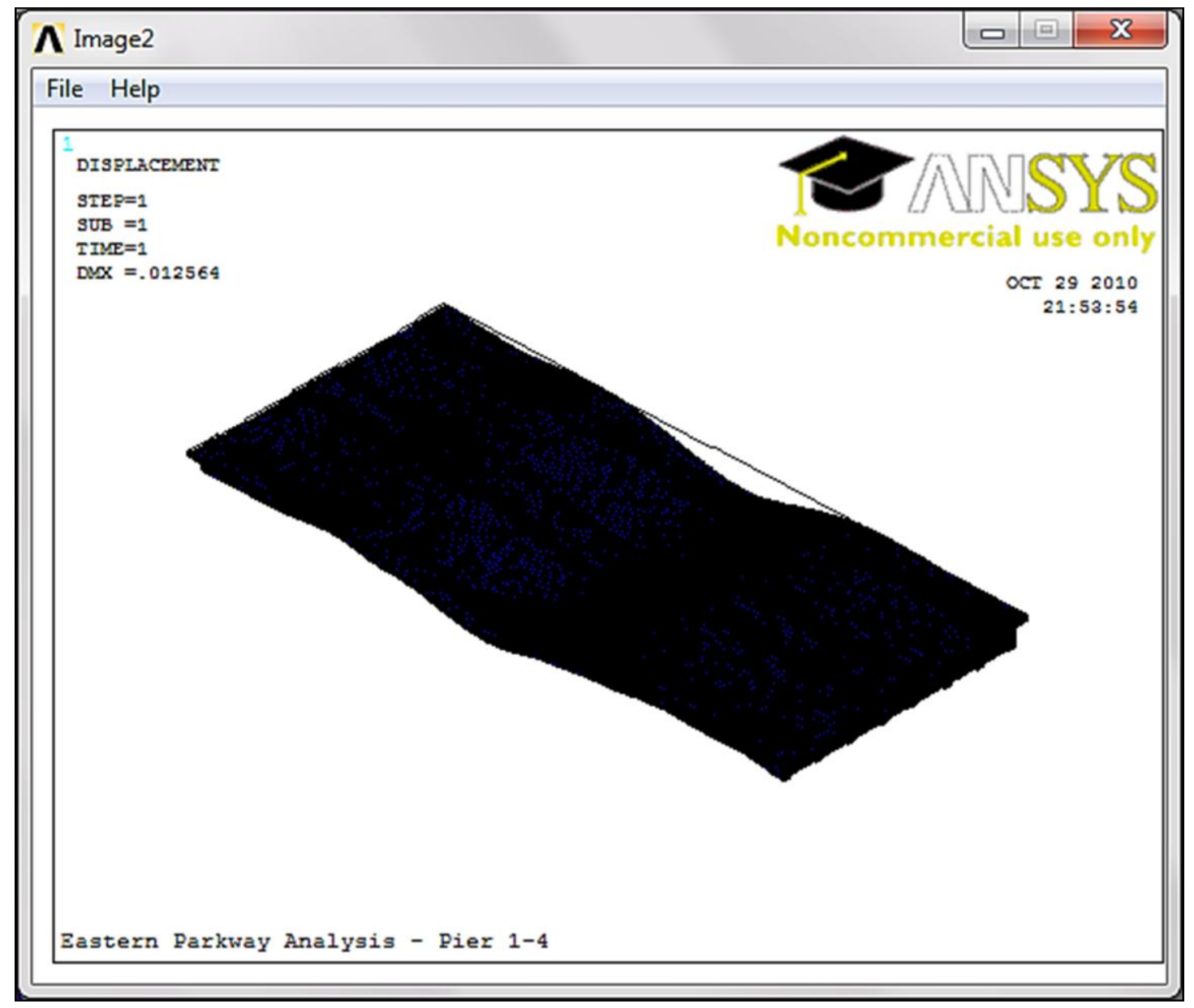

FIGURE 63 - Deformed Shape for Iteration 12 


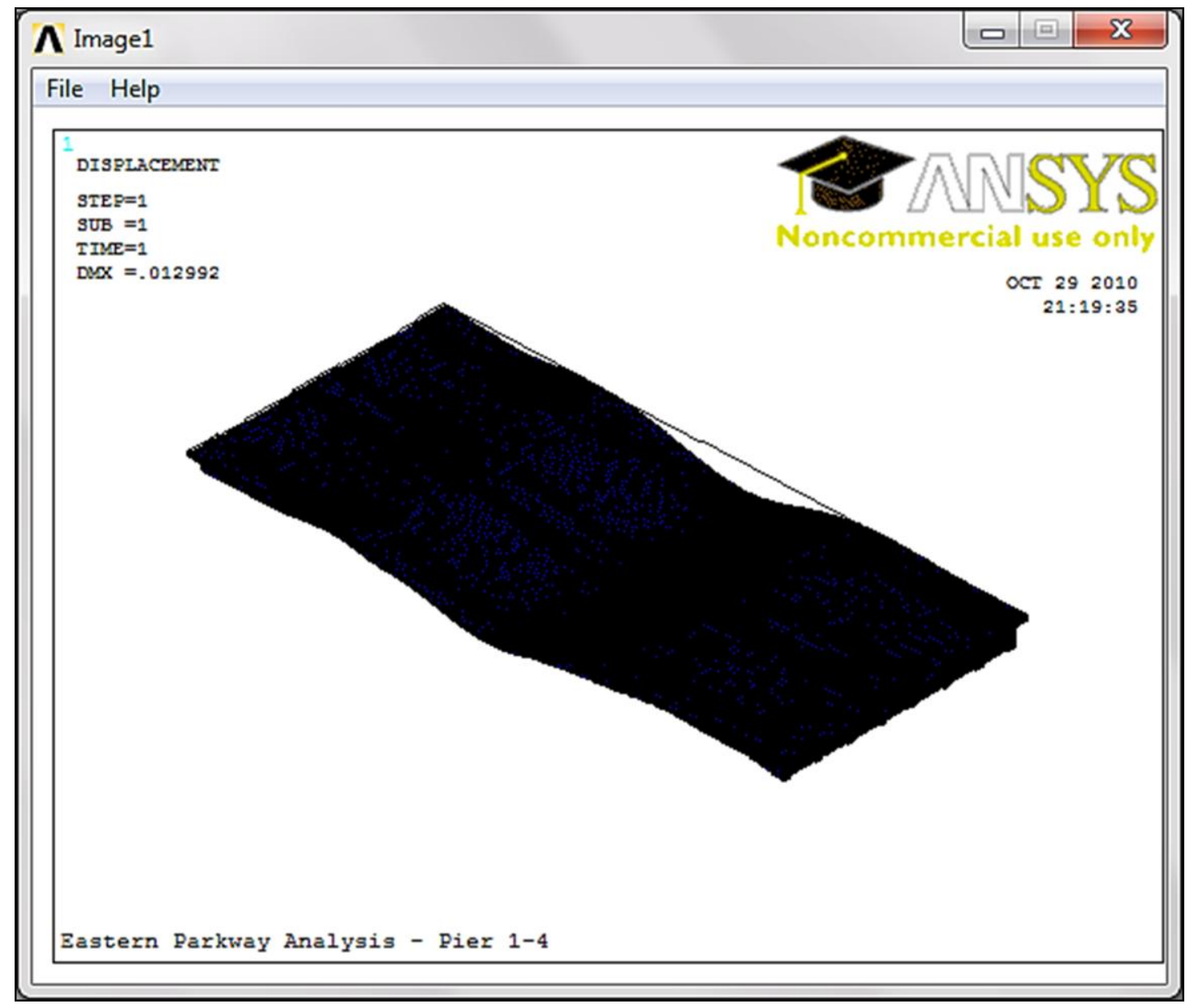

FIGURE 64 - Deformed Shape for Iteration 13 


\section{APPENDIX VII}

\section{SCREEN CAPTURES OF Y-COMPONENTS OF DISPLACEMENT}

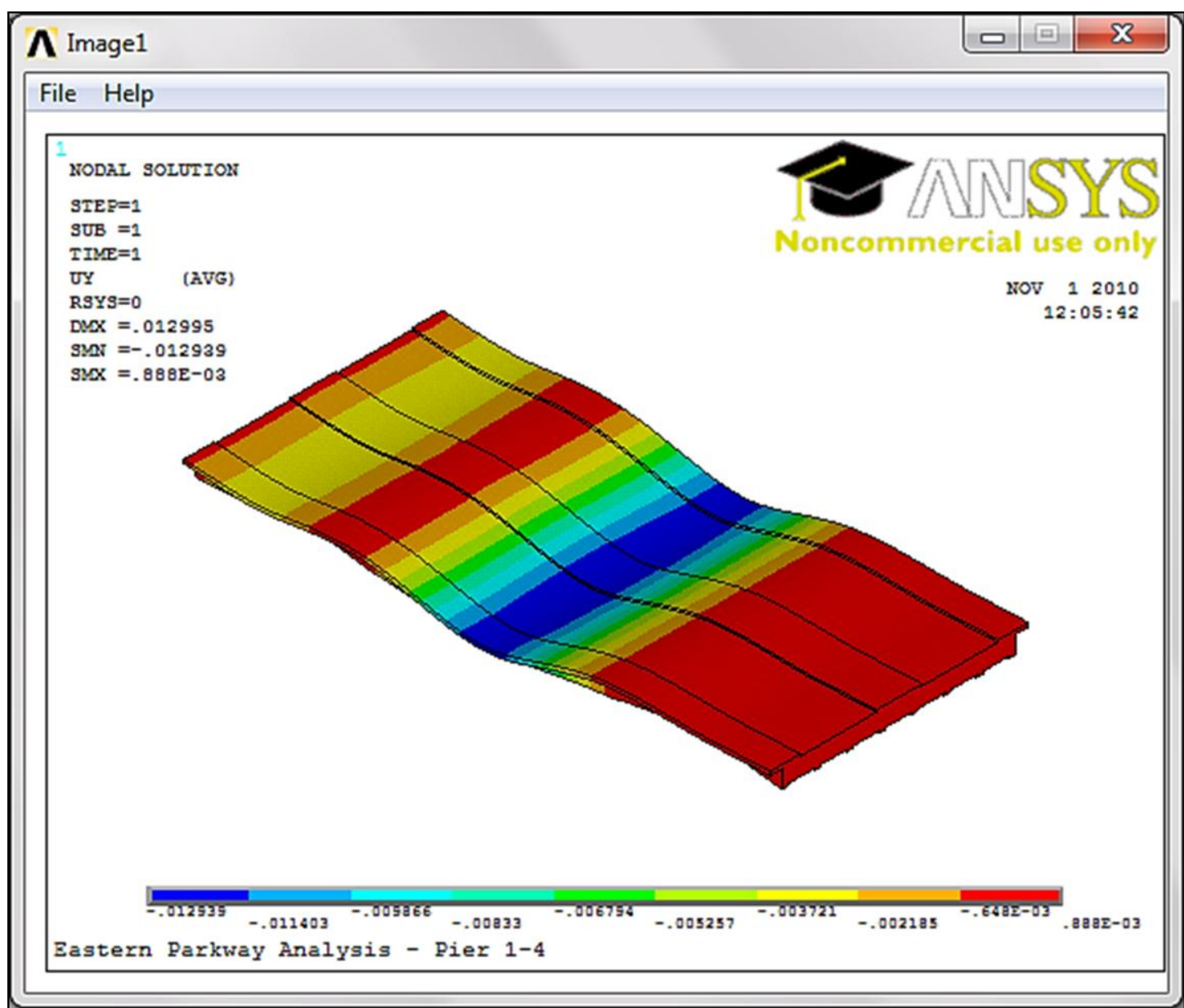

FIGURE 65 - Y-Component of Displacement for Iteration One 


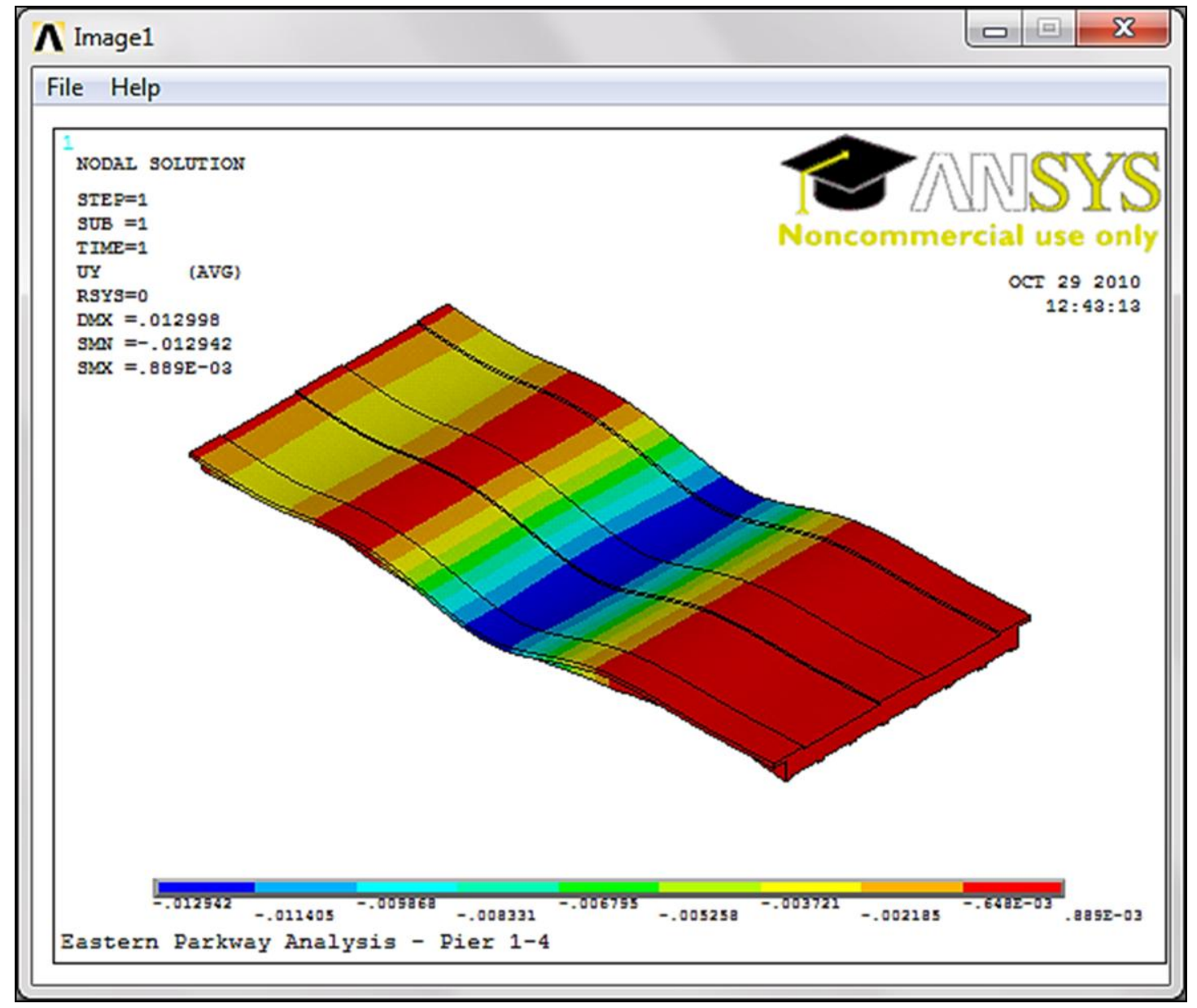

FIGURE 66 - Y-Component of Displacement for Iteration Two 


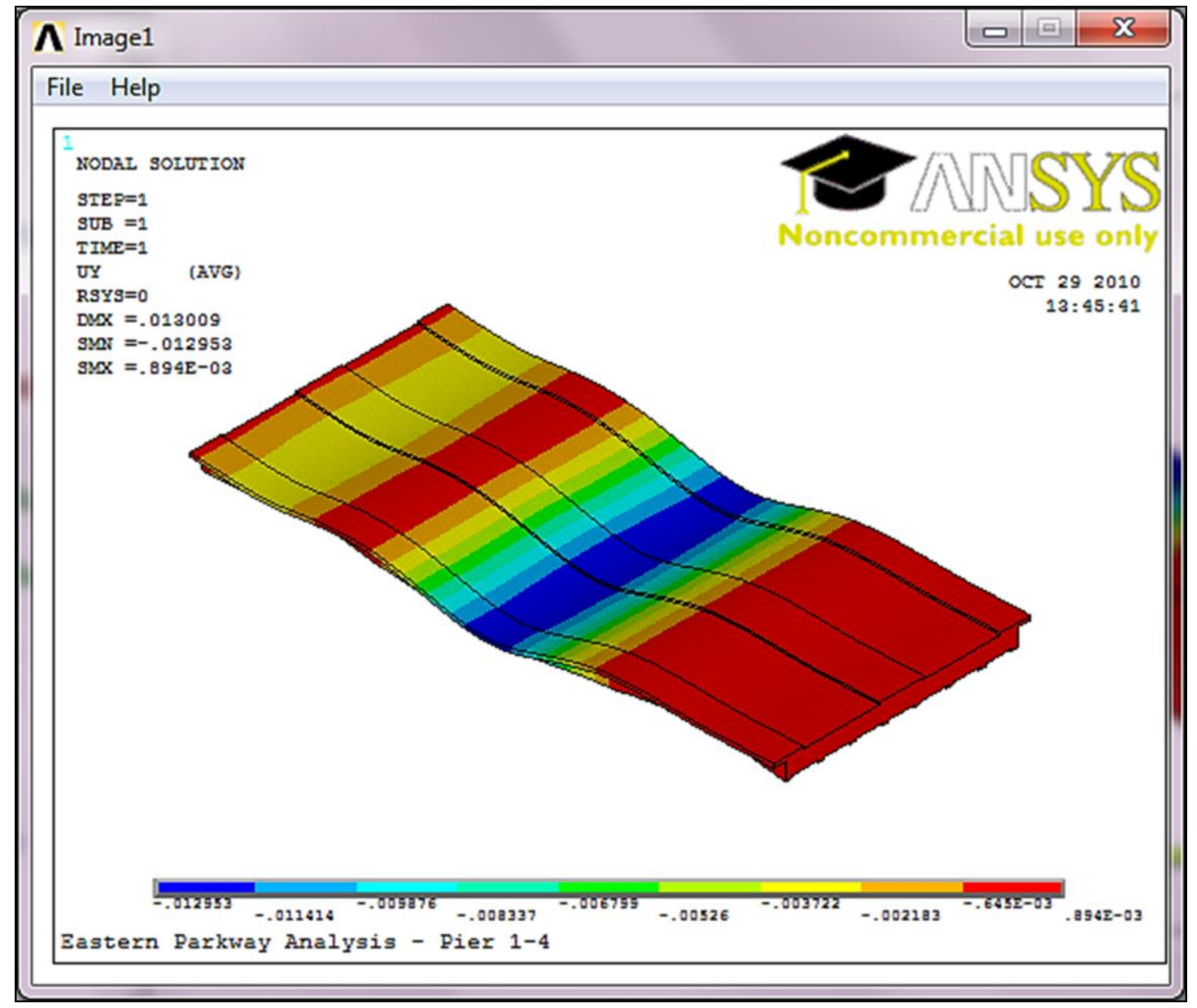

FIGURE 67 - Y-Component of Displacement for Iteration Three 


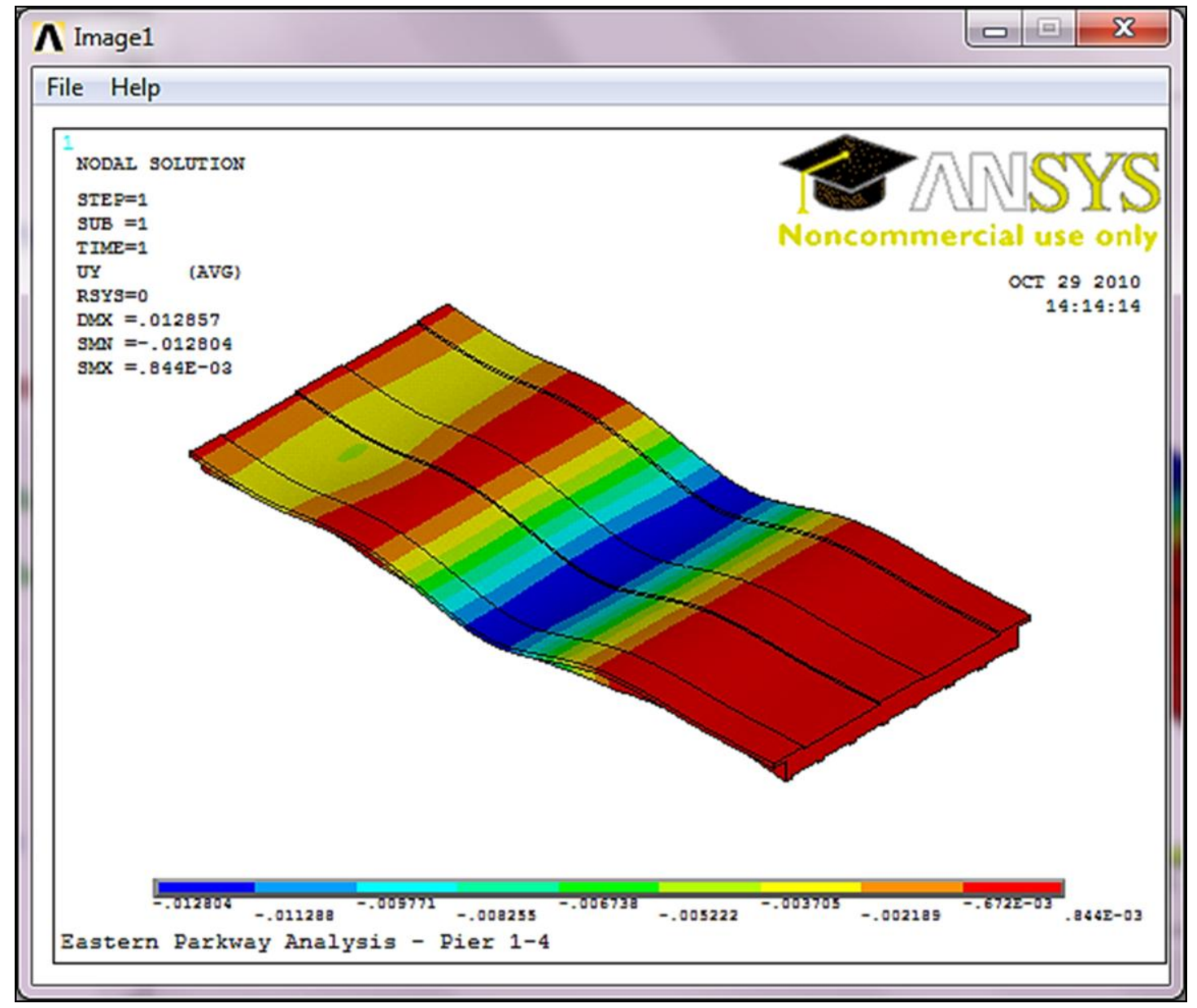

FIGURE 68 - Y-Component of Displacement for Iteration Four 


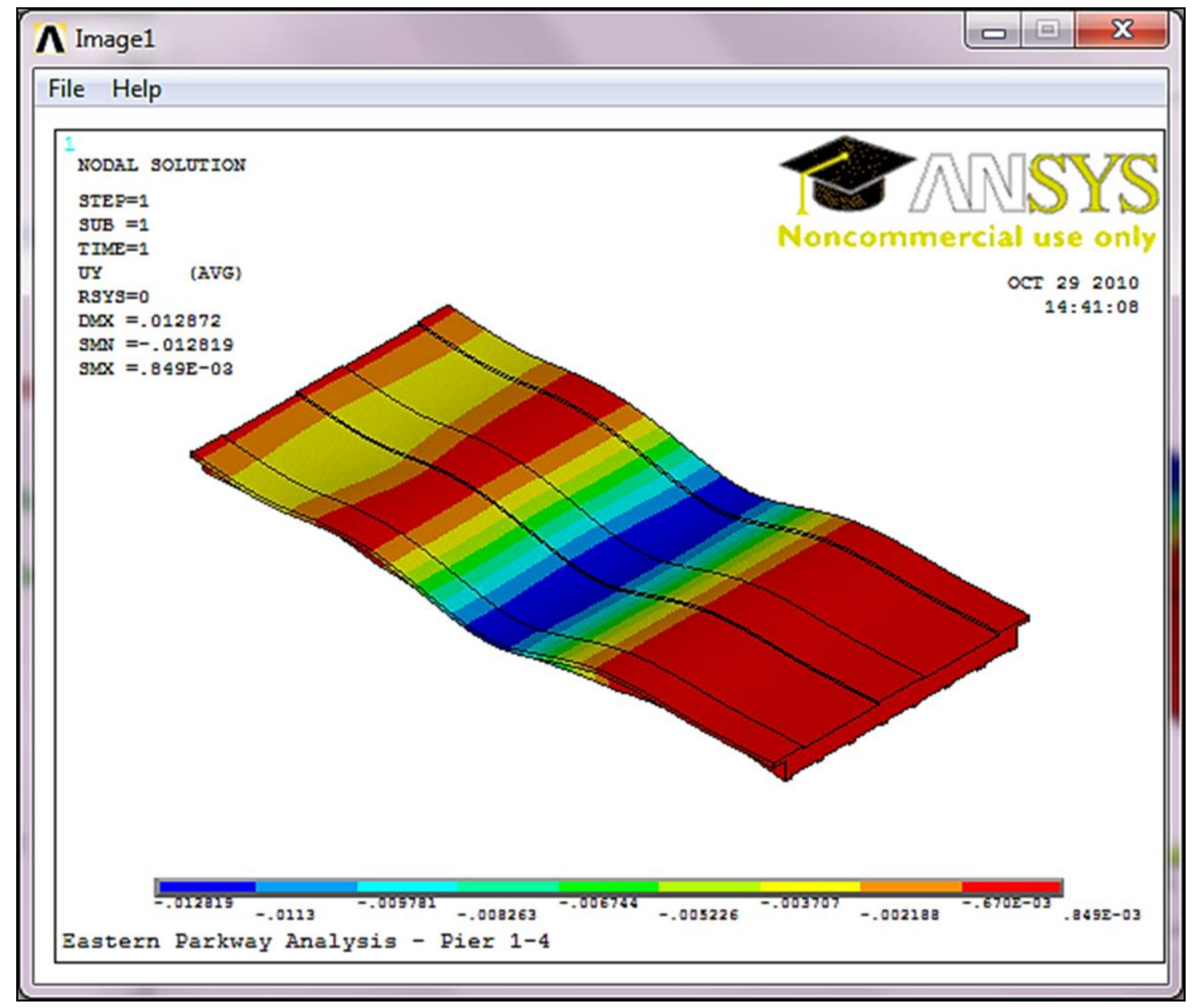

FIGURE 69 - Y-Component of Displacement for Iteration Five 


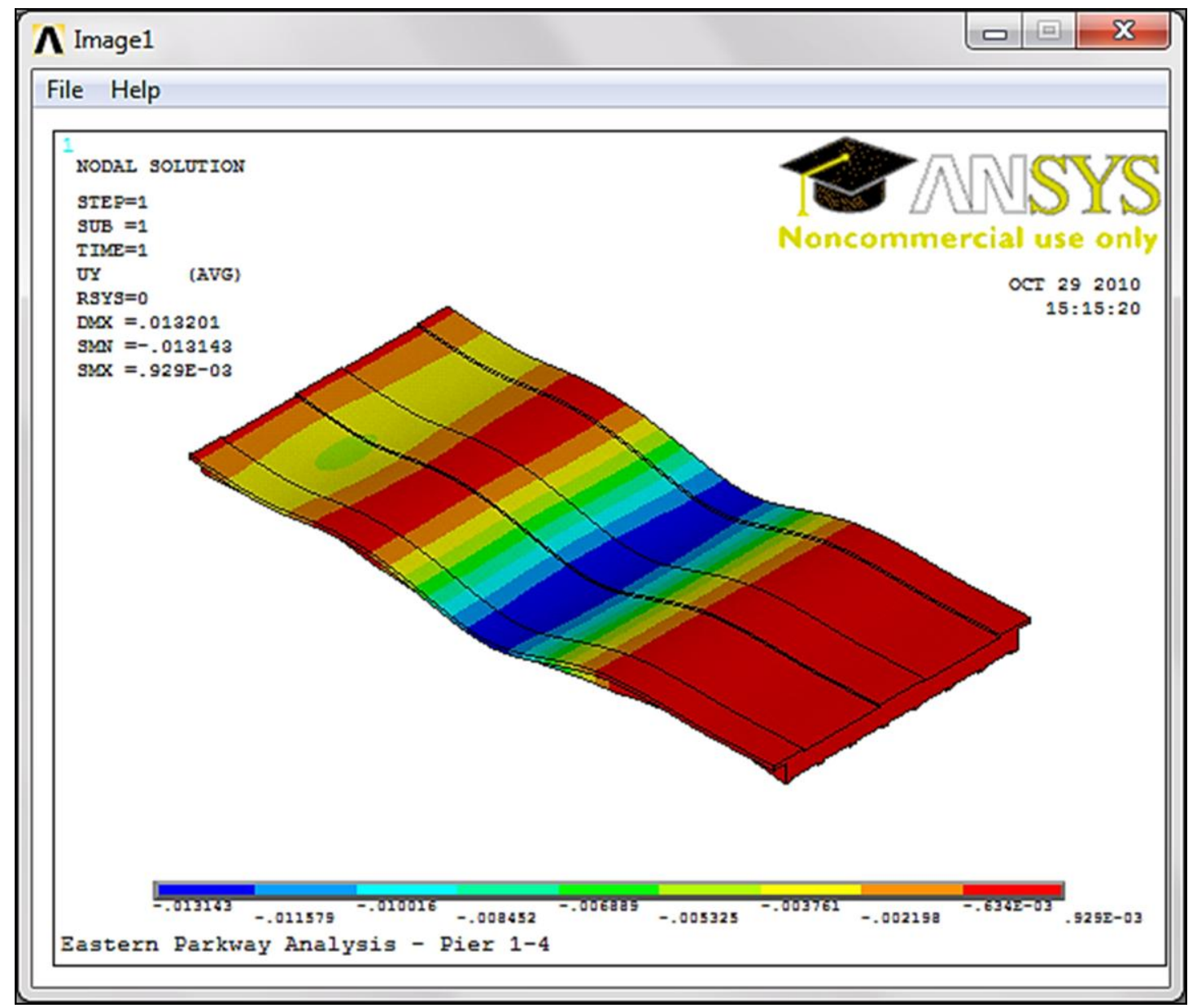

FIGURE 70 - Y-Component of Displacement for Iteration Six 


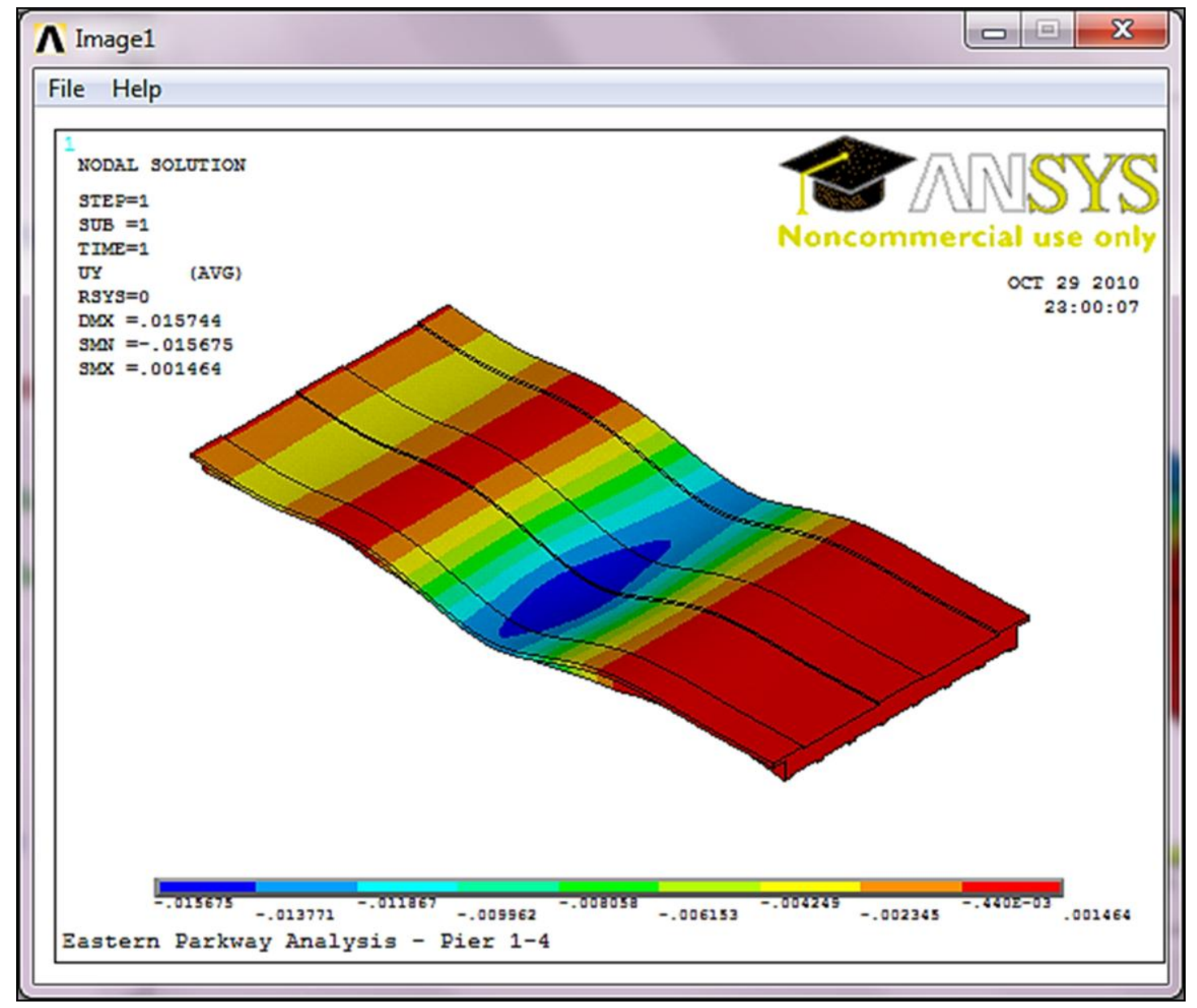

FIGURE 71 - Y-Component of Displacement for Iteration Seven 


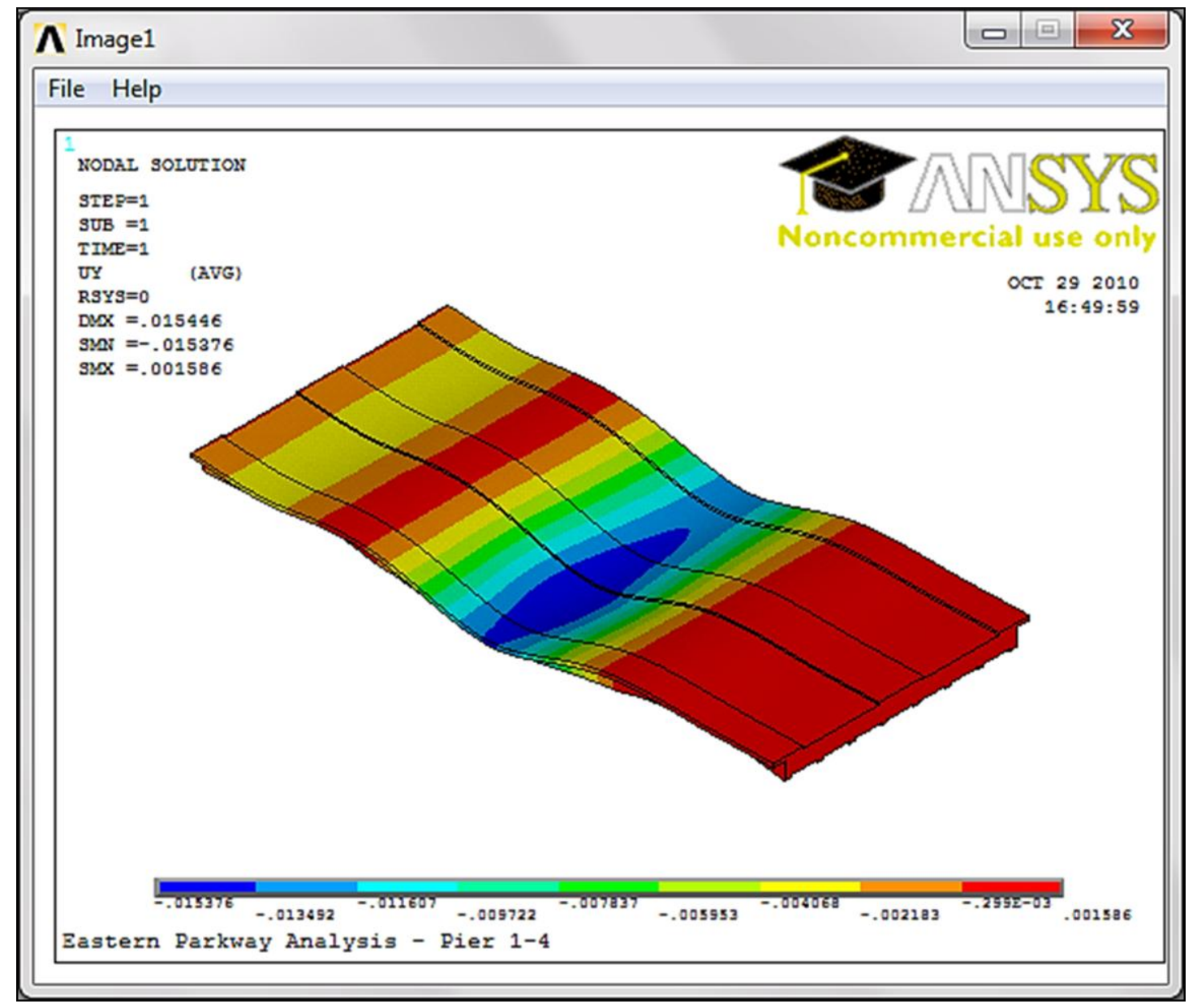

FIGURE 72 - Y-Component of Displacement for Iteration Eight 


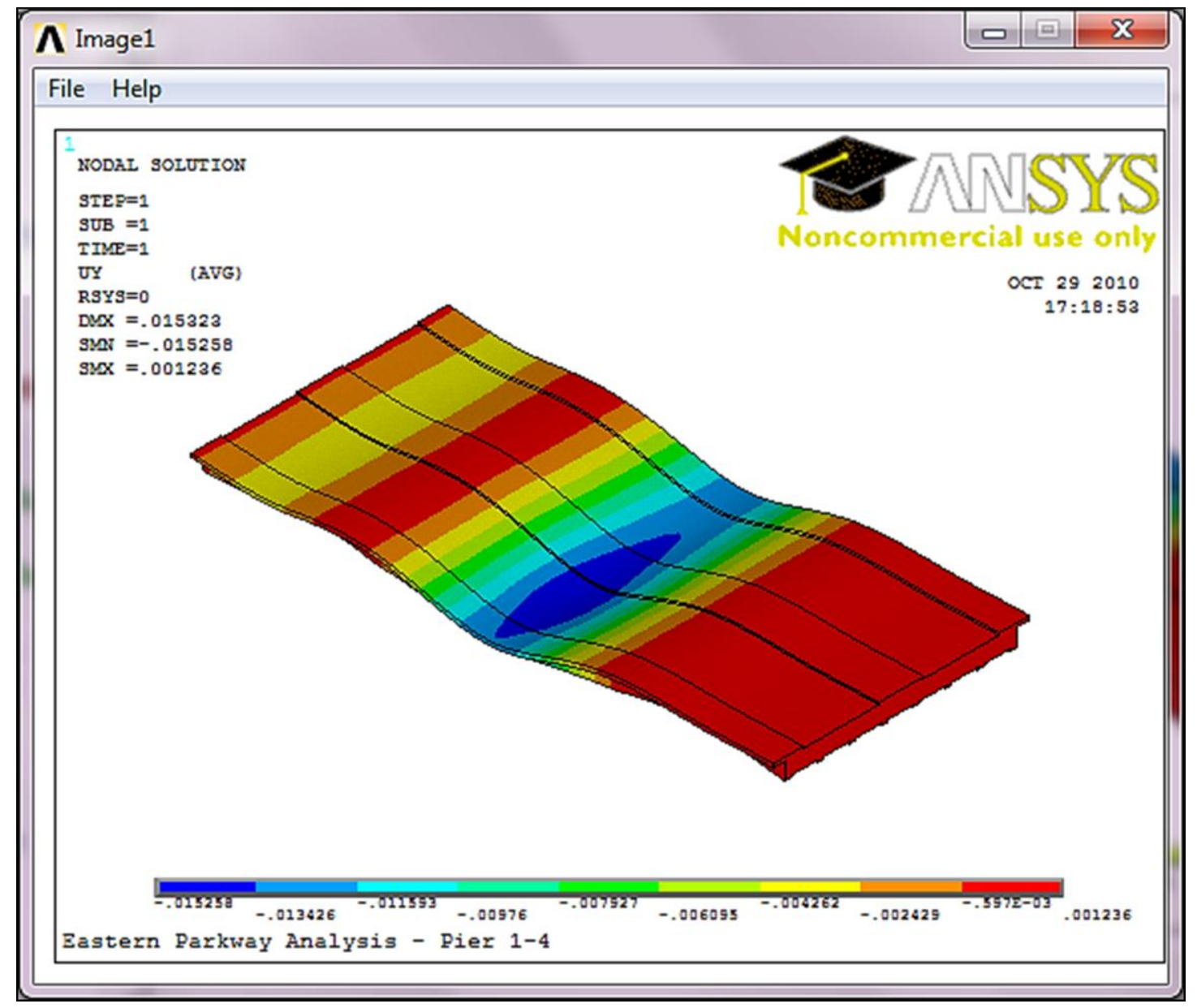

FIGURE 73 - Y-Component of Displacement for Iteration Nine 


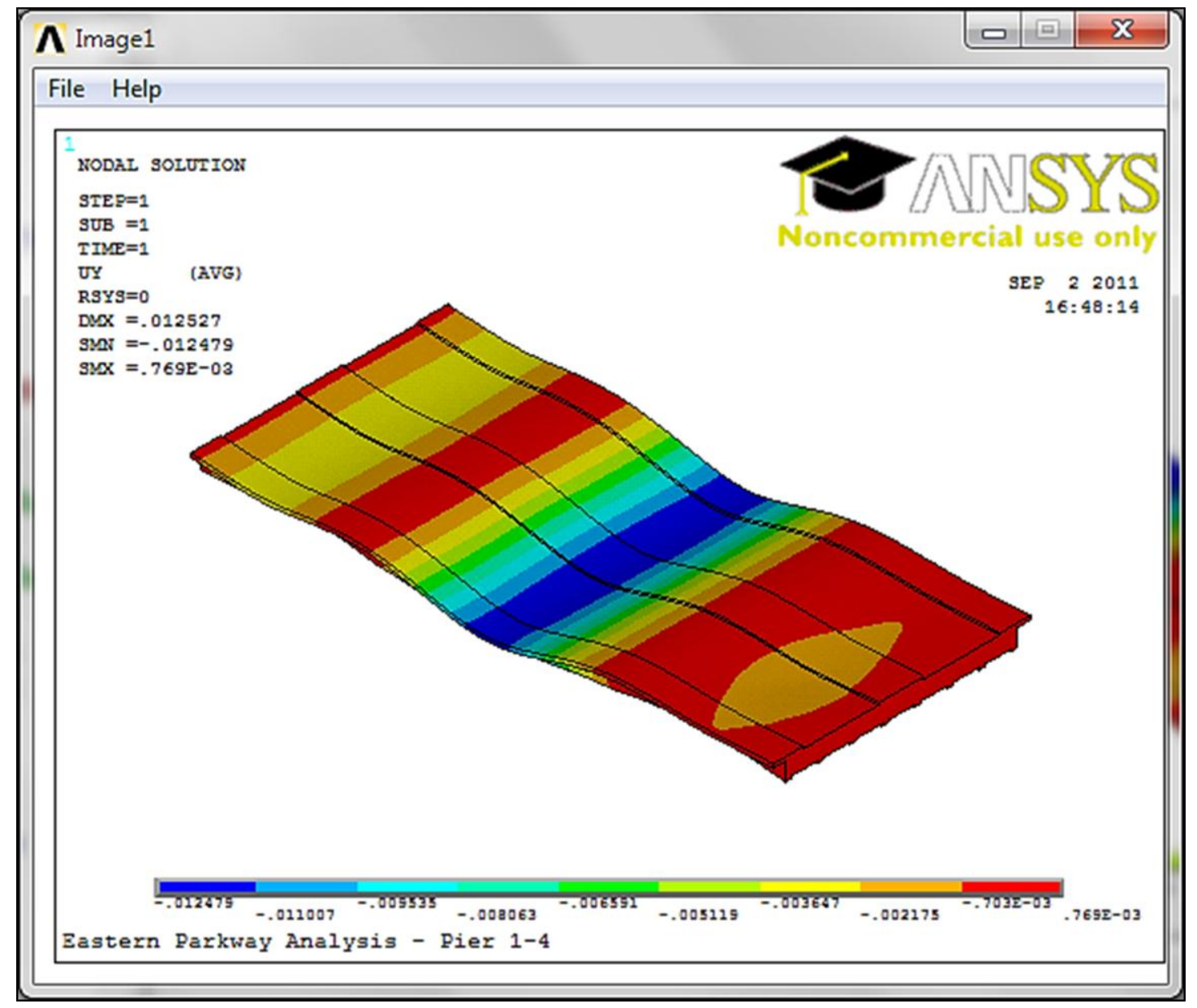

FIGURE 74 - Y-Component of Displacement for Iteration 10 


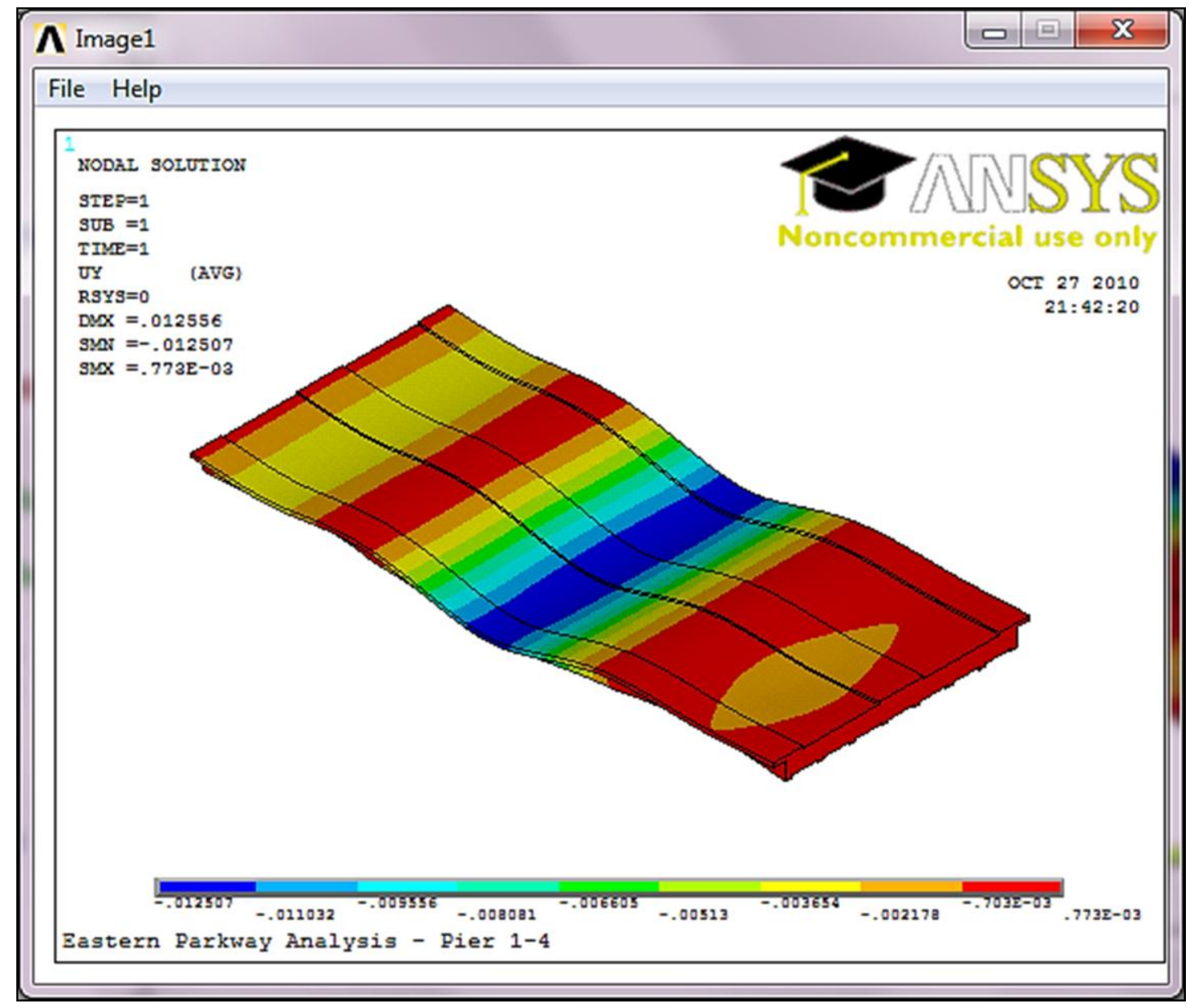

FIGURE 75 - Y-Component of Displacement for Iteration 11 


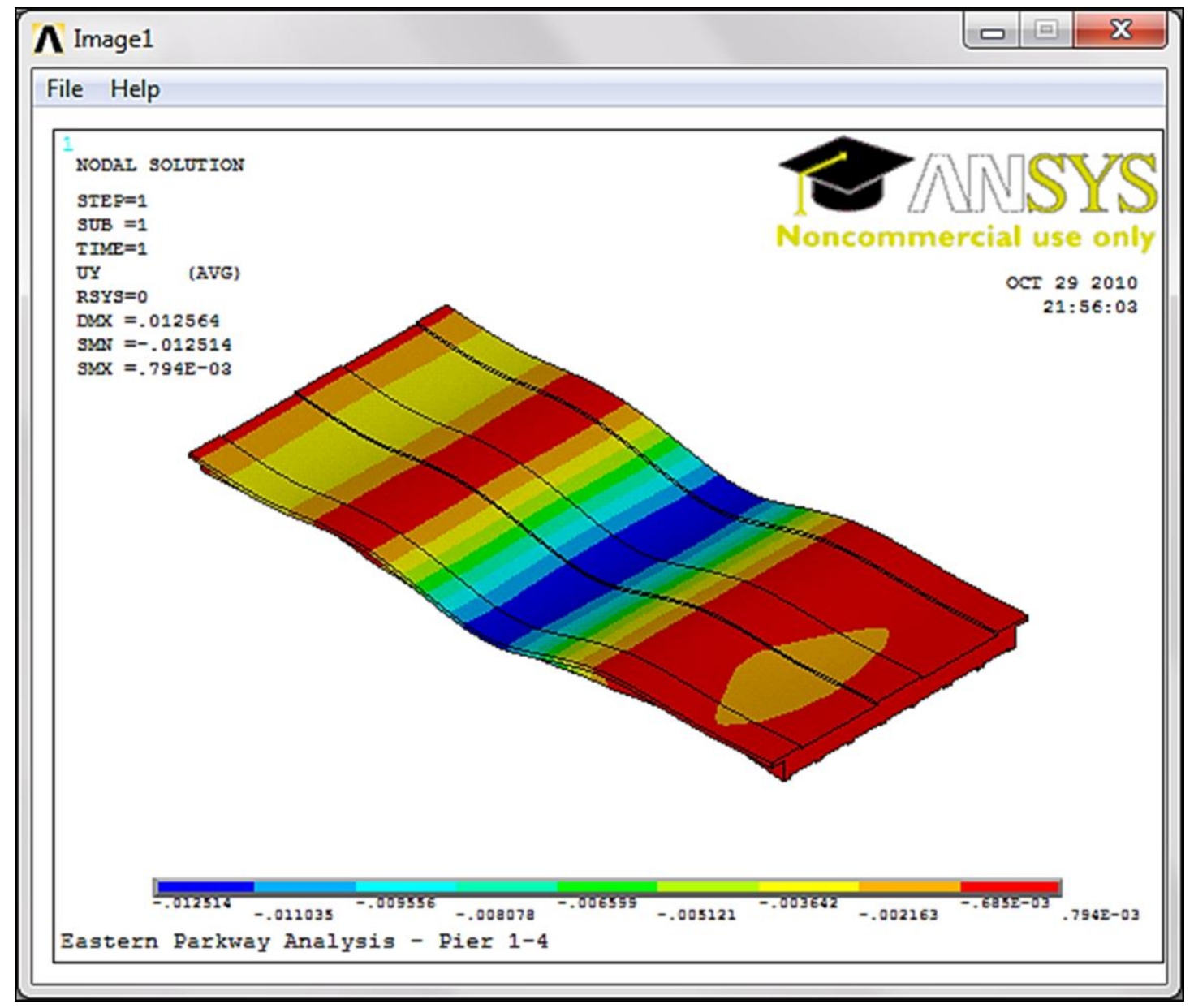

FIGURE 76 - Y-Component of Displacement for Iteration 12 


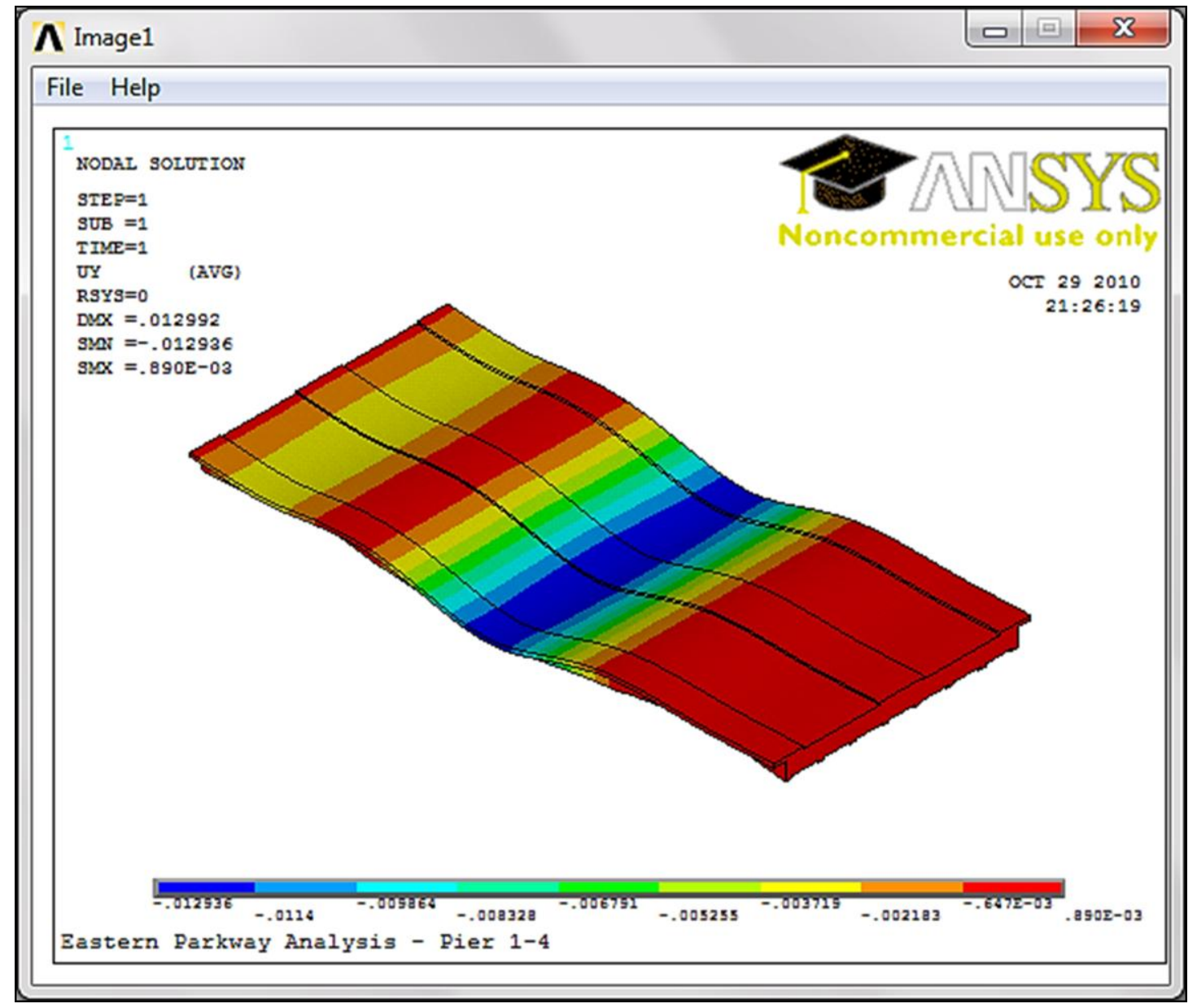

FIGURE 77 - Y-Component of Displacement for Iteration 13 
APPENDIX VIII

SCREEN CAPTURES OF Y-COMPONENTS OF STRESS

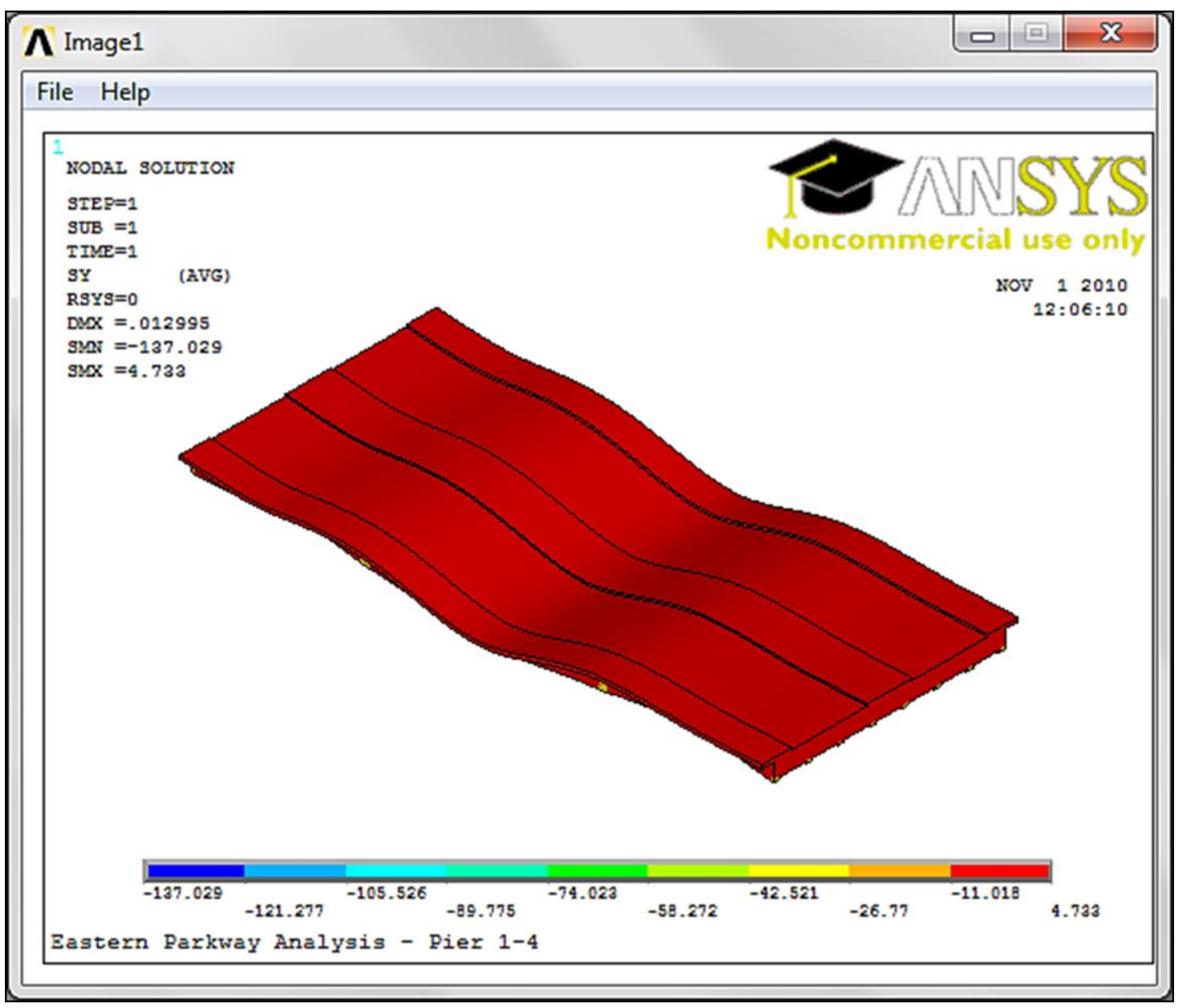

FIGURE 78 - Y-Component of Stress for Iteration One 


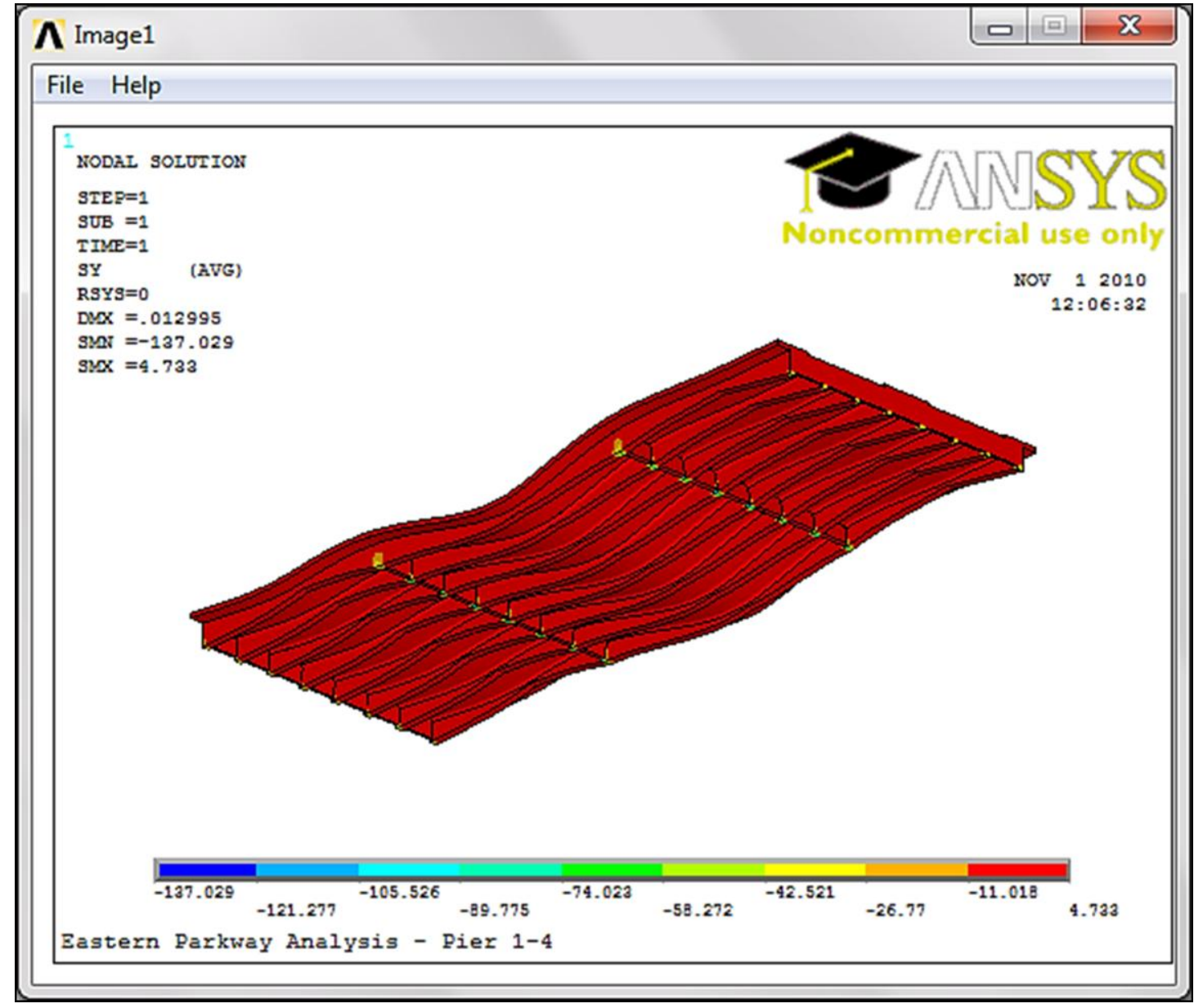

FIGURE 79 - Y-Component of Stress for Iteration One As Viewed From Below 


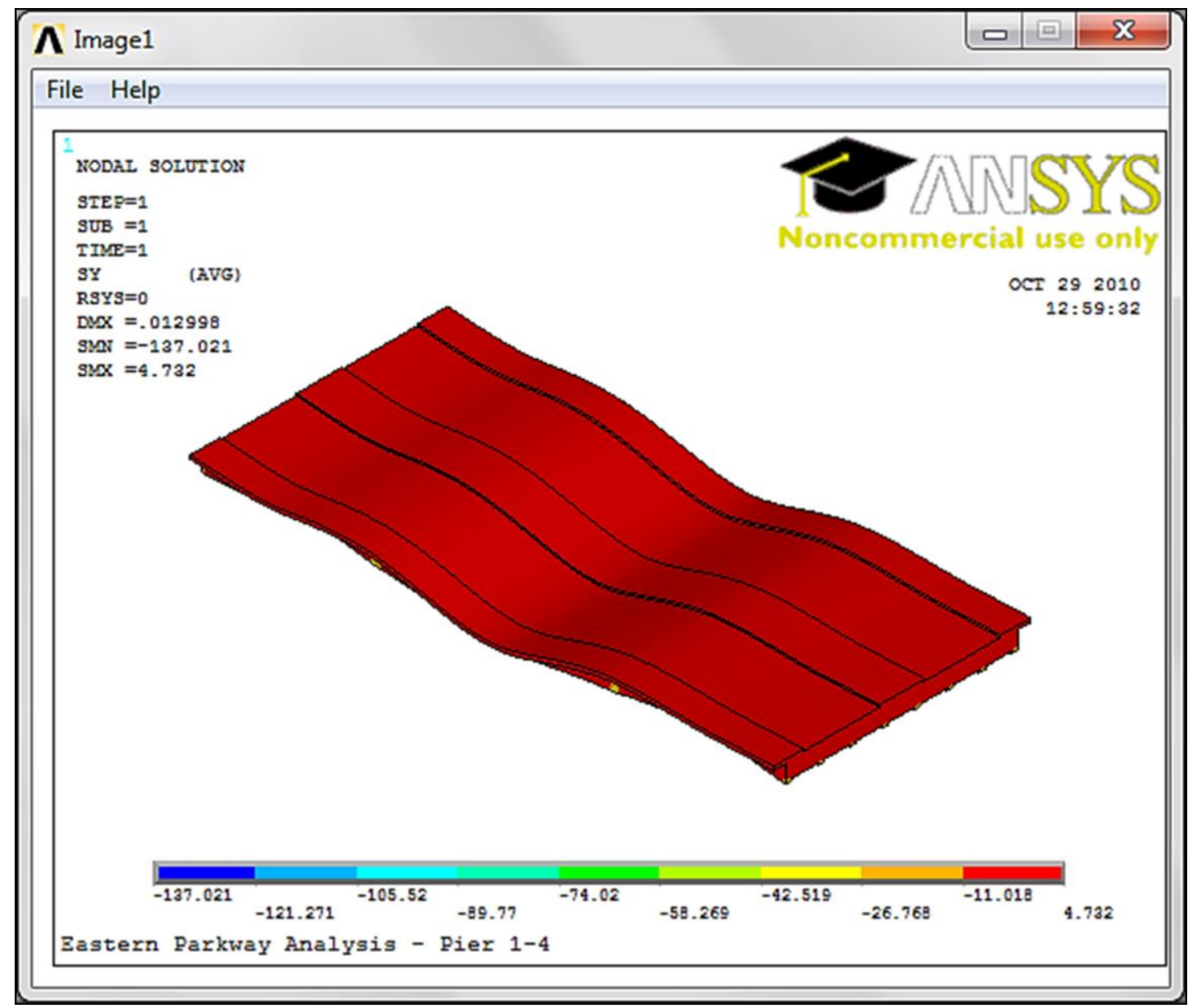

FIGURE 80 - Y-Component of Stress for Iteration Two 


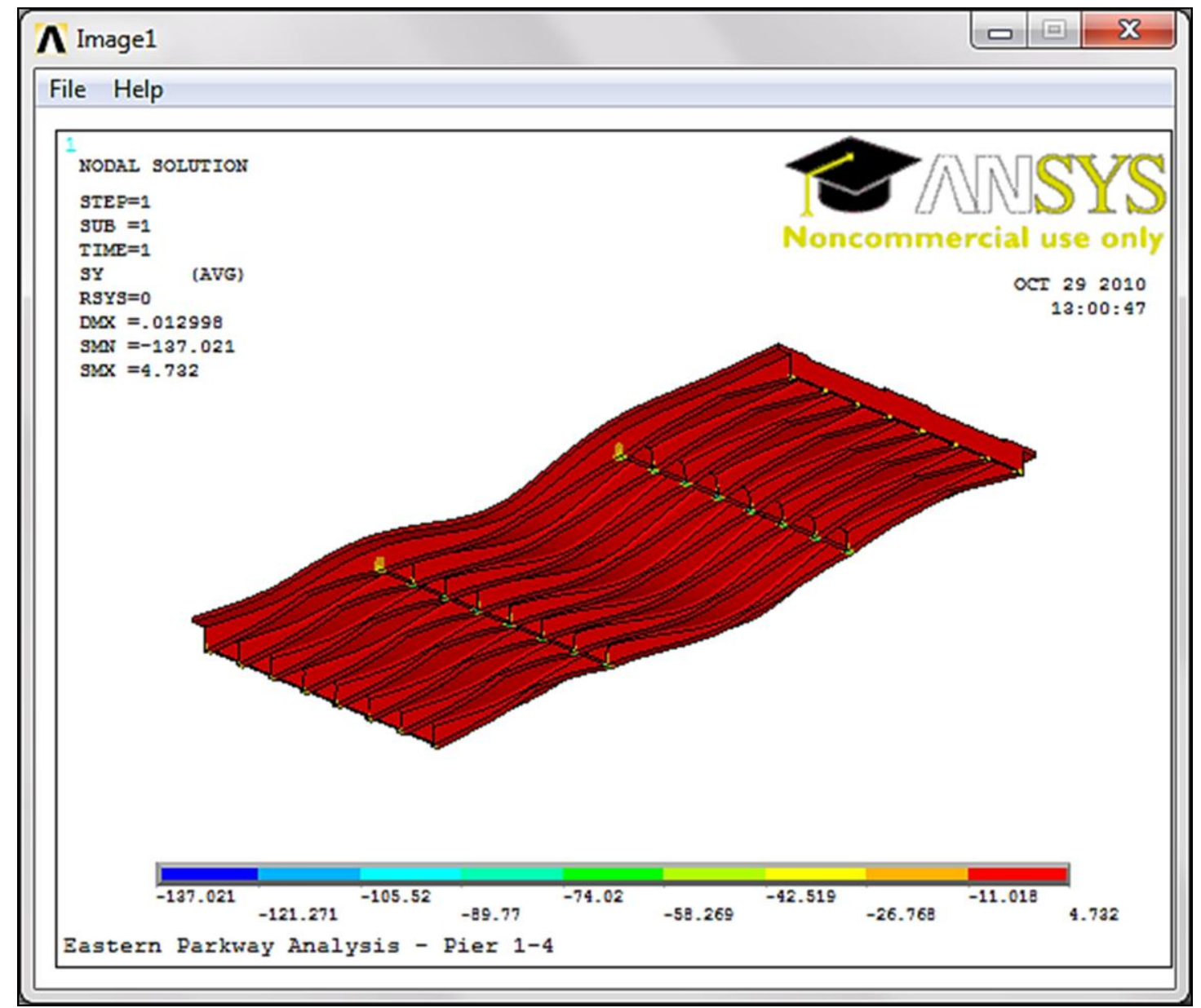

FIGURE 81 - Y-Component of Stress for Iteration Two As Viewed From Below 


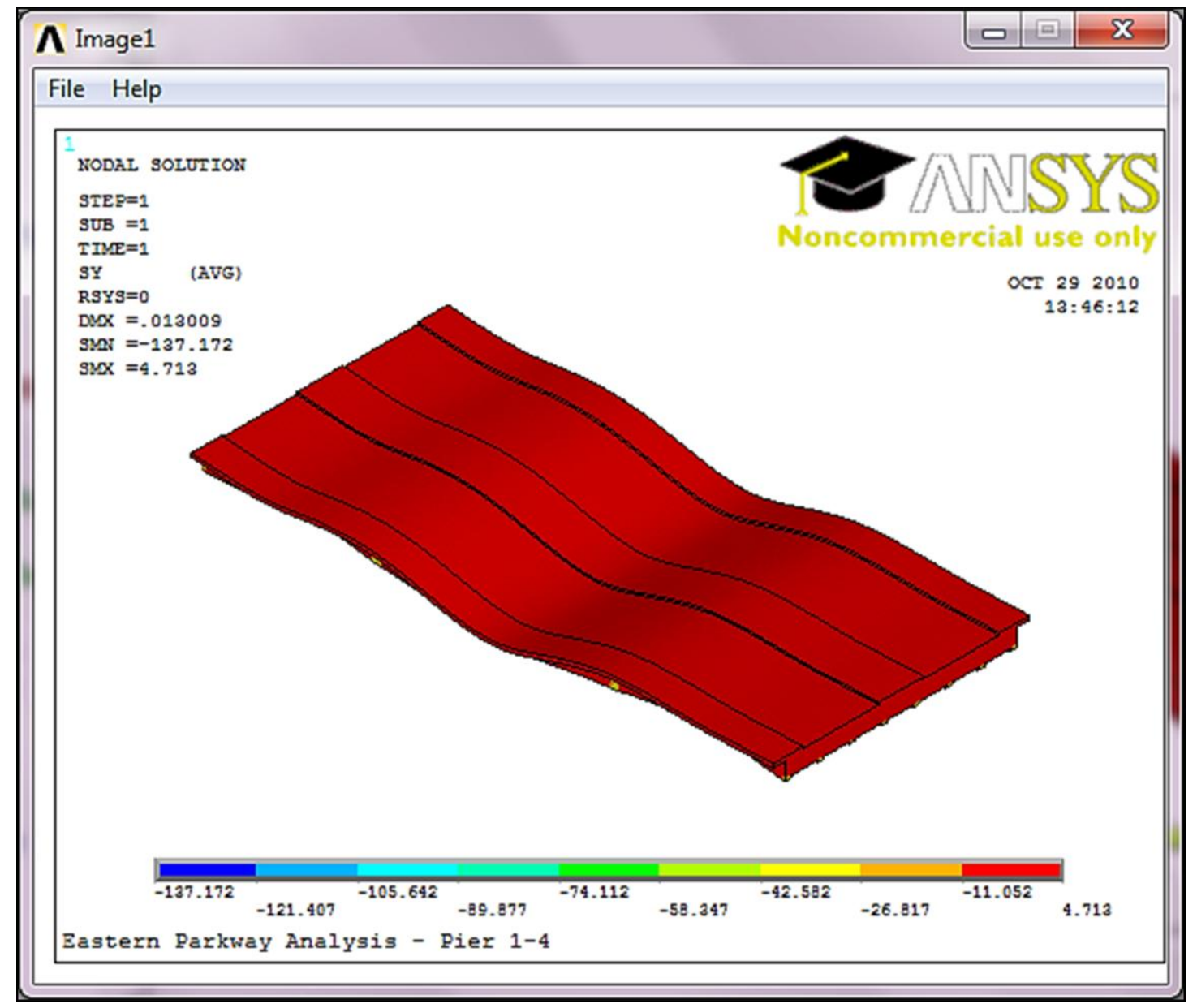

FIGURE 82 - Y-Component of Stress for Iteration Three 


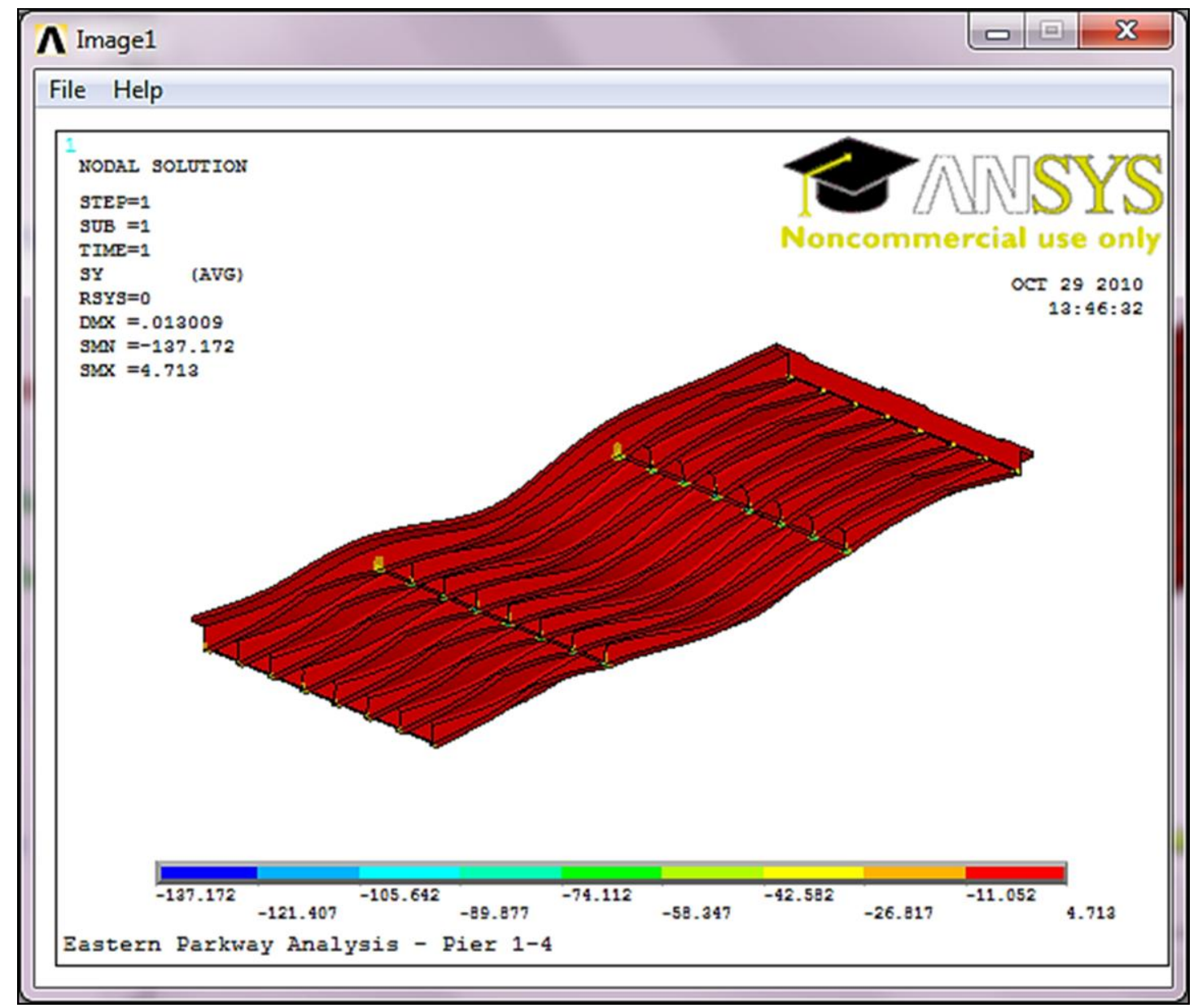

FIGURE 83 - Y-Component of Stress for Iteration Three As Viewed From Below 


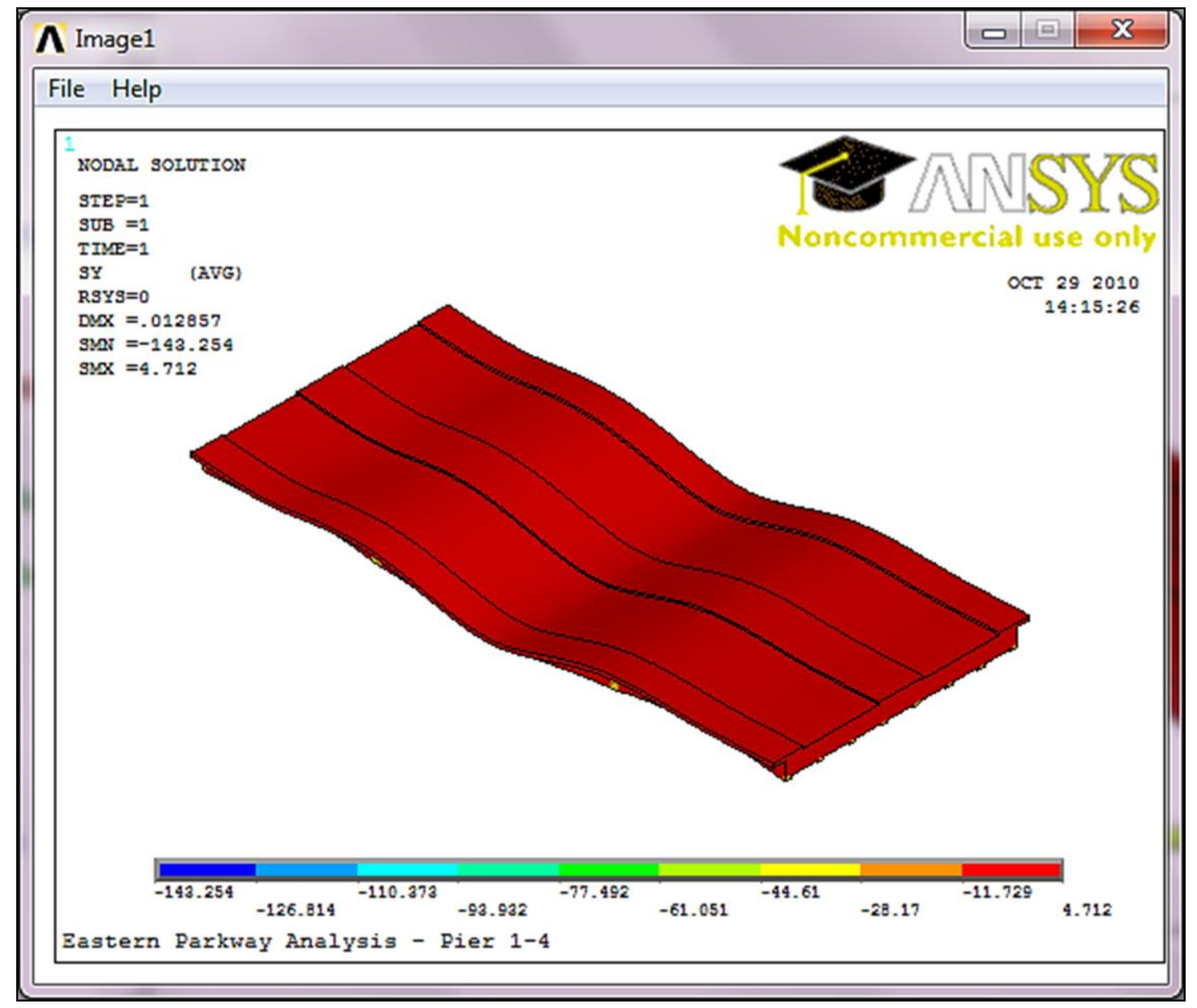

FIGURE 84 - Y-Component of Stress for Iteration Four 


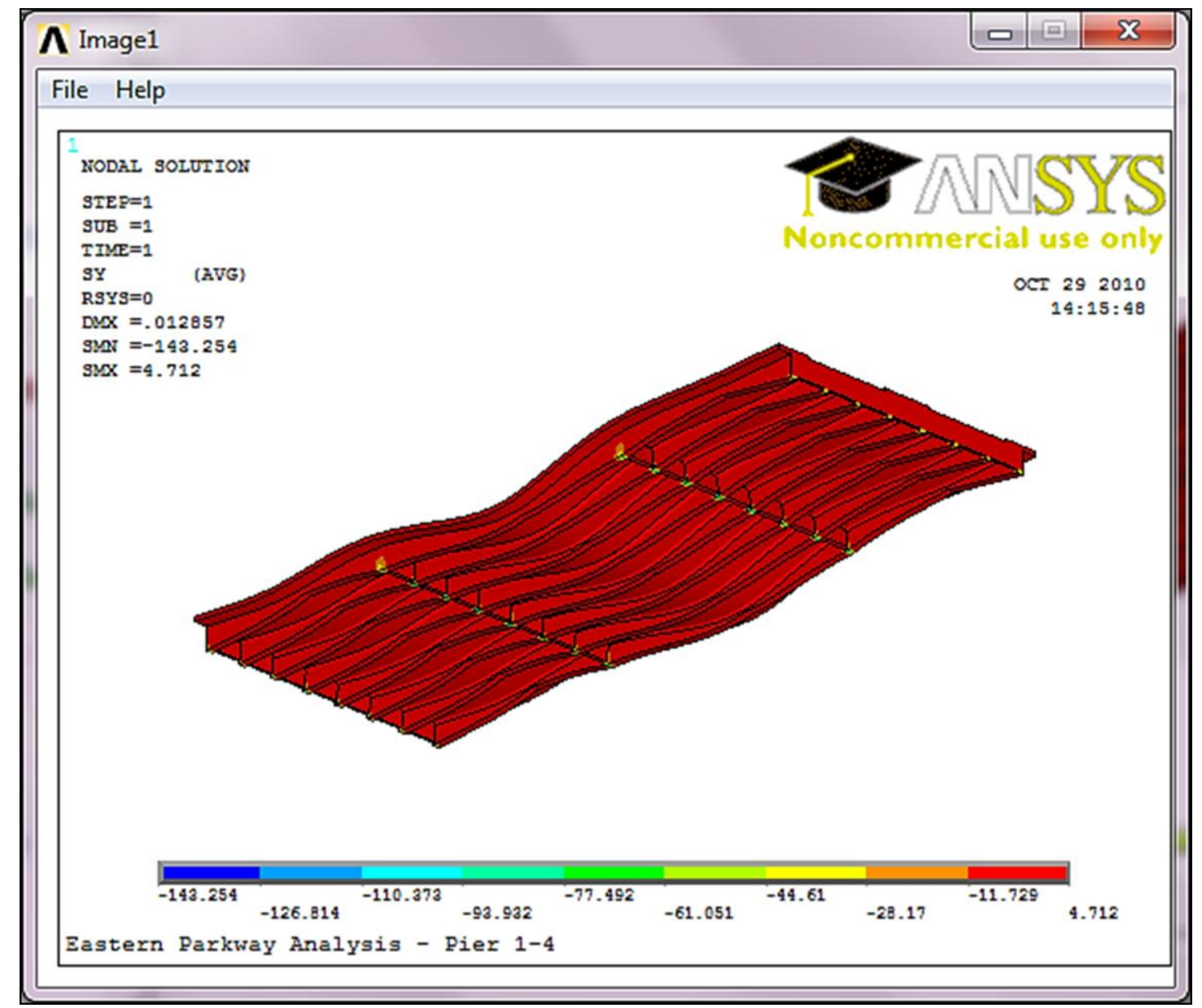

FIGURE 85 - Y-Component of Stress for Iteration Four As Viewed From Below 


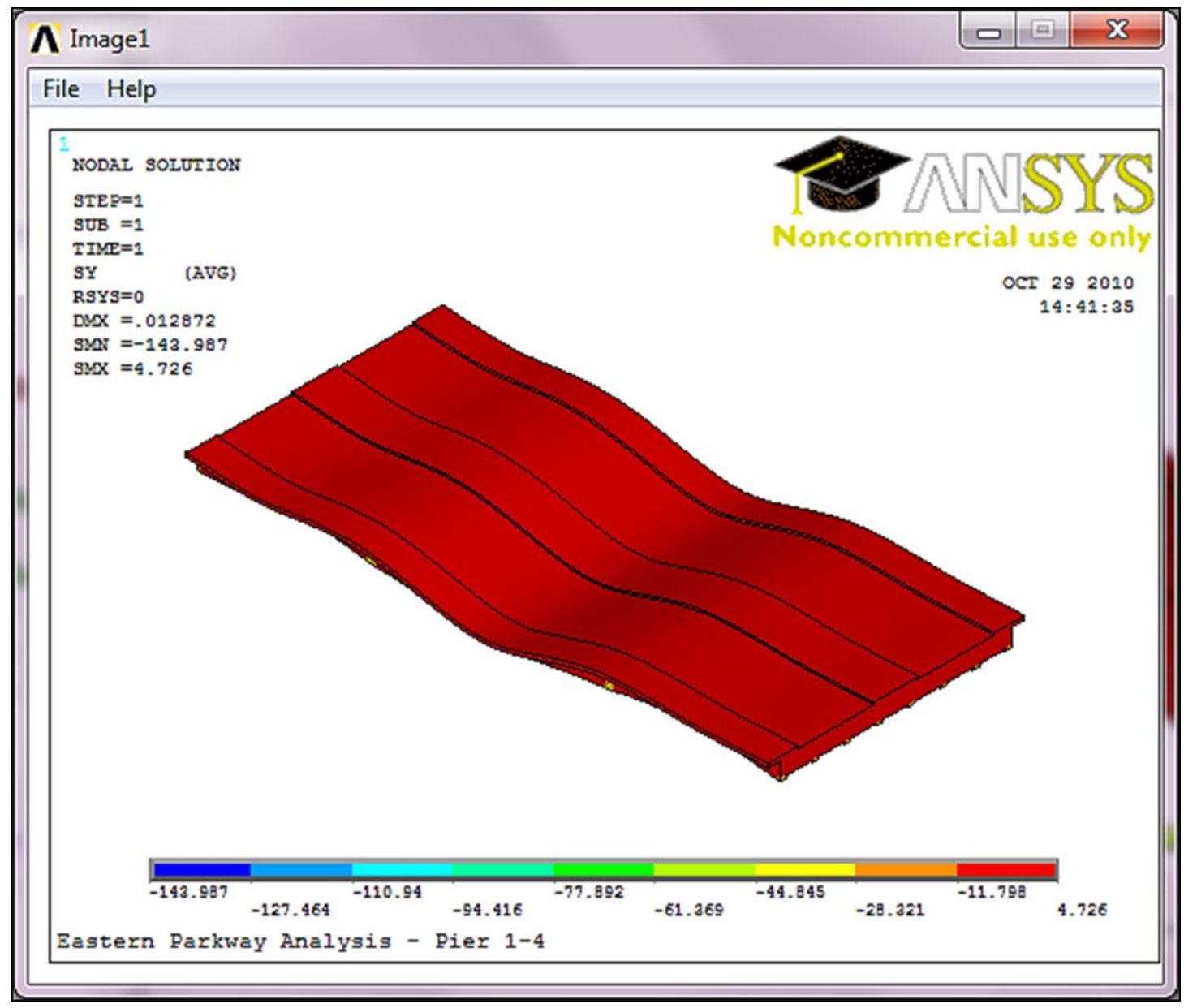

FIGURE 86 - Y-Component of Stress for Iteration Five 


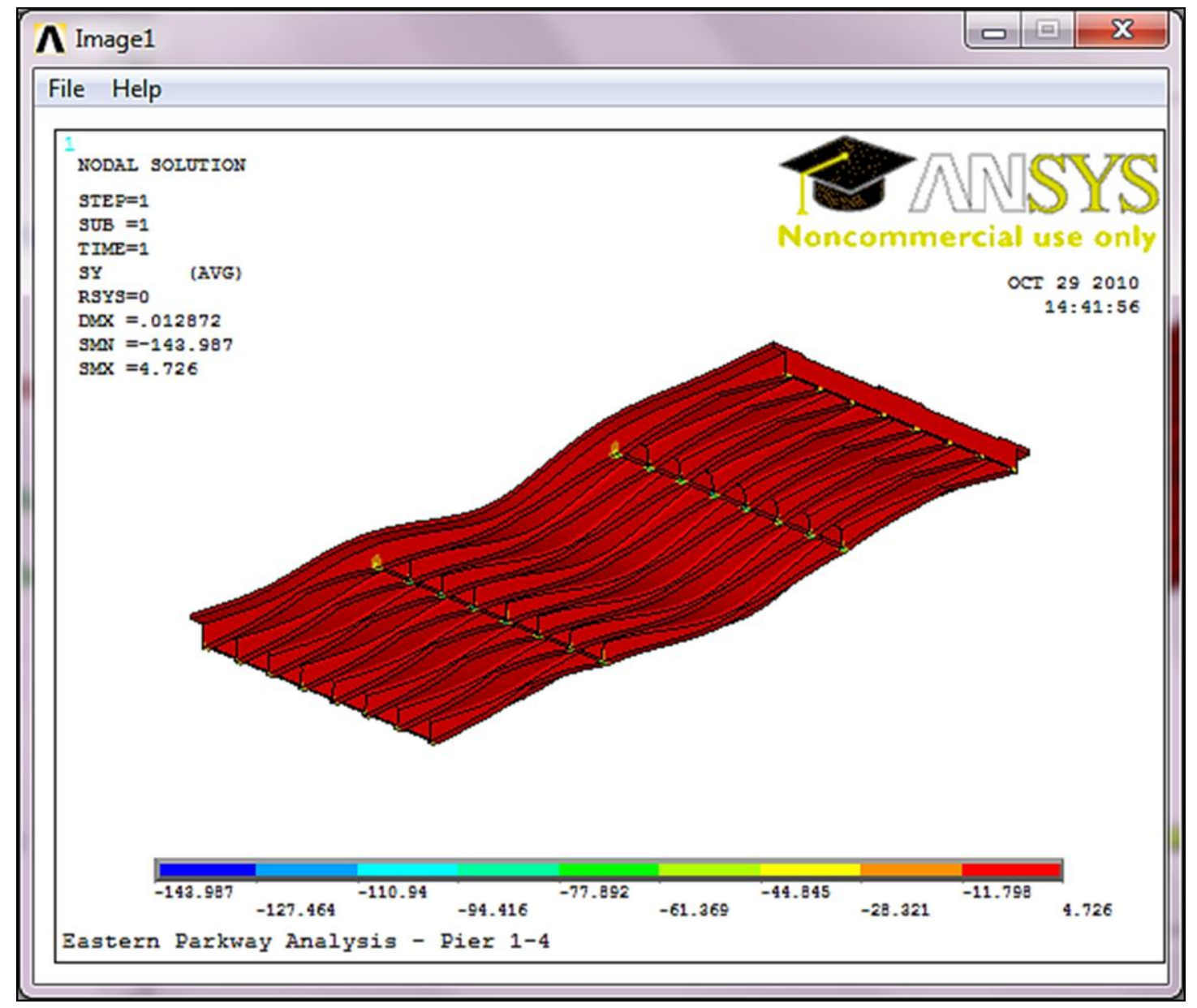

FIGURE 87 - Y-Component of Stress for Iteration Five As Viewed From Below 


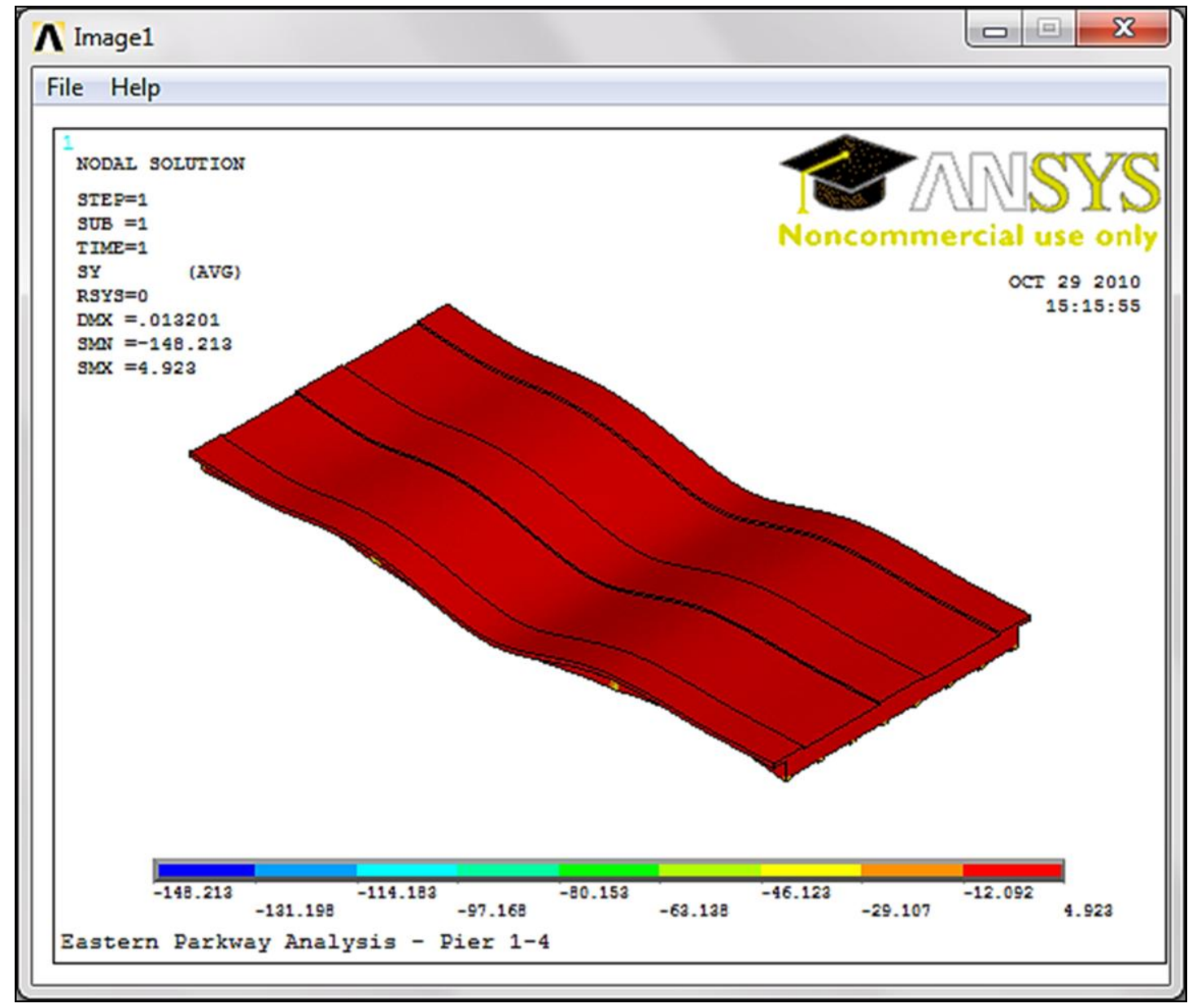

FIGURE 88 - Y-Component of Stress for Iteration Six 


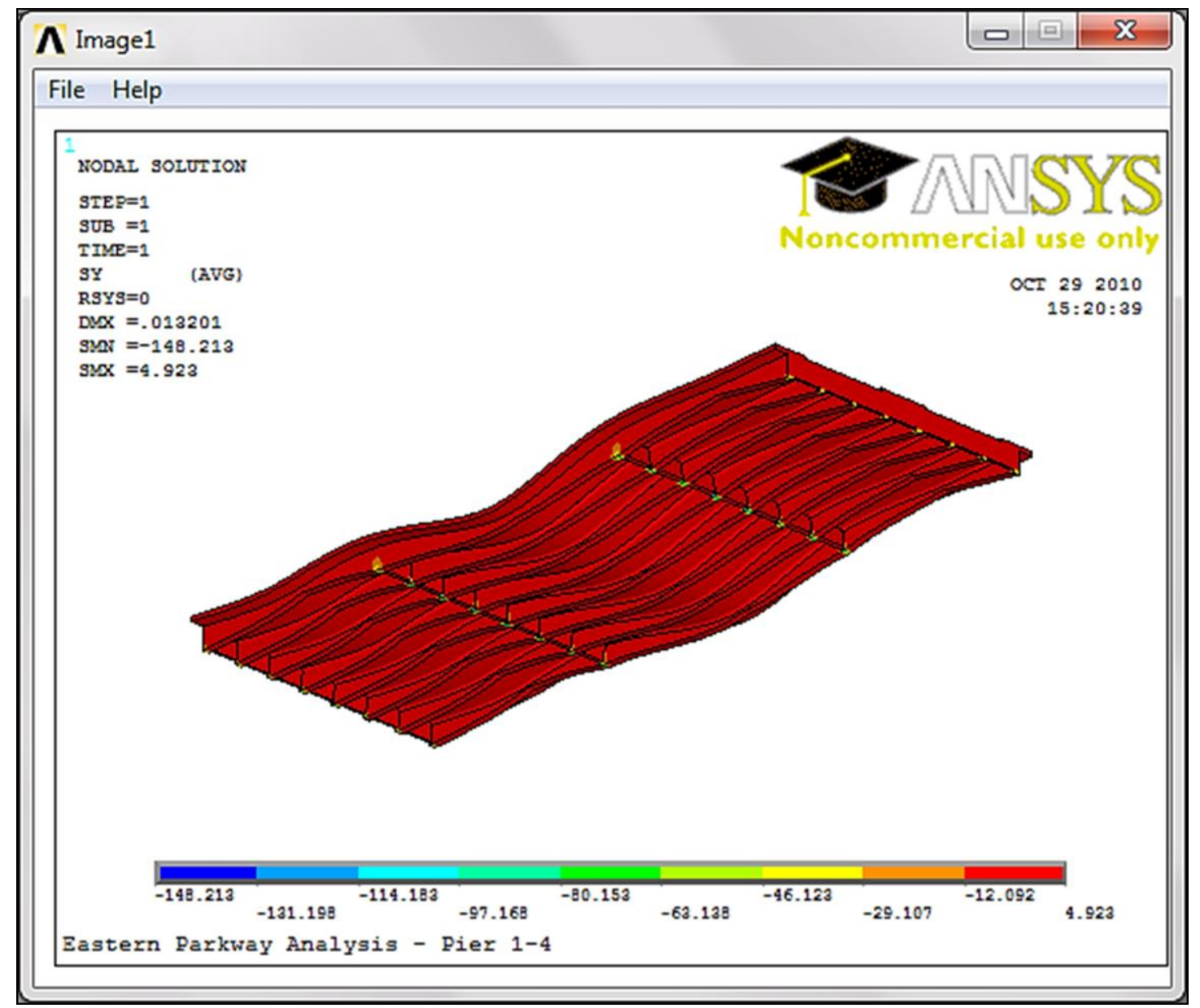

FIGURE 89 - Y-Component of Stress for Iteration Six As Viewed From Below 


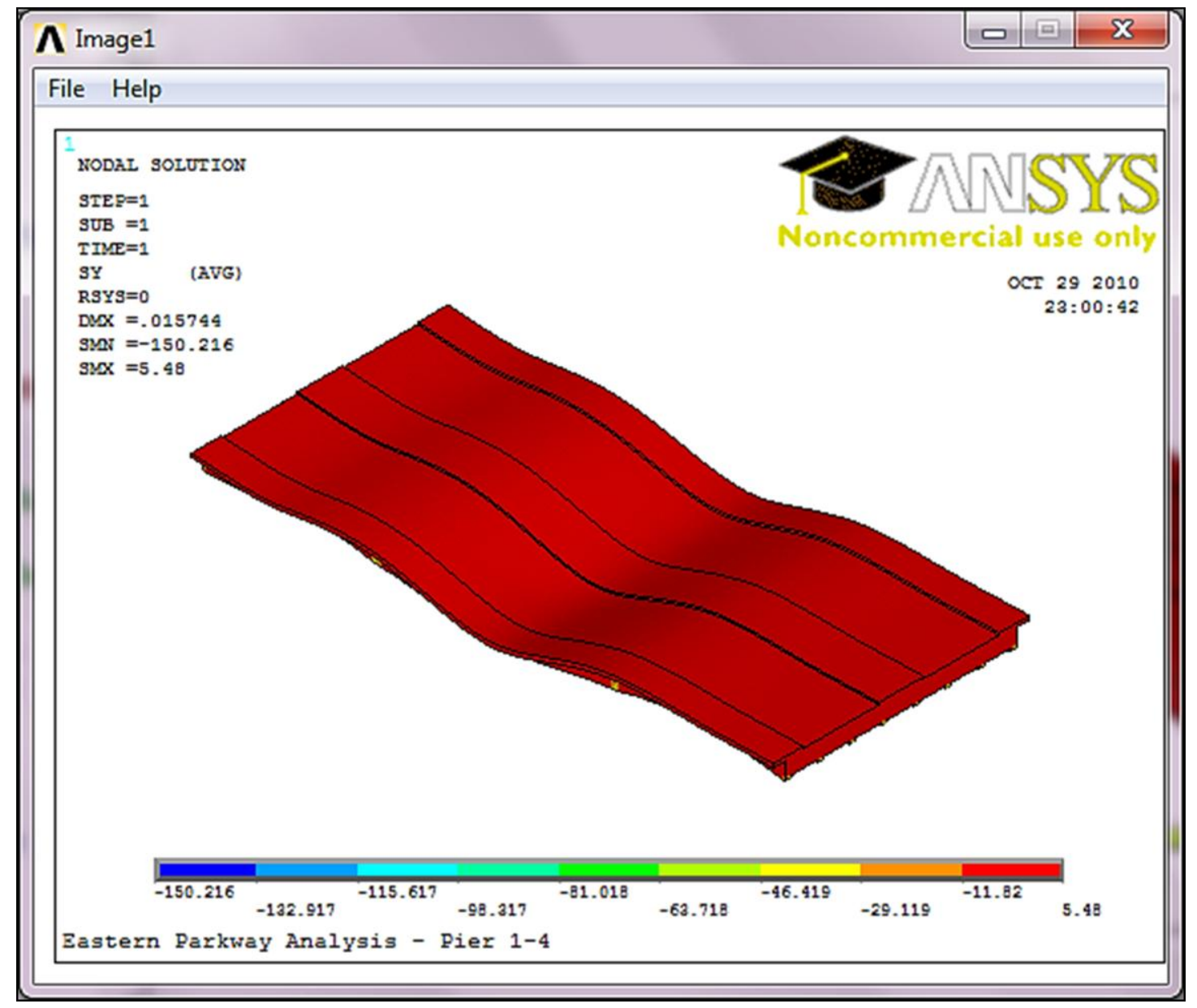

FIGURE 90 - Y-Component of Stress for Iteration Seven 


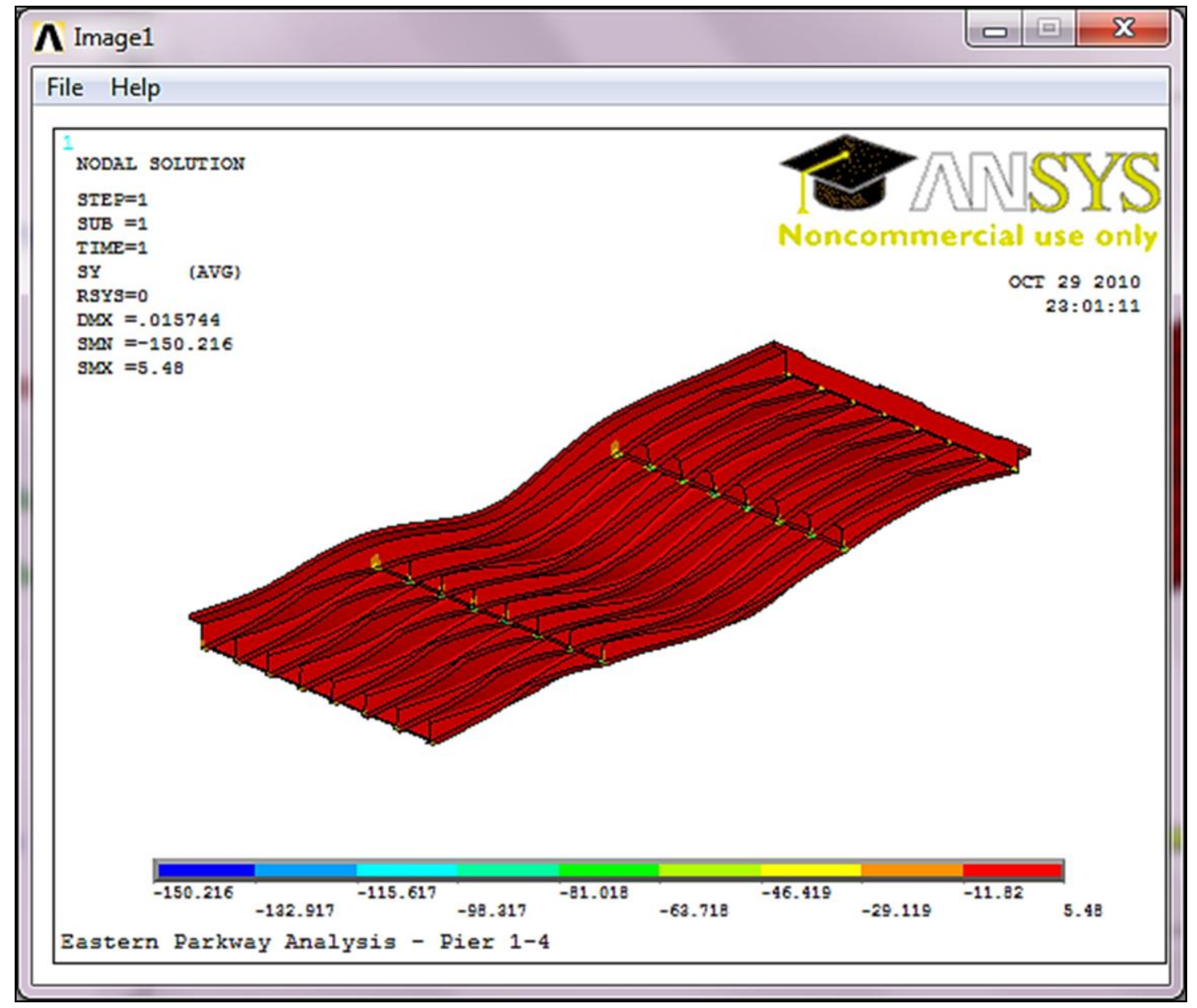

FIGURE 91 - Y-Component of Stress for Iteration Seven As Viewed From Below 


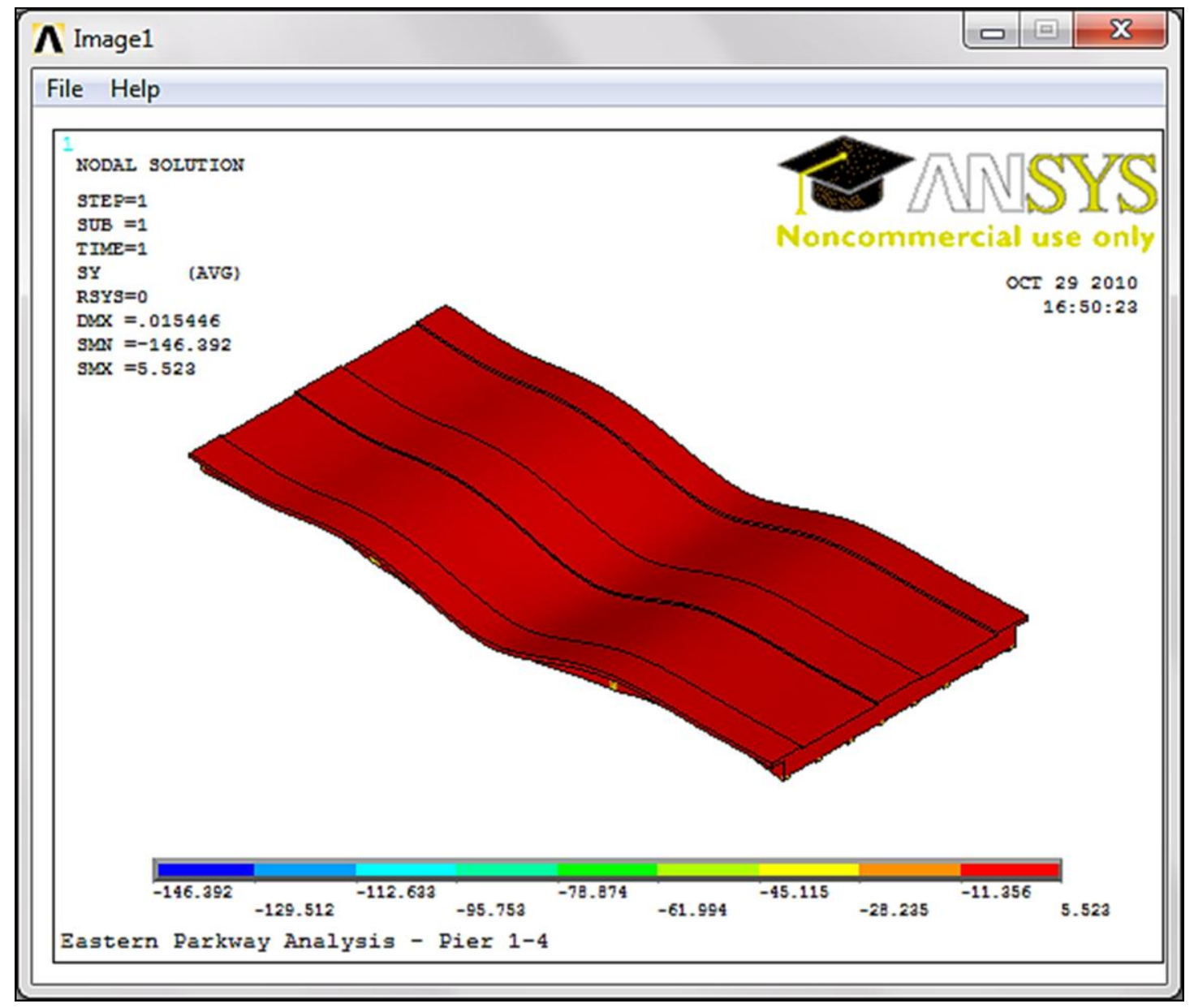

FIGURE 92 - Y-Component of Stress for Iteration Eight 


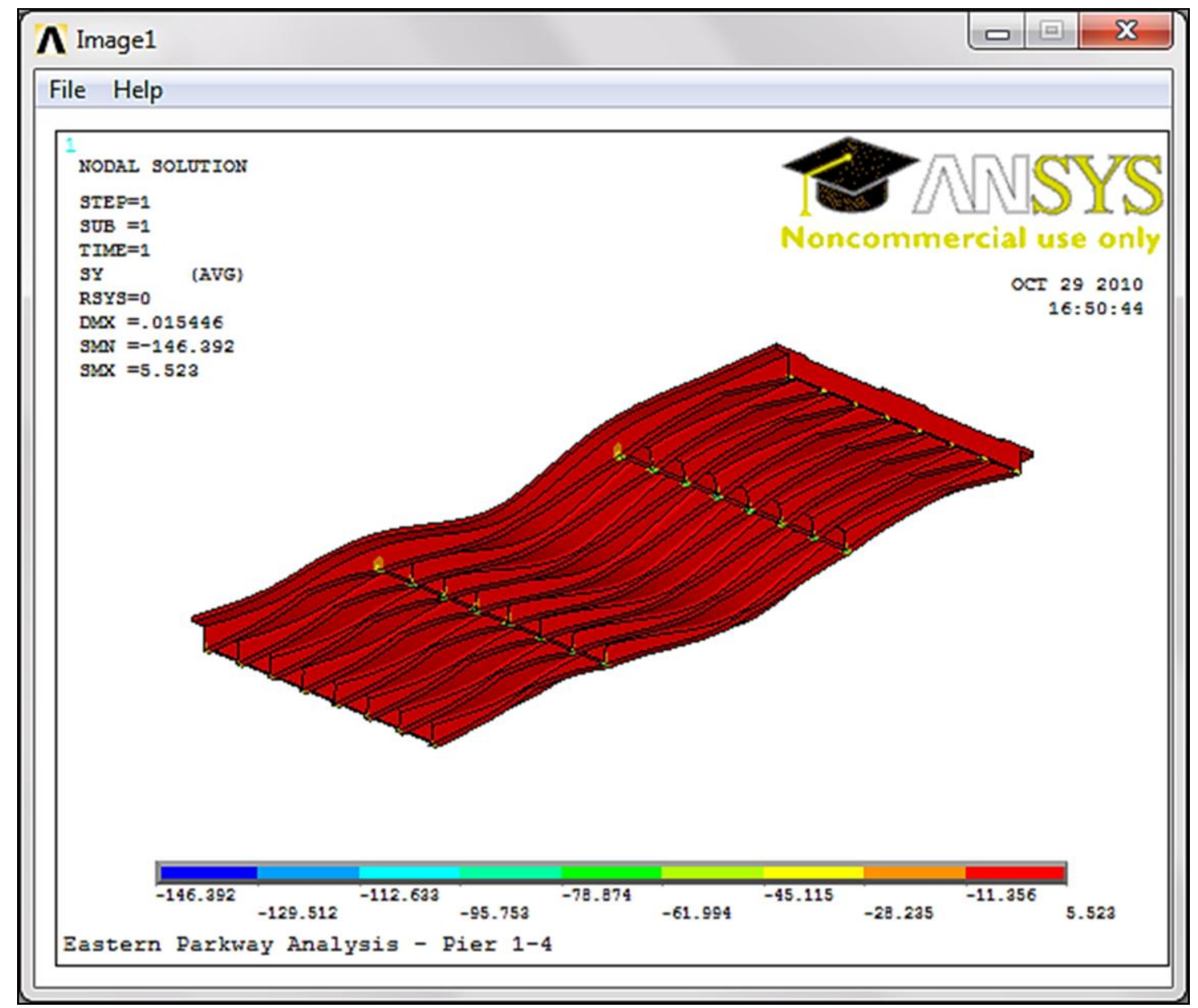

FIGURE 93 - Y-Component of Stress for Iteration Eight As Viewed From Below 


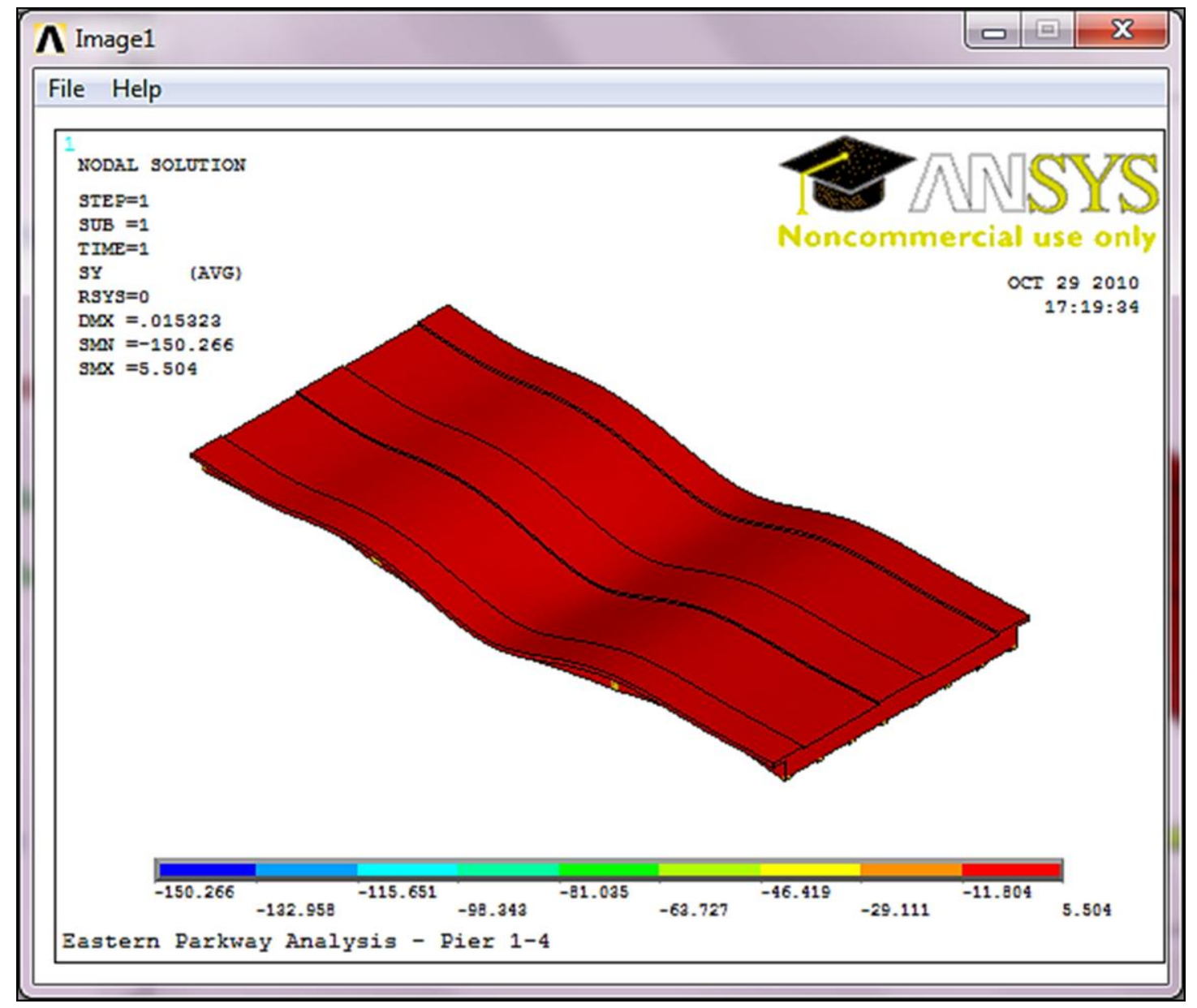

FIGURE 94 - Y-Component of Stress for Iteration Nine 


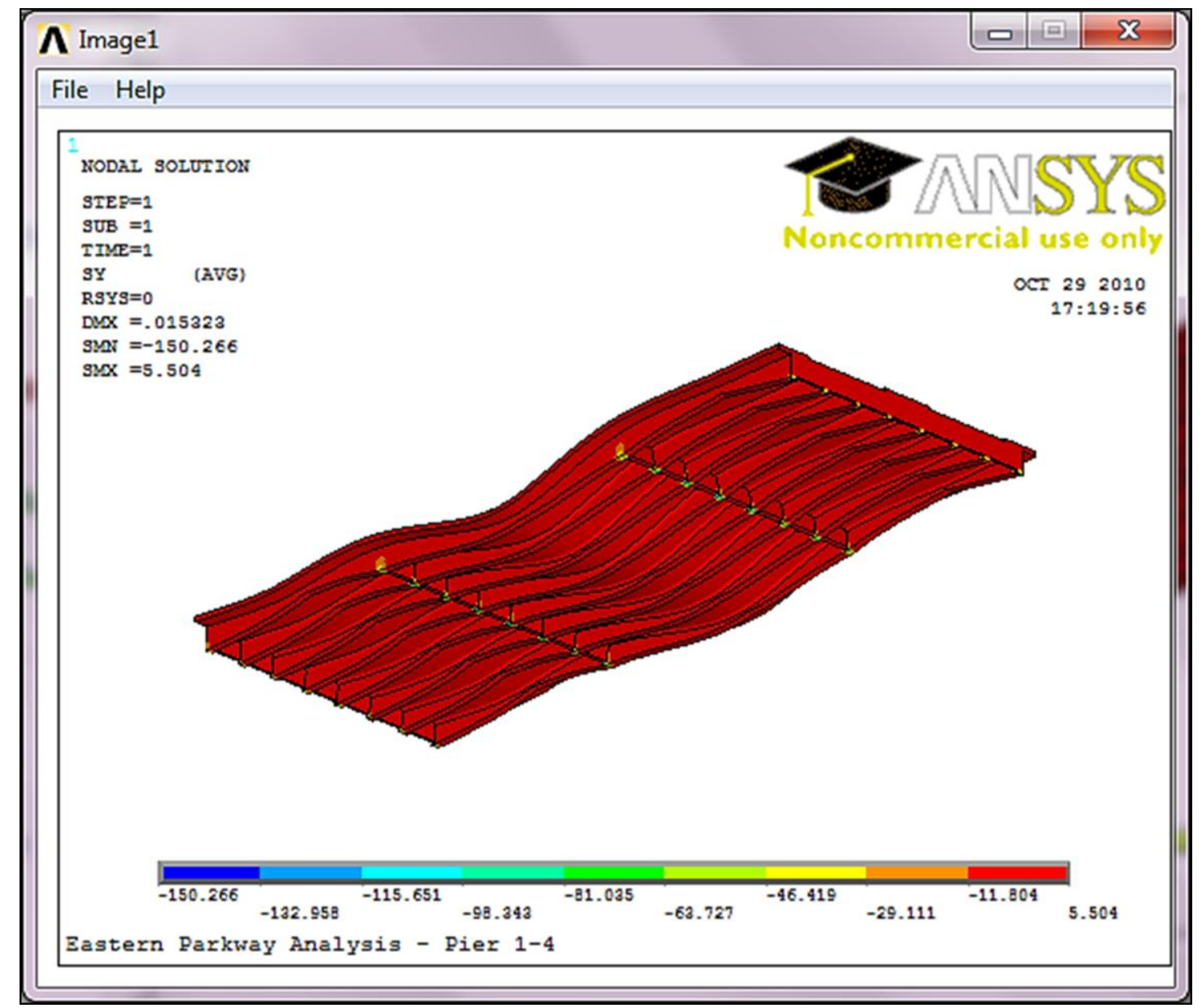

FIGURE 95 - Y-Component of Stress for Iteration Nine As Viewed From Below 


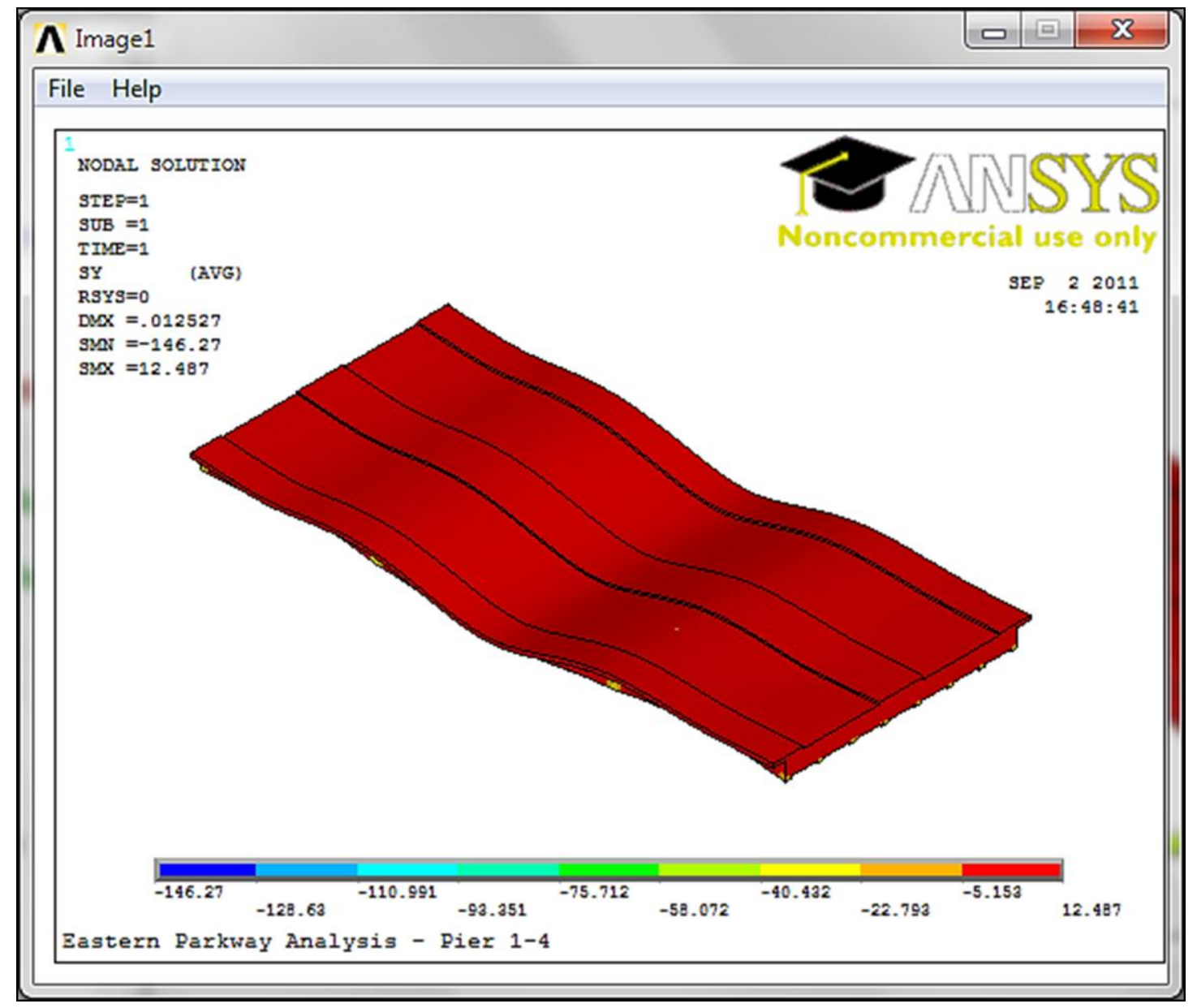

FIGURE 96 - Y-Component of Stress for Iteration 10 


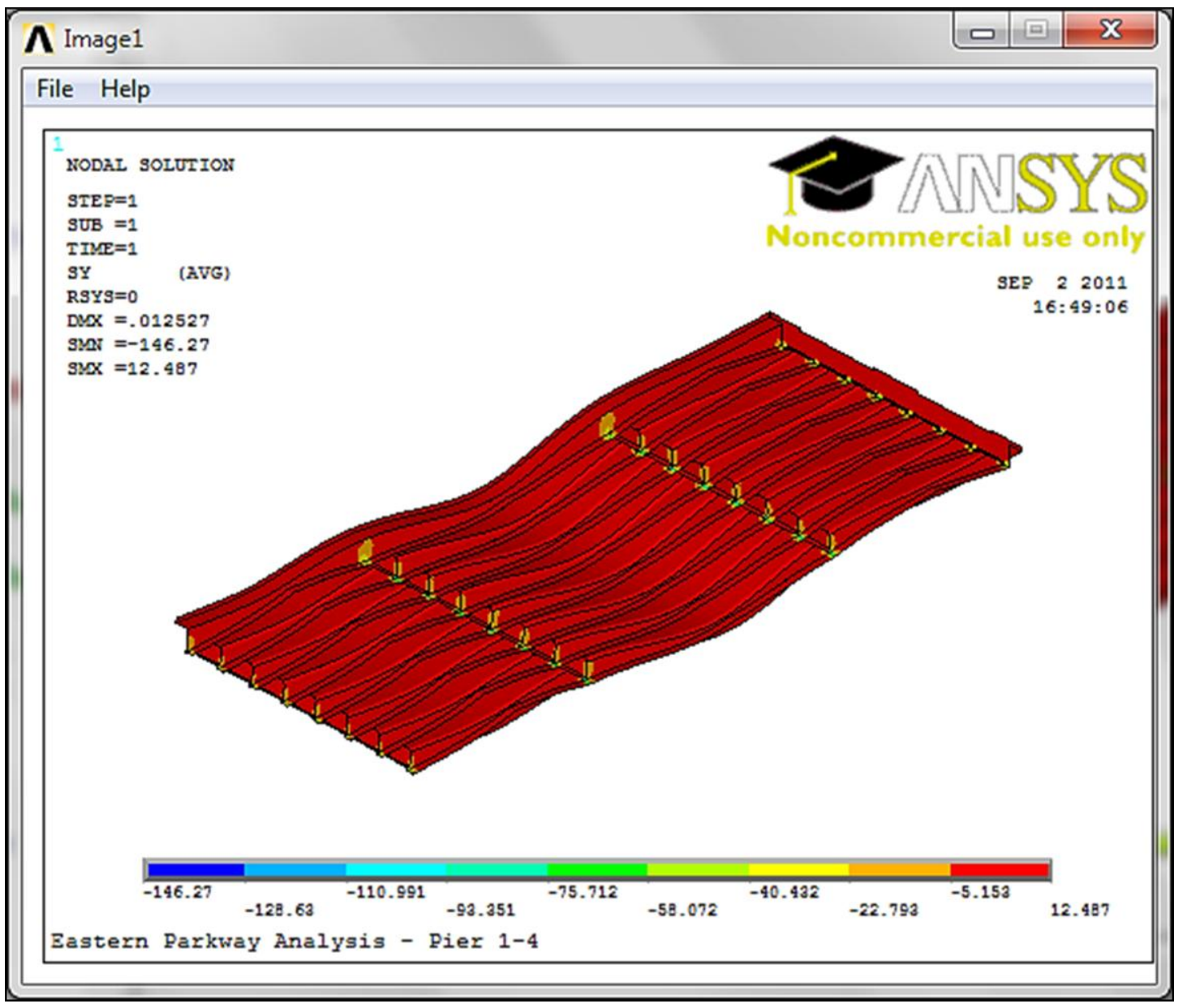

FIGURE 97 - Y-Component of Stress for Iteration 10 As Viewed From Below 


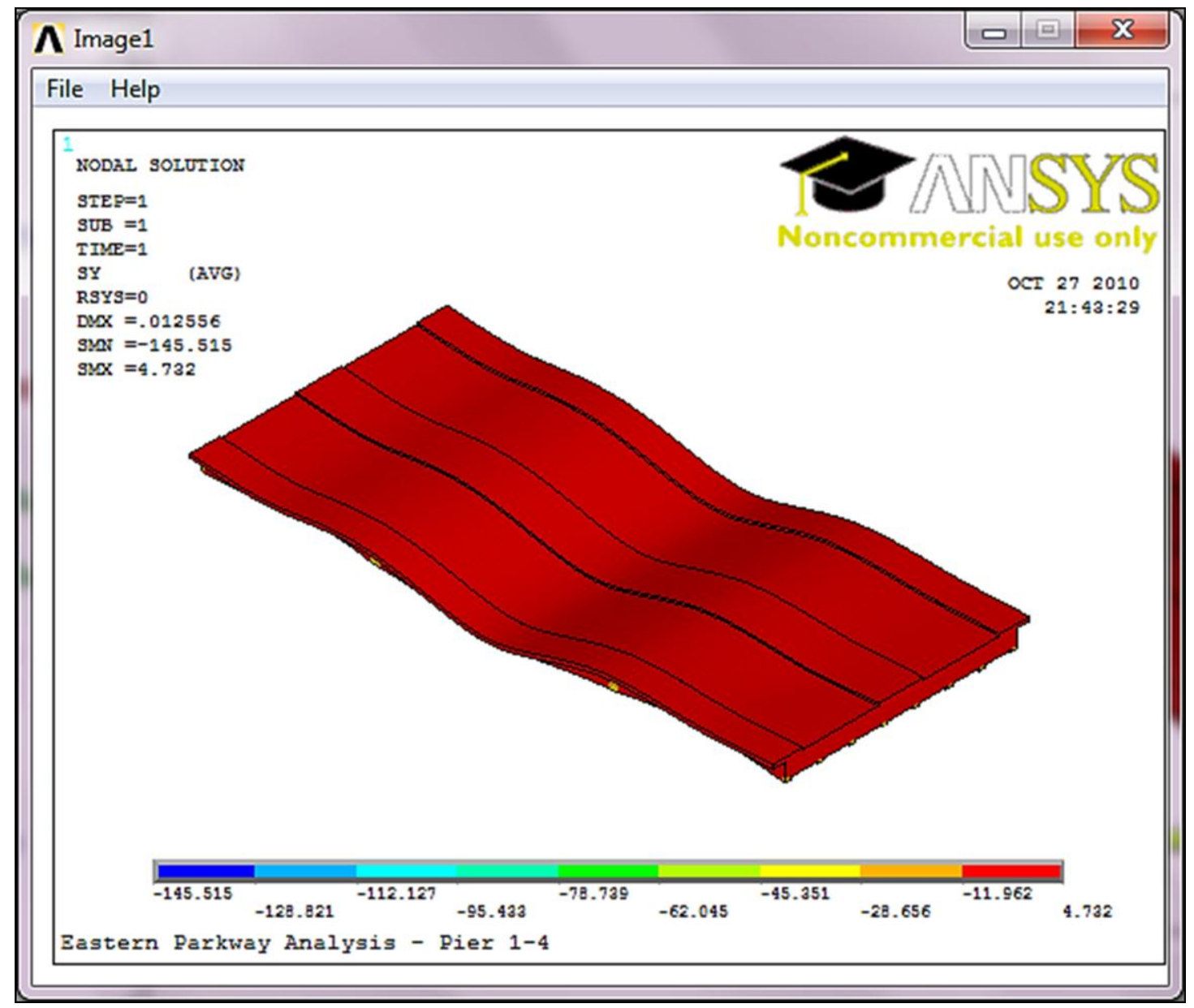

FIGURE 98 - Y-Component of Stress for Iteration 11 


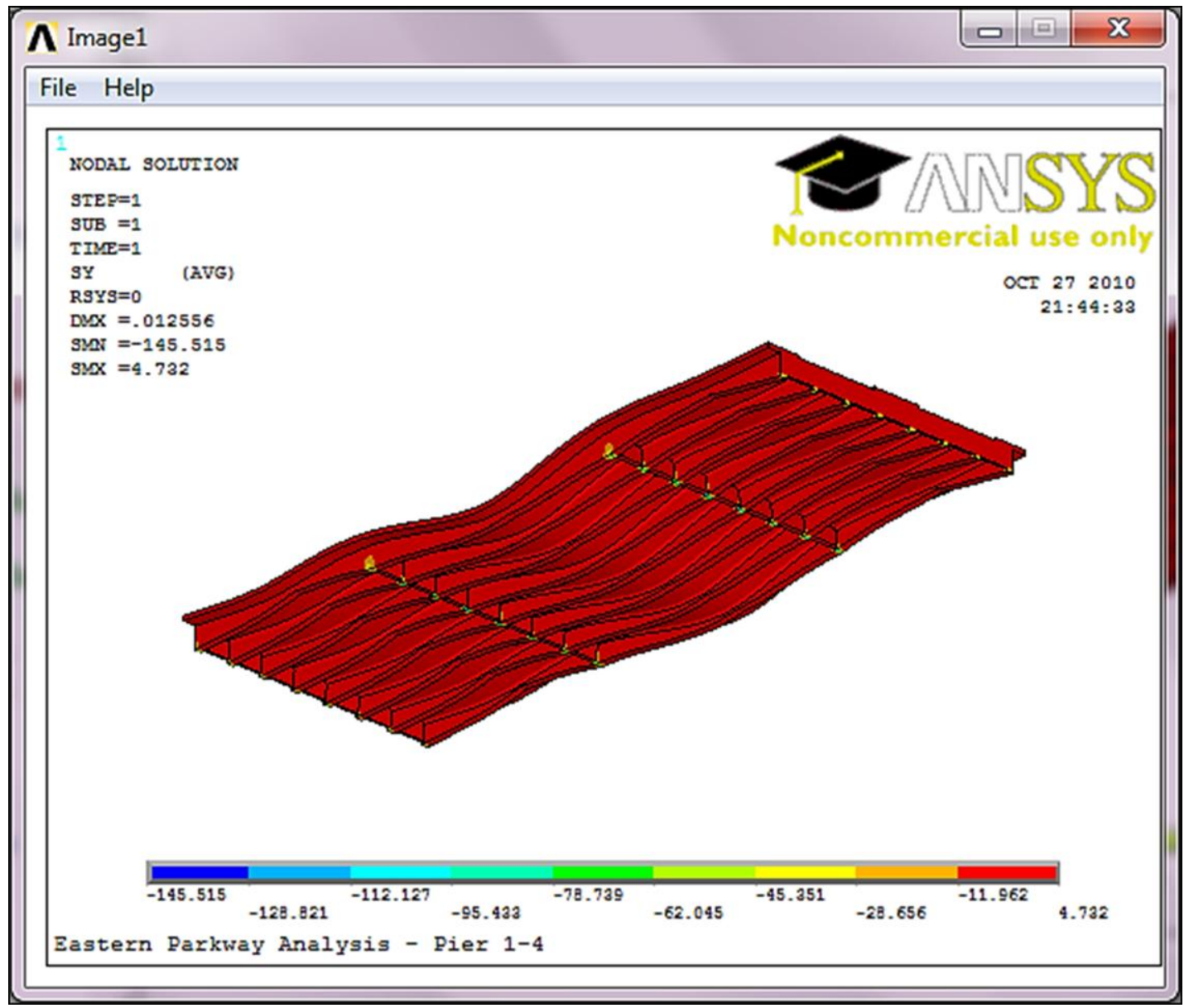

FIGURE 99 - Y-Component of Stress for Iteration 11 As Viewed From Below 


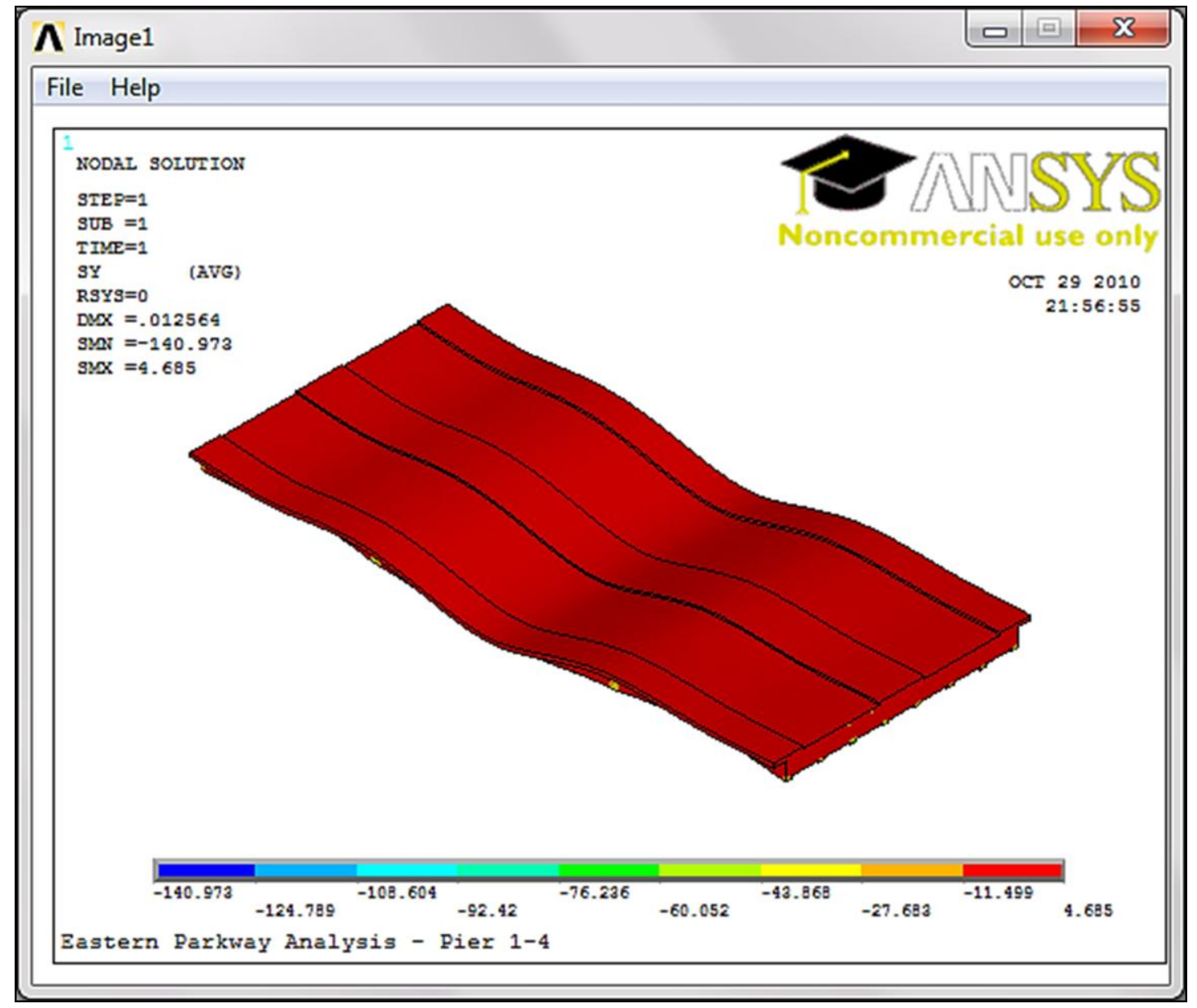

FIGURE 100 - Y-Component of Stress for Iteration 12 


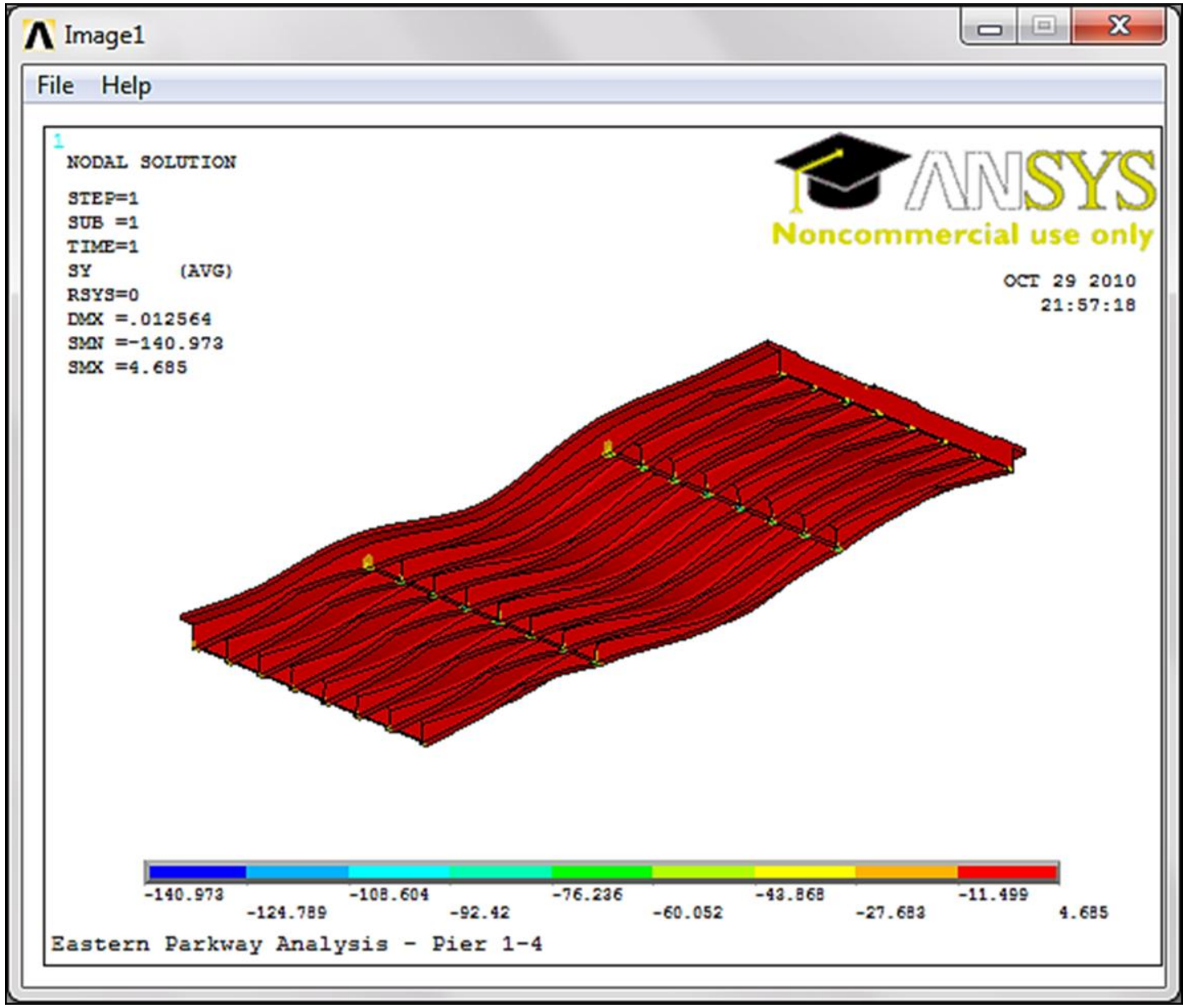

FIGURE 101 - Y-Component of Stress for Iteration 12 As Viewed From Below 


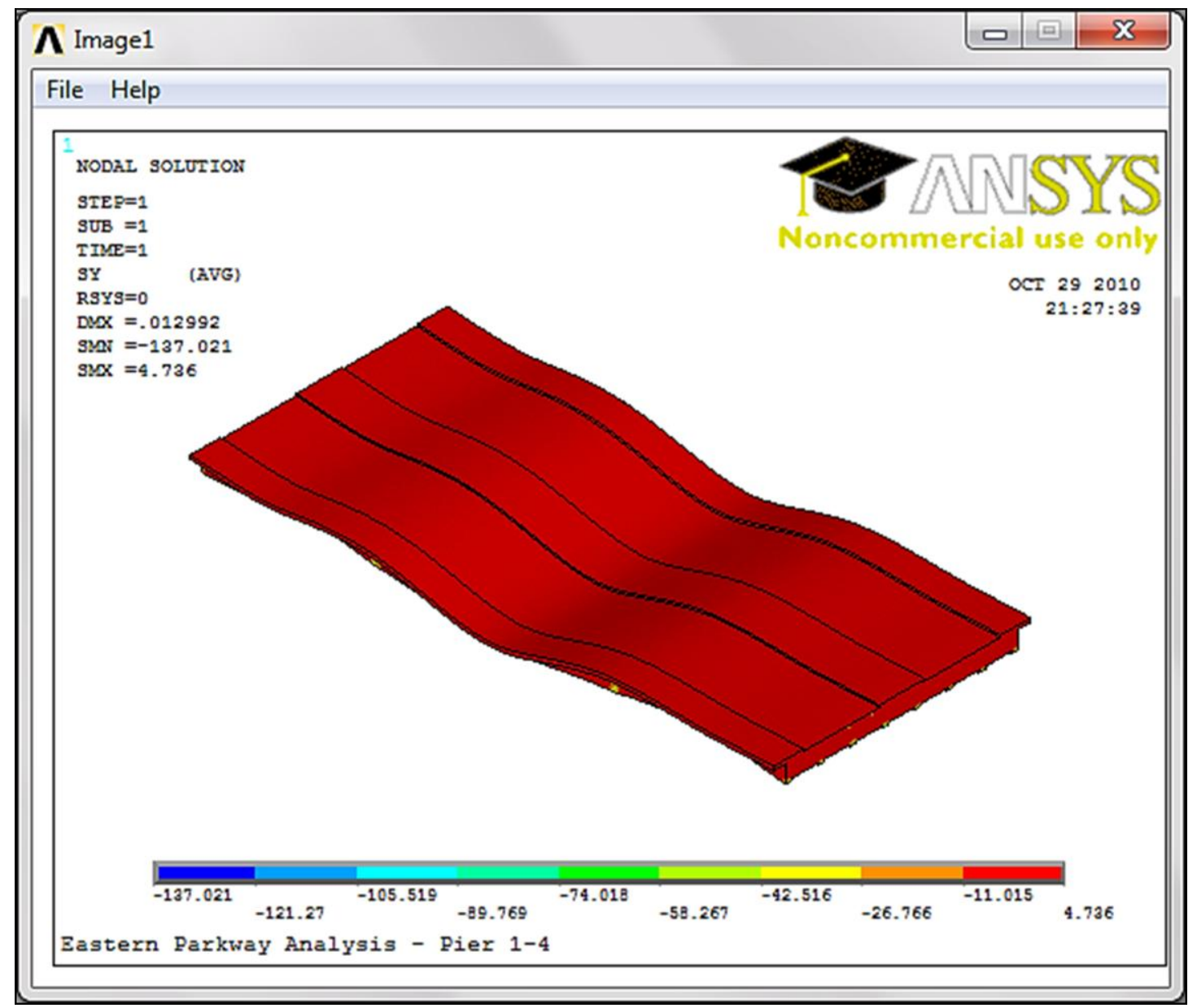

FIGURE 102 - Y-Component of Stress for Iteration 13 


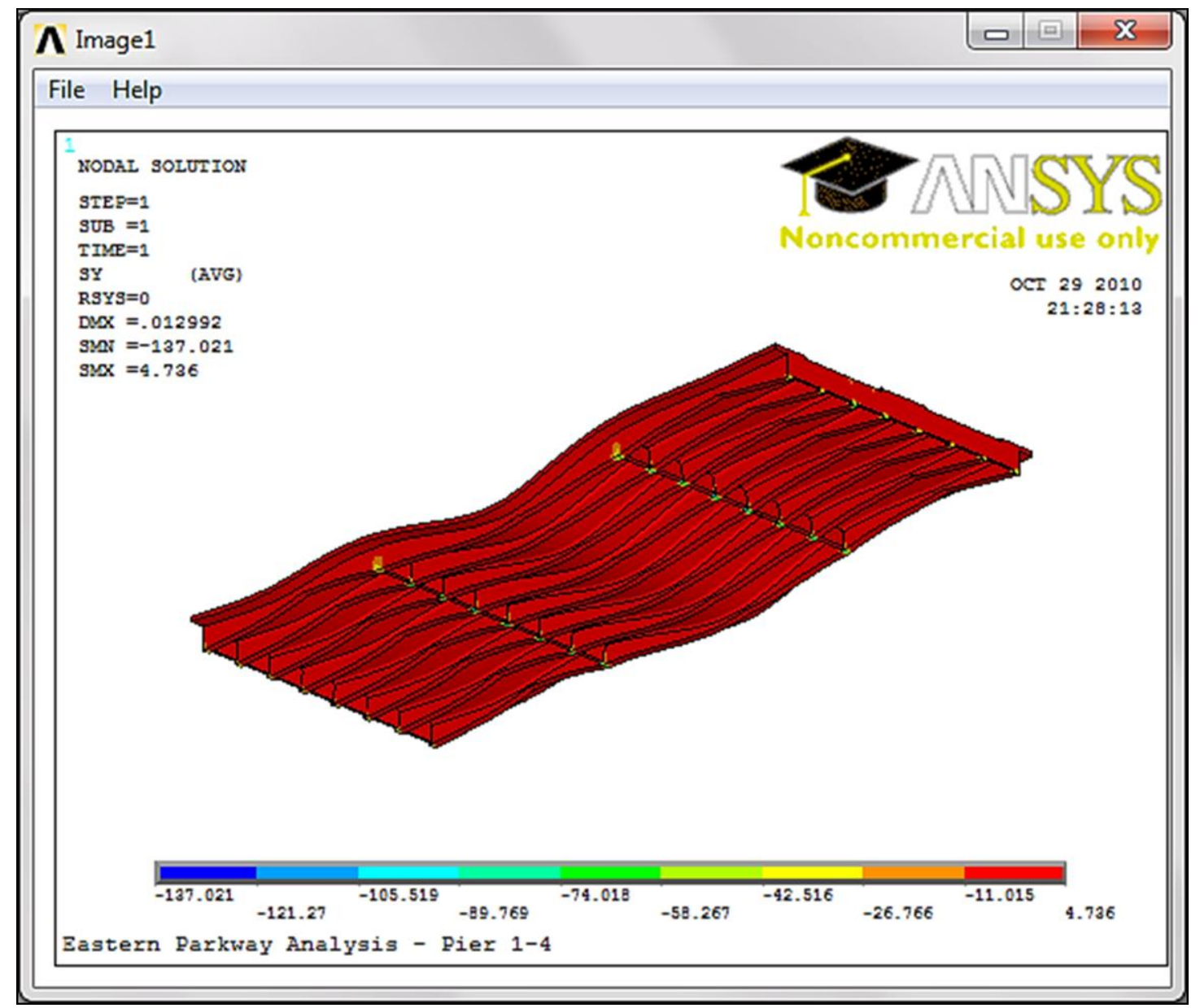

FIGURE 103 - Y-Component of Stress for Iteration 13 As Viewed From Below 
APPENDIX IX

SCREEN CAPTURES OF FIRST PRINCIPAL STRESSES

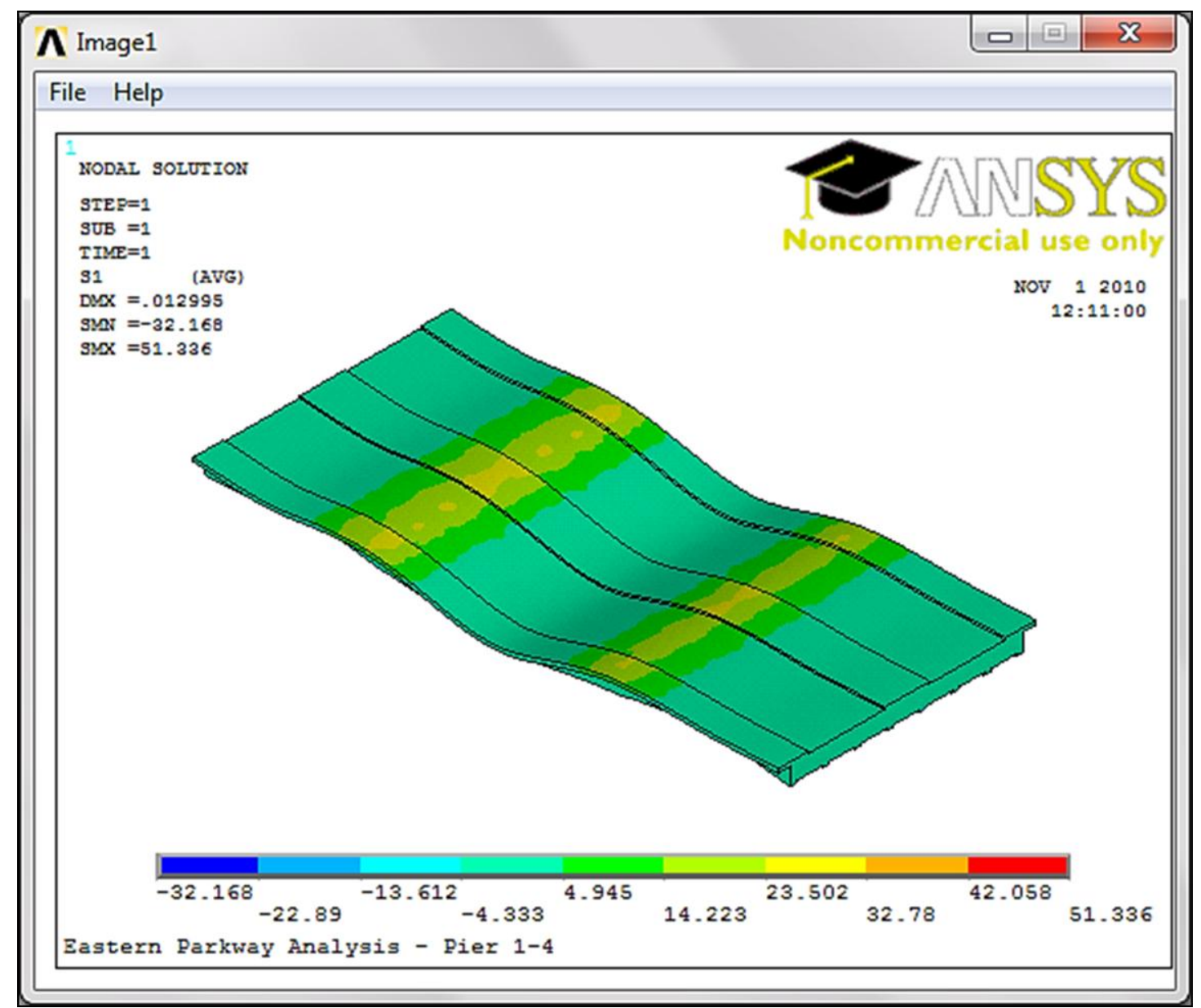

FIGURE 104 - First Principal Stress for Iteration One 


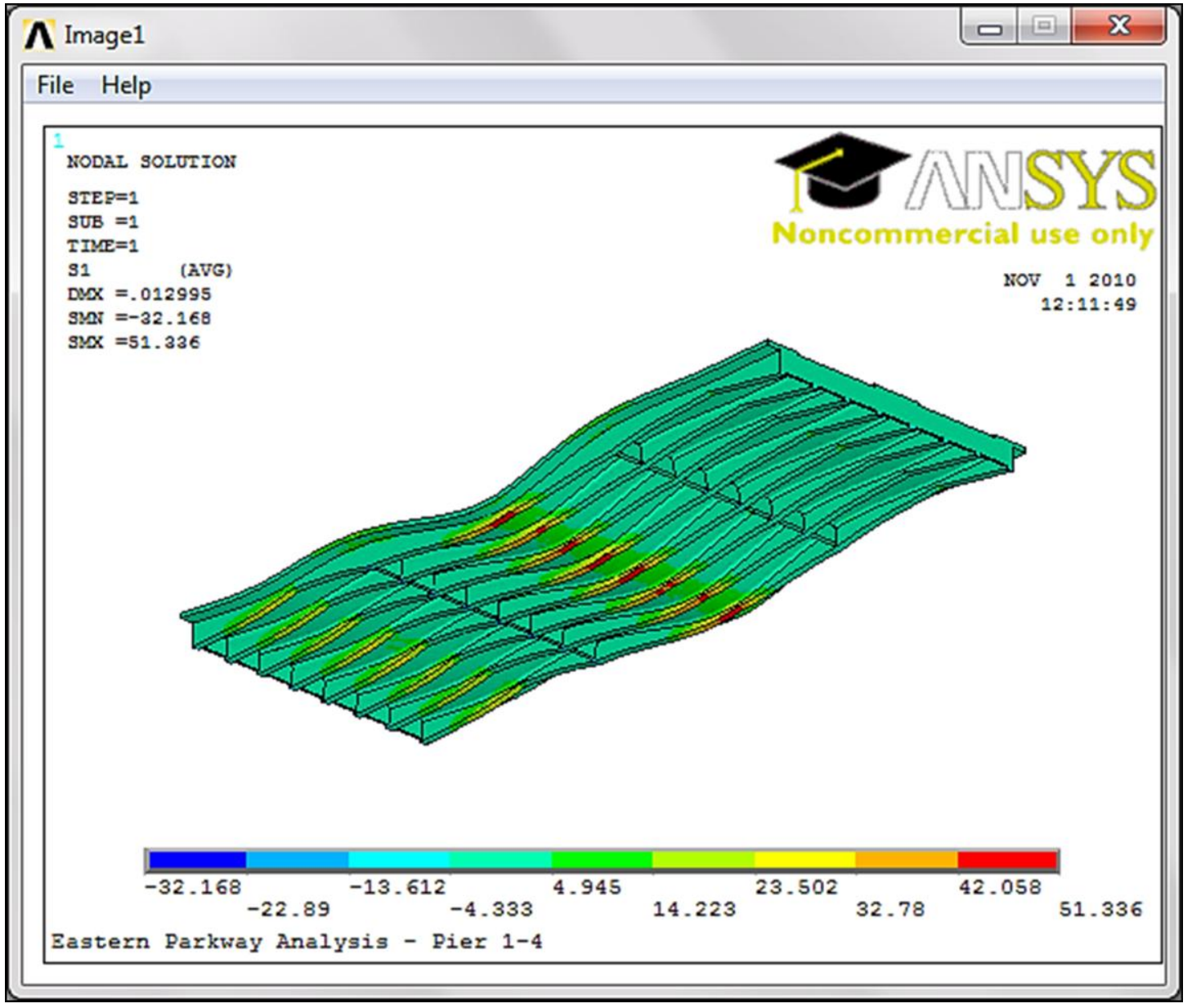

FIGURE 105 - First Principal Stress for Iteration One As Viewed From Below 


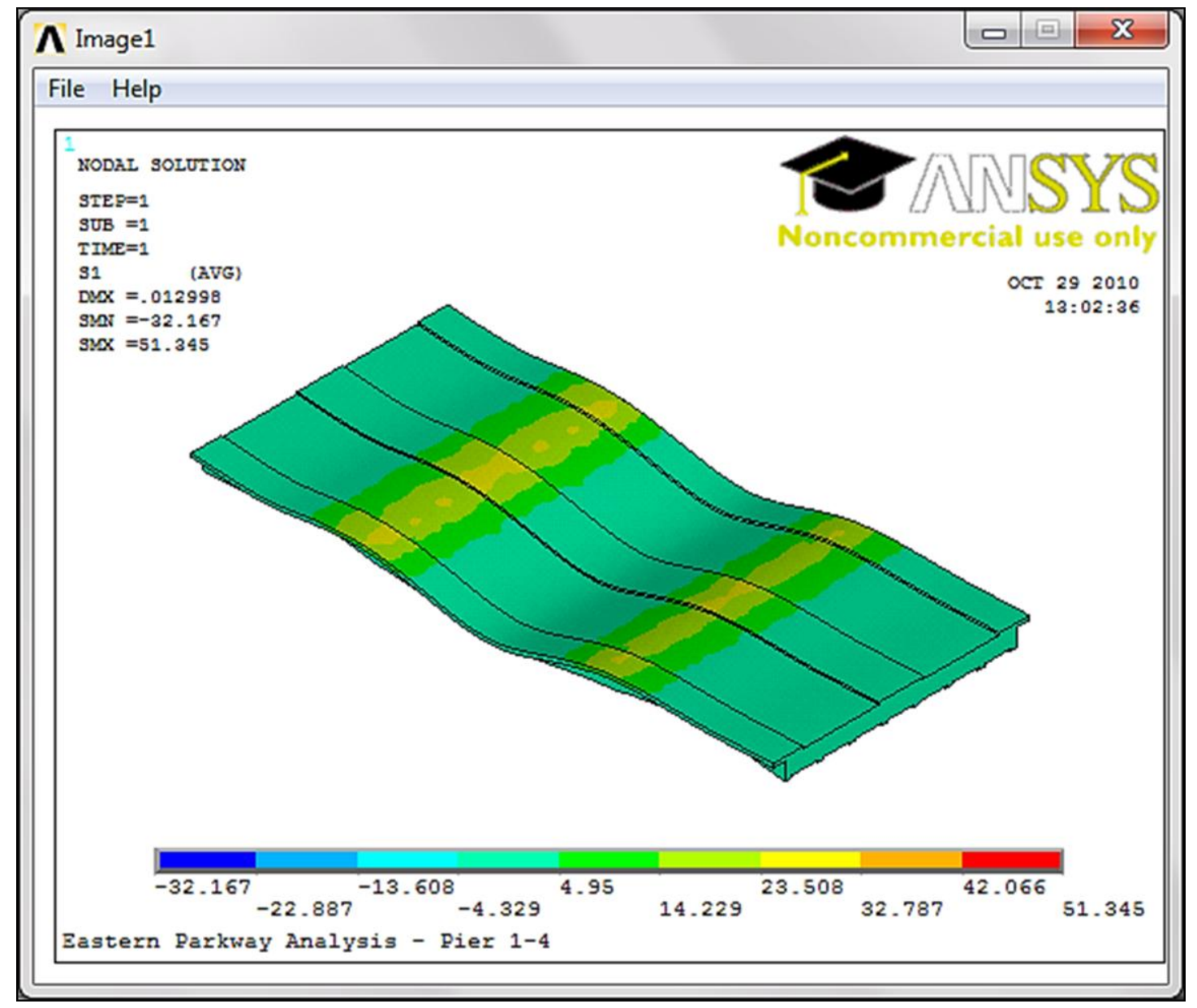

FIGURE 106 - First Principal Stress for Iteration Two 


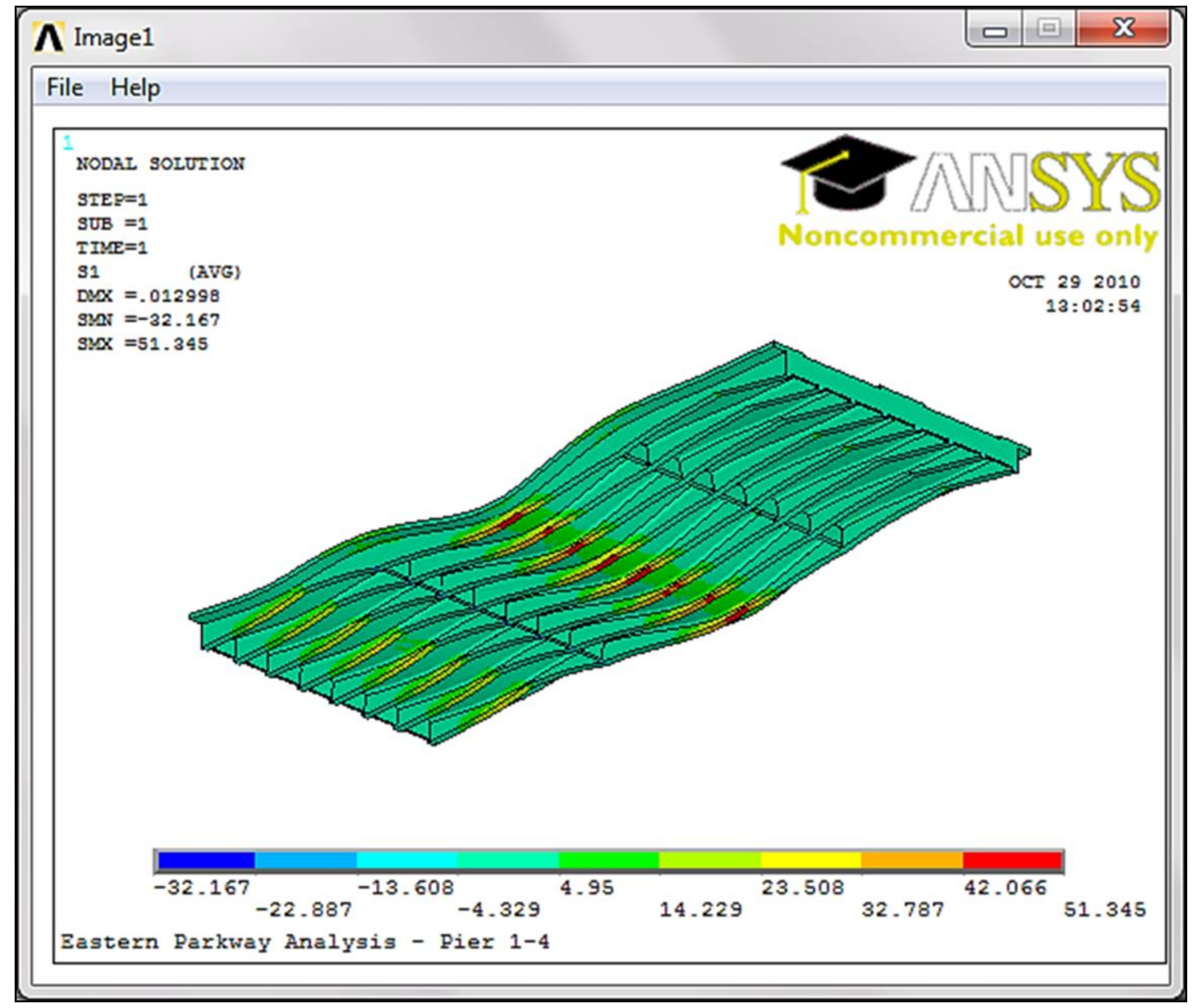

FIGURE 107 - First Principal Stress for Iteration Two As Viewed From Below 


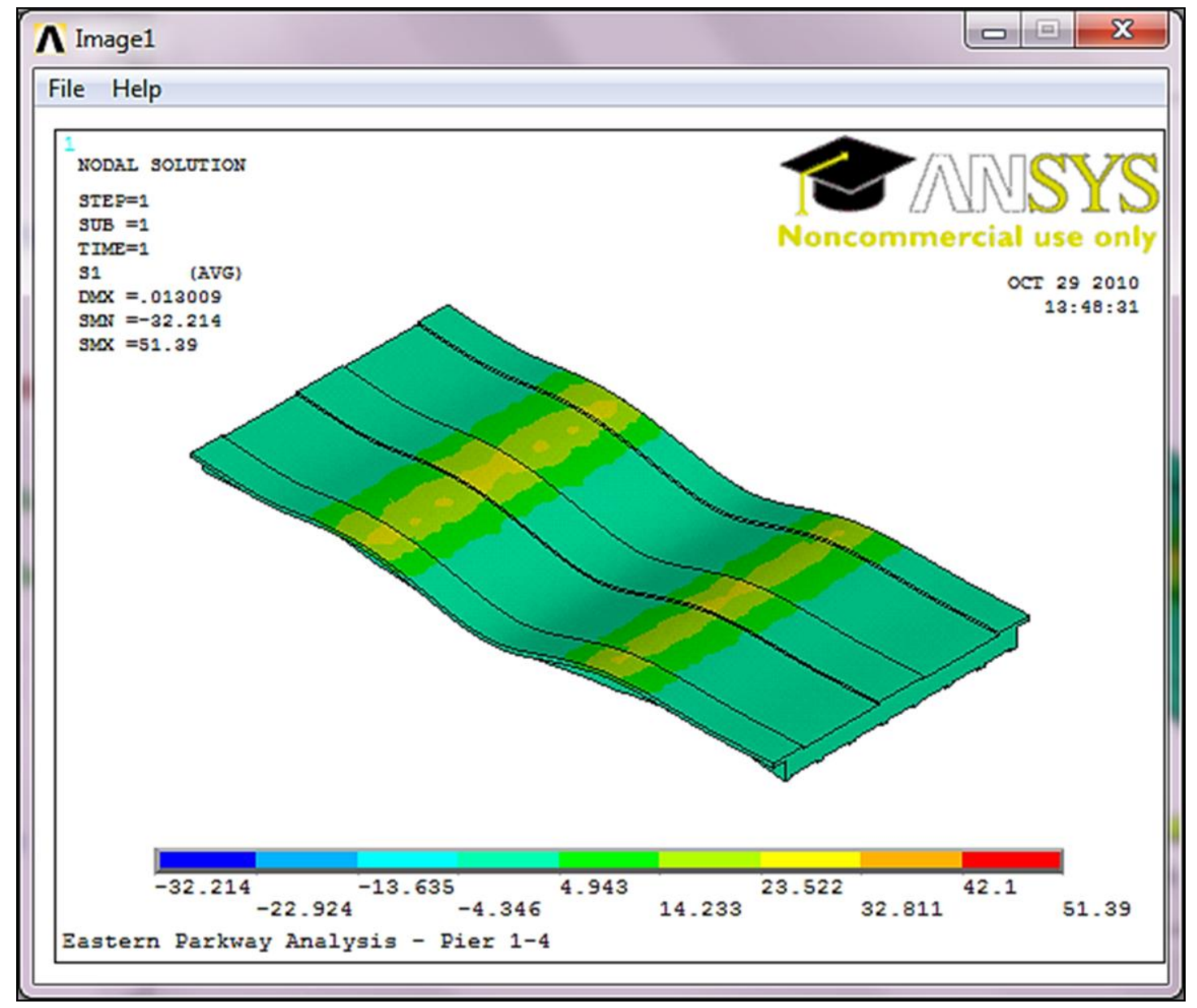

FIGURE 108 - First Principal Stress for Iteration Three 


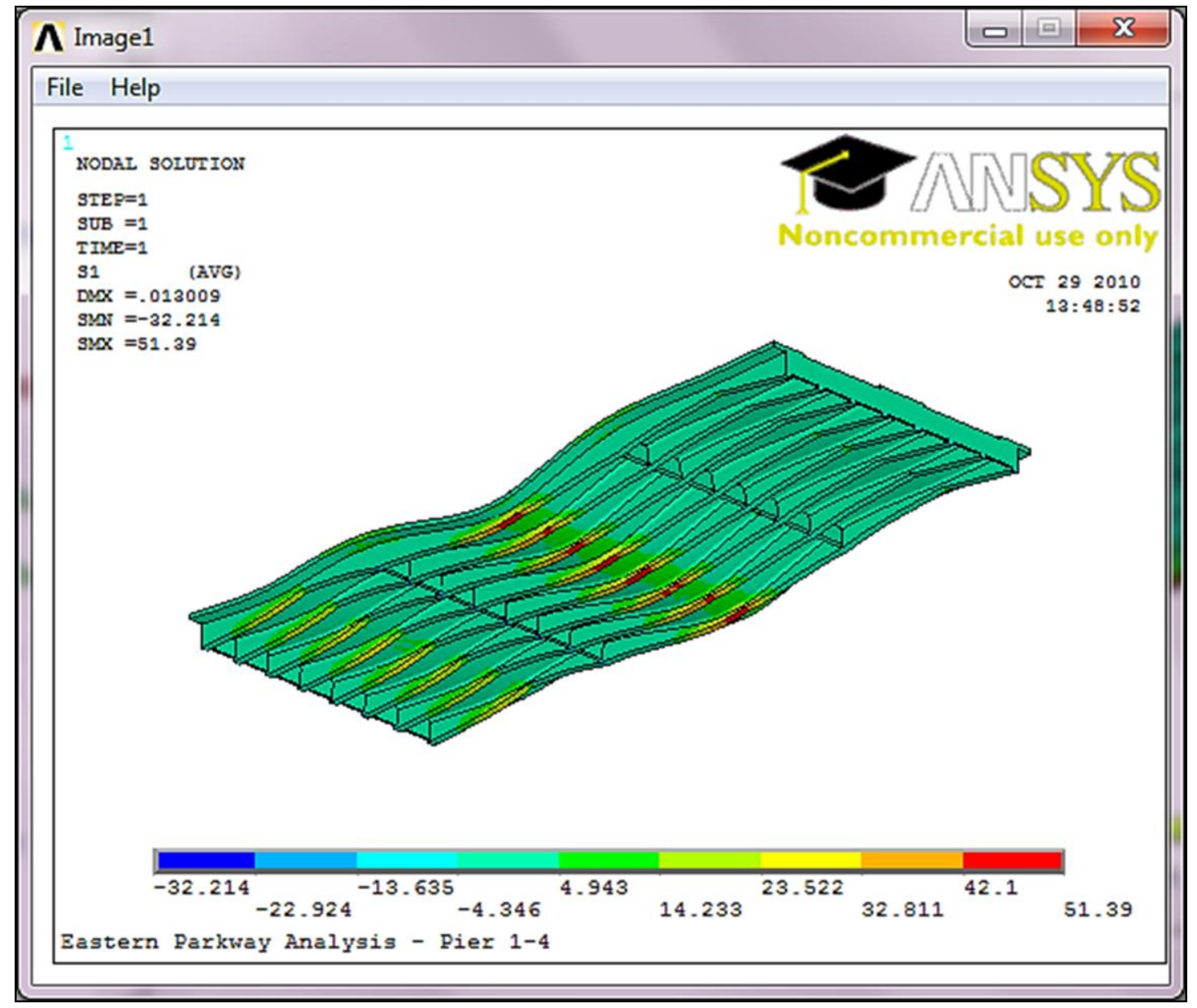

FIGURE 109 - First Principal Stress for Iteration Three As Viewed From Below 


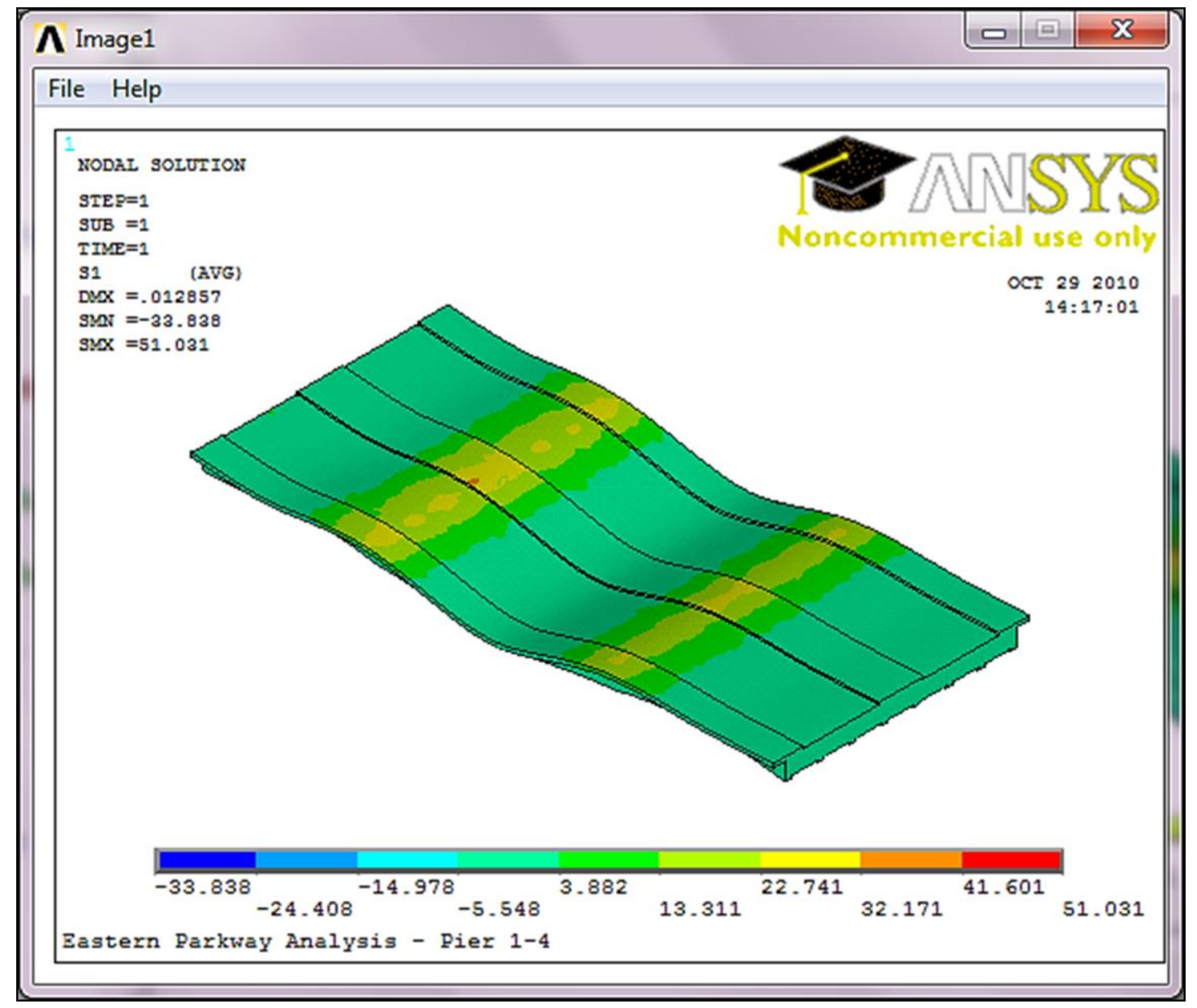

FIGURE 110 - First Principal Stress for Iteration Four 


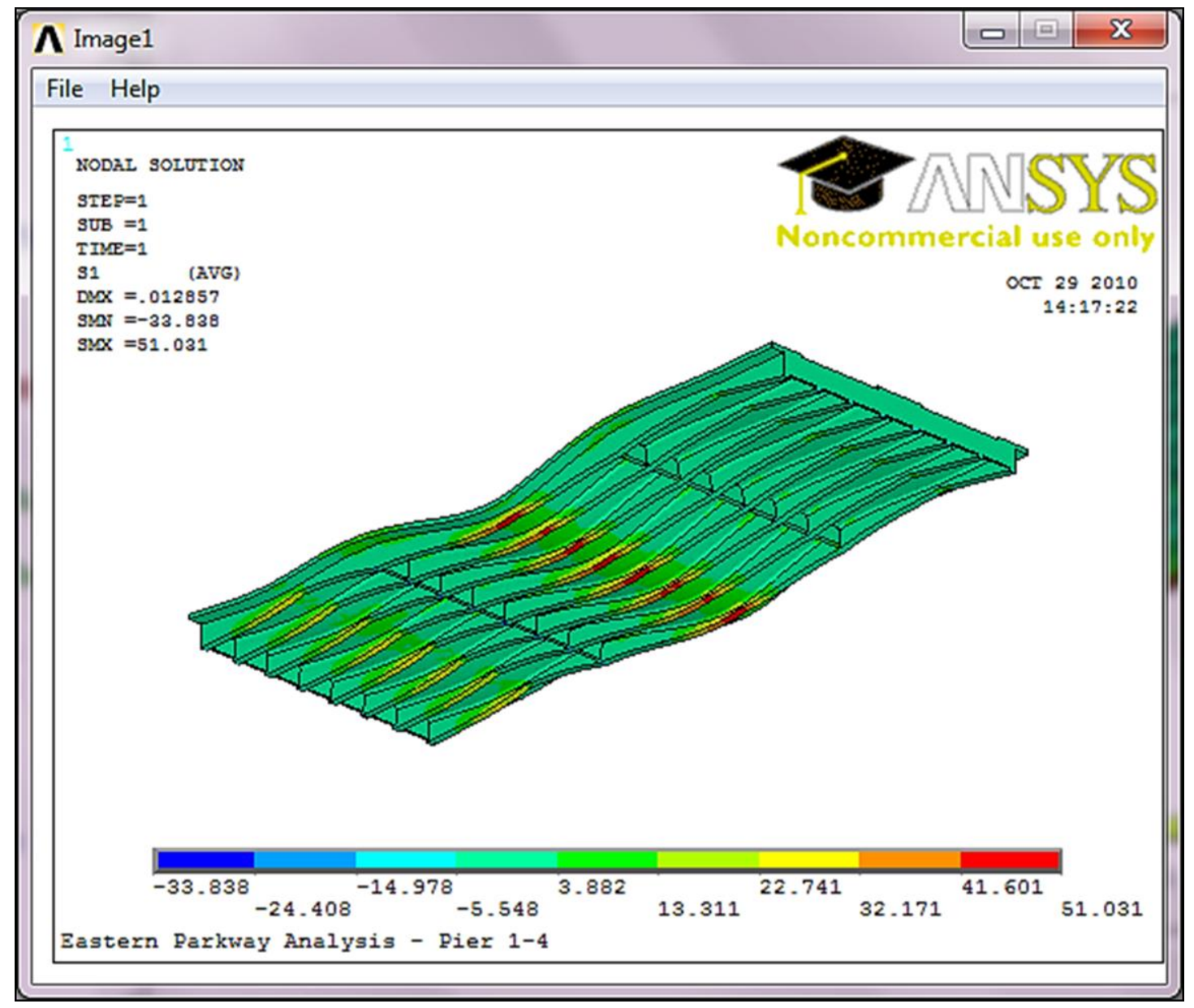

FIGURE 111 - First Principal Stress for Iteration Four As Viewed From Below 


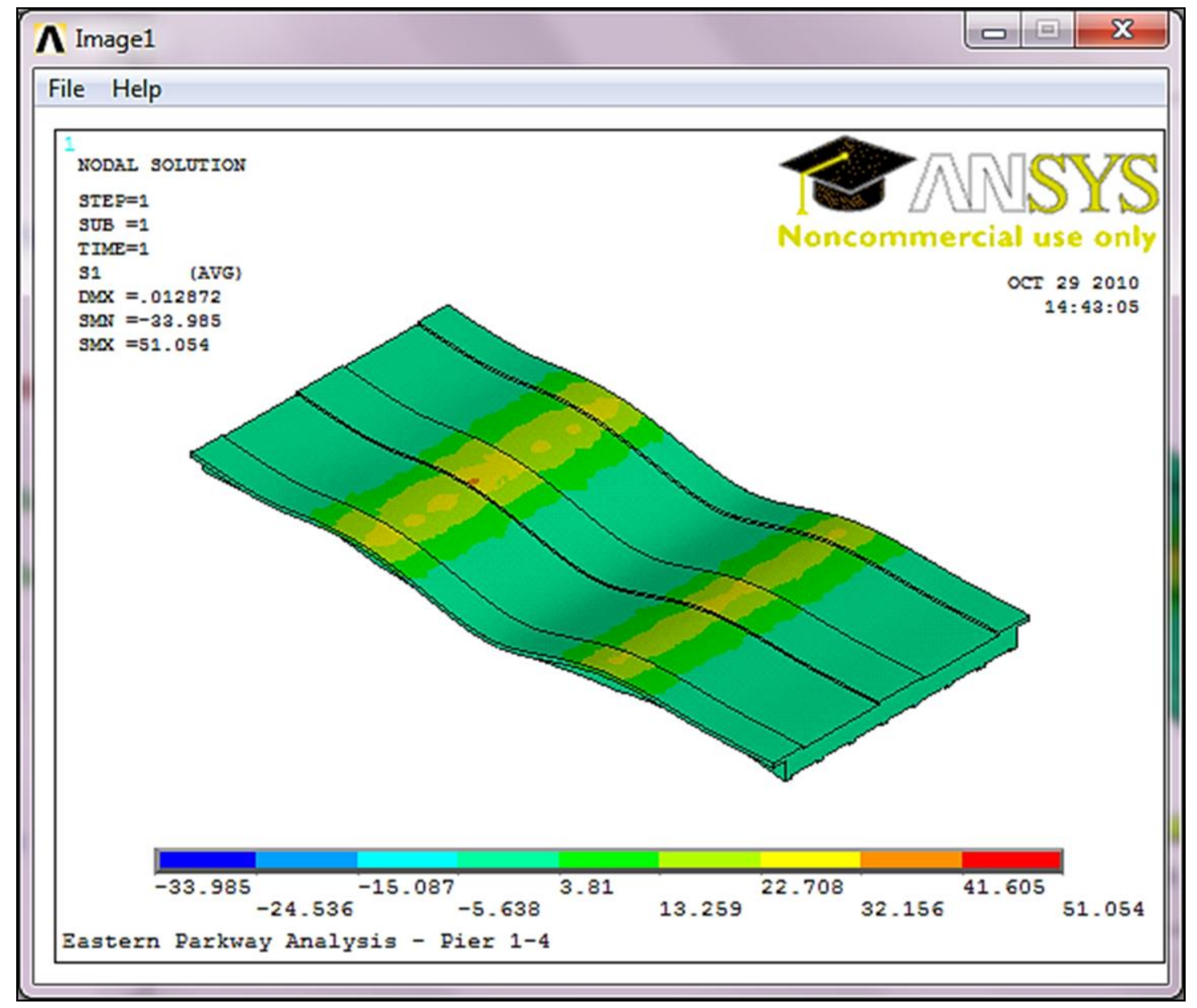

FIGURE 112 - First Principal Stress for Iteration Five 


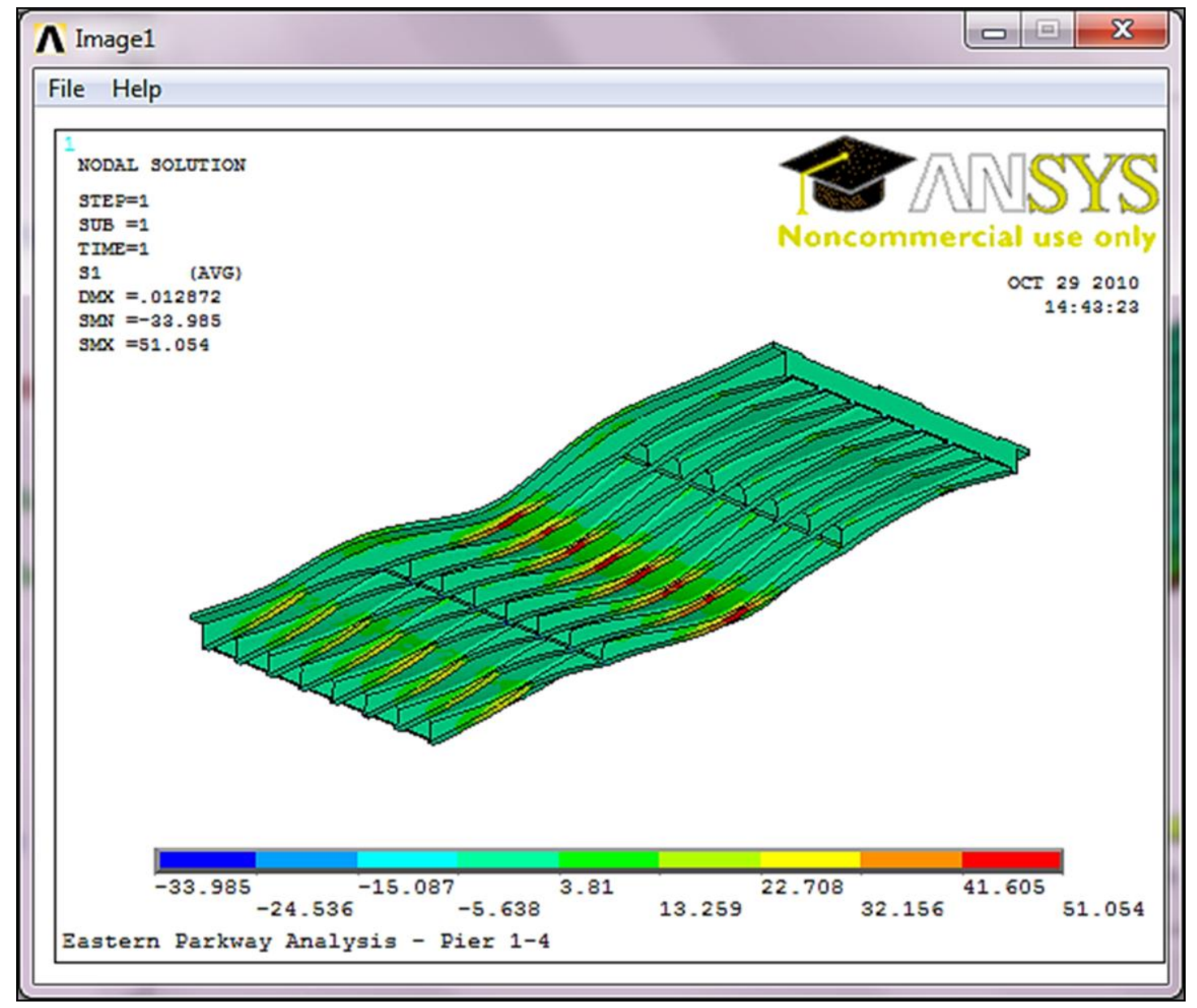

FIGURE 113 - First Principal Stress for Iteration Five As Viewed From Below 


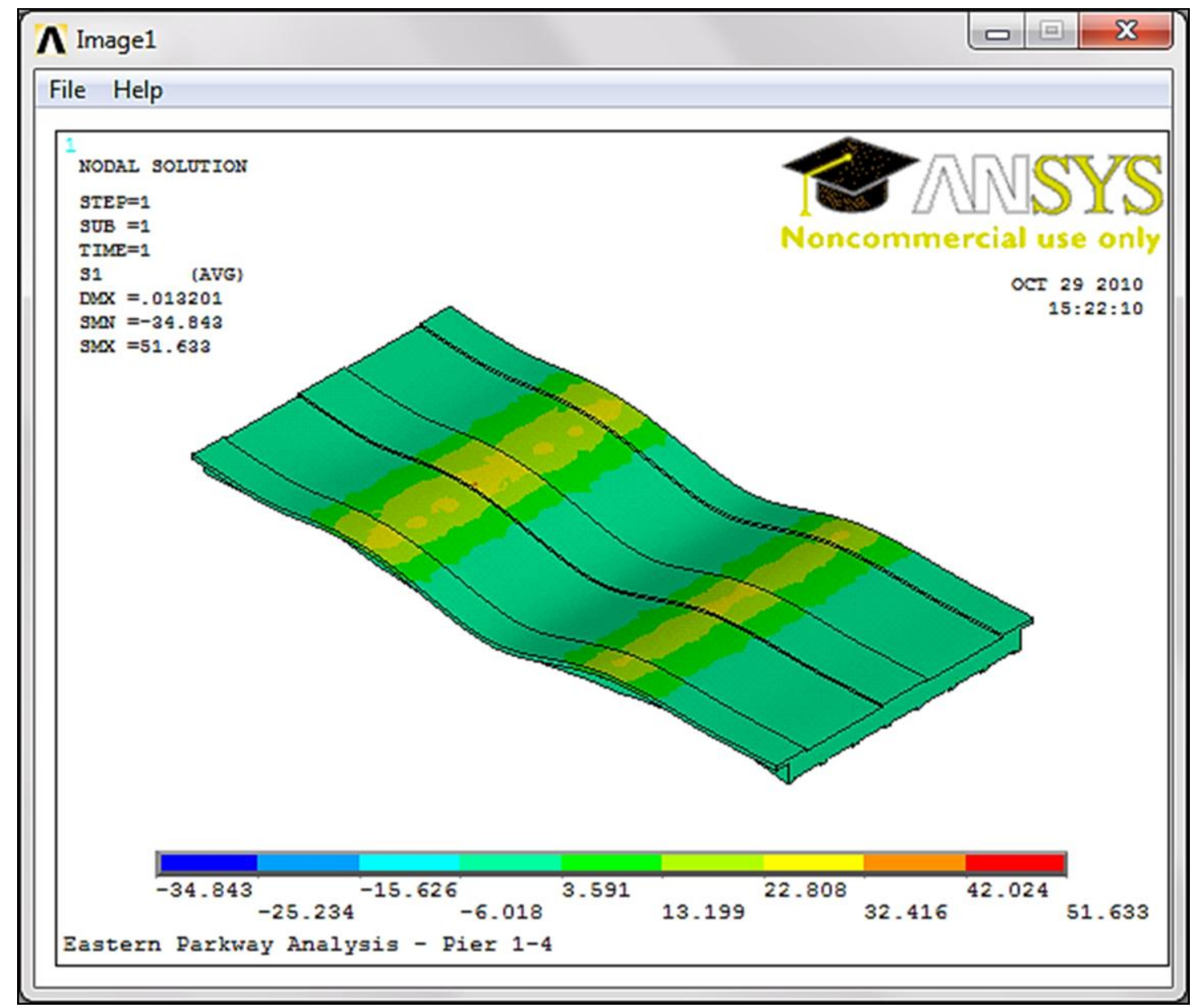

FIGURE 114 - First Principal Stress for Iteration Six 


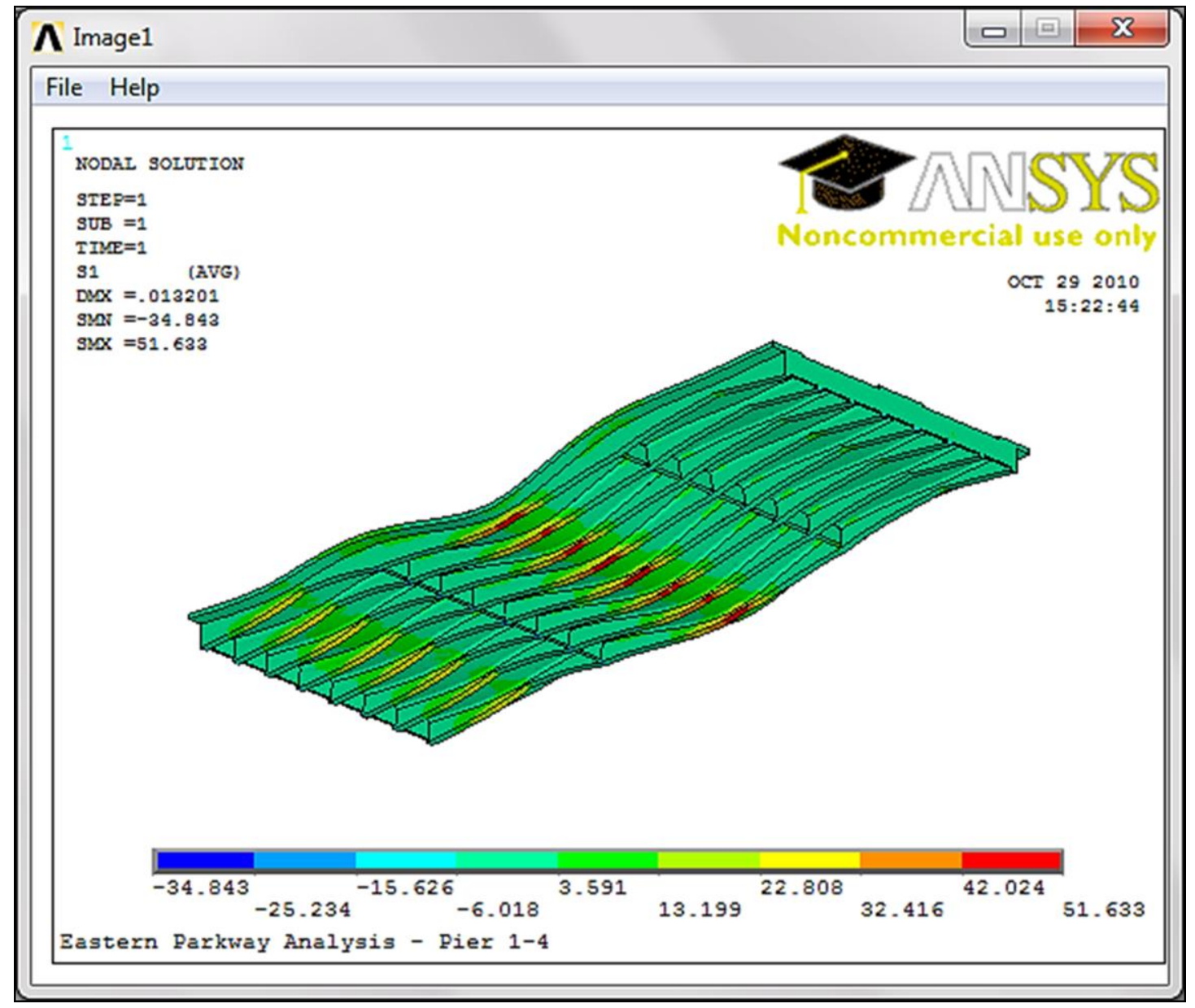

FIGURE 115 - First Principal Stress for Iteration Six As Viewed From Below 


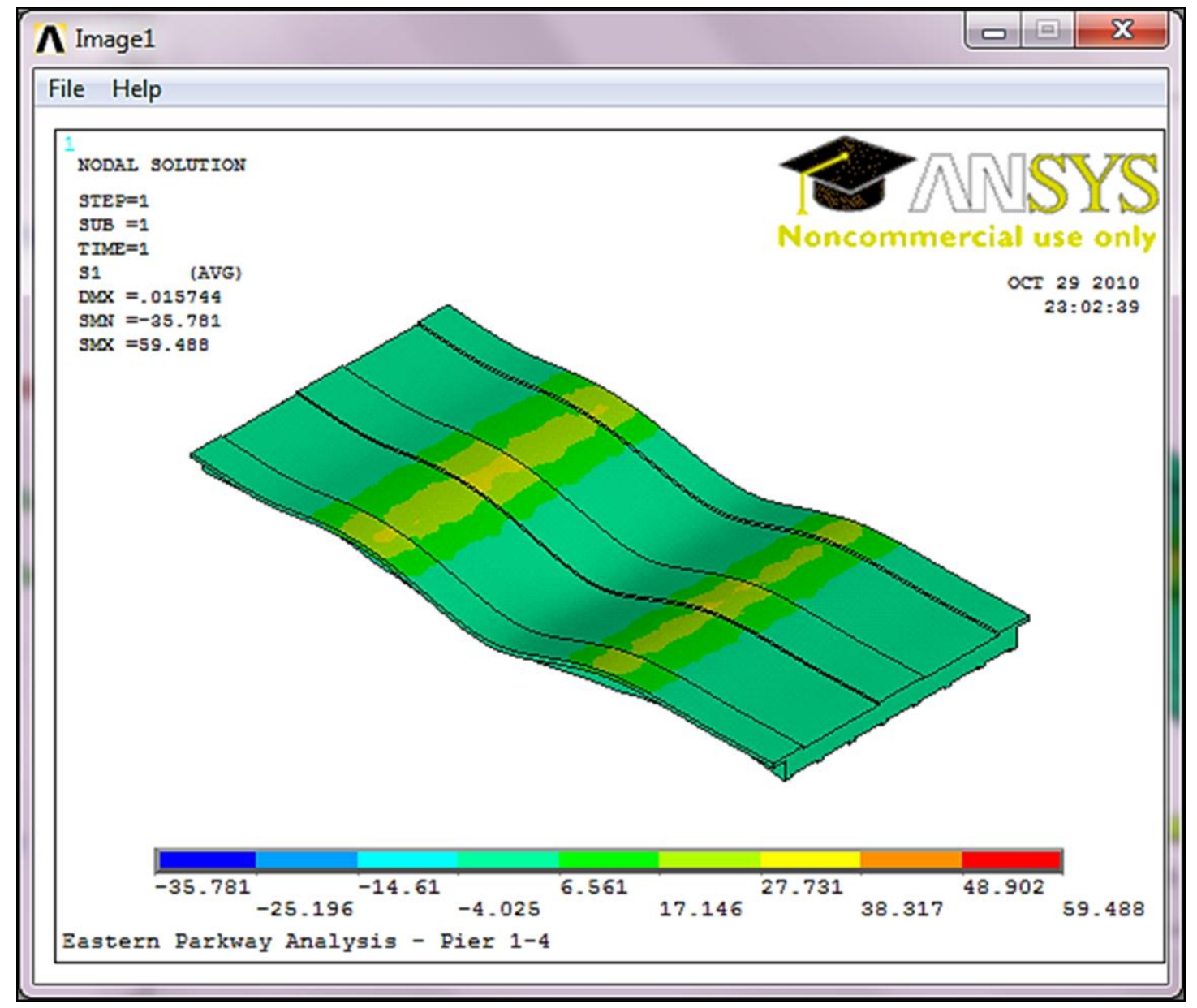

FIGURE 116 - First Principal Stress for Iteration Seven 


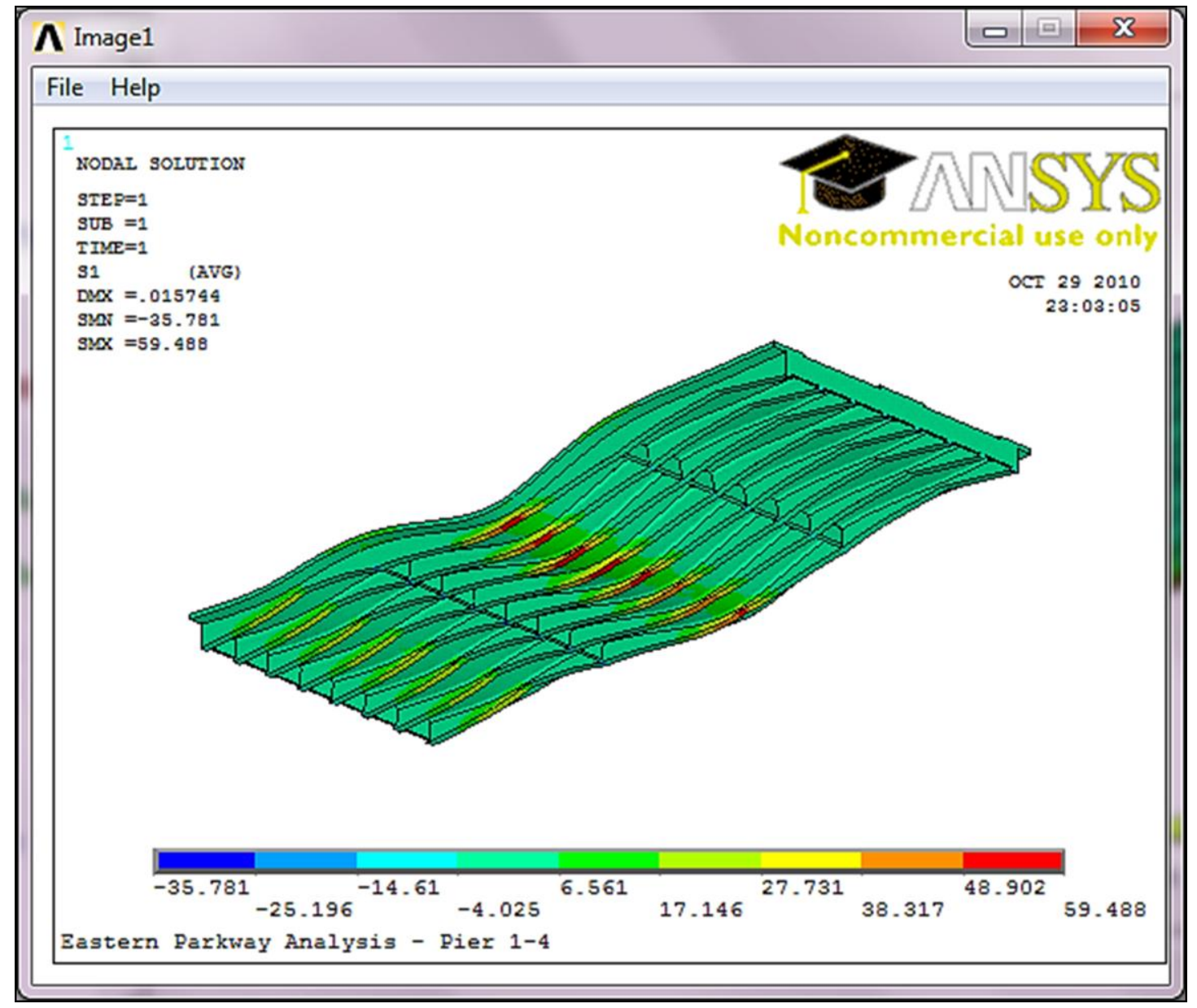

FIGURE 117 - First Principal Stress for Iteration Seven As Viewed From Below 


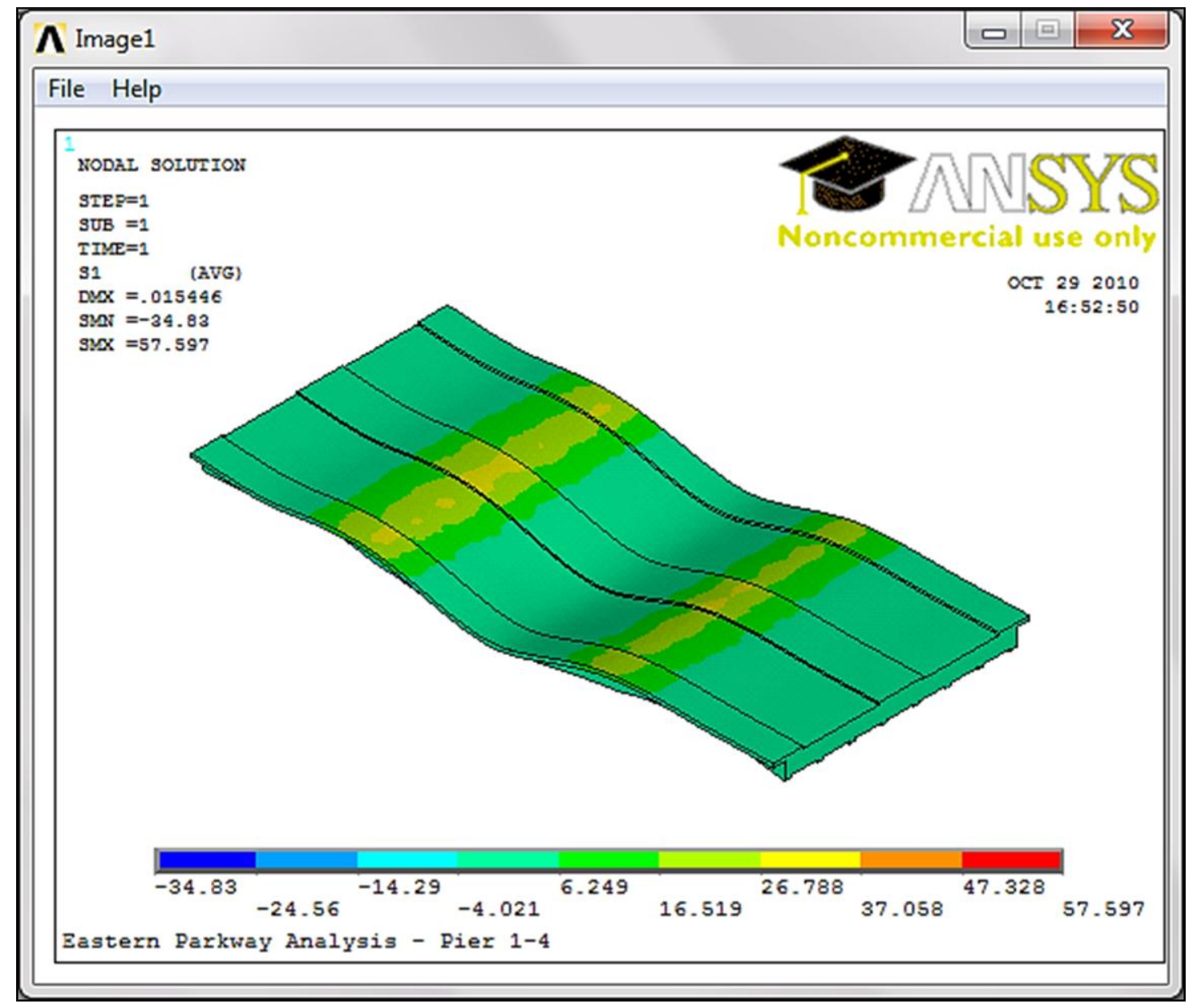

FIGURE 118 - First Principal Stress for Iteration Eight 


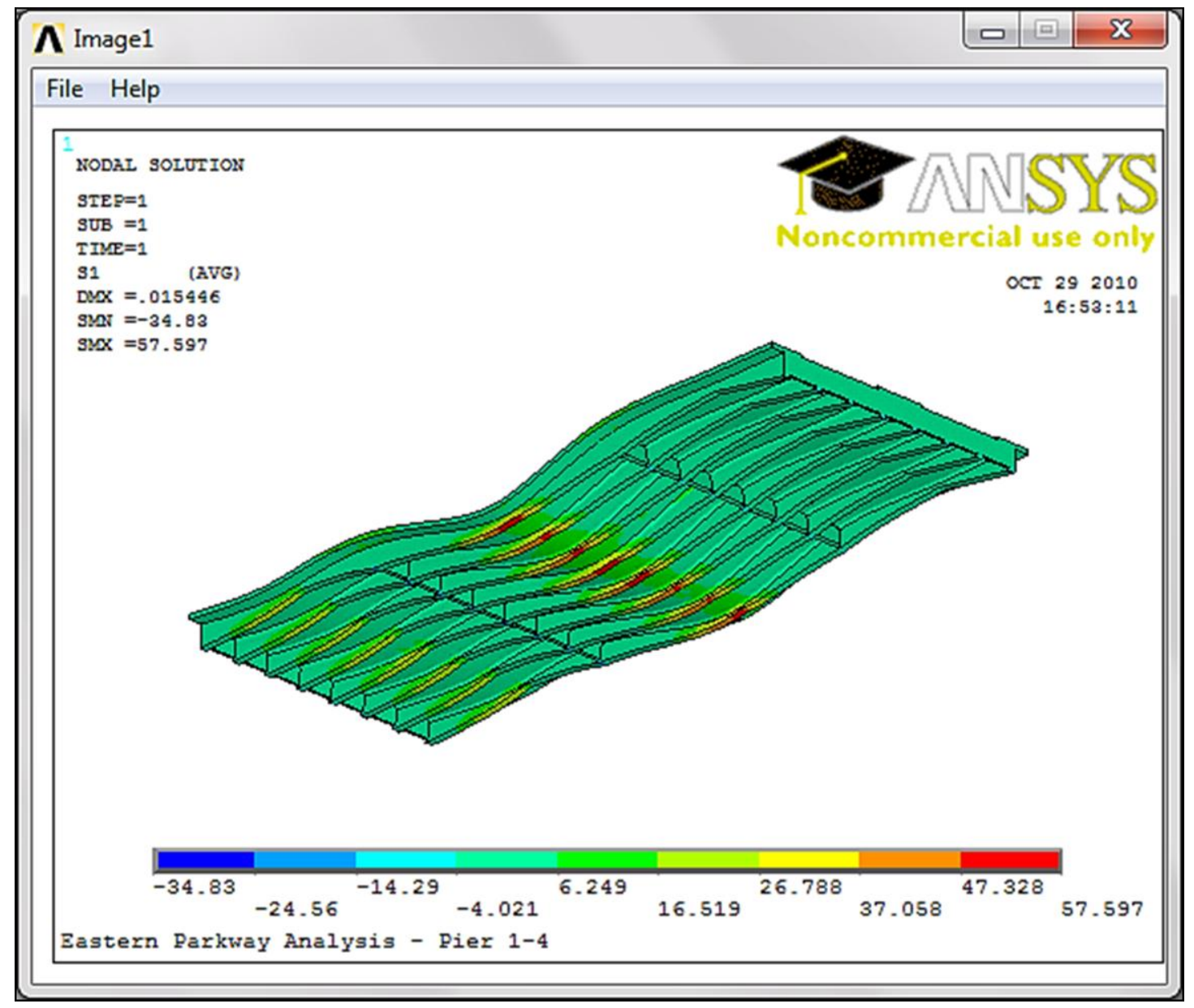

FIGURE 119 - First Principal Stress for Iteration Eight As Viewed From Below 


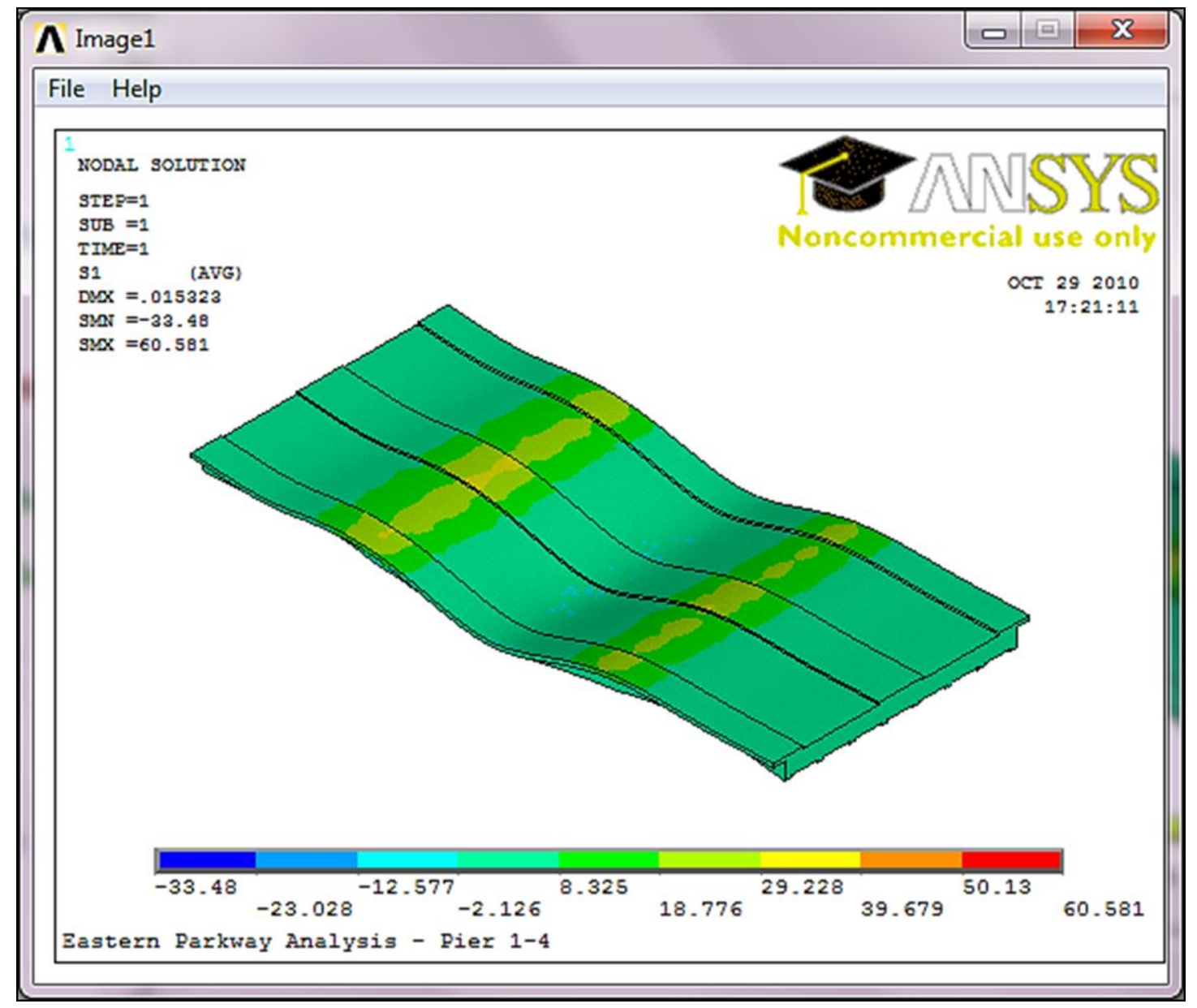

FIGURE 120 - First Principal Stress for Iteration Nine 


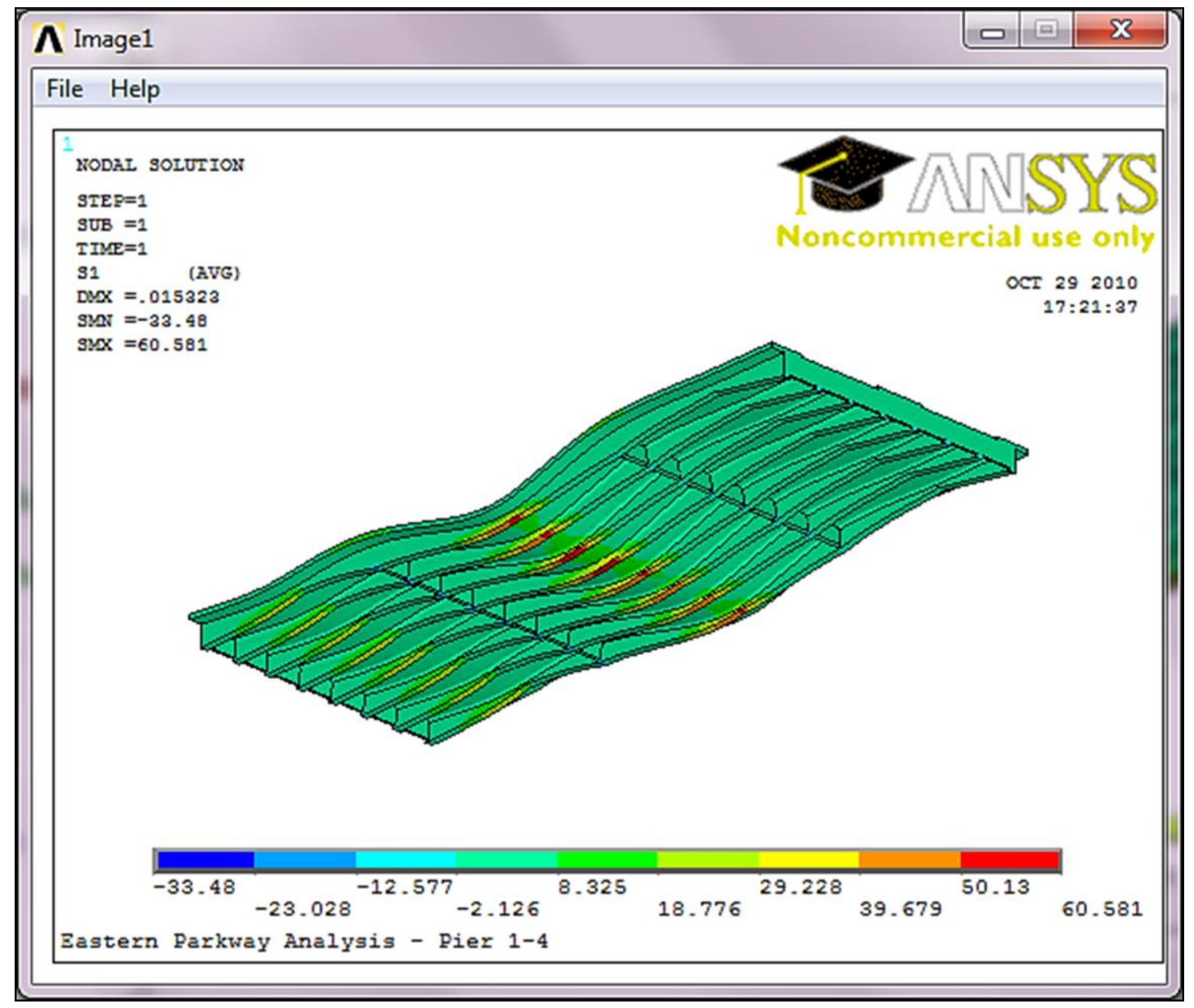

FIGURE 121 - First Principal Stress for Iteration Nine As Viewed From Below 


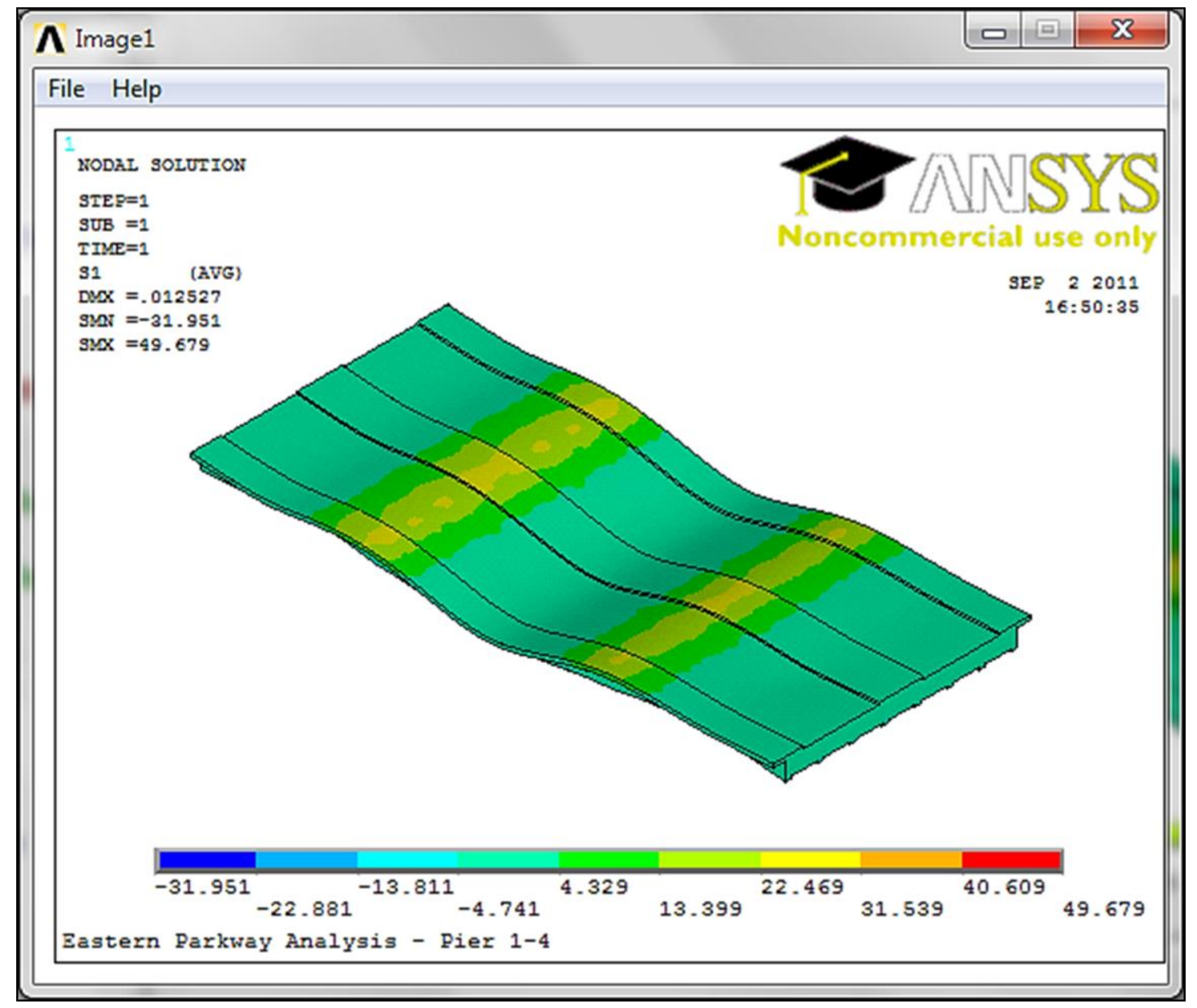

FIGURE 122 - First Principal Stress for Iteration 10 


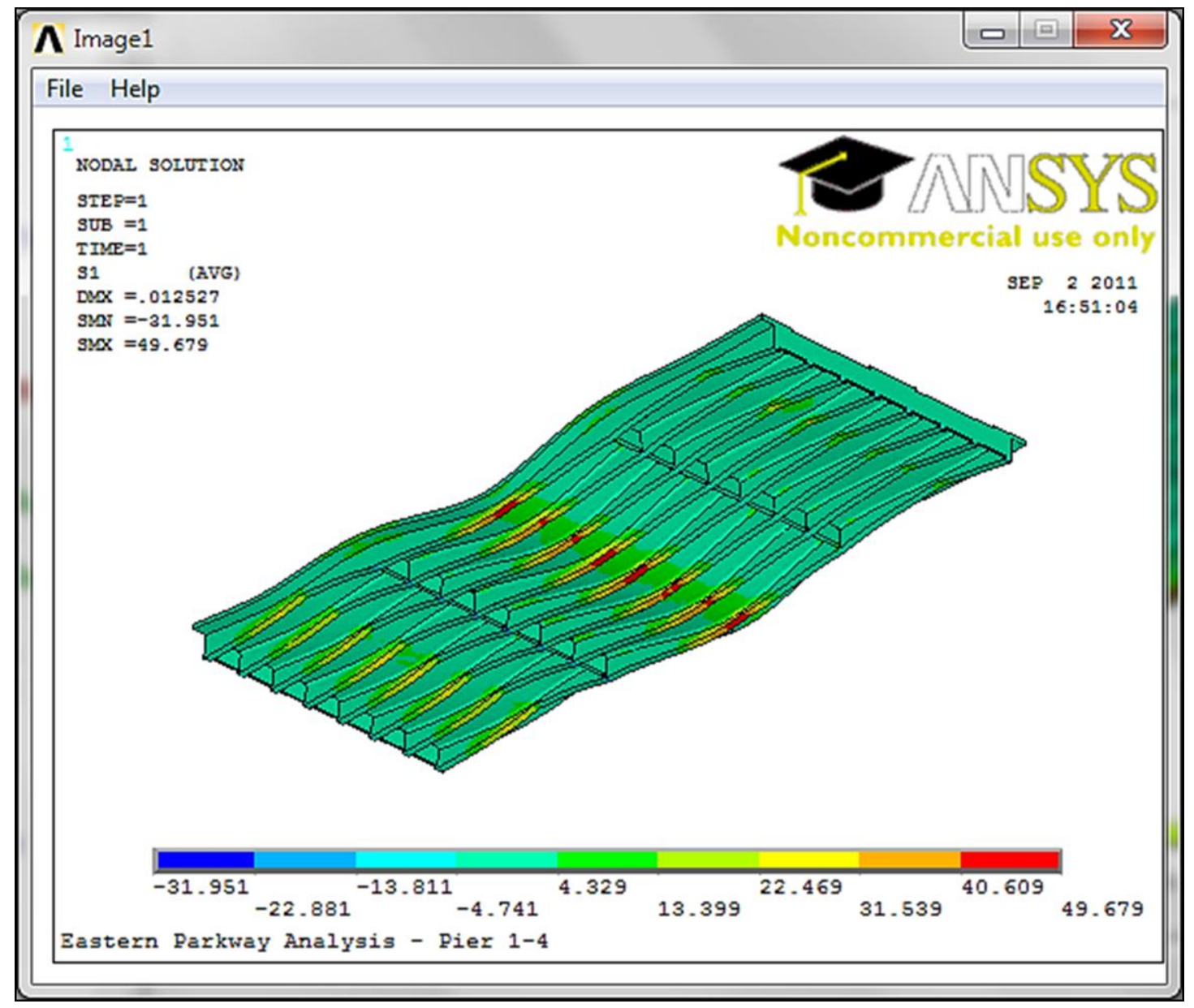

FIGURE 123 - First Principal Stress for Iteration 10 As Viewed From Below 


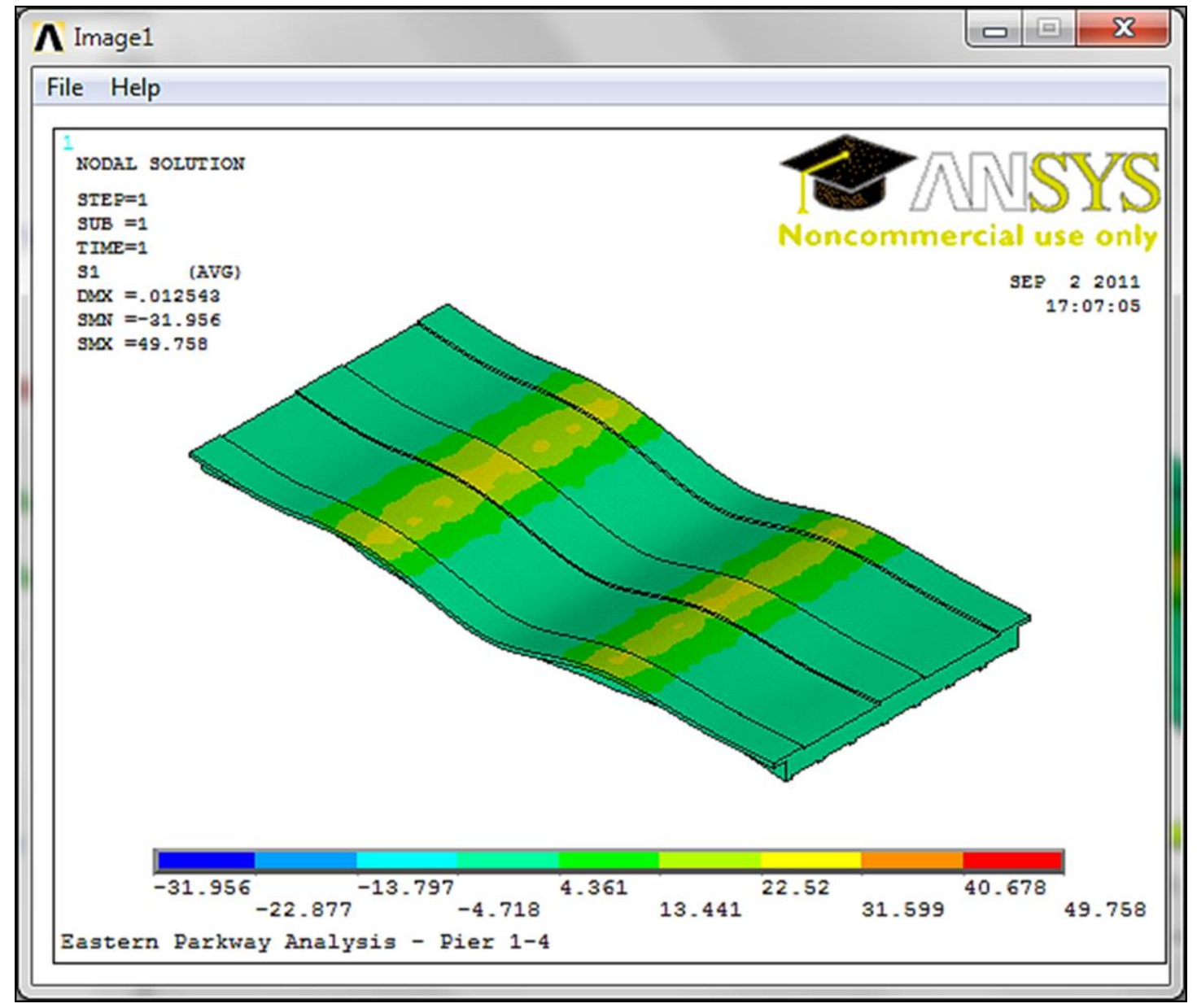

FIGURE 124 - First Principal Stress for Iteration 11 


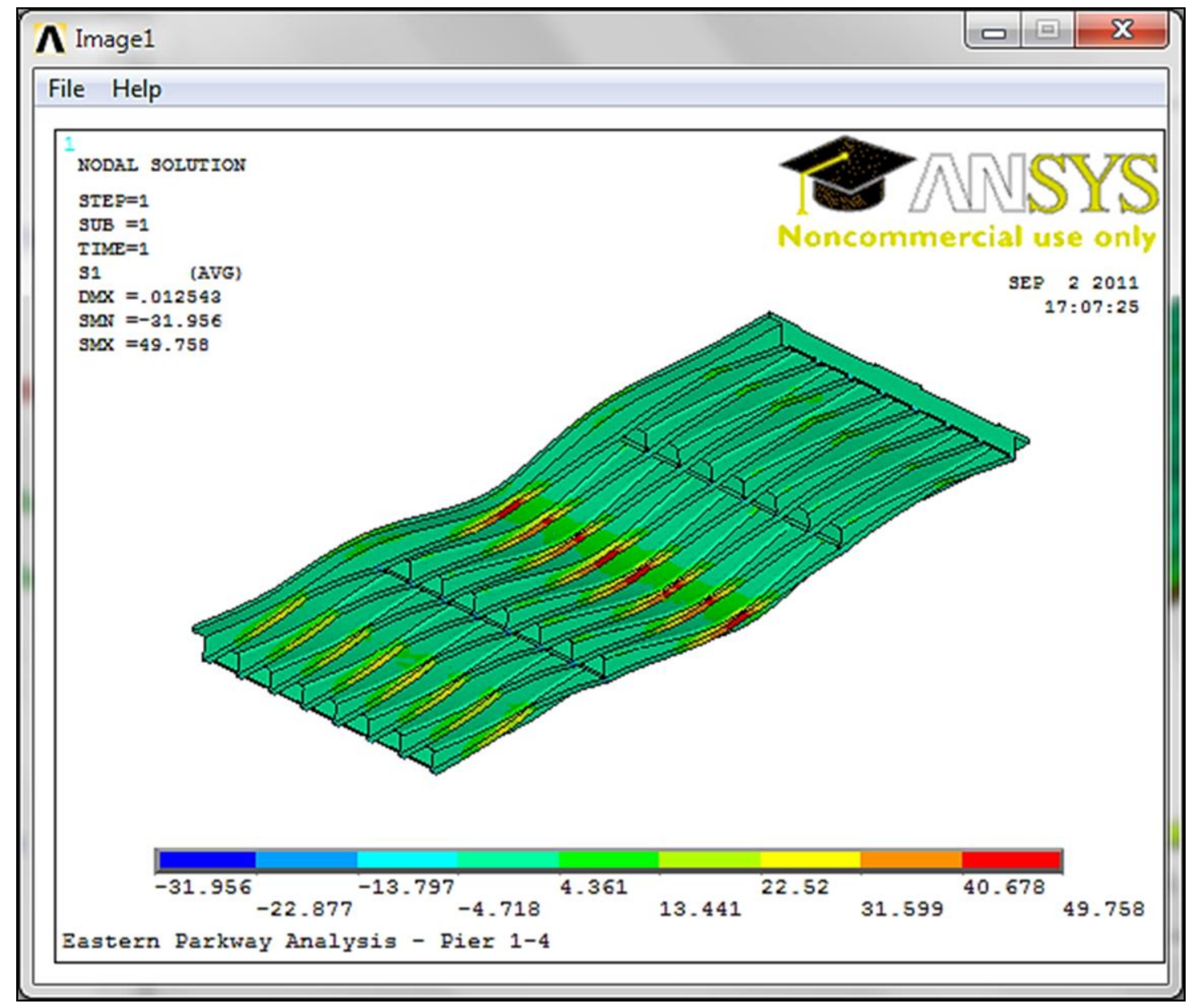

FIGURE 125 - First Principal Stress for Iteration 11 As Viewed From Below 


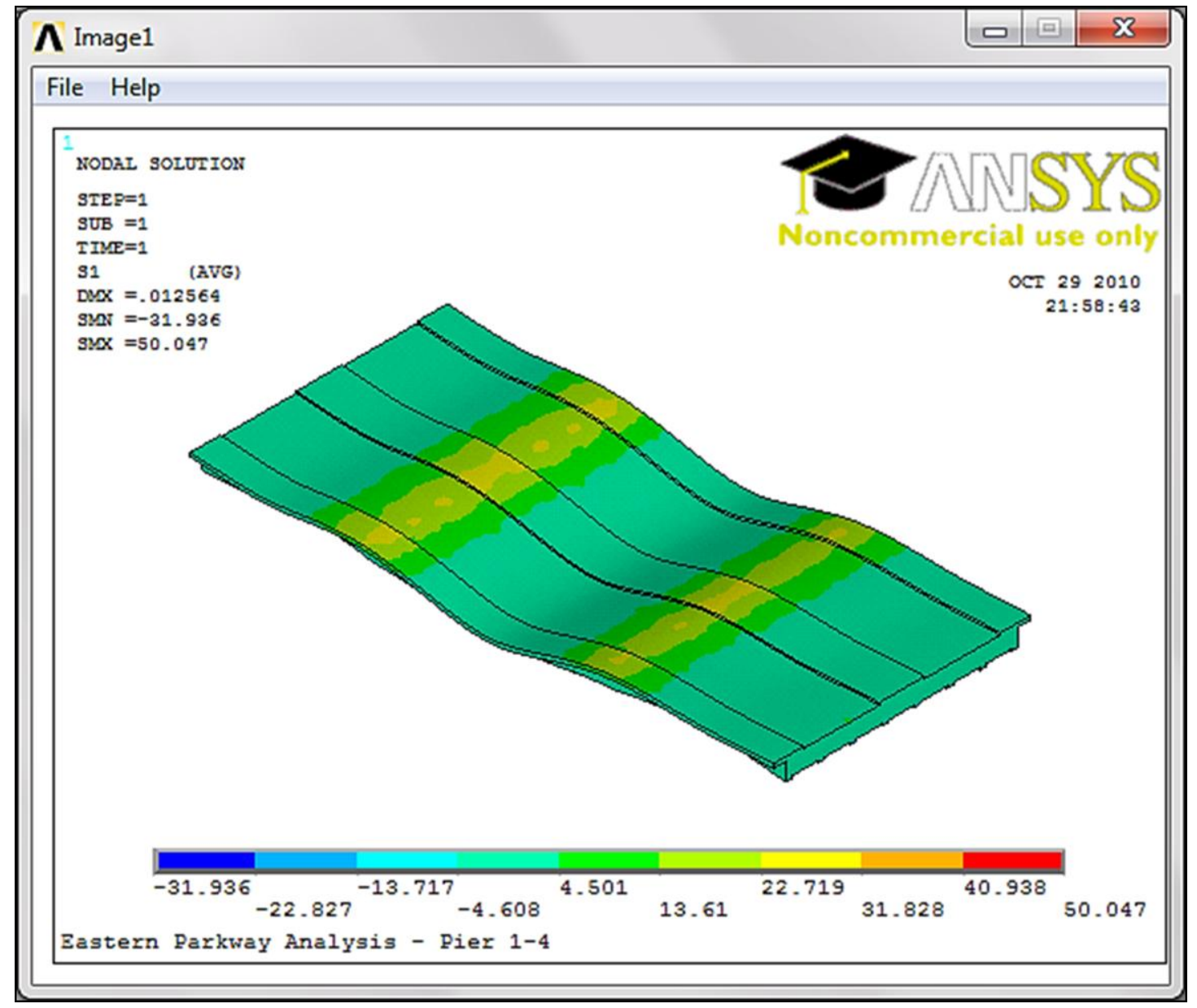

FIGURE 126 - First Principal Stress for Iteration 12 


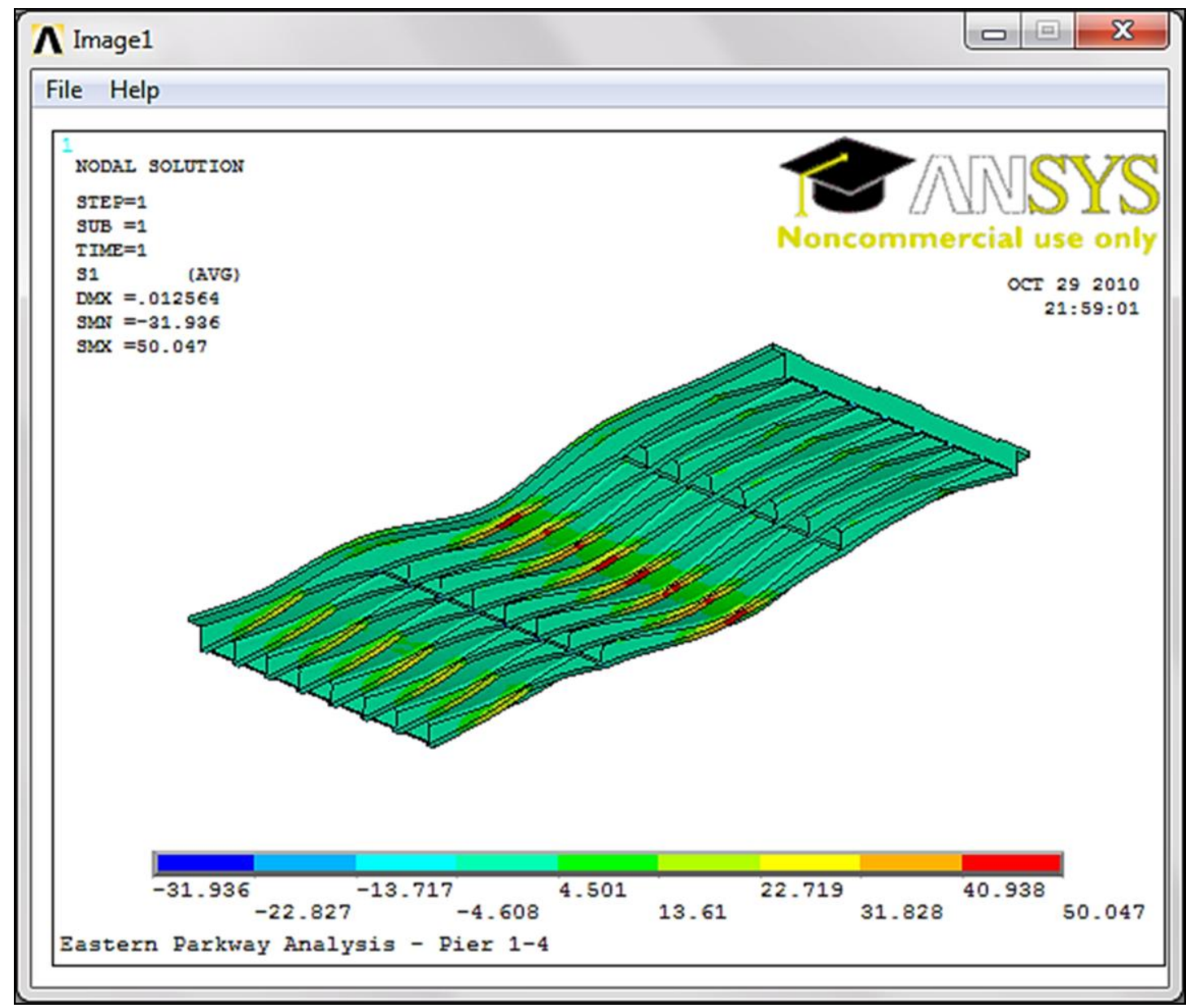

FIGURE 127 - First Principal Stress for Iteration 12 As Viewed From Below 


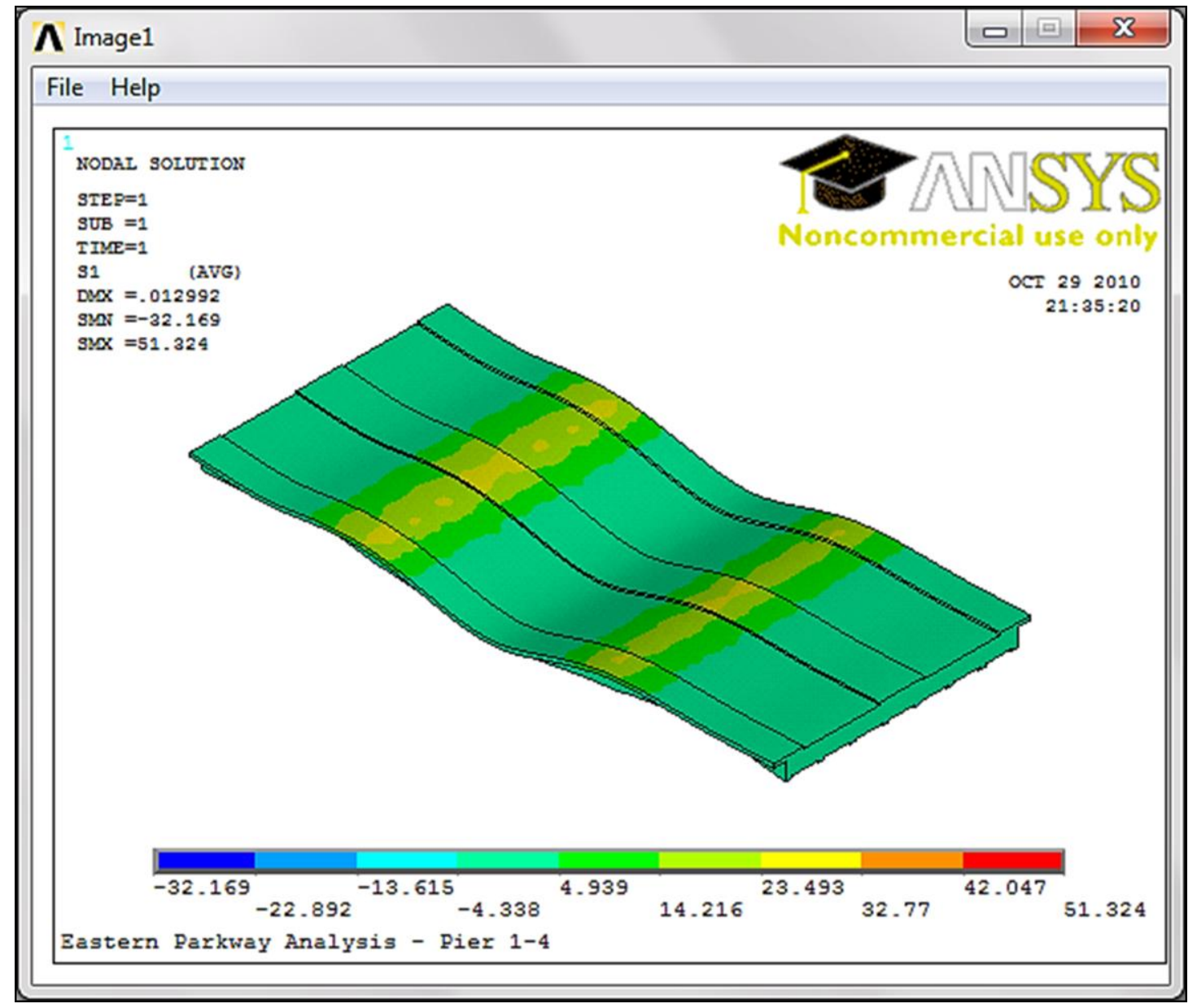

FIGURE 128 - First Principal Stress for Iteration 13 


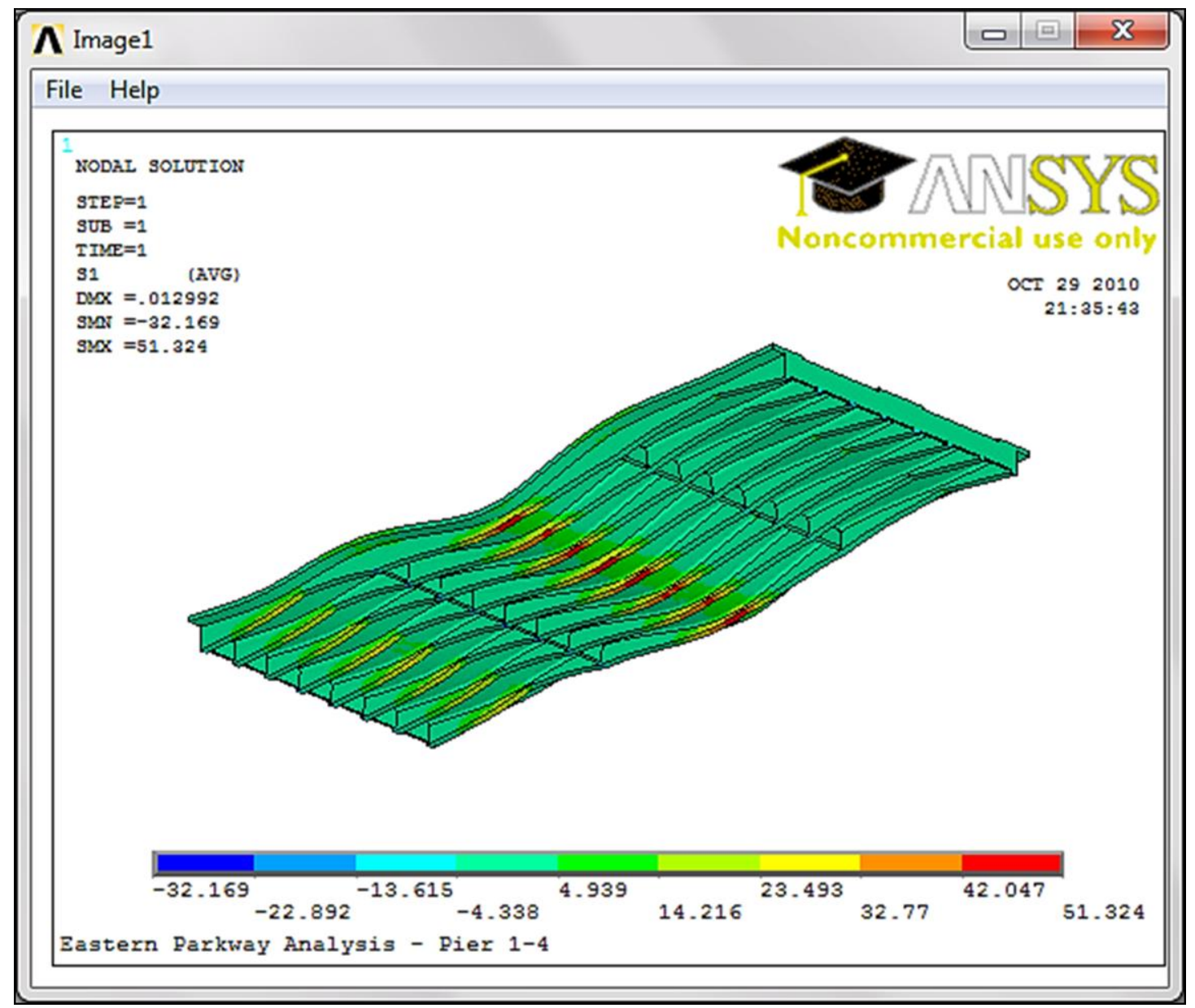

FIGURE 129 - First Principal Stress for Iteration 13 As Viewed From Below 


\section{APPENDIX X}

\section{SCREEN CAPTURES OF VON MISES STRESSES}

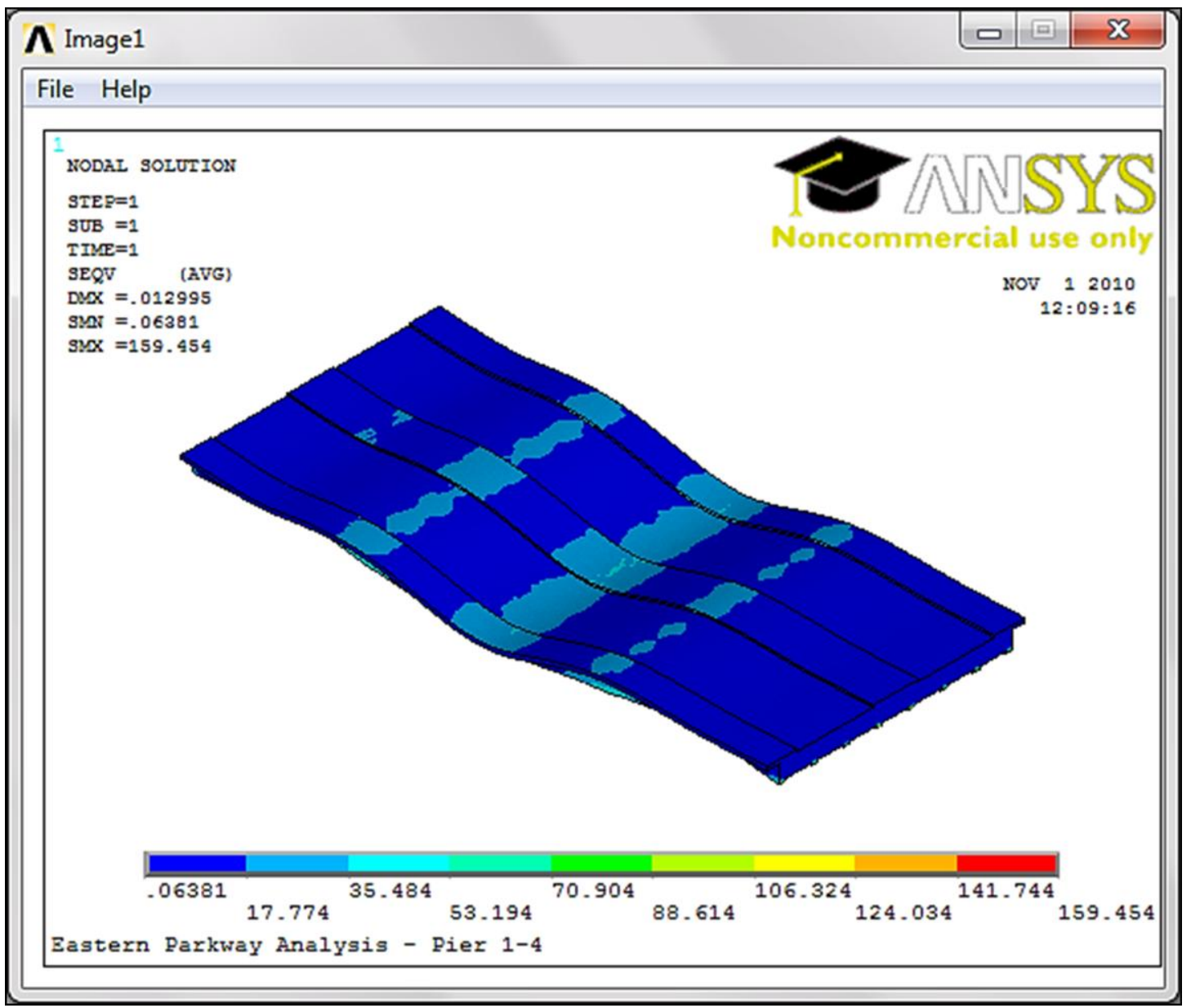

FIGURE 130 - Von Mises Stress for Iteration One 


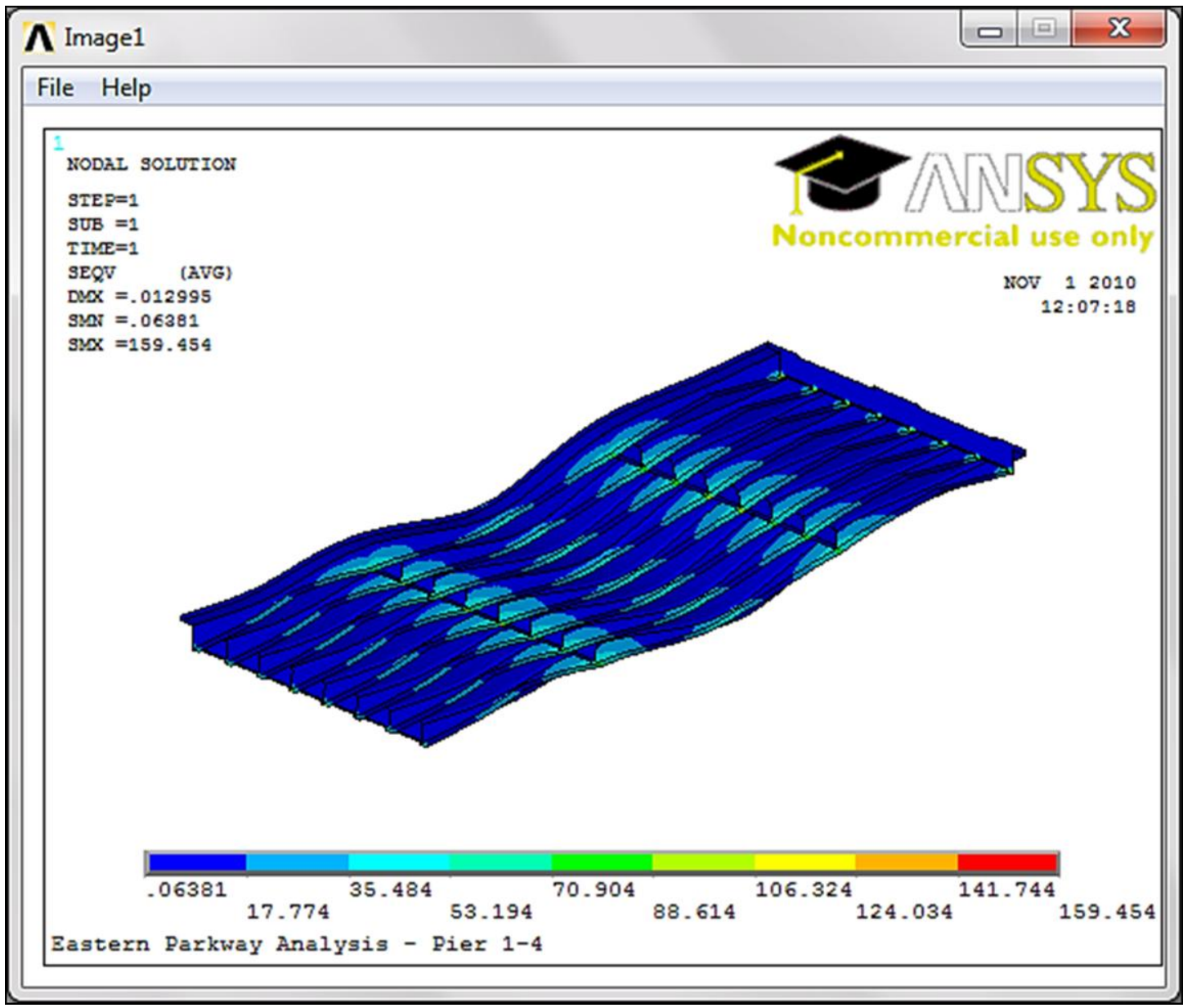

FIGURE 131 - Von Mises Stress for Iteration One As Viewed From Below 


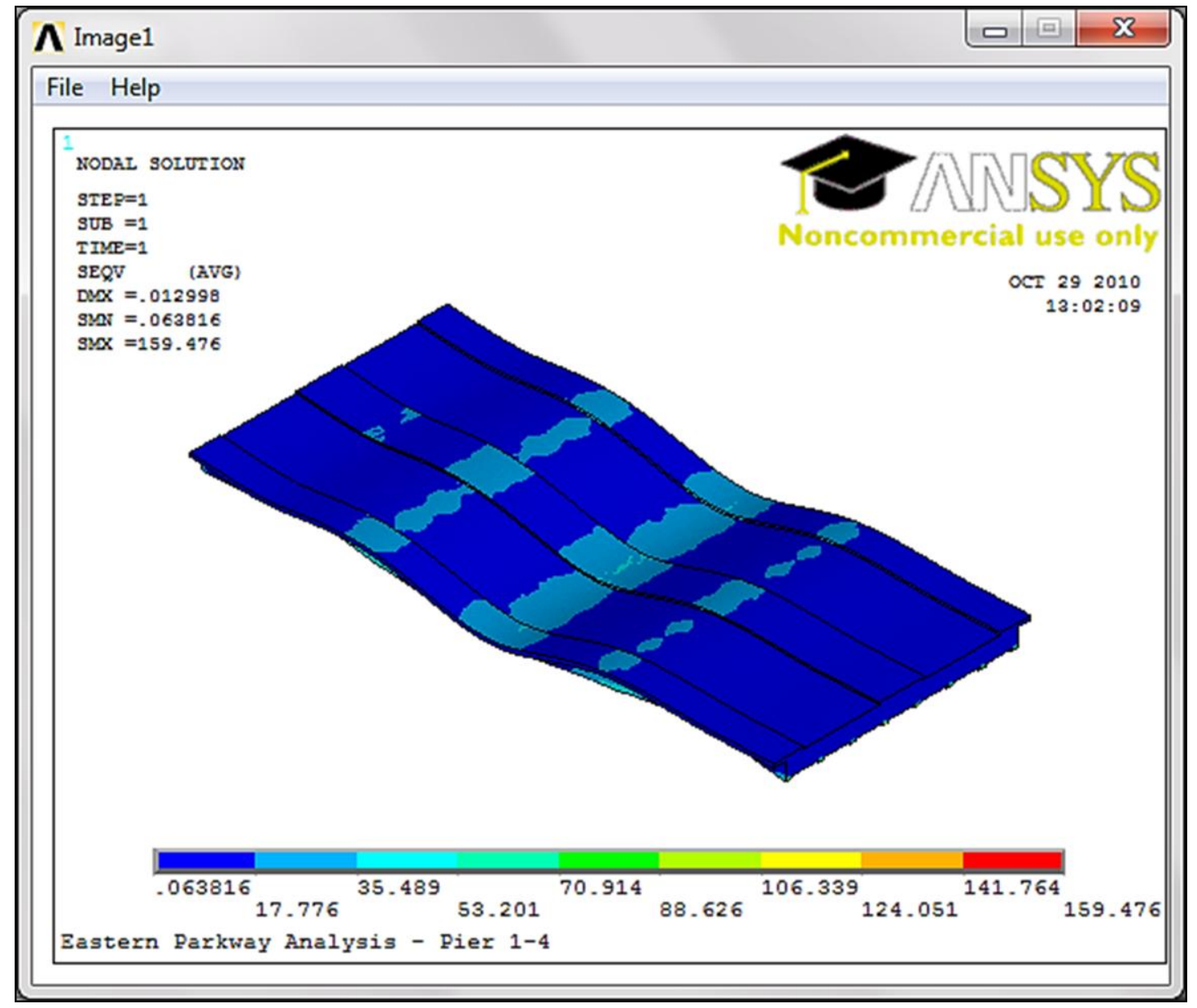

FIGURE 132 - Von Mises Stress for Iteration Two 


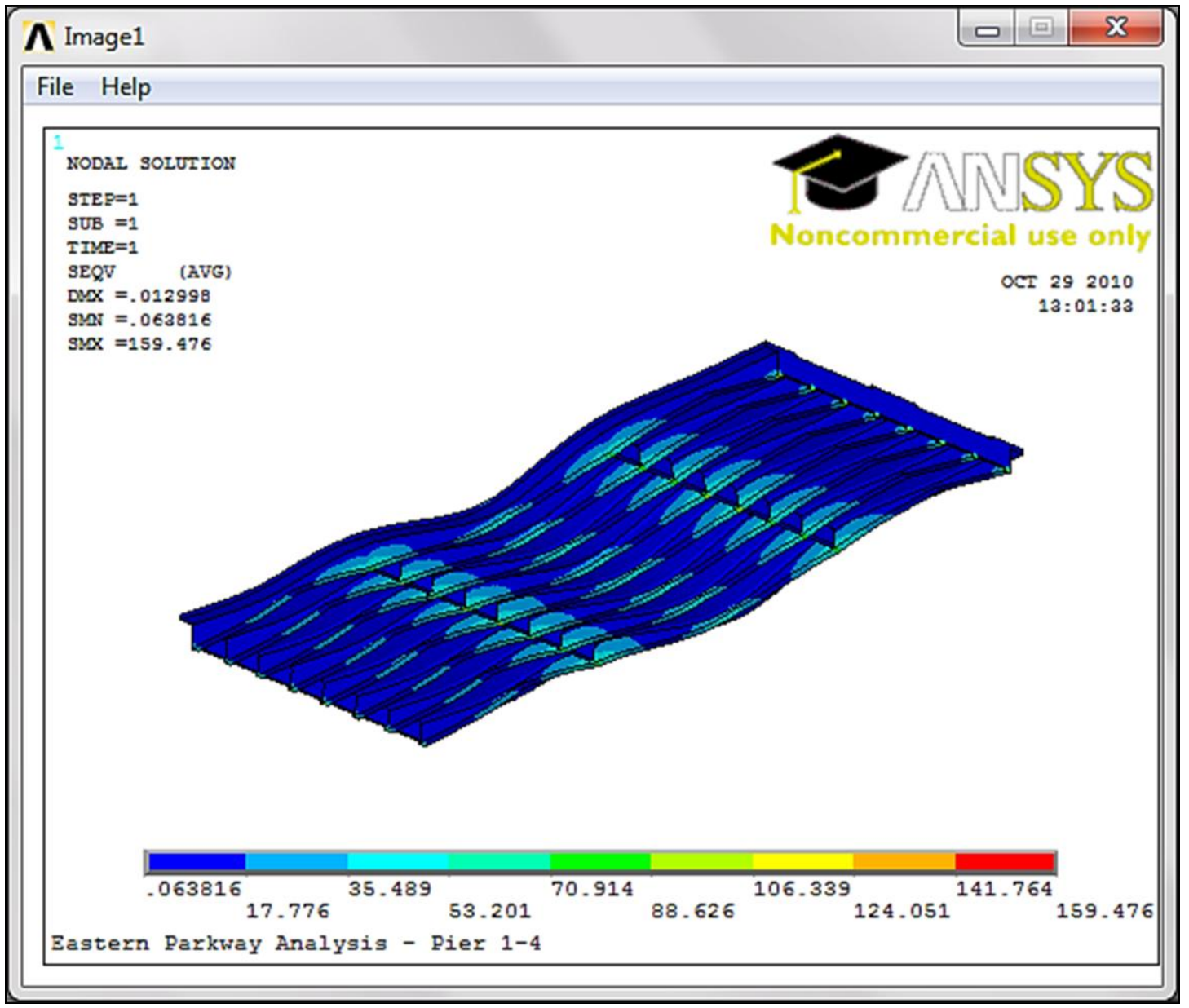

FIGURE 133 - Von Mises Stress for Iteration Two As Viewed From Below 


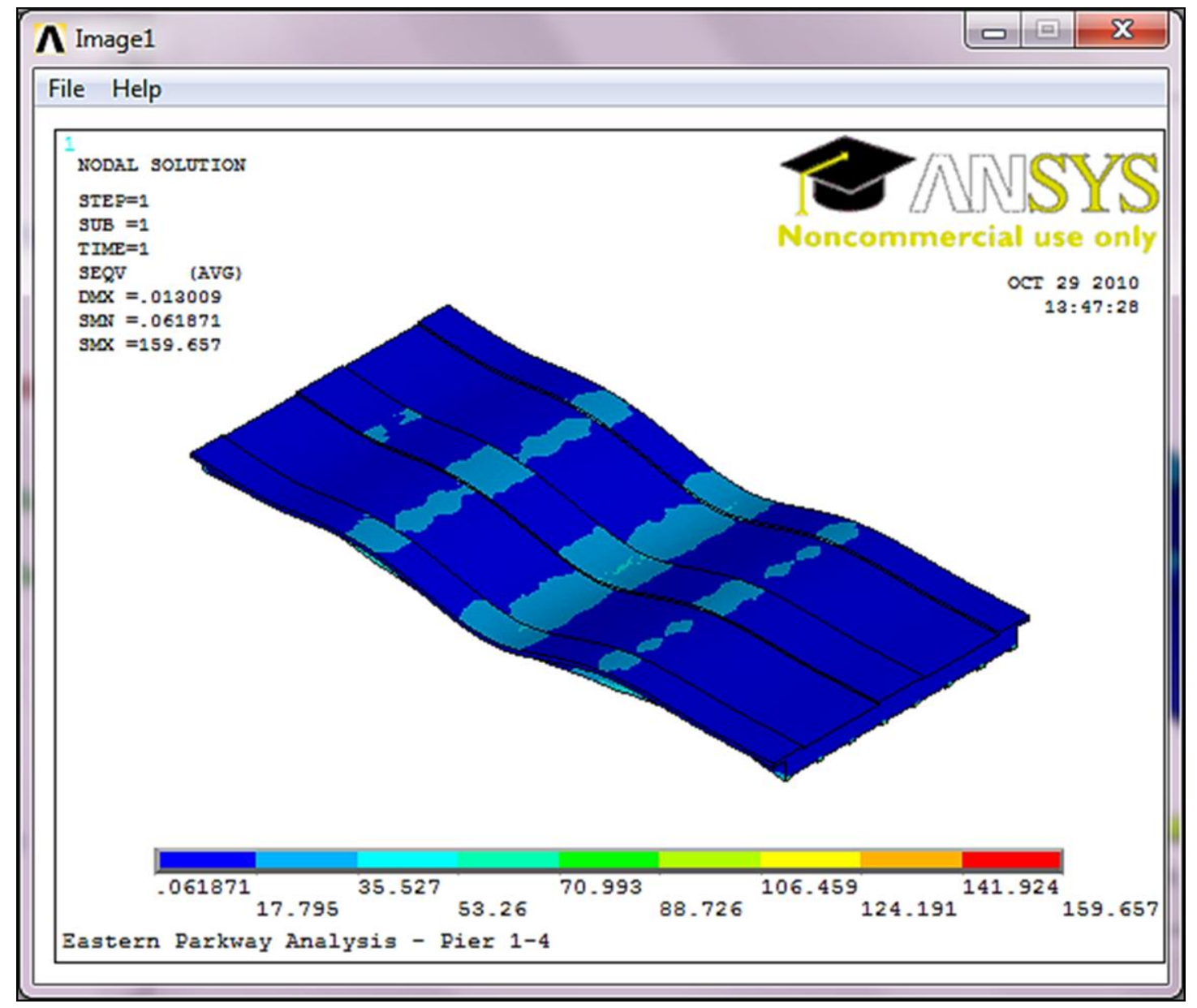

FIGURE 134 - Von Mises Stress for Iteration Three 


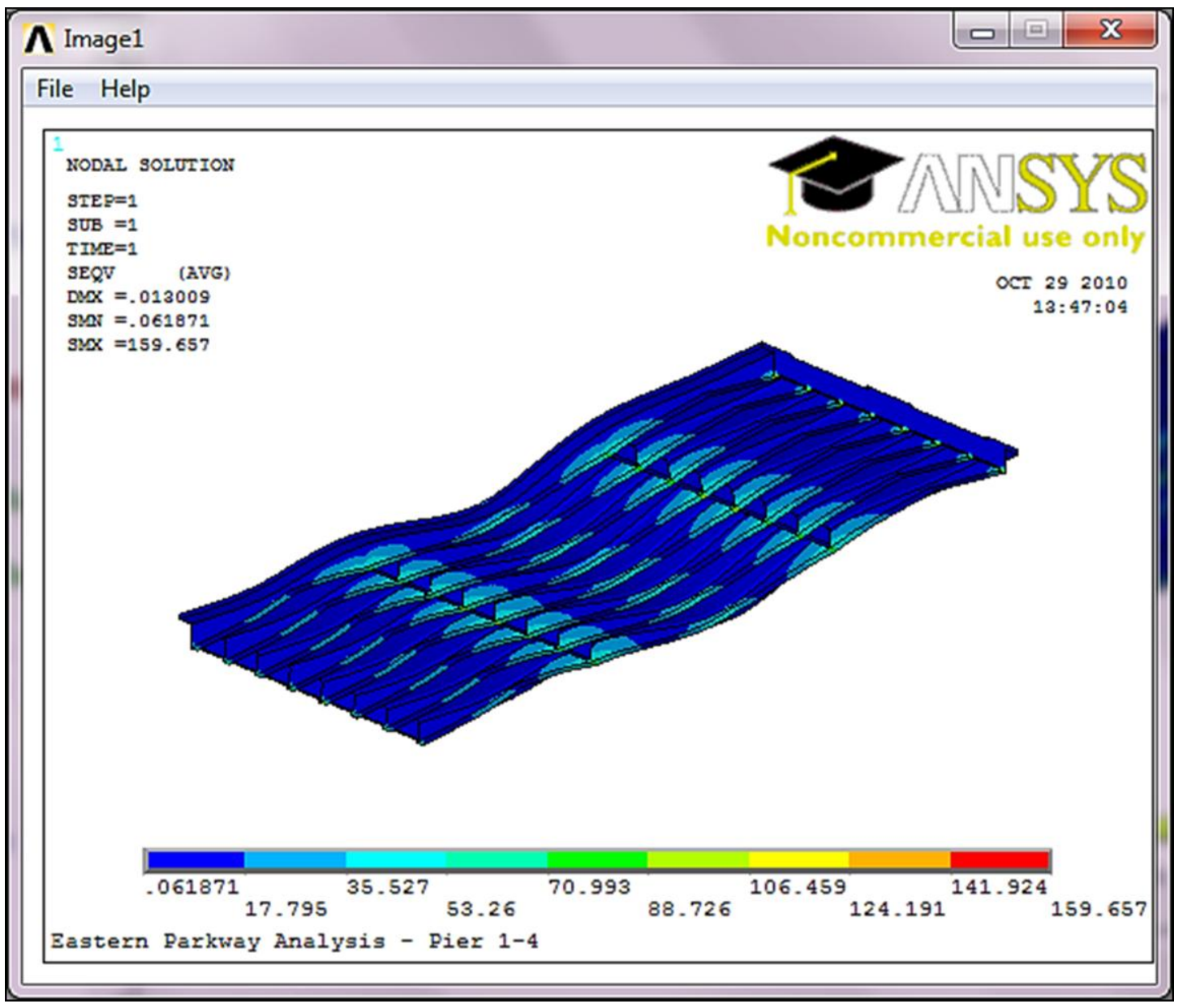

FIGURE 135 - Von Mises Stress for Iteration Three As Viewed From Below 


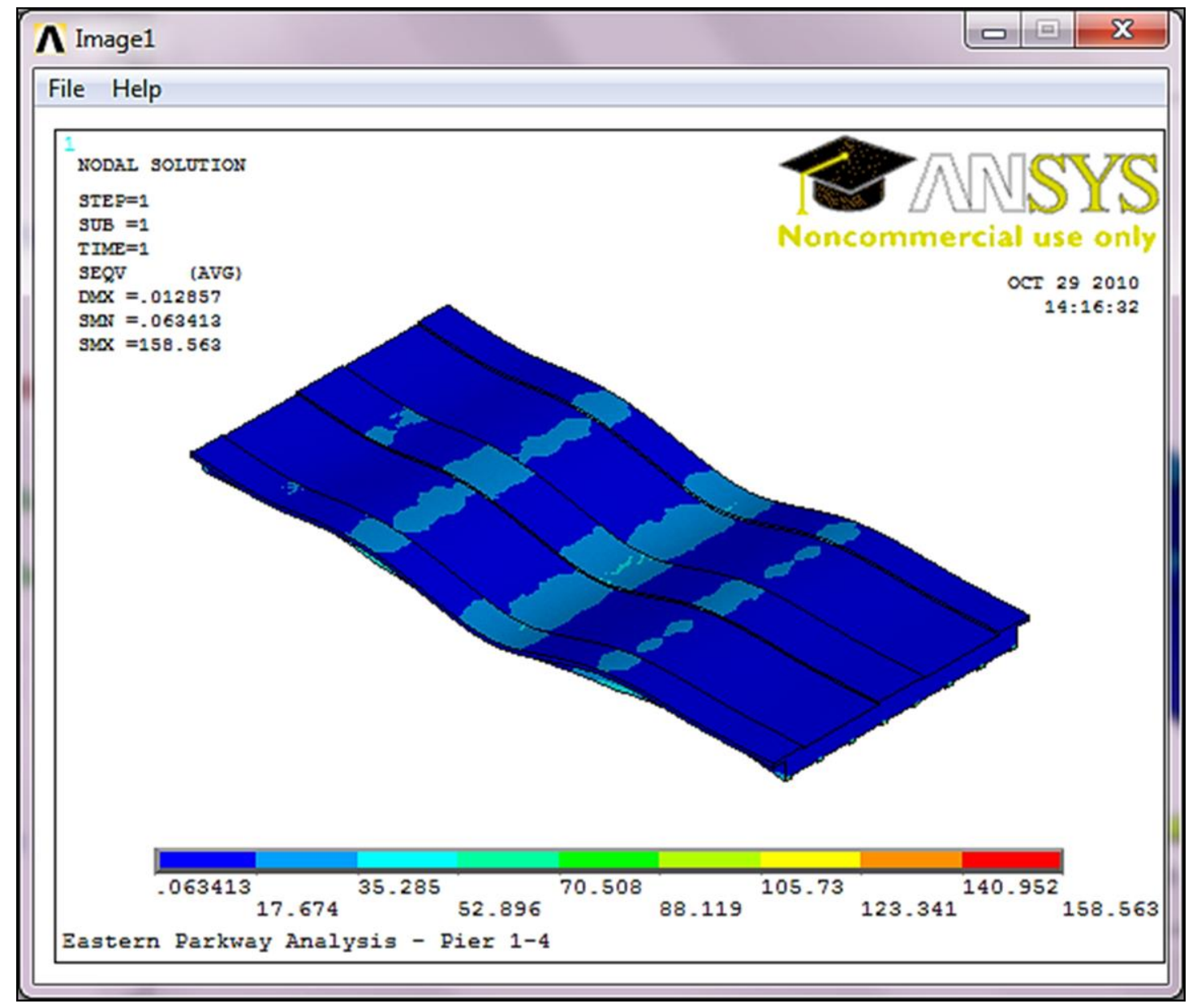

FIGURE 136 - Von Mises Stress for Iteration Four 


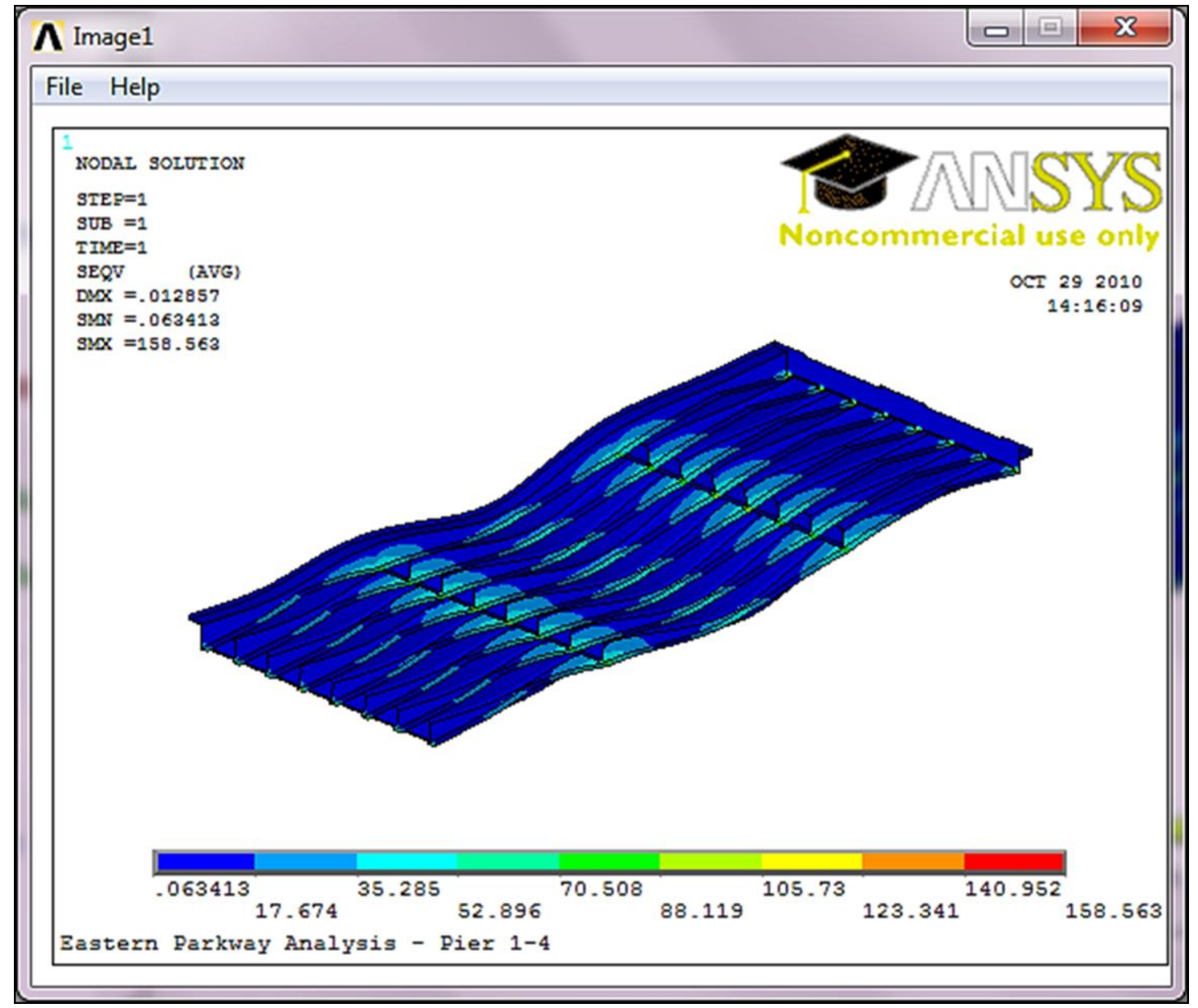

FIGURE 137 - Von Mises Stress for Iteration Four As Viewed From Below 


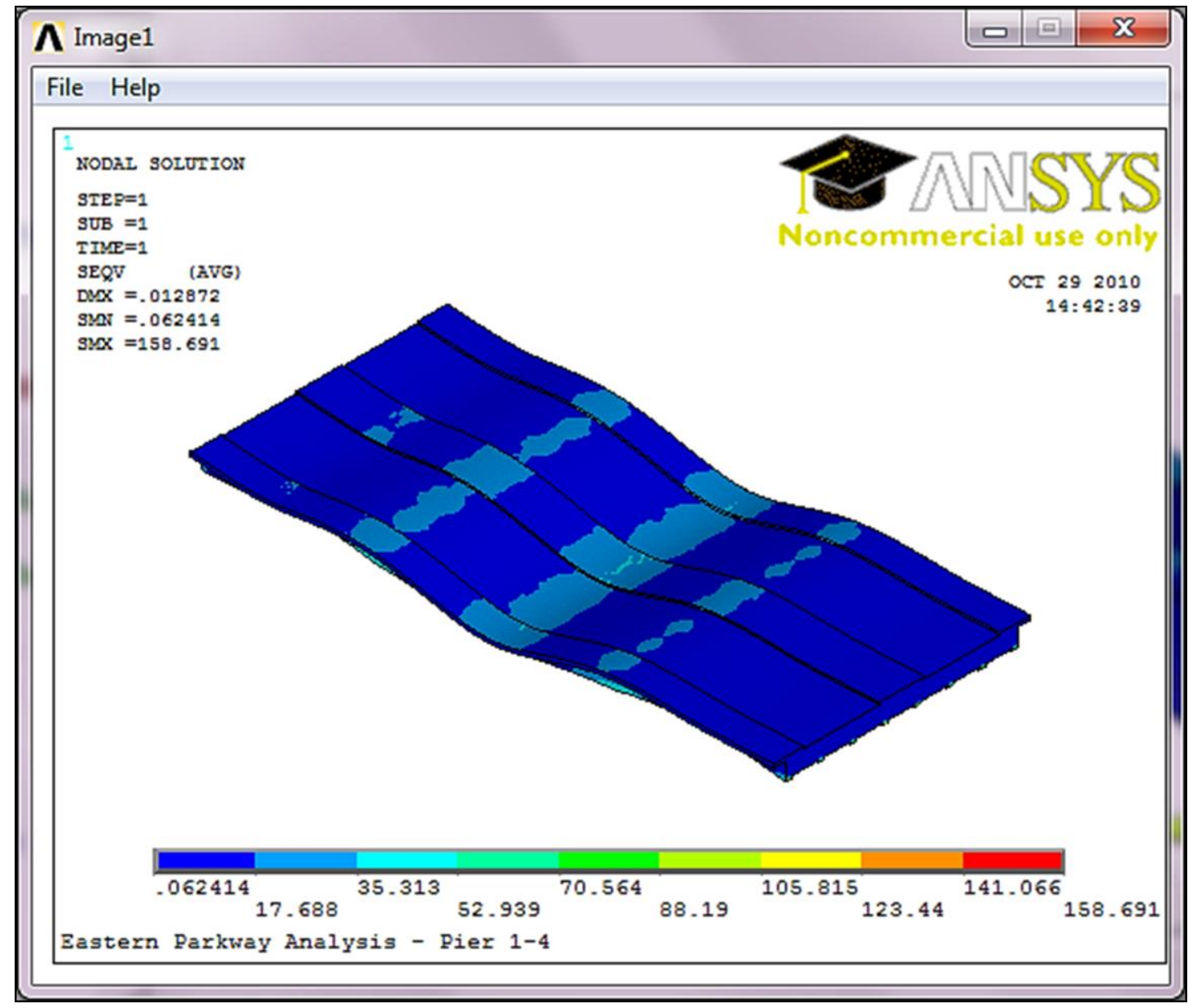

FIGURE 138 - Von Mises Stress for Iteration Five 


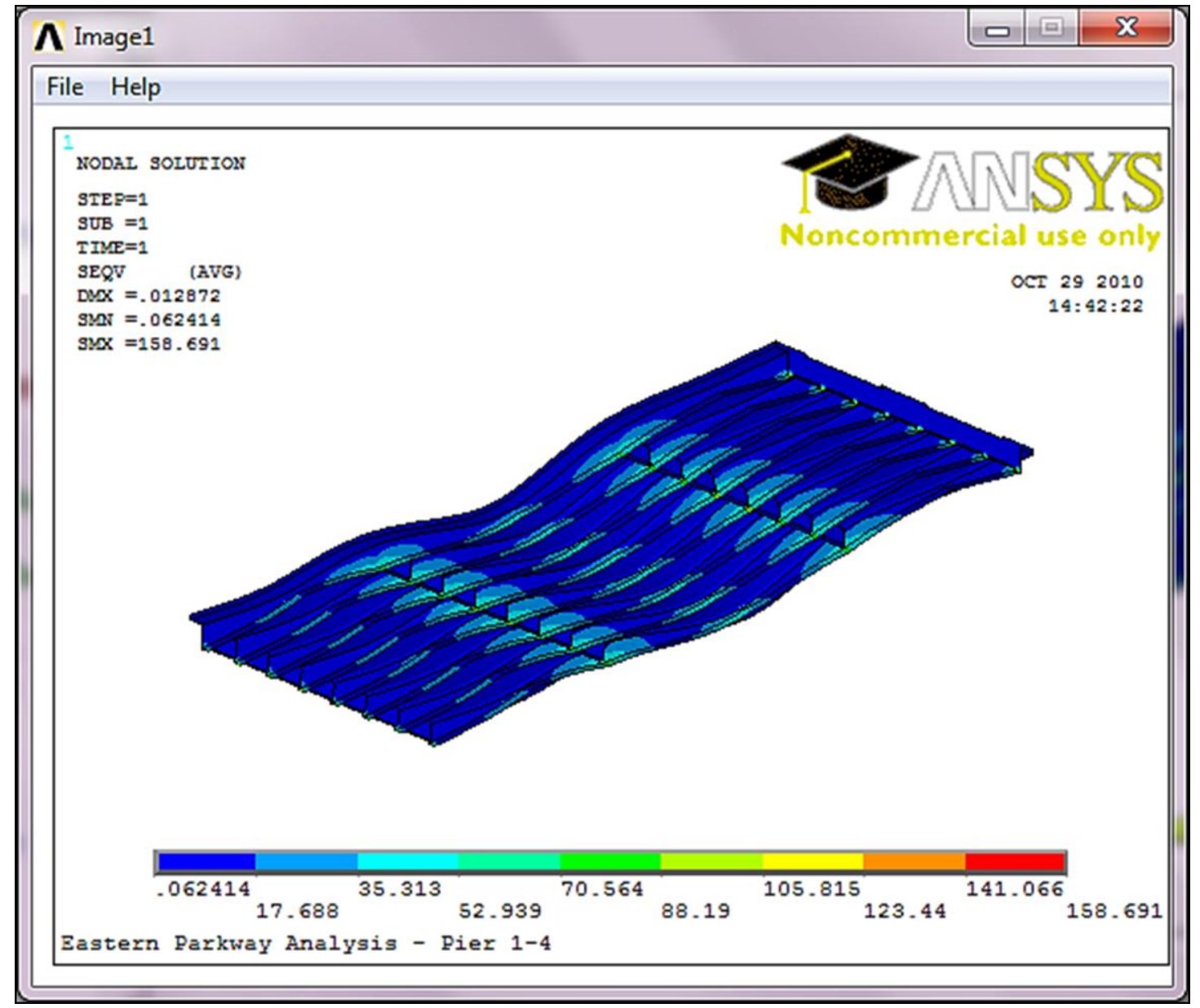

FIGURE 139 - Von Mises Stress for Iteration Five As Viewed From Below 


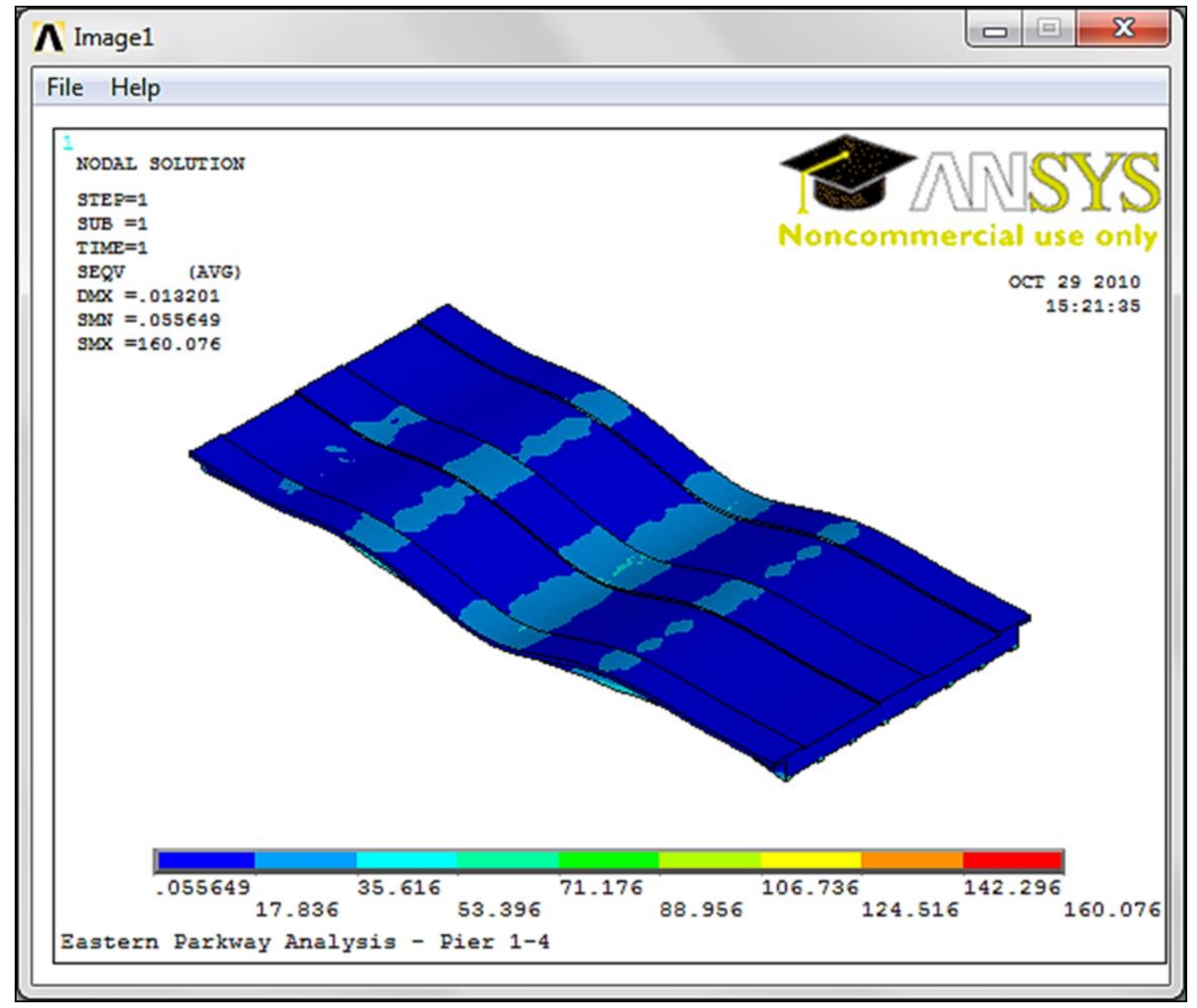

FIGURE 140 - Von Mises Stress for Iteration Six 


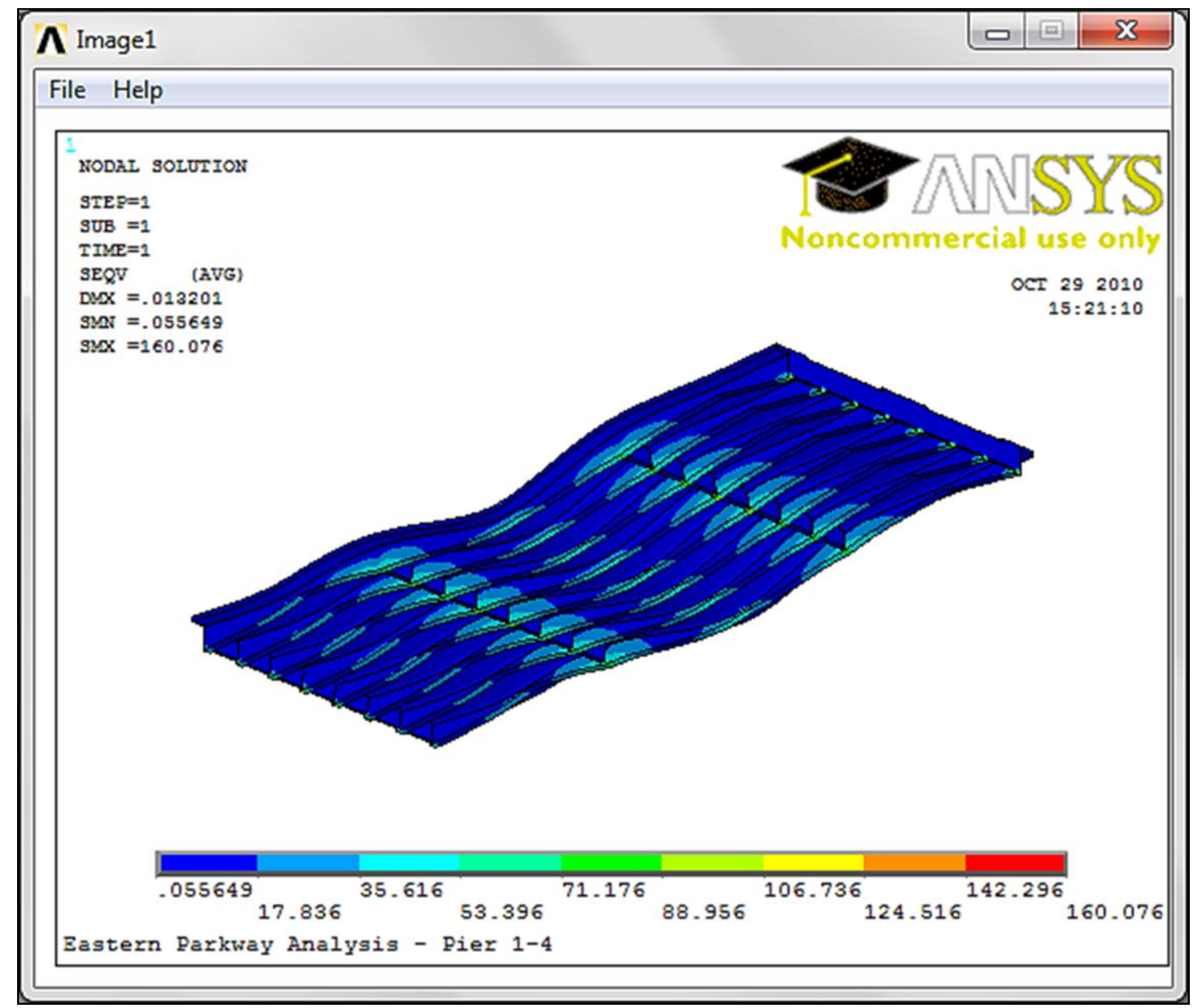

FIGURE 141 - Von Mises Stress for Iteration Six As Viewed From Below 


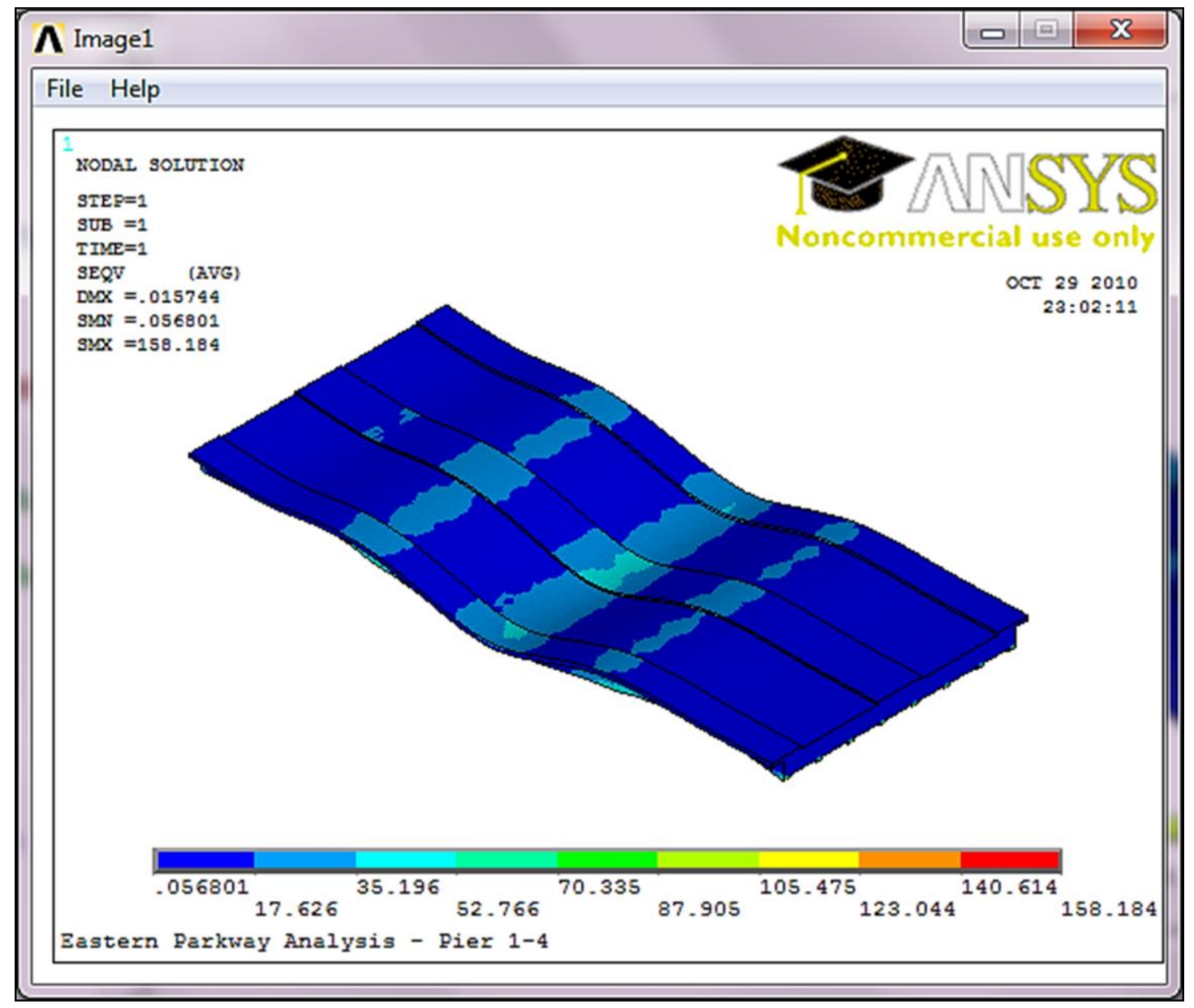

FIGURE 142 - Von Mises Stress for Iteration Seven 


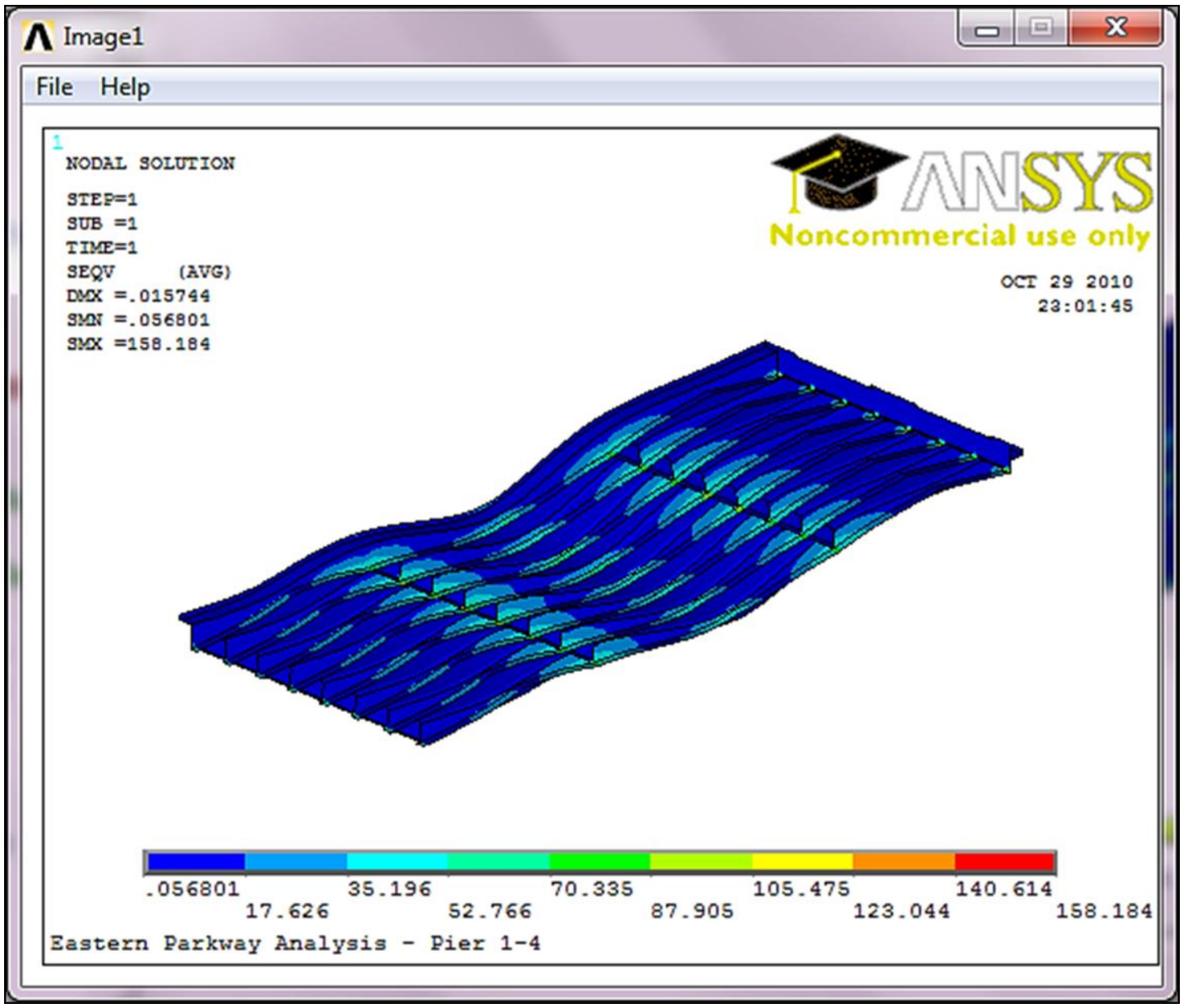

FIGURE 143 - Von Mises Stress for Iteration Seven As Viewed From Below 


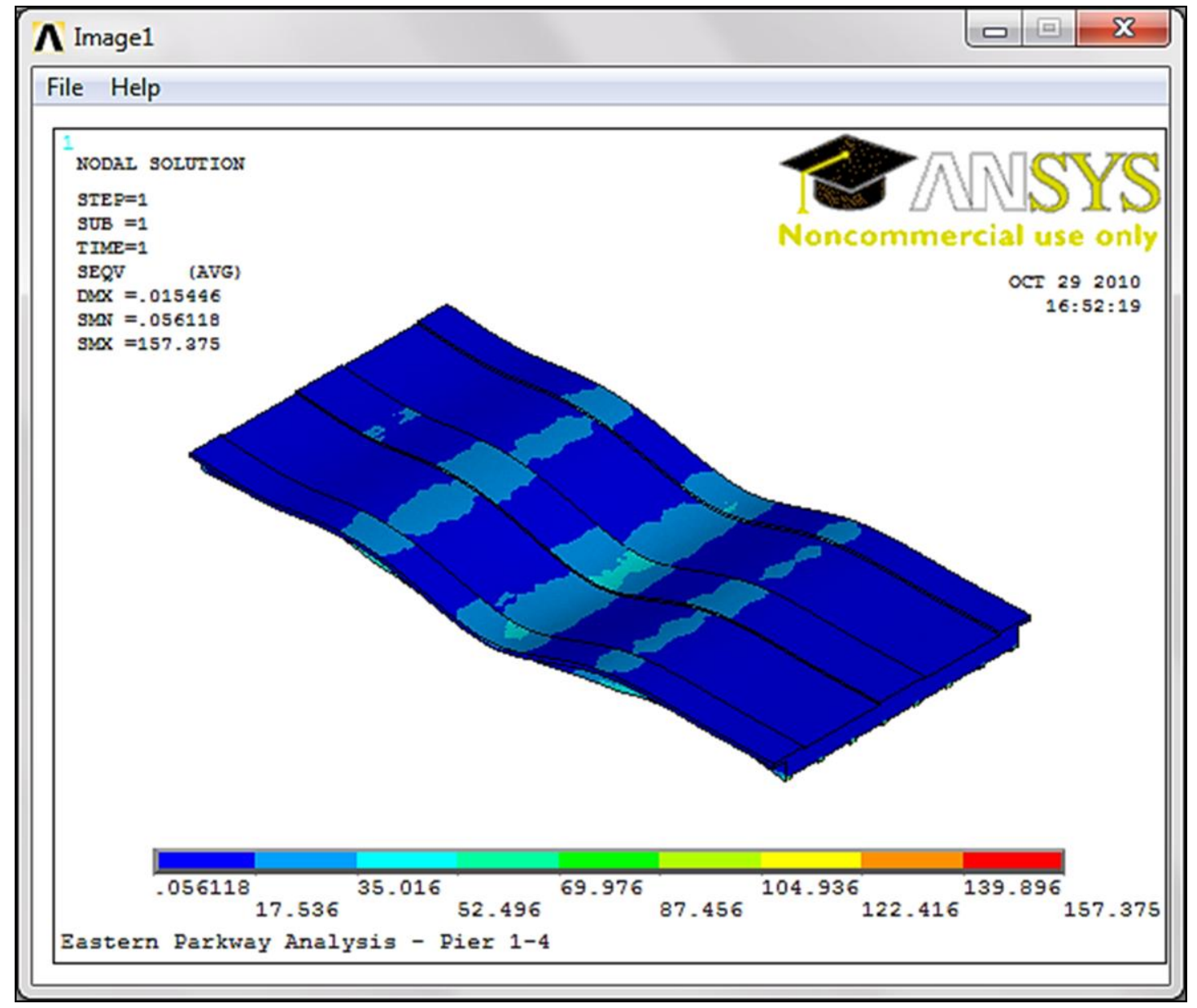

FIGURE 144 - Von Mises Stress for Iteration Eight 


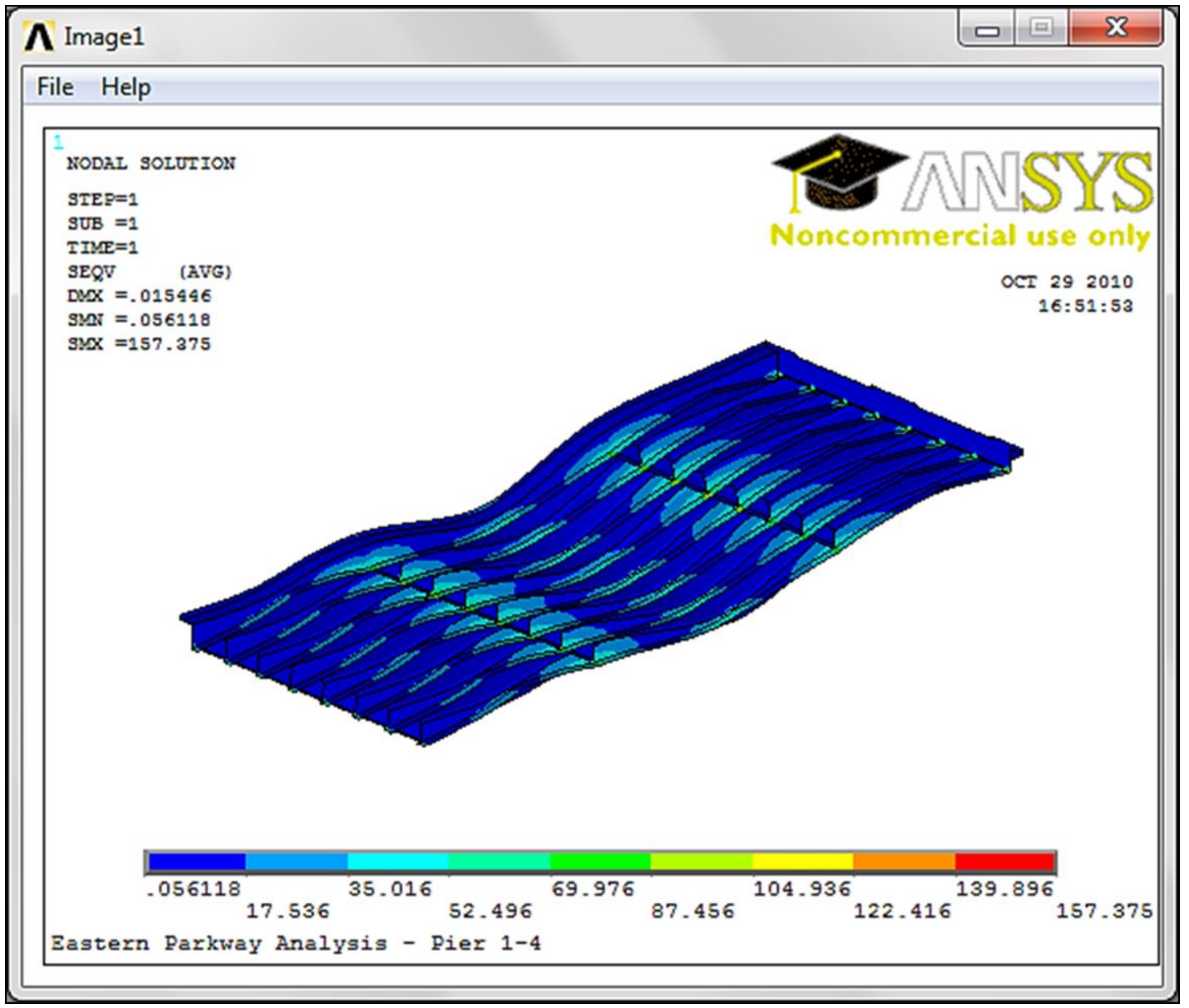

FIGURE 145 - Von Mises Stress for Iteration Eight As Viewed From Below 


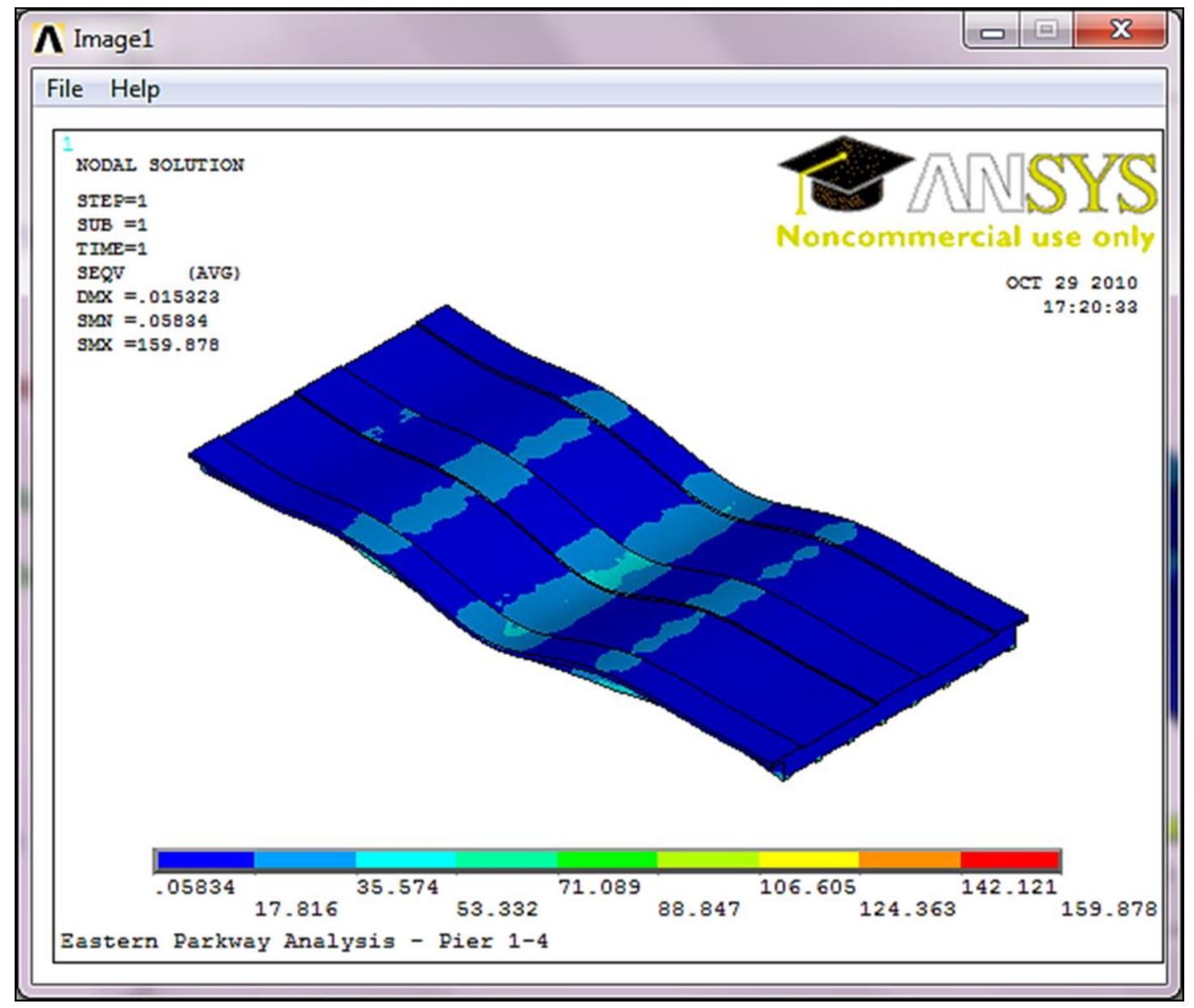

FIGURE 146 - Von Mises Stress for Iteration Nine 


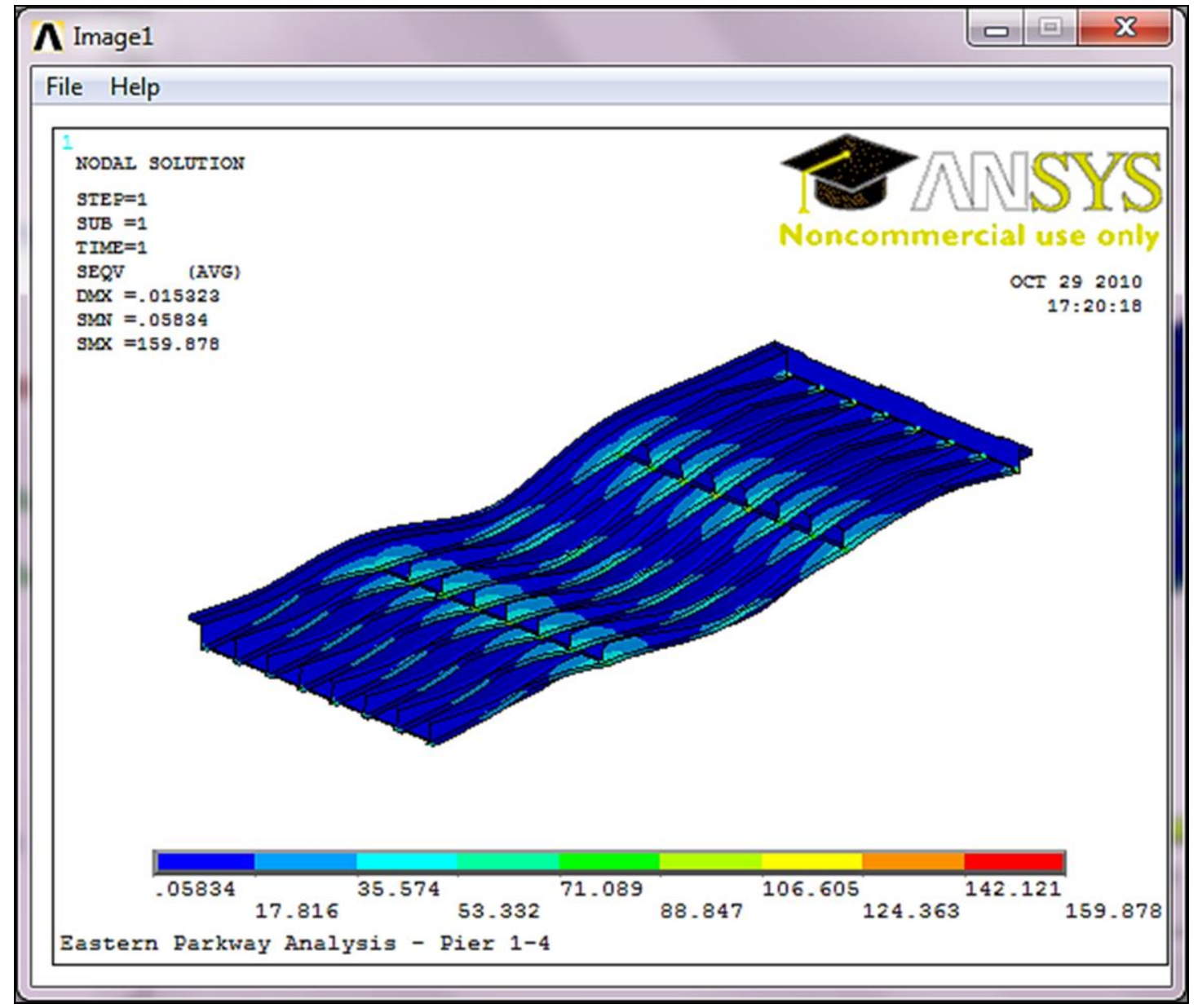

FIGURE 147 - Von Mises Stress for Iteration Nine As Viewed From Below 


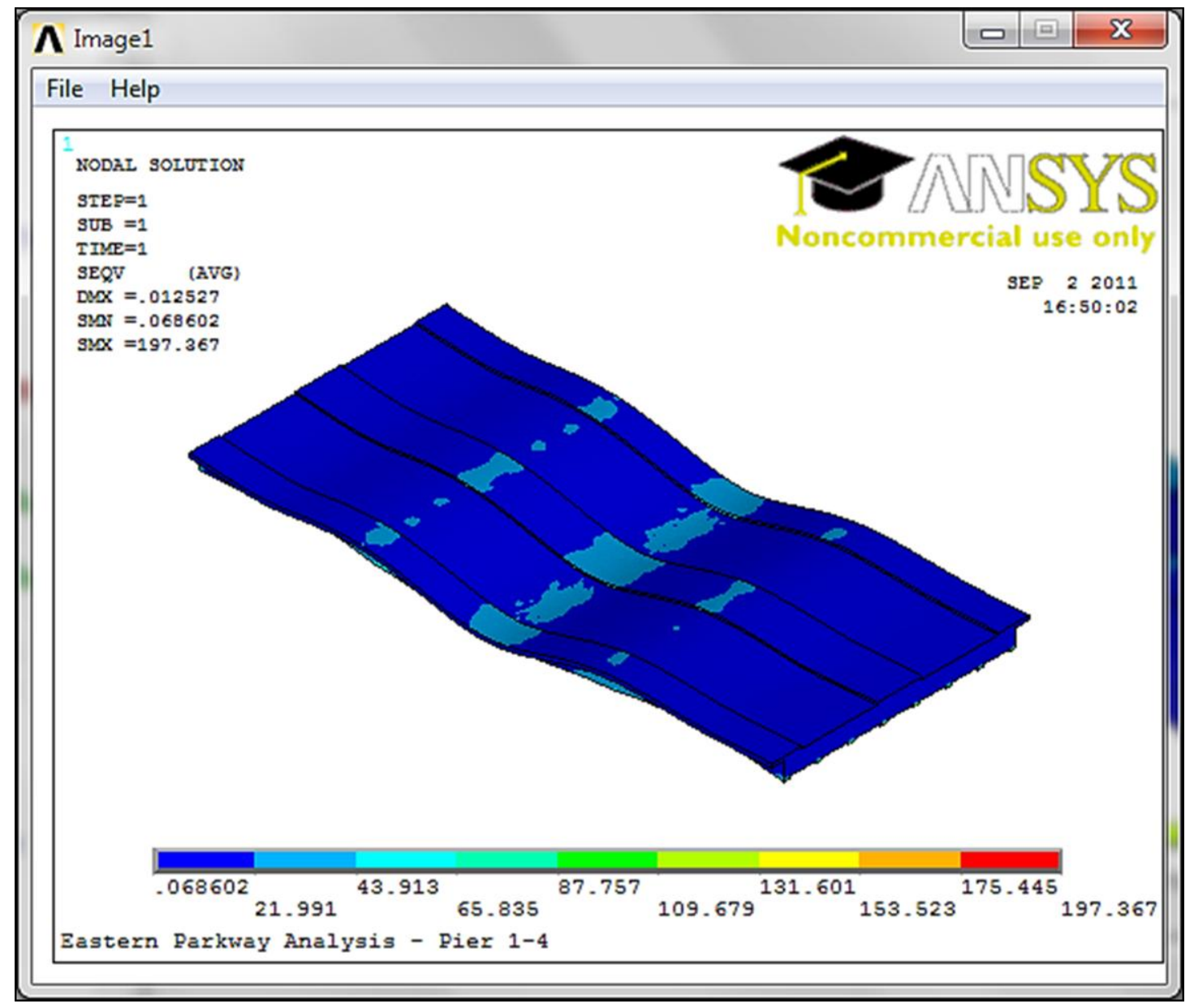

FIGURE 148 - Von Mises Stress for Iteration 10 


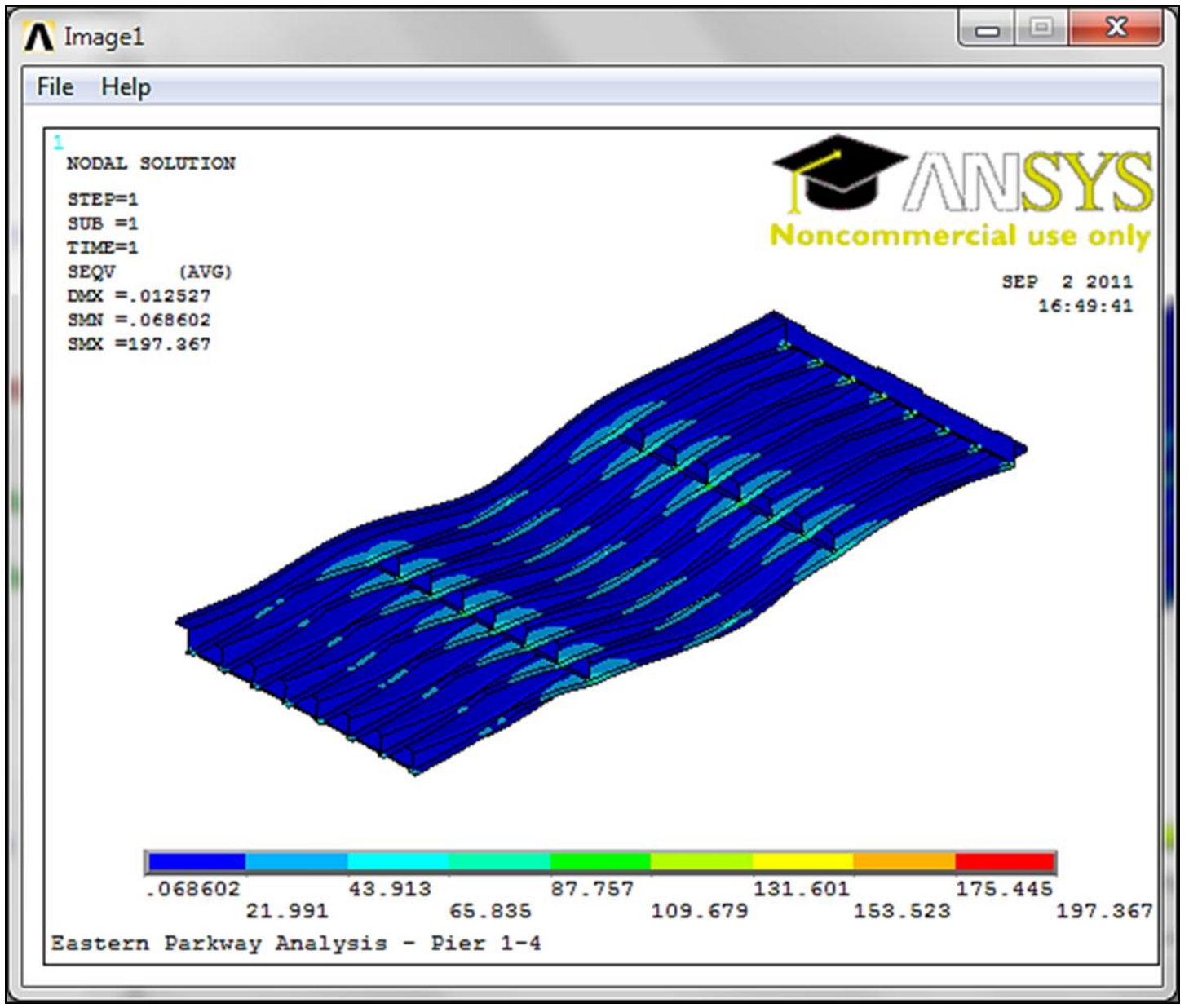

FIGURE 149 - Von Mises Stress for Iteration 10 As Viewed From Below 


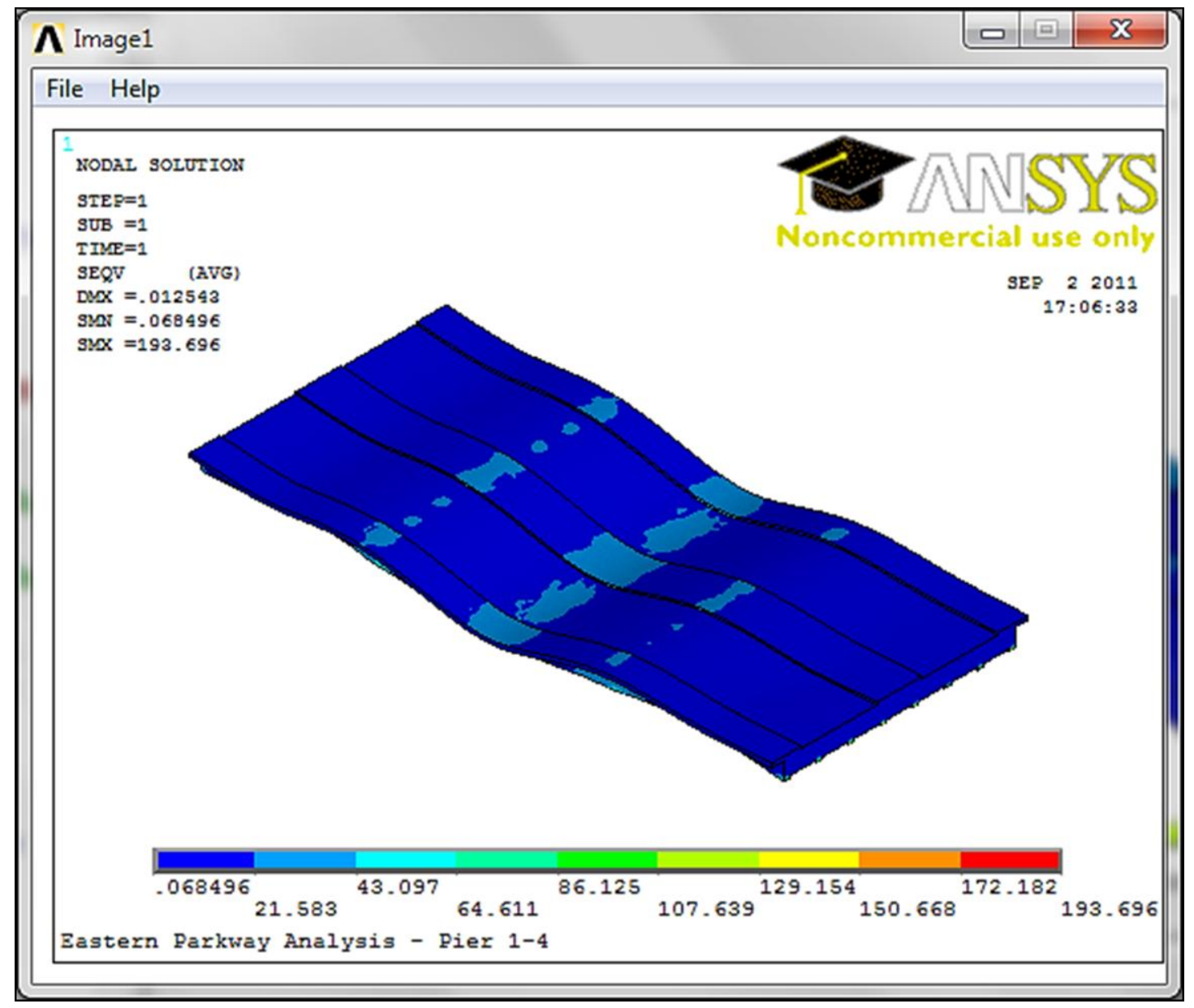

FIGURE 150 - Von Mises Stress for Iteration 11 


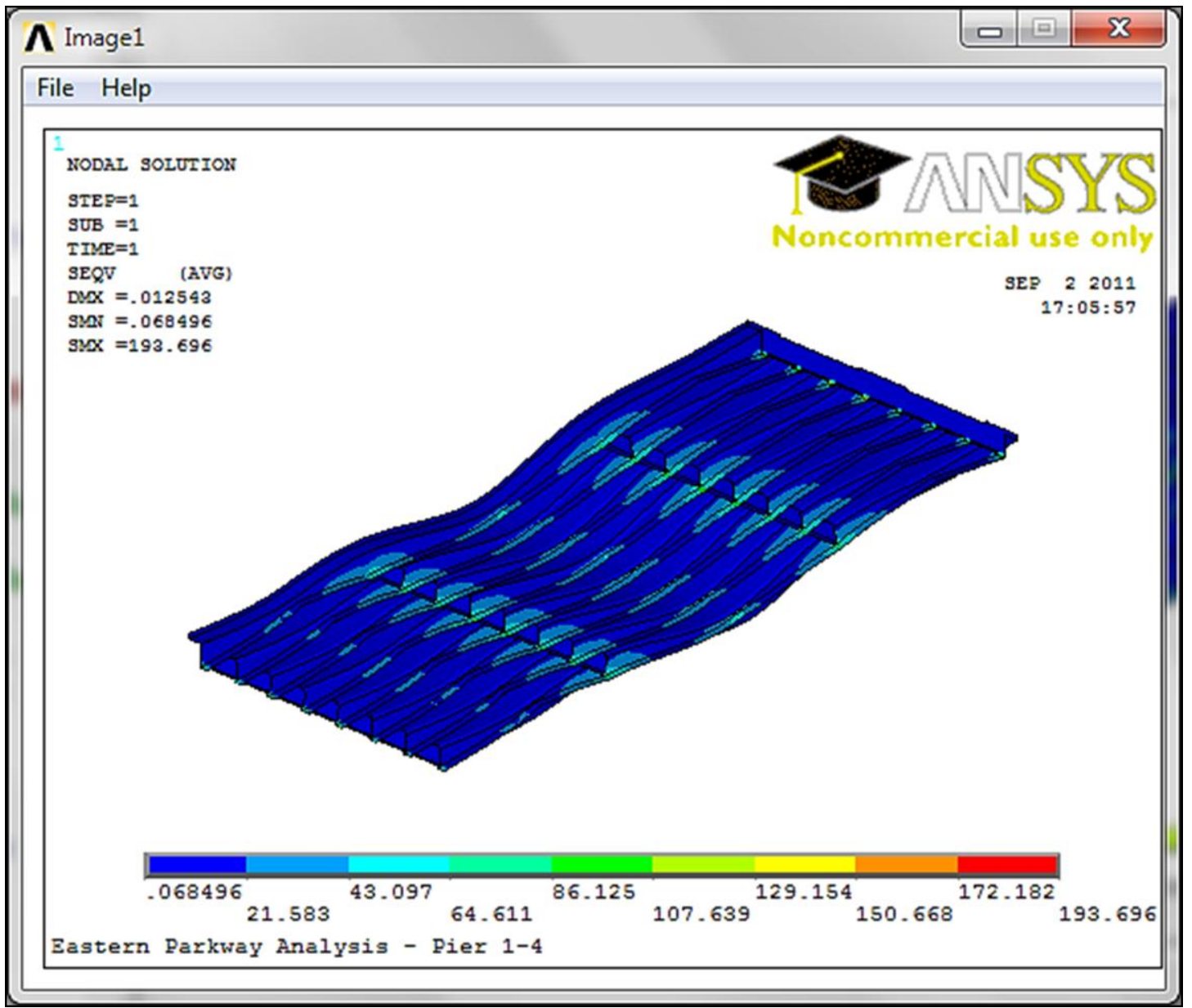

FIGURE 151 - Von Mises Stress for Iteration 11 As Viewed from Below 


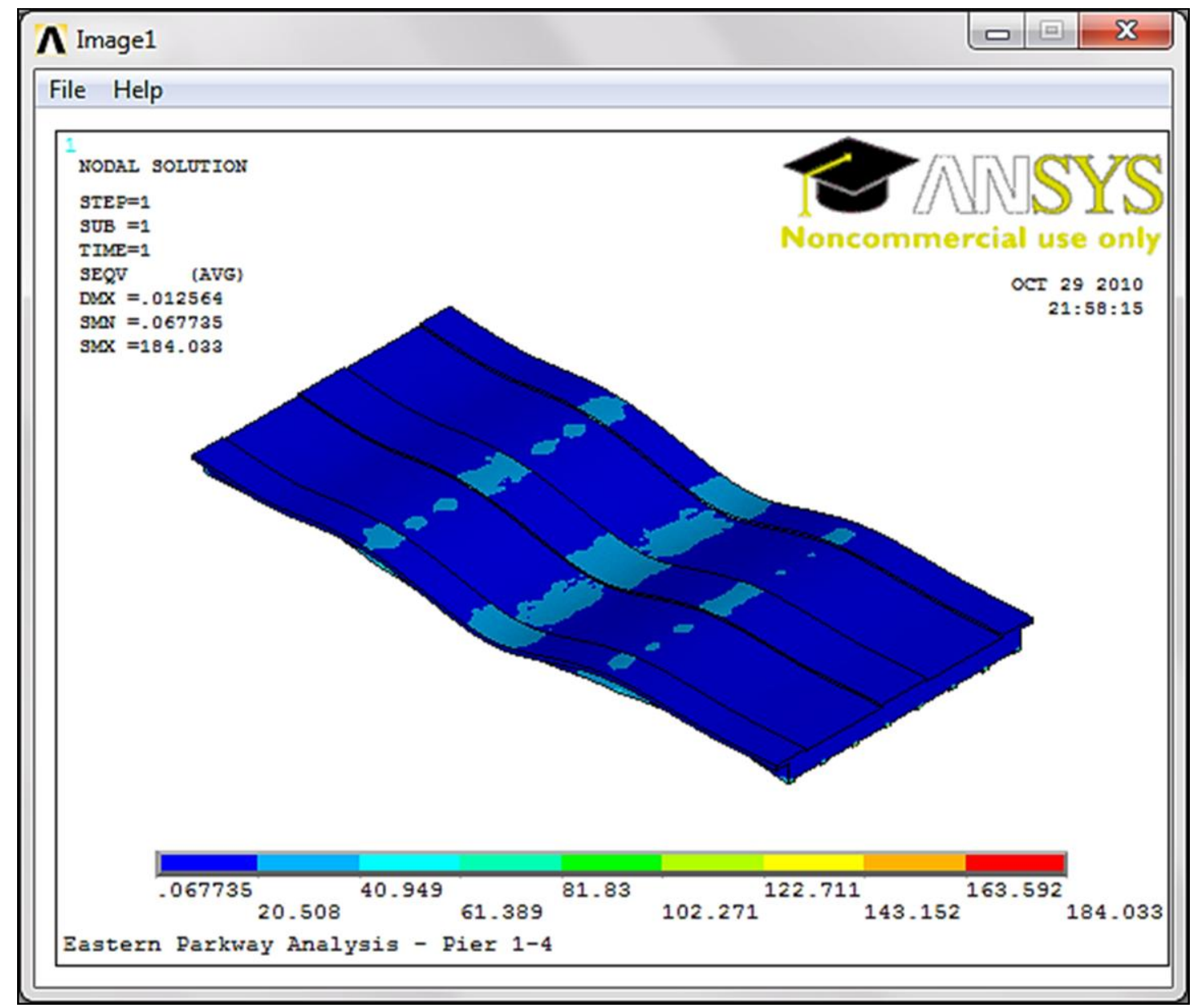

FIGURE 152 - Von Mises Stress for Iteration 12 


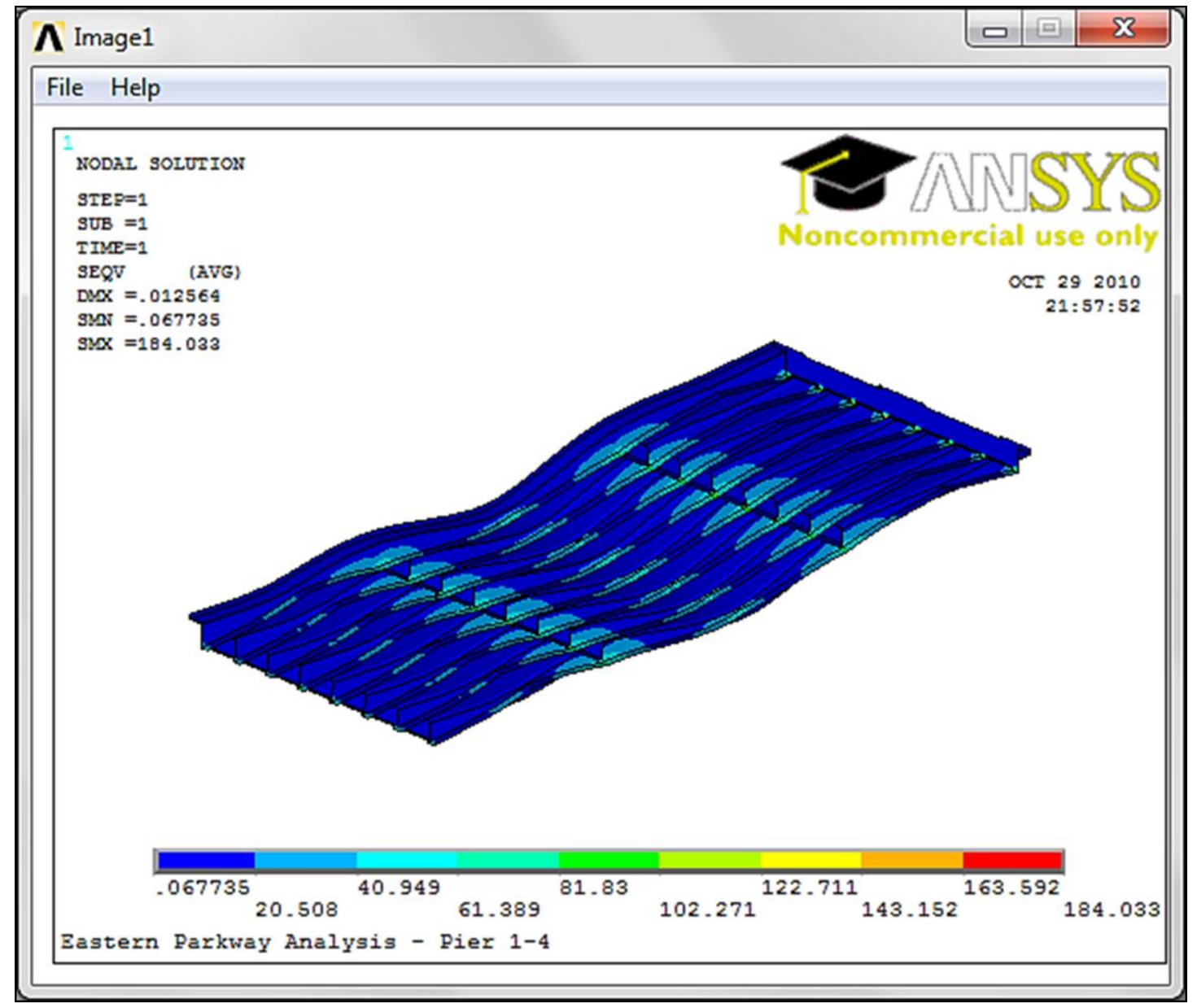

FIGURE 153 - Von Mises Stress for Iteration 12 As Viewed From Below 


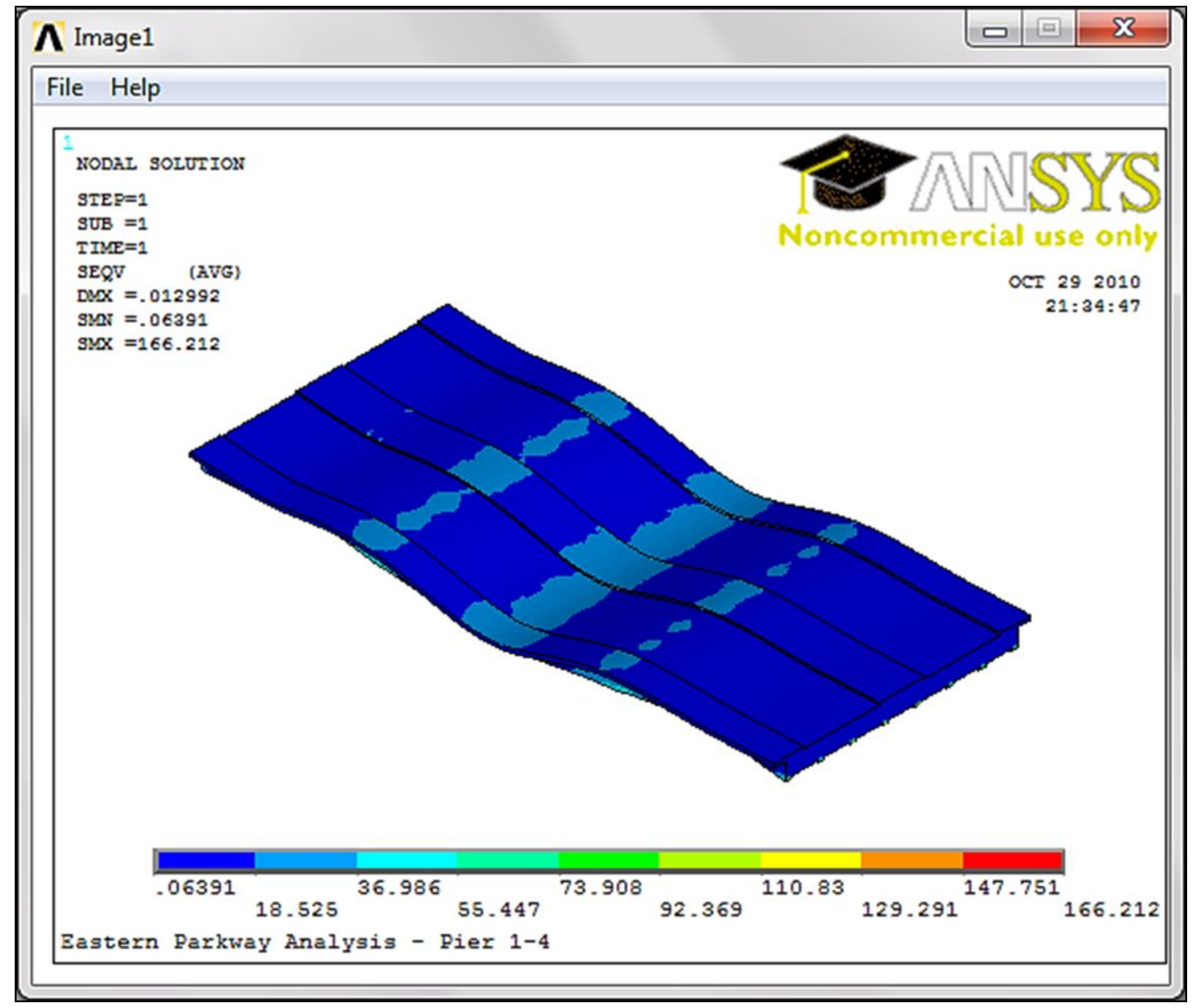

FIGURE 154 - Von Mises Stress for Iteration 13 


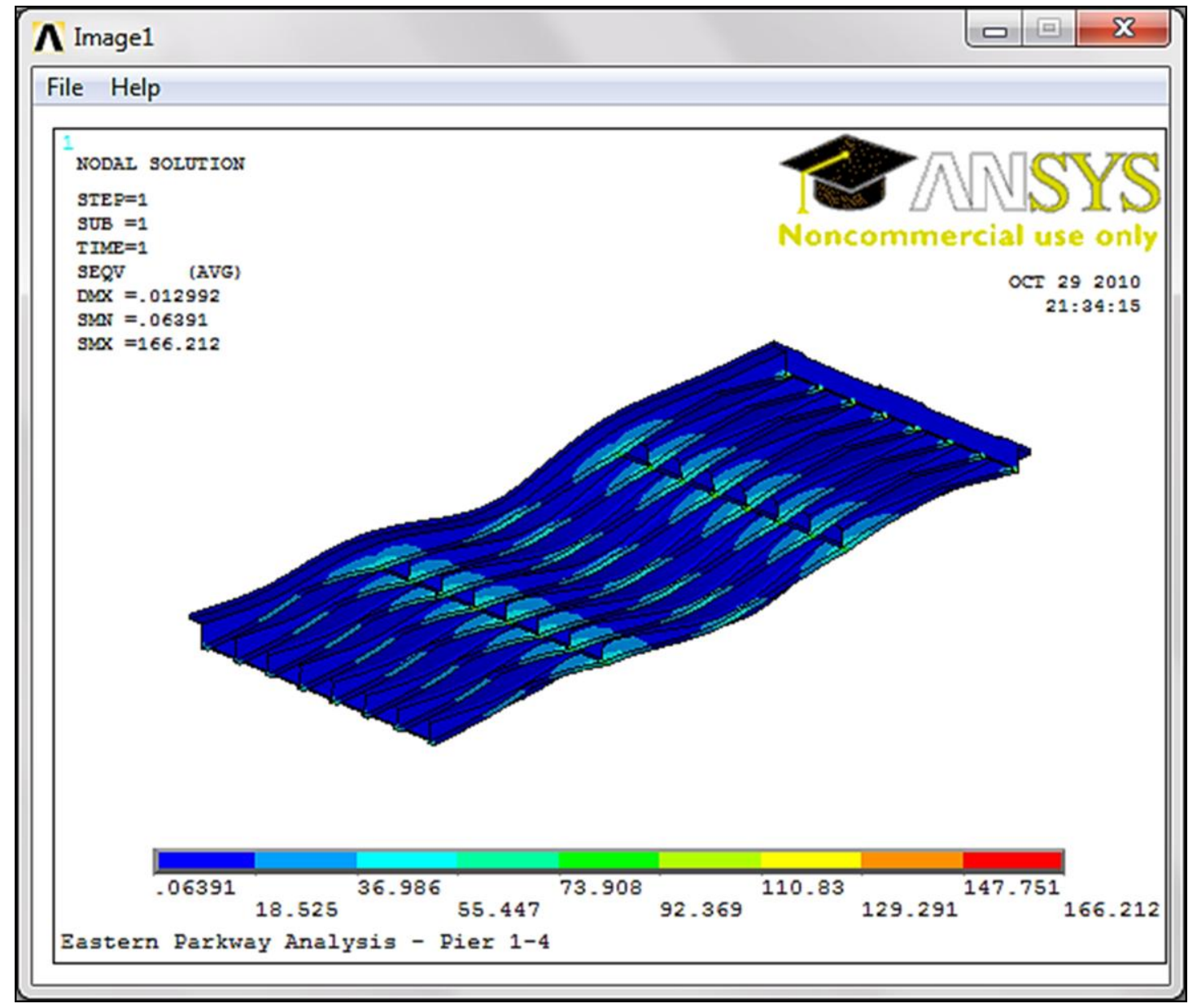

FIGURE 155 - Von Mises Stress for Iteration 13 As Viewed From Below 
APPENDIX XI

SCREEN CAPTURES OF Y-COMPONENTS OF STRAIN

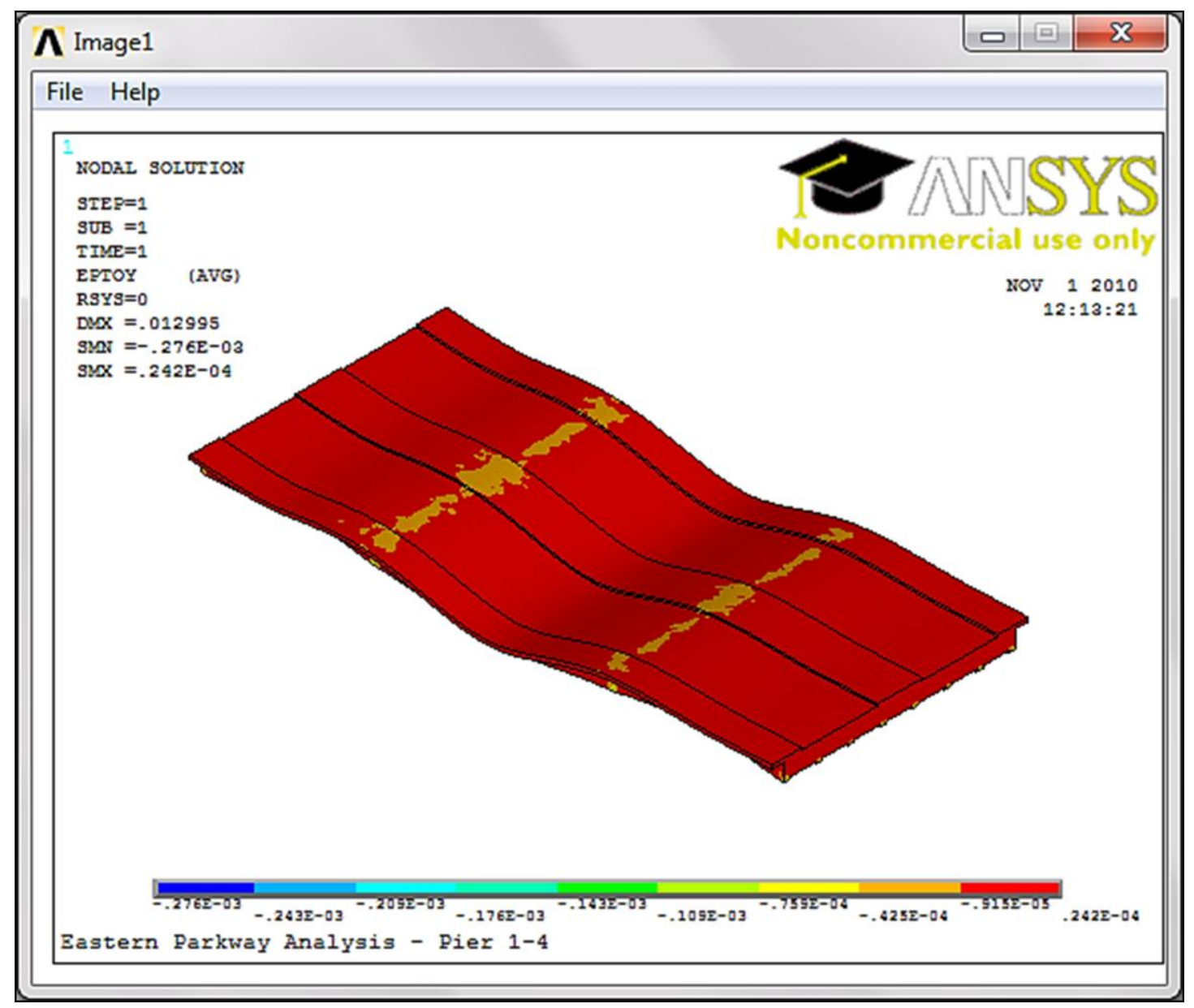

FIGURE 156 - Y-Component of Strain for Iteration One 


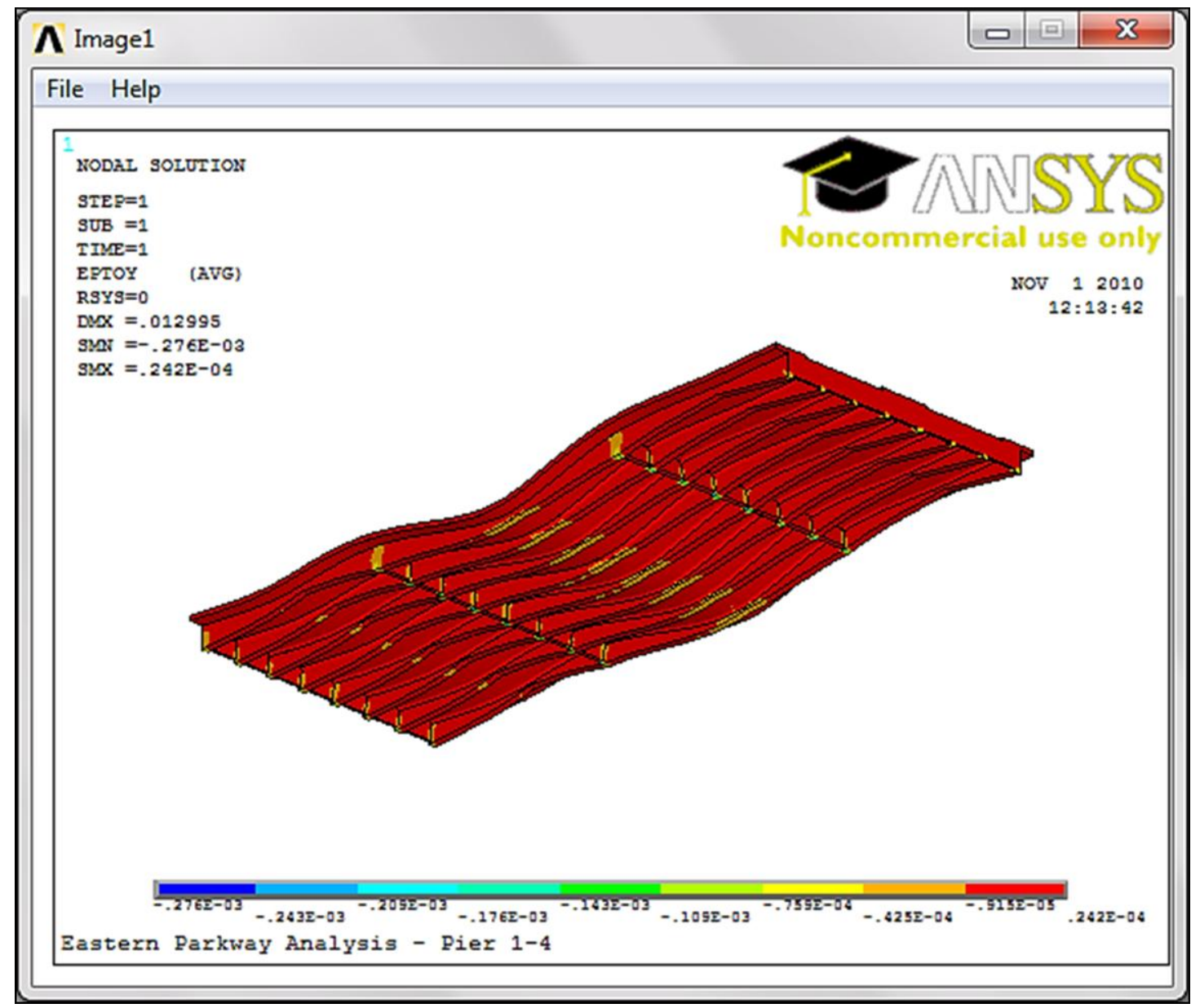

FIGURE 157 - Y-Component of Strain for Iteration One As Viewed From Below 


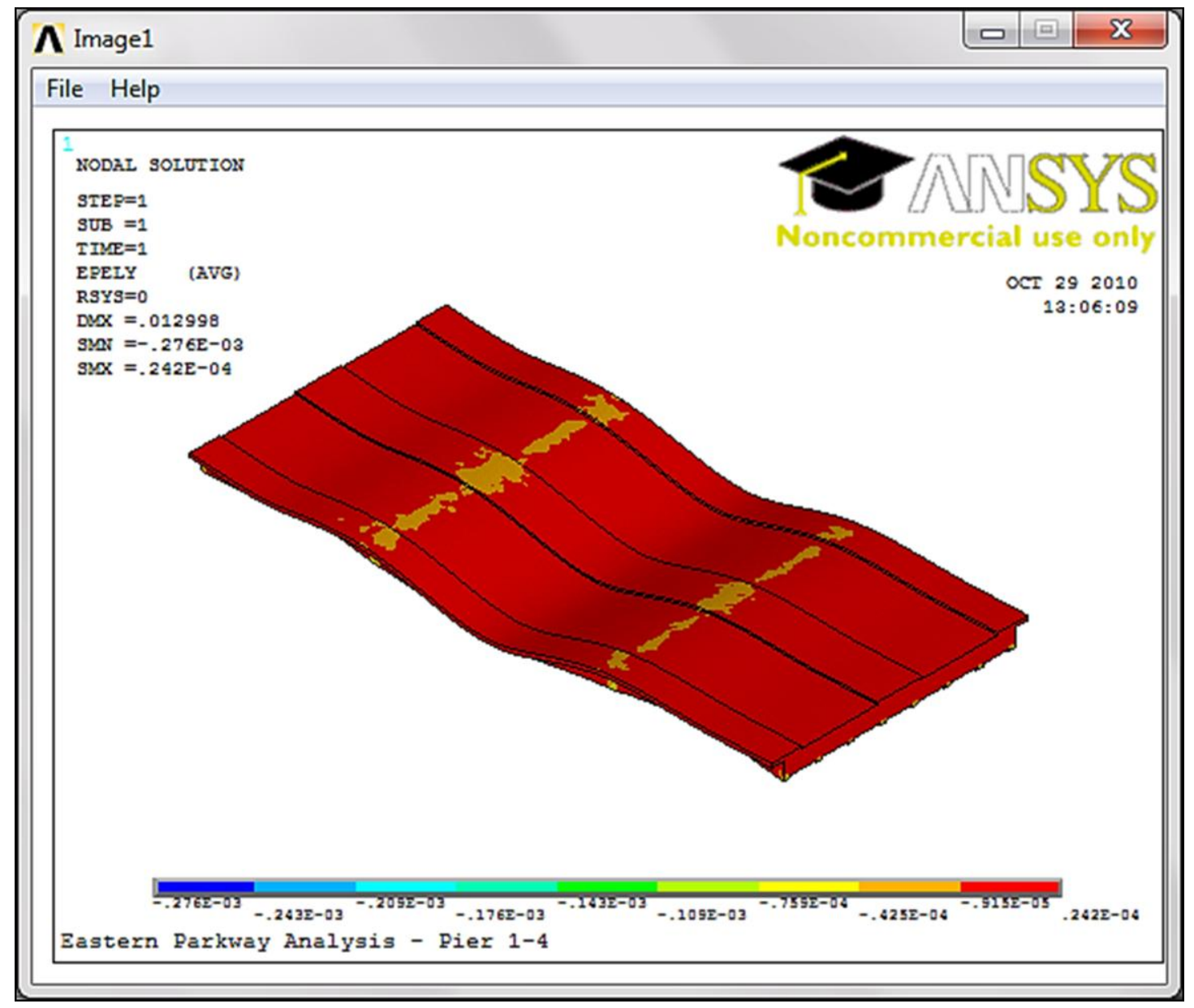

FIGURE 158 - Y-Component of Strain for Iteration Two 


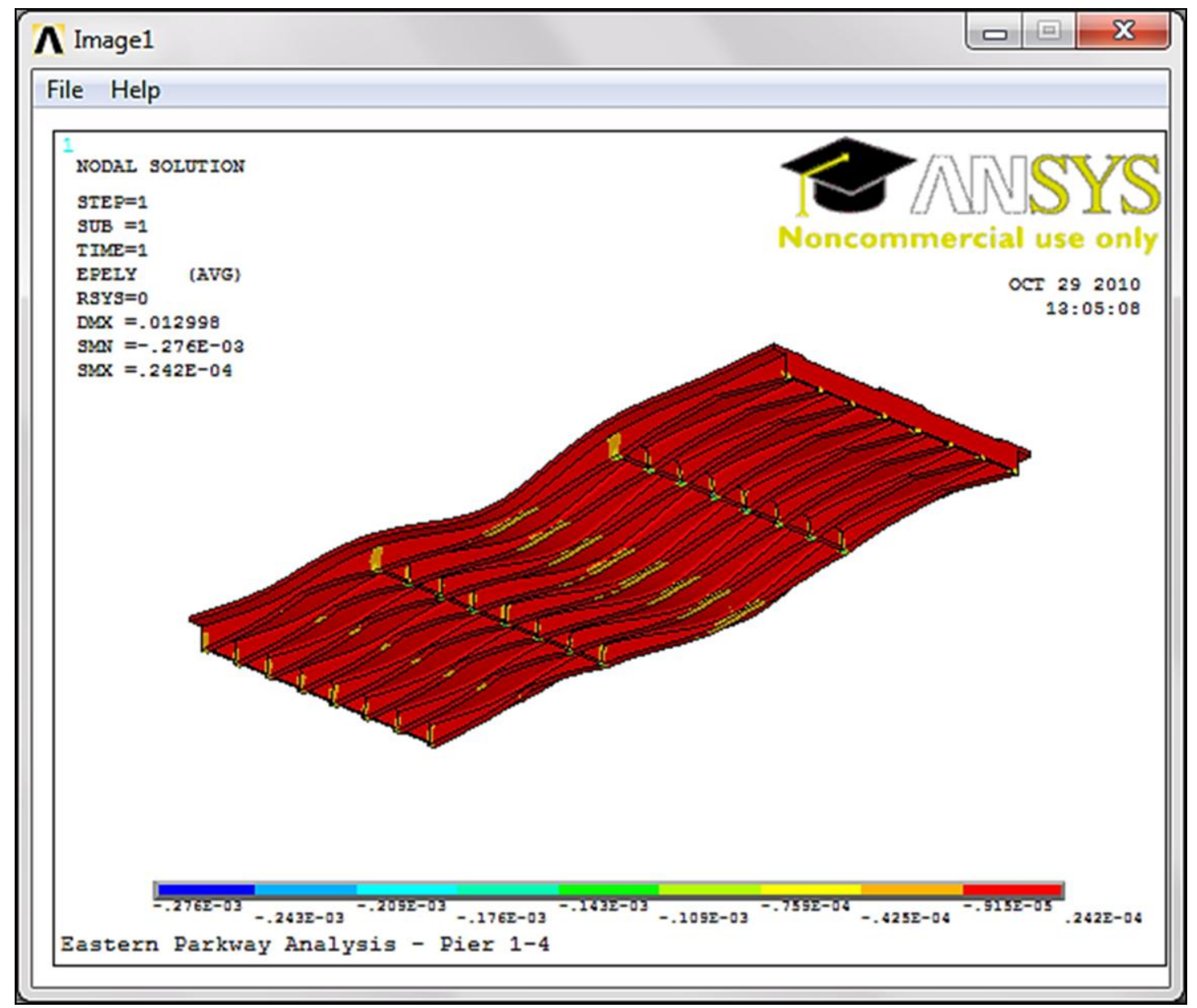

FIGURE 159 - Y-Component of Strain for Iteration Two As Viewed From Below 


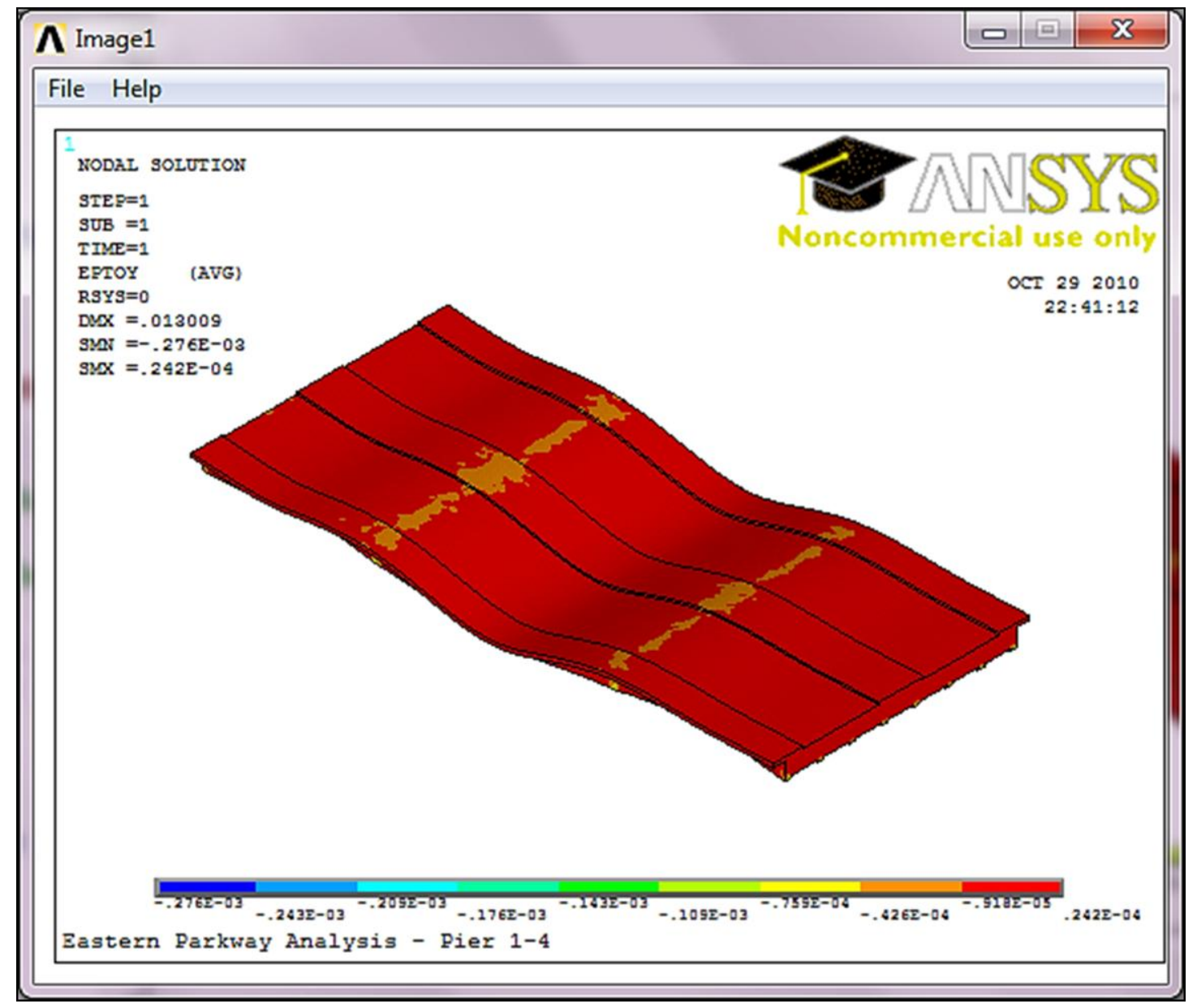

FIGURE 160 - Y-Component of Strain for Iteration Three 


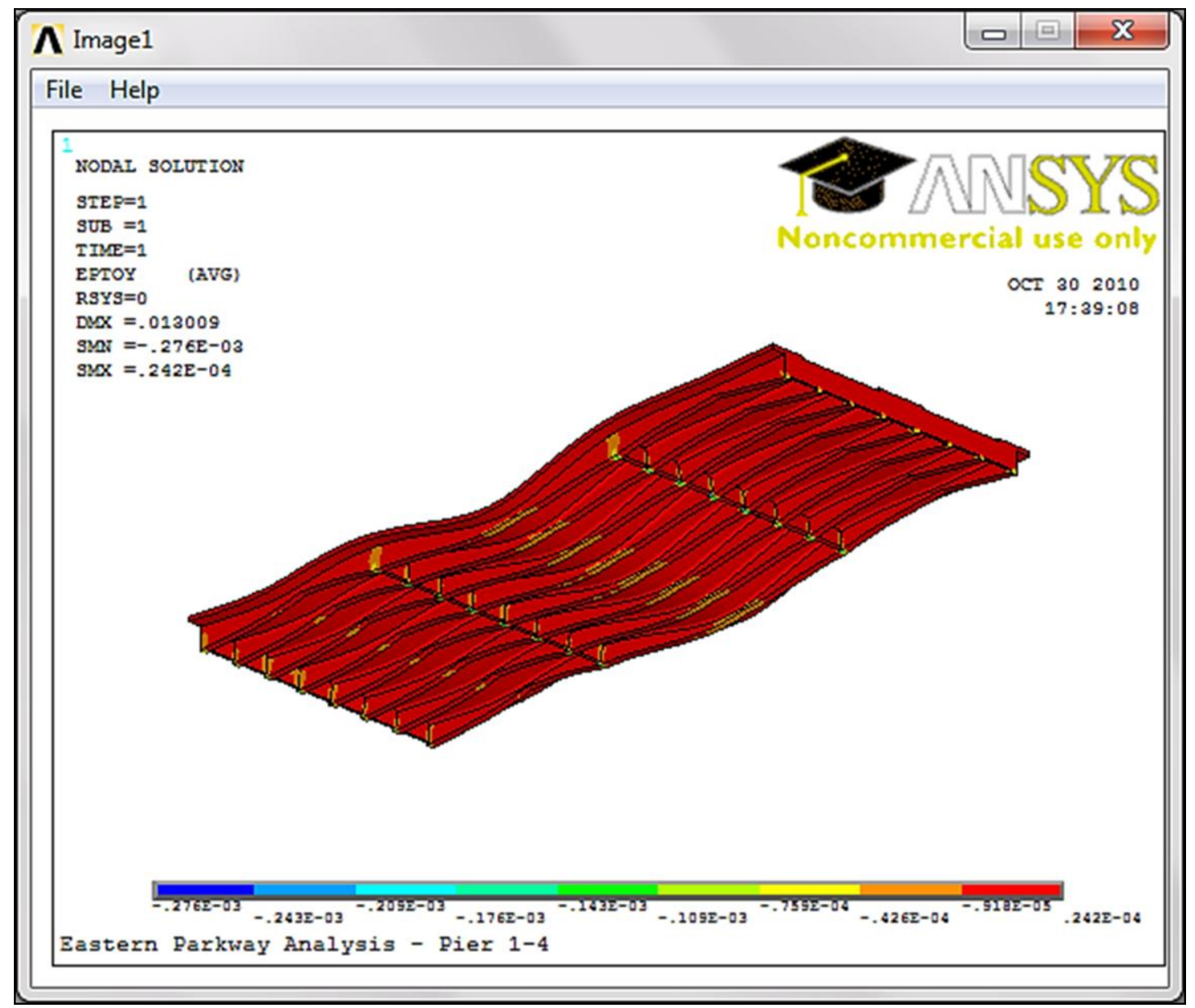

FIGURE 161 - Y-Component of Strain for Iteration Three As Viewed From Below 


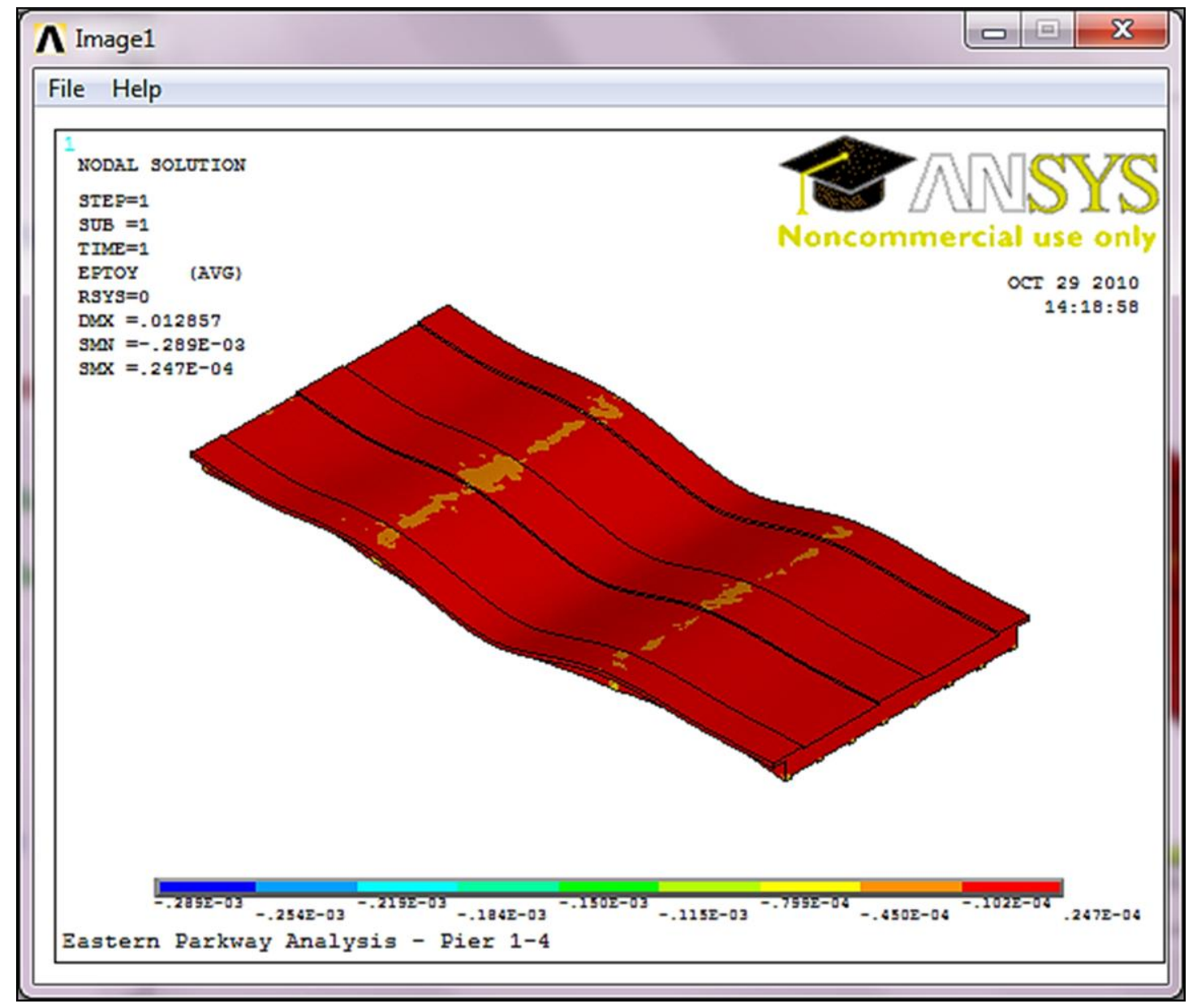

FIGURE 162 - Y-Component of Strain for Iteration Four 


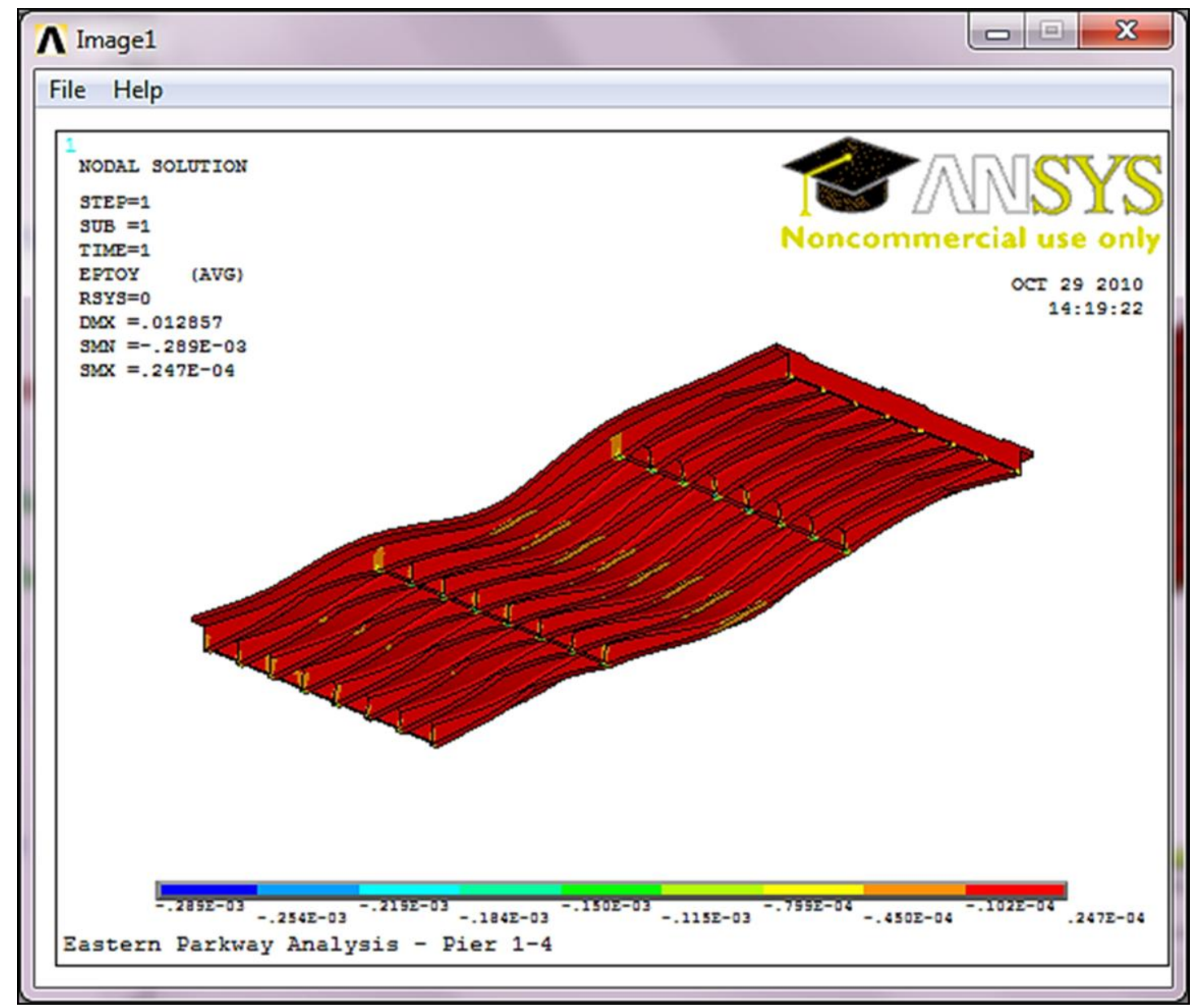

FIGURE 163 - Y-Component of Strain for Iteration Four As Viewed From Below 


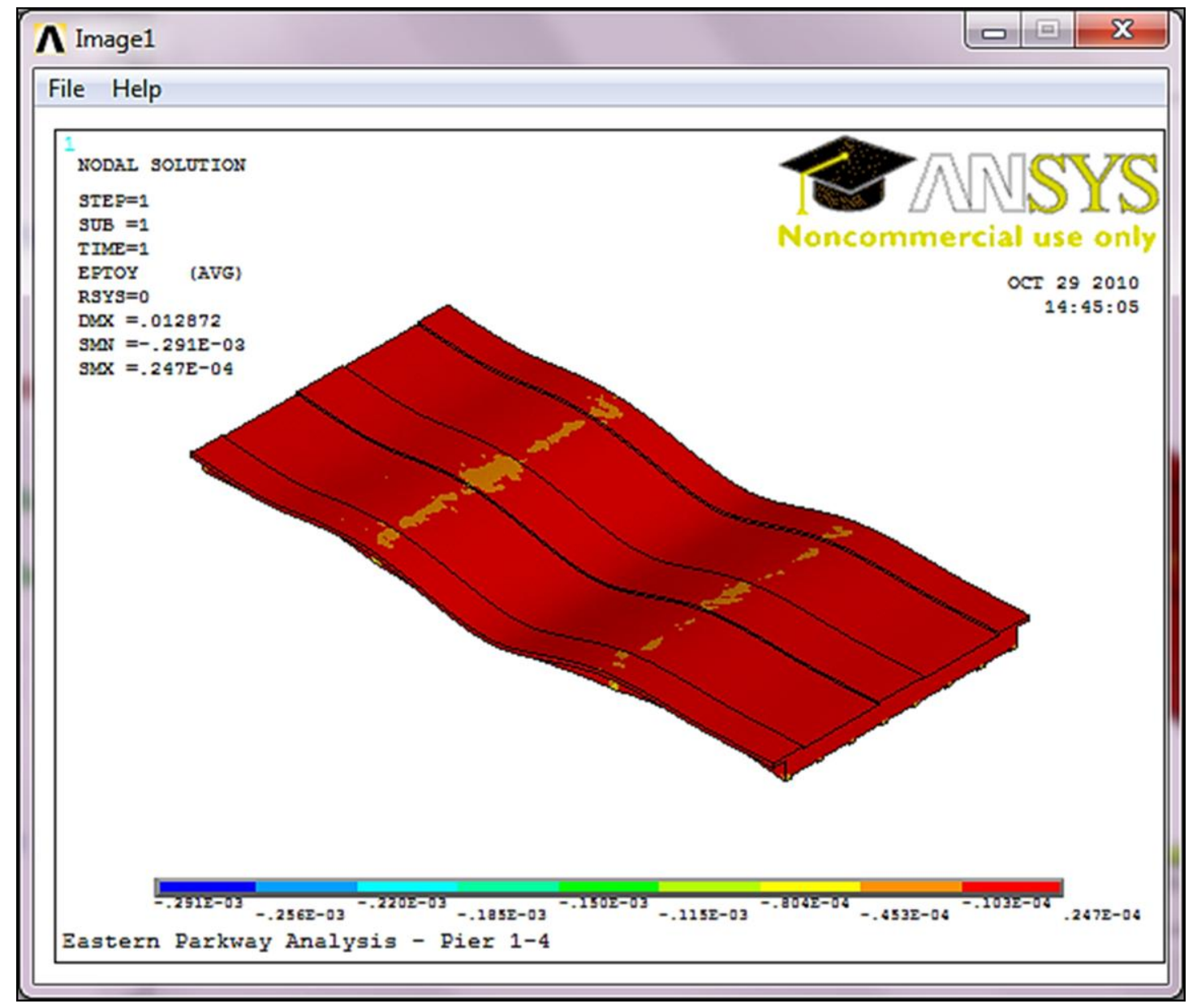

FIGURE 164 - Y-Component of Strain for Iteration Five 


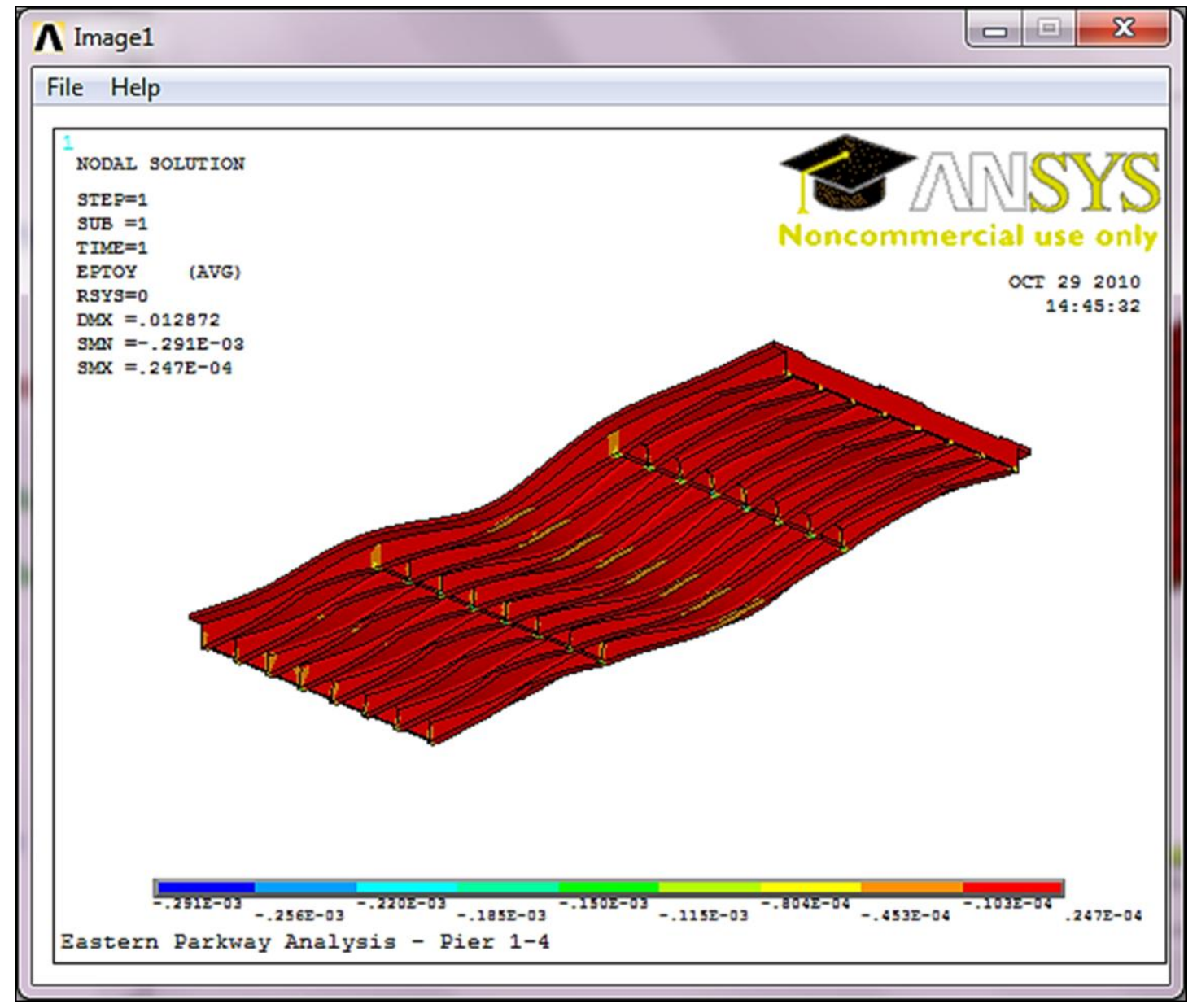

FIGURE 165 - Y-Component of Strain for Iteration Five As Viewed From Below 


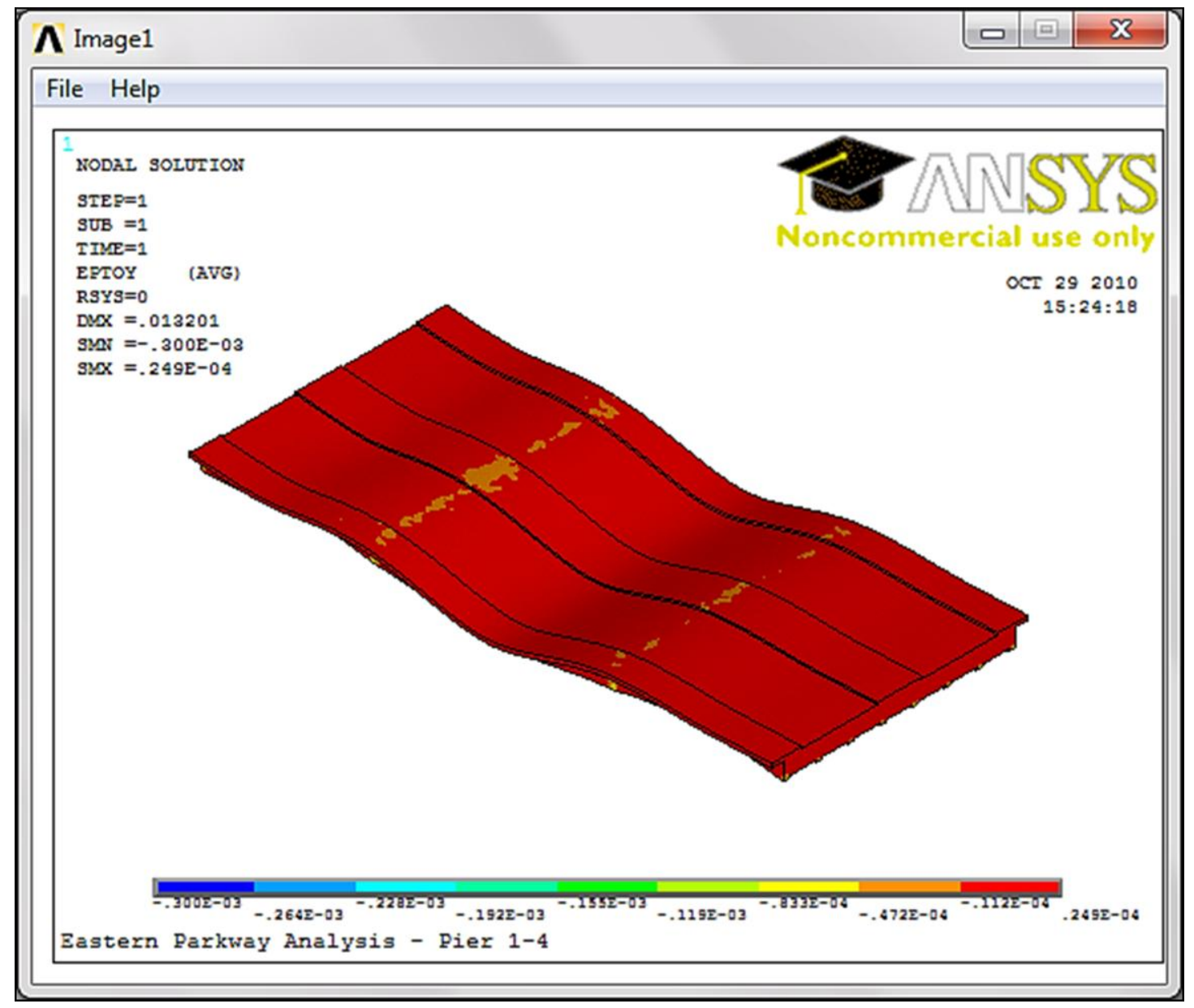

FIGURE 166 - Y-Component of Strain for Iteration Six 


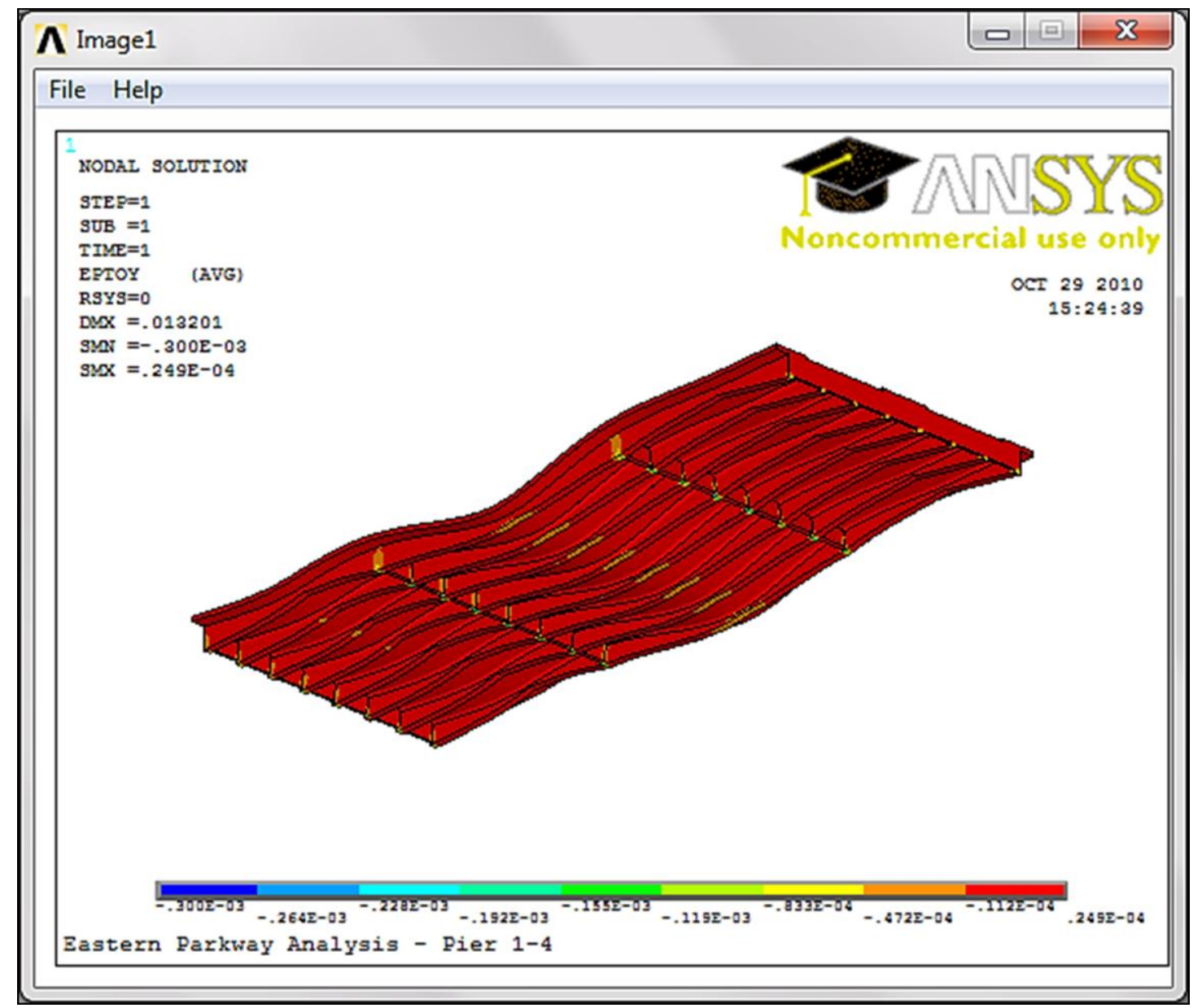

FIGURE 167 - Y-Component of Strain for Iteration Six As Viewed From Below 


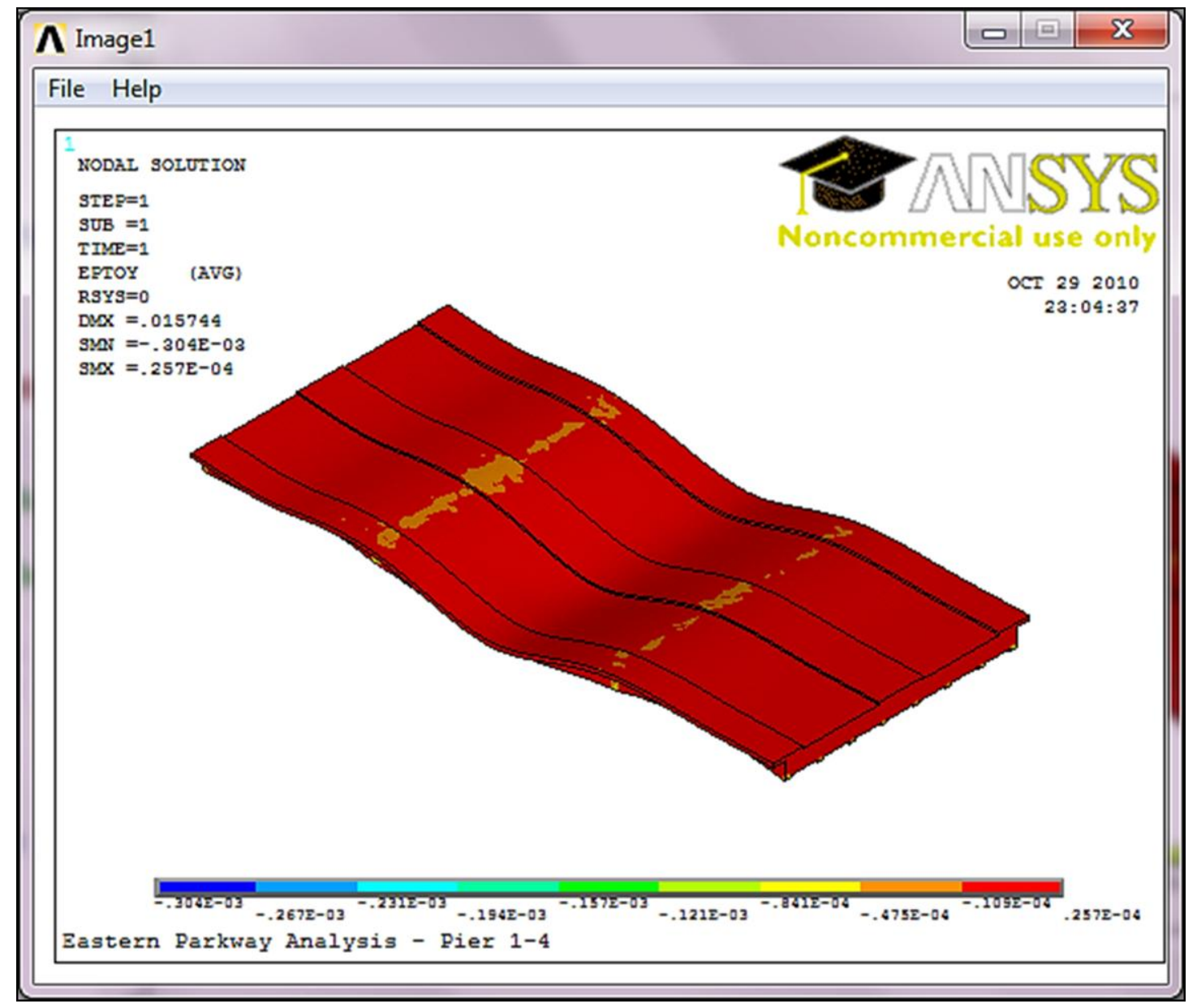

FIGURE 168 - Y-Component of Strain for Iteration Seven 


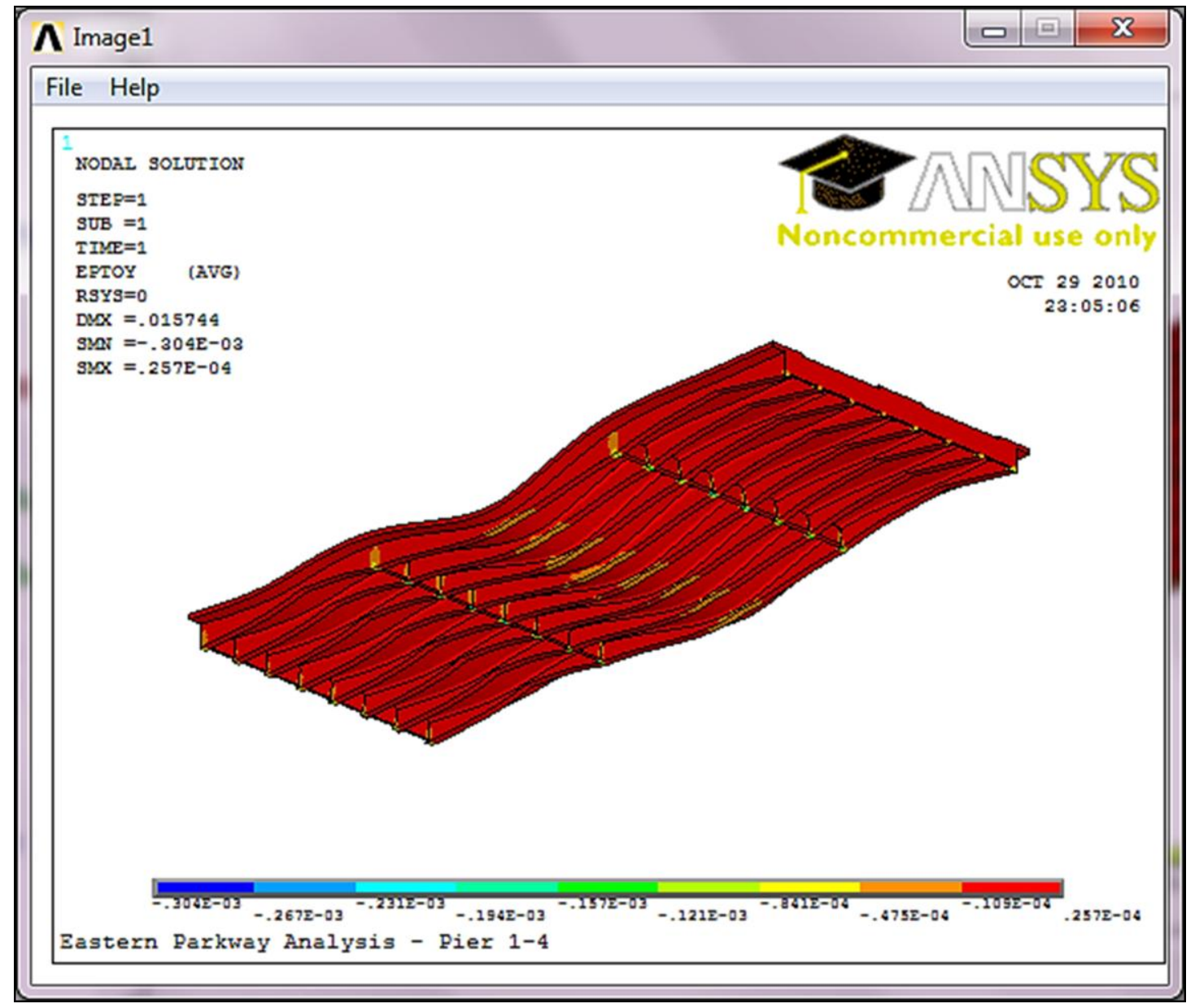

FIGURE 169 - Y-Component of Strain for Iteration Seven As Viewed From Below 


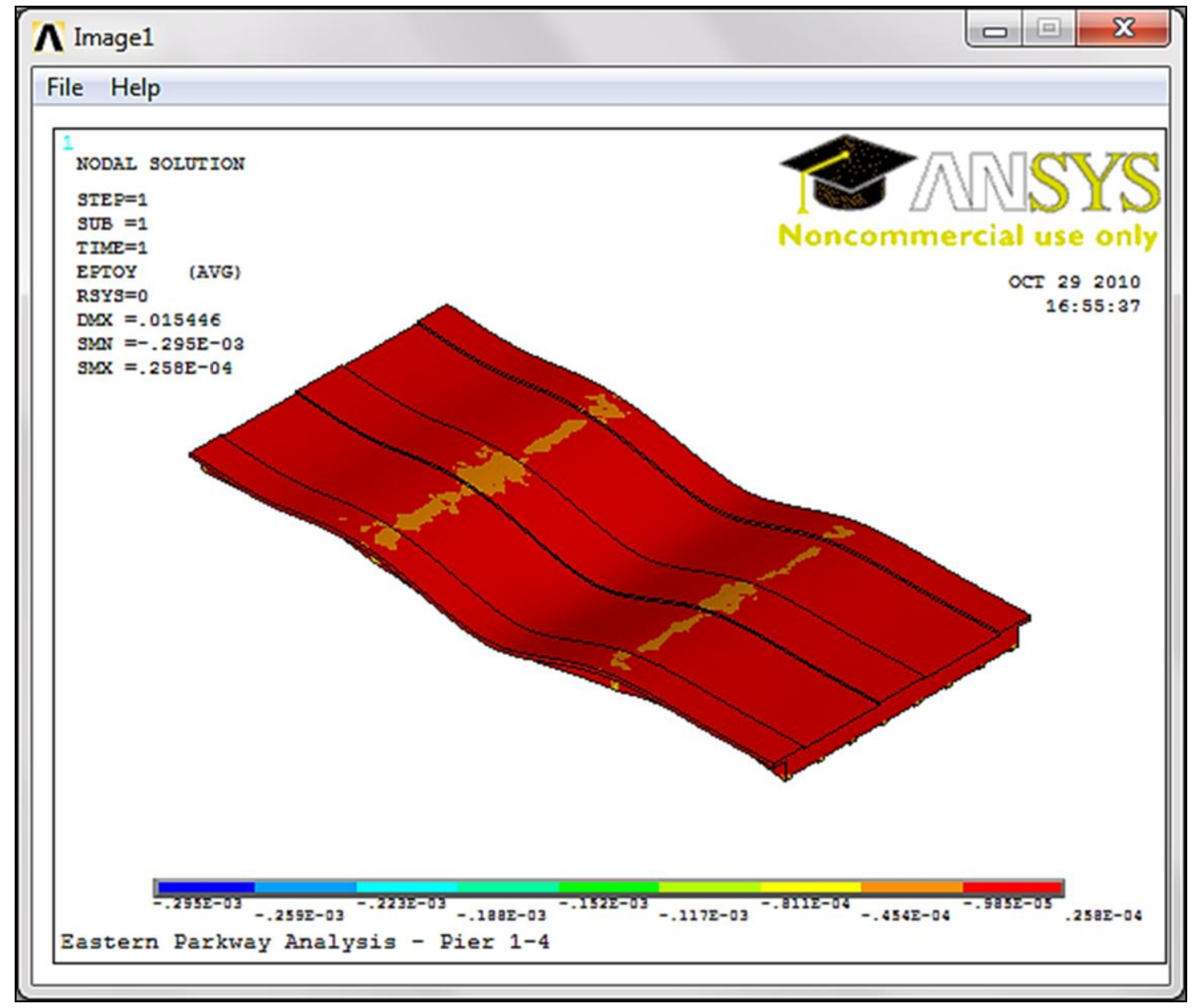

FIGURE 170 - Y-Component of Strain for Iteration Eight 


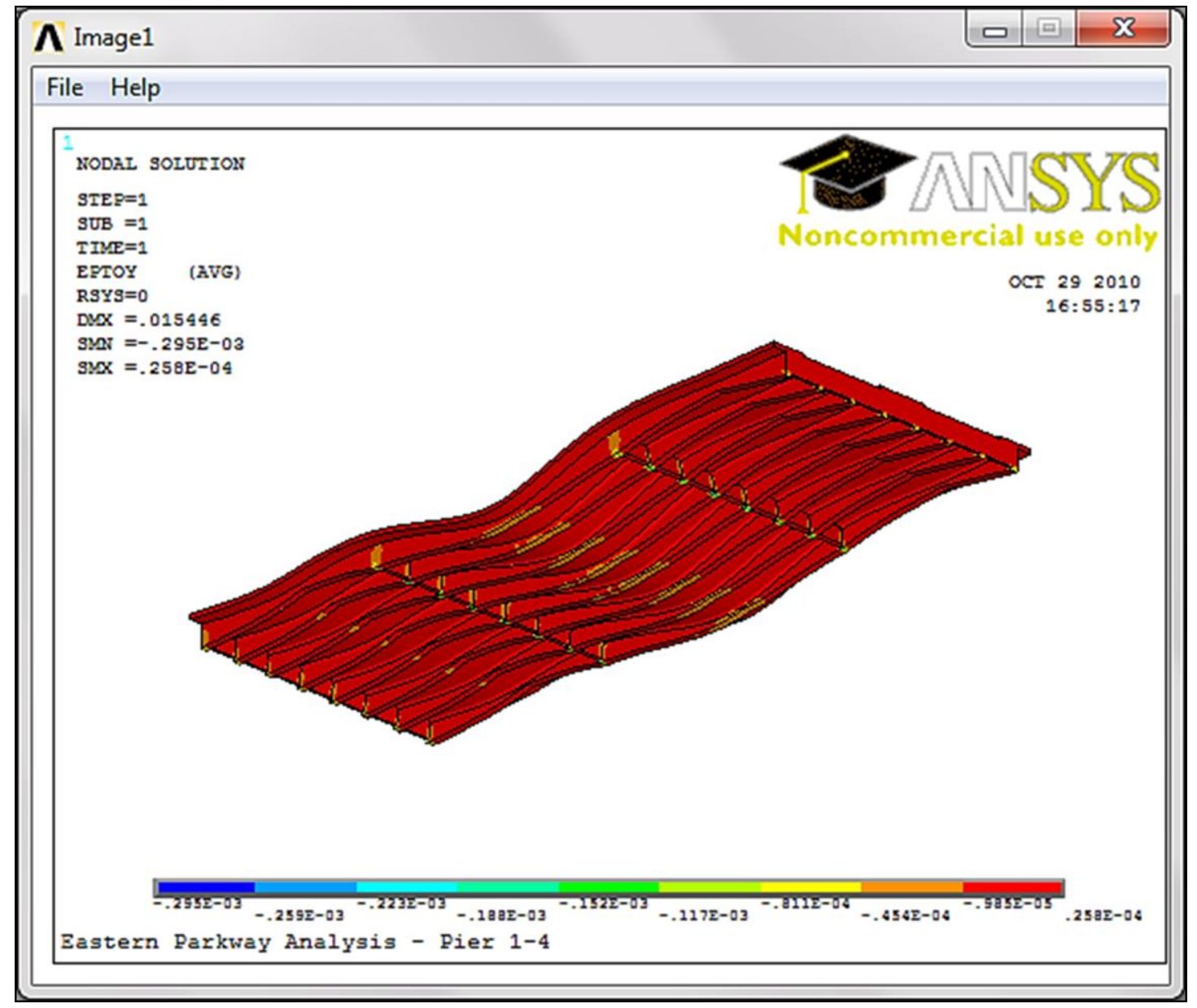

FIGURE 171 - Y-Component of Strain for Iteration Eight As Viewed From Below 


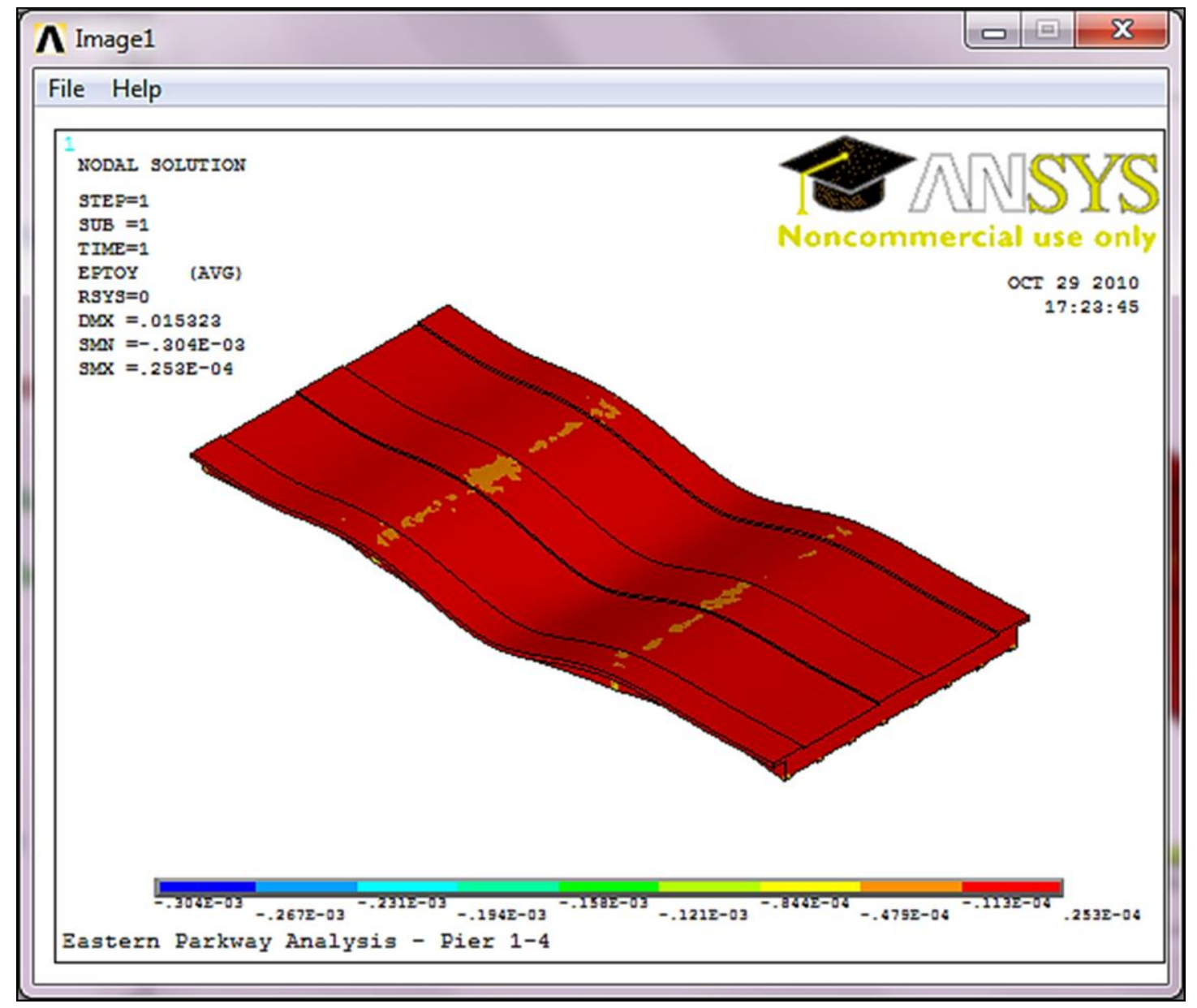

FIGURE 172 - Y-Component of Strain for Iteration Nine 


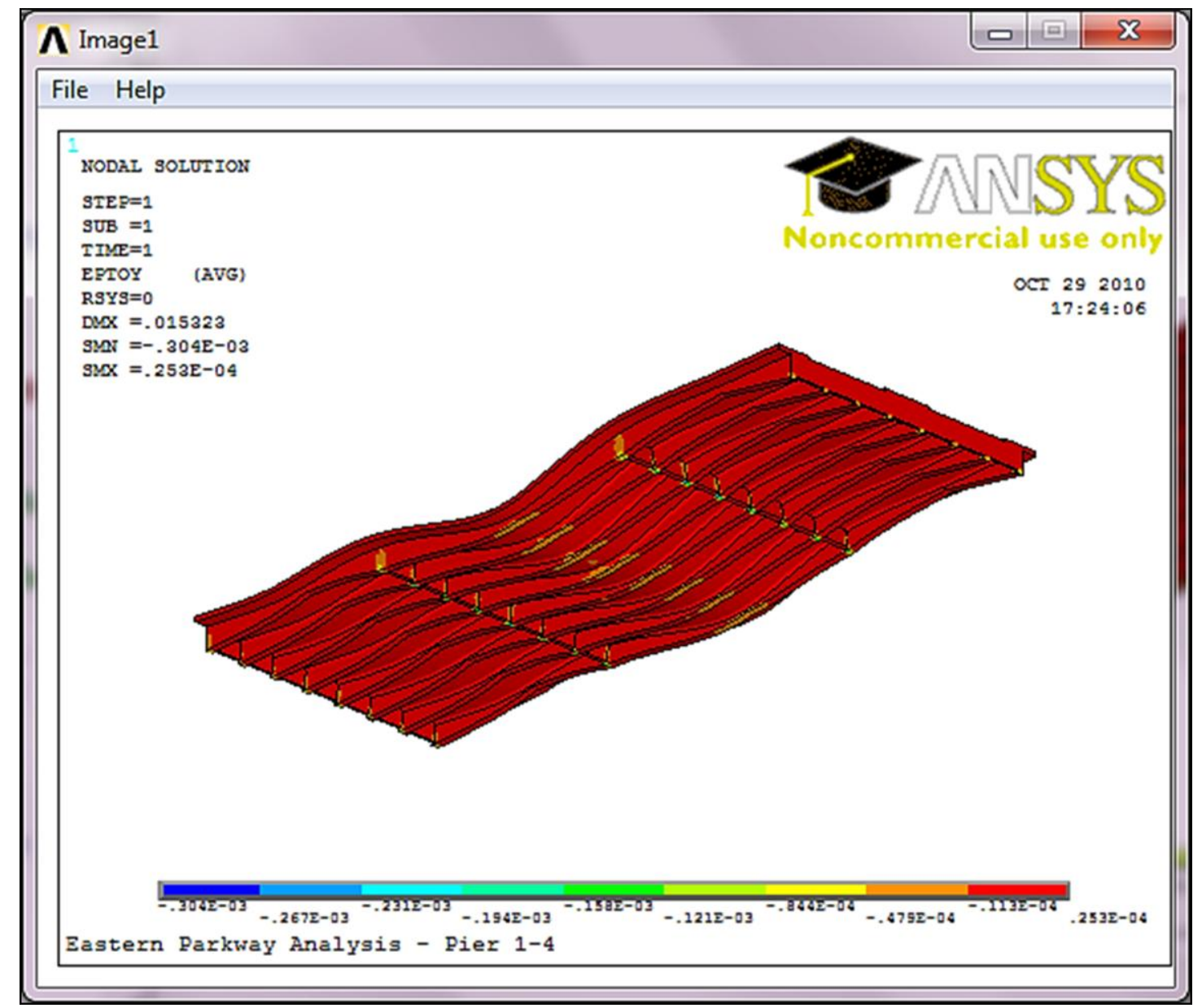

FIGURE 173 - Y-Component of Strain for Iteration Nine As Viewed From Below 


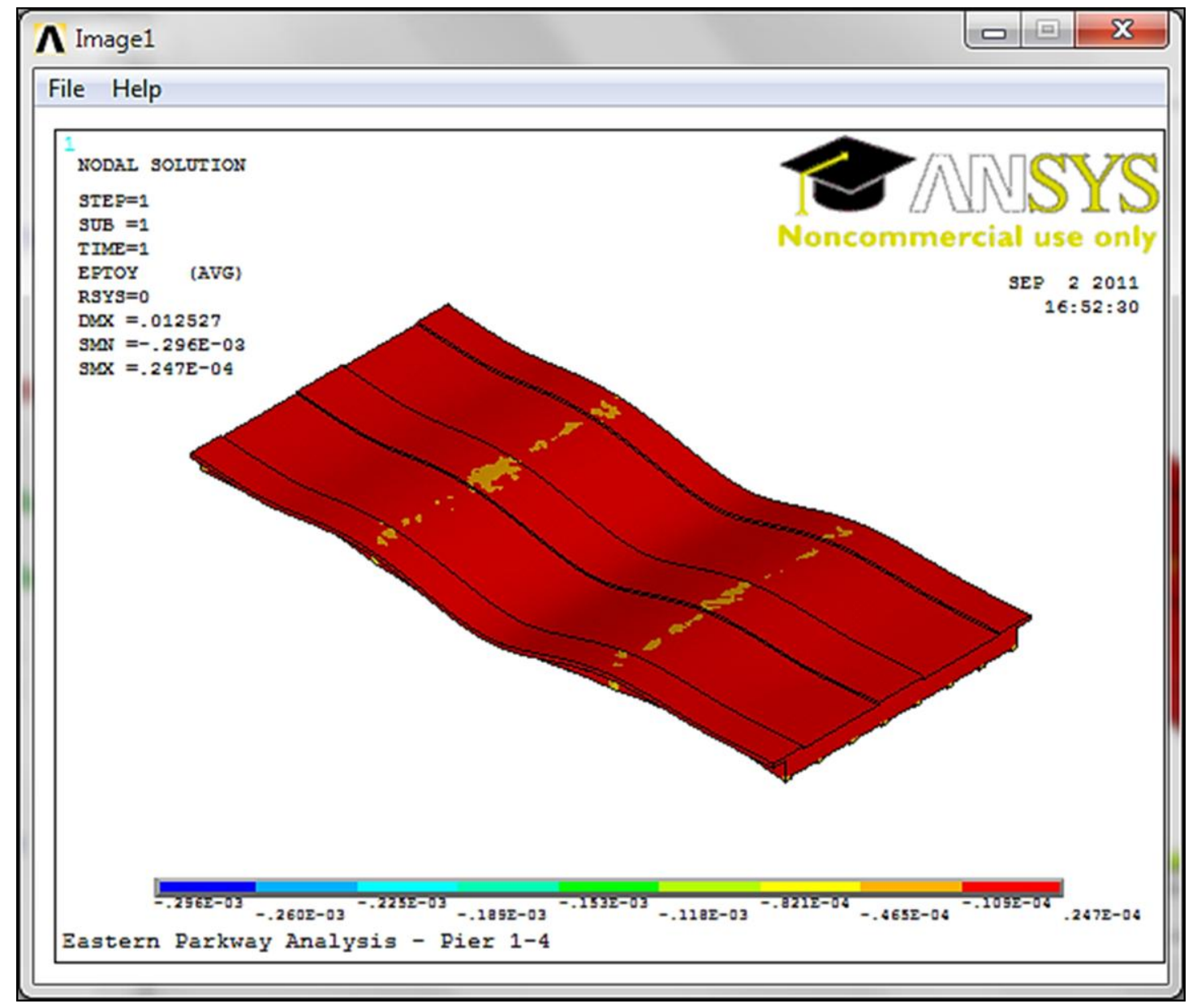

FIGURE 174 - Y-Component of Strain for Iteration 10 


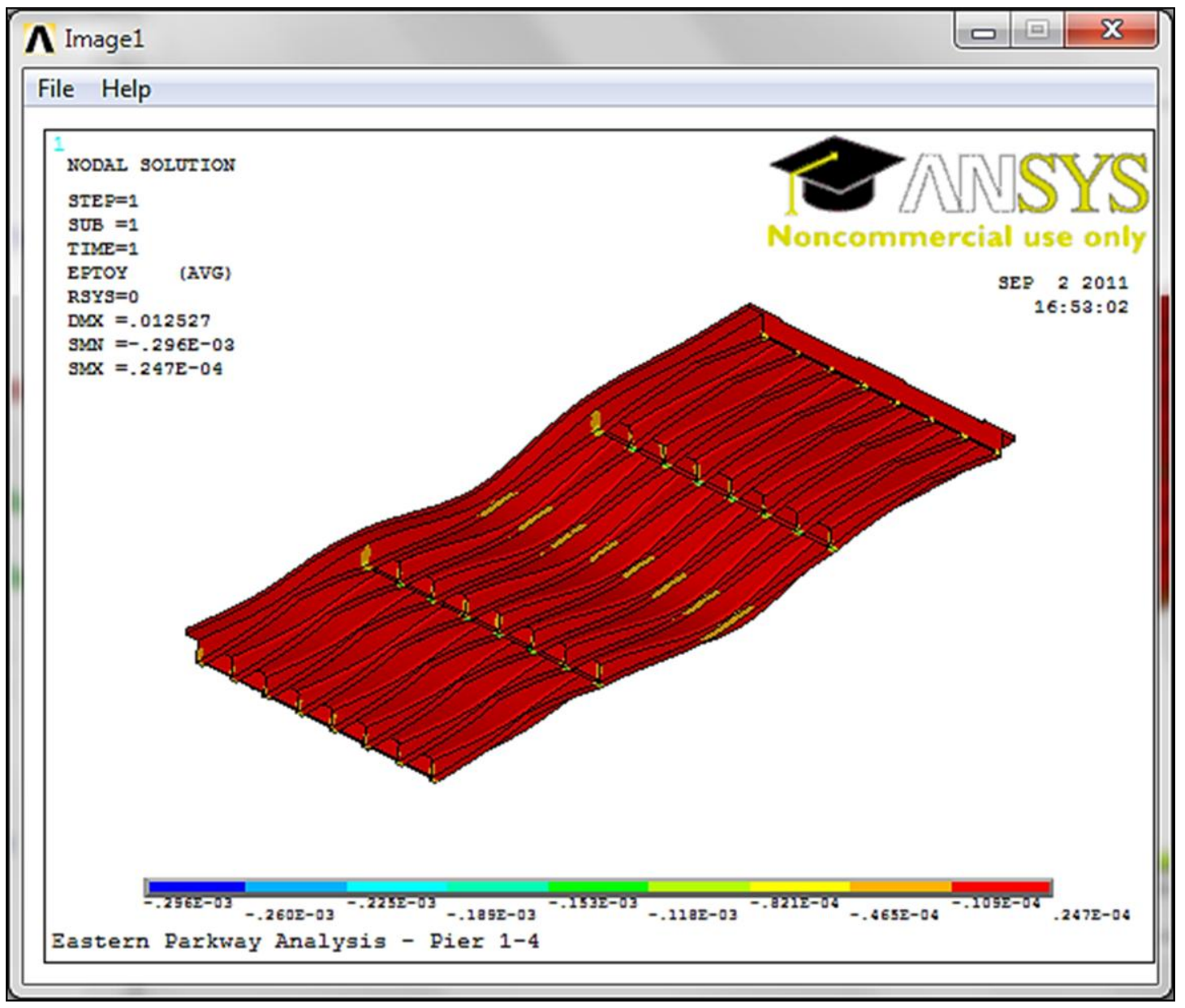

FIGURE 175 - Y-Component of Strain for Iteration 10 As Viewed From Below 


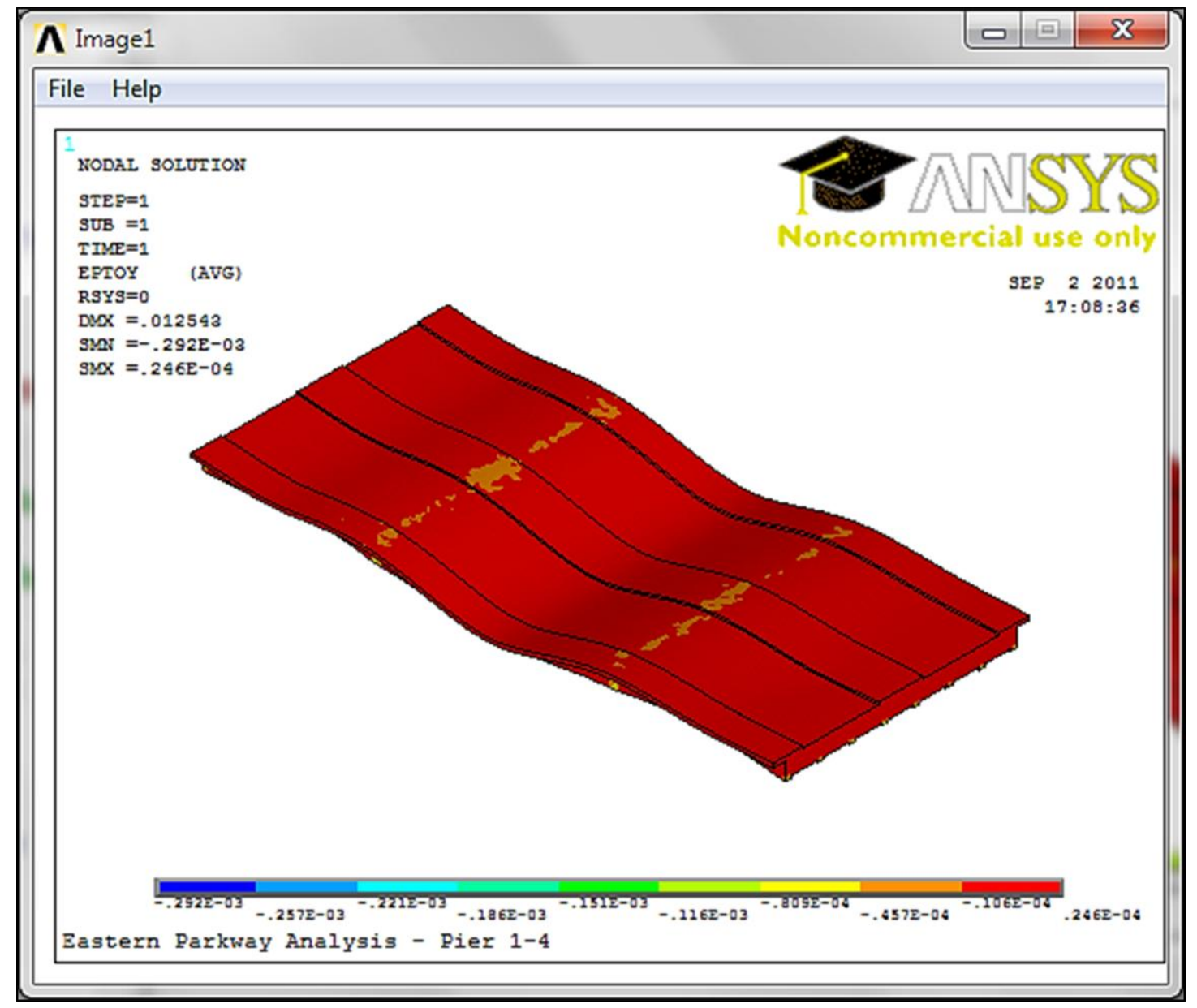

FIGURE 176 - Y-Component of Strain for Iteration 11 


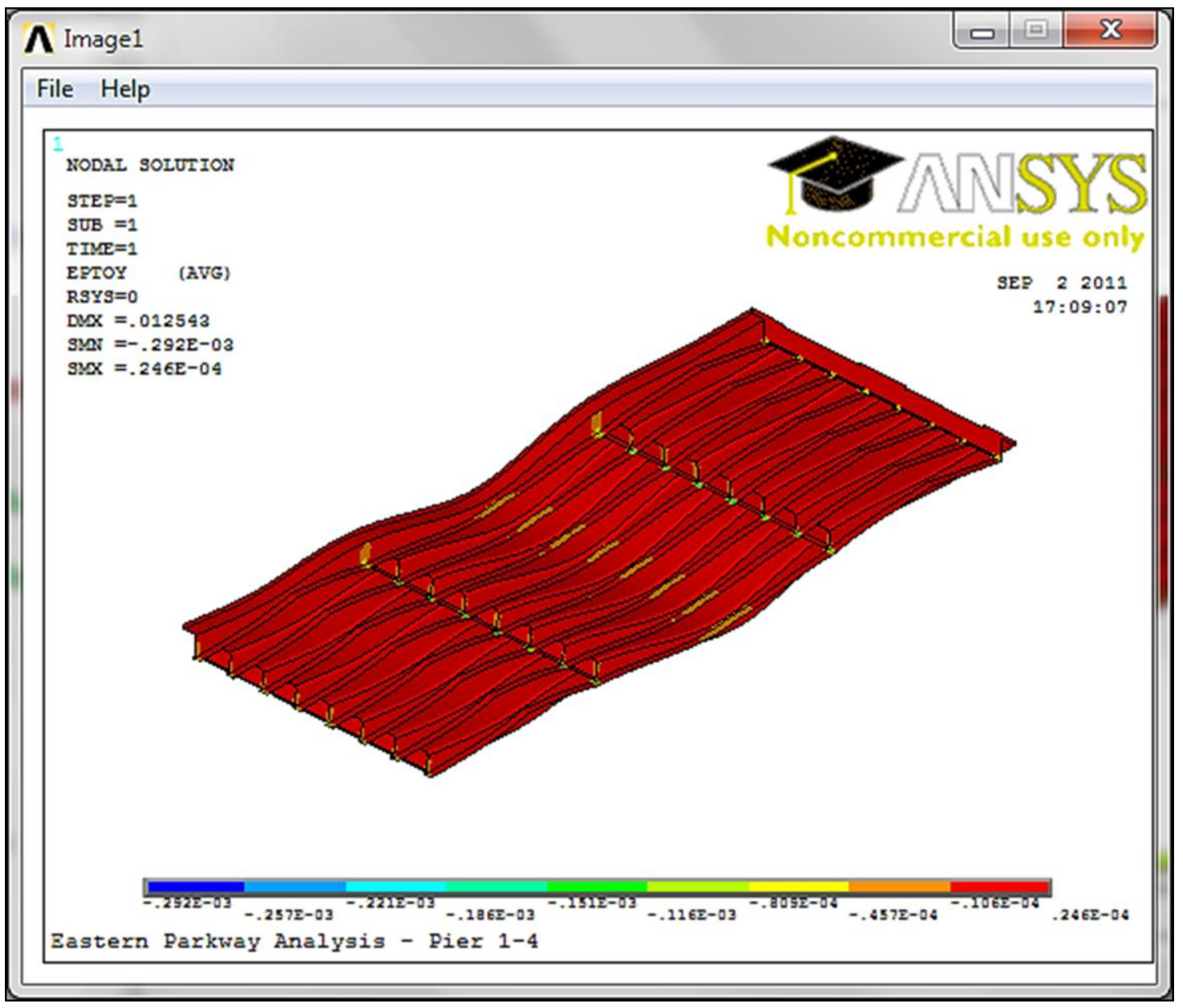

FIGURE 177 - Y-Component of Strain for Iteration 11 As Viewed From Below 


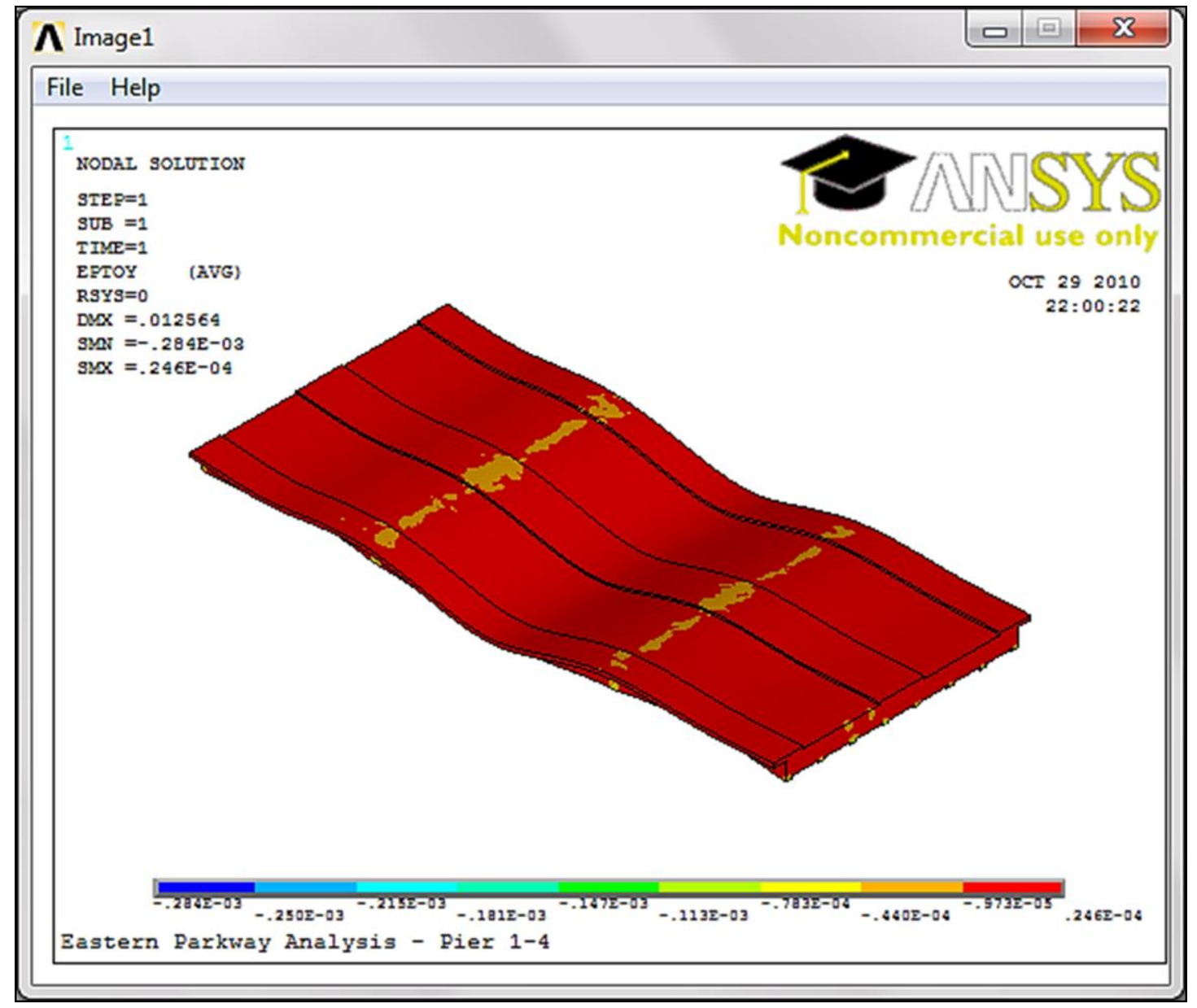

FIGURE 178 - Y-Component of Strain for Iteration 12 


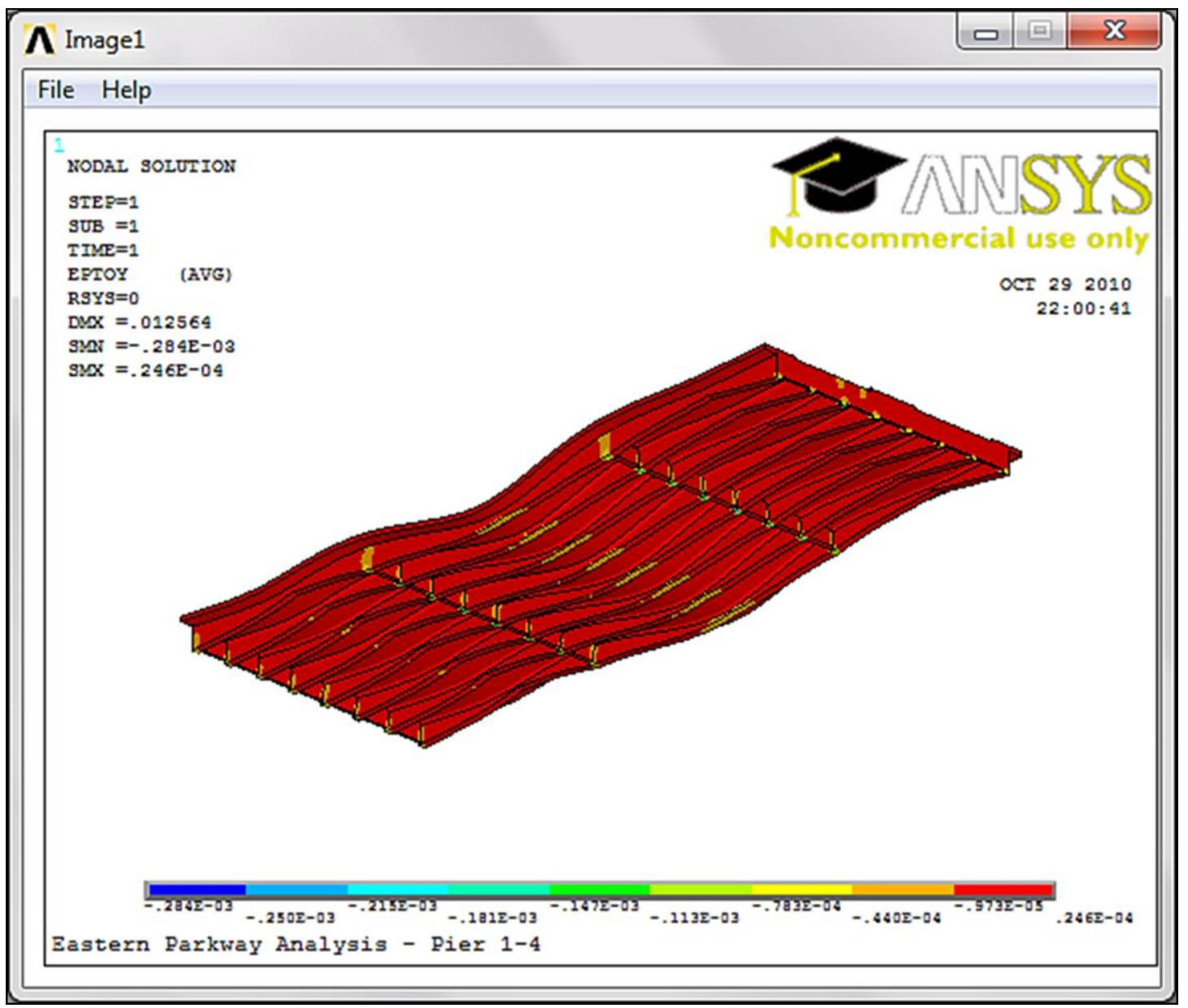

FIGURE 179 - Y-Component of Strain for Iteration 12 As Viewed From Below 


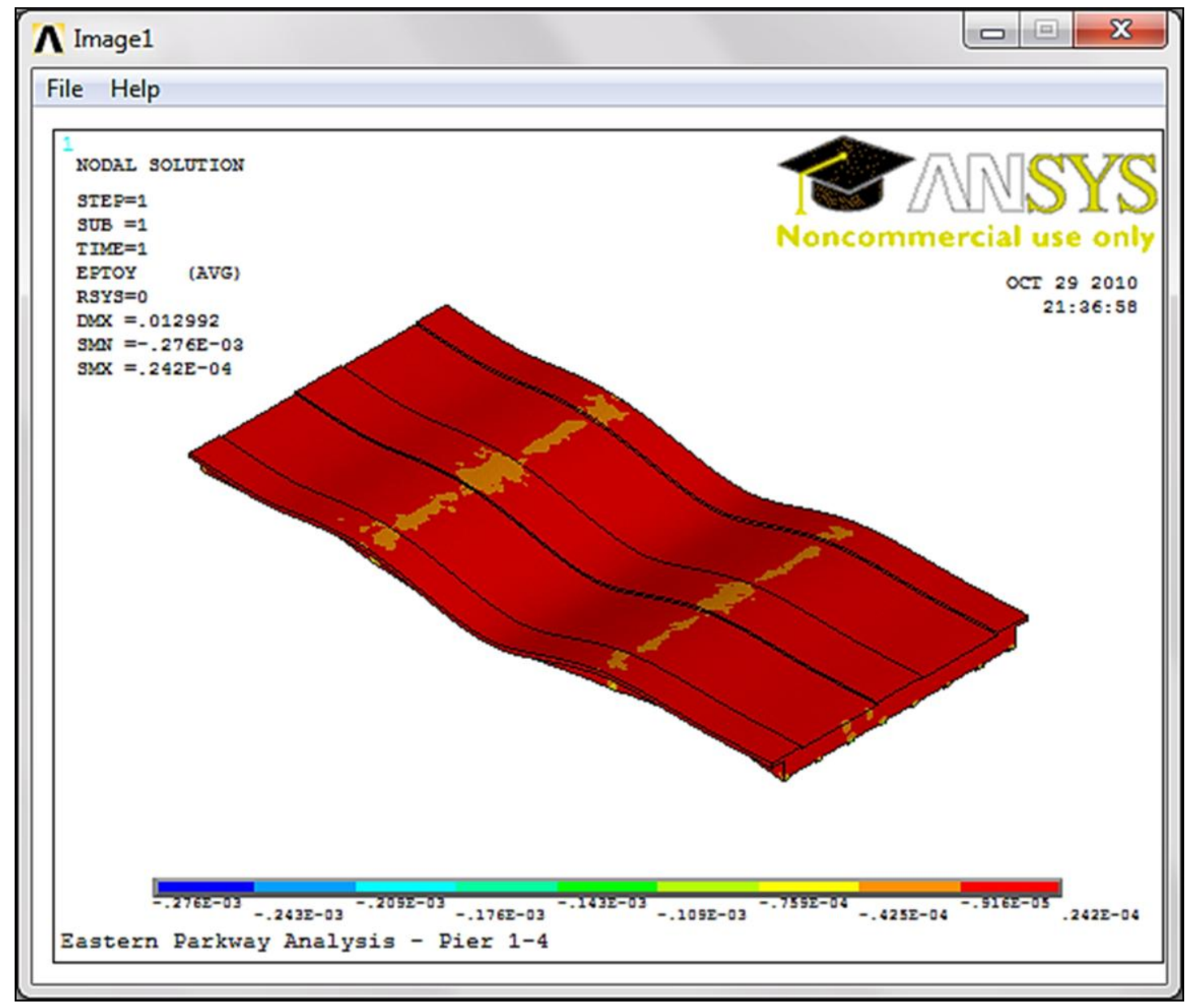

FIGURE 180 - Y-Component of Strain for Iteration 13 


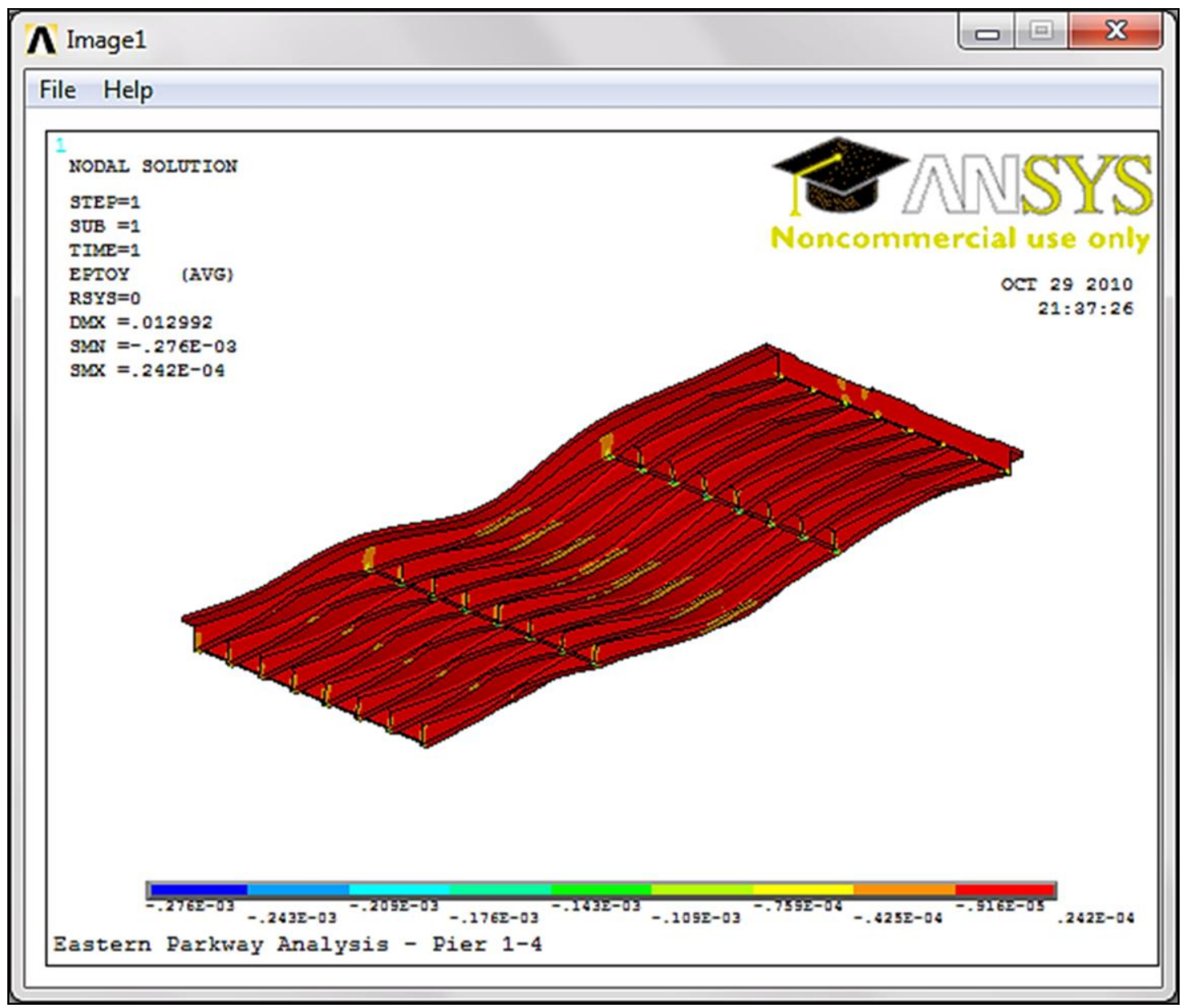

FIGURE 181 - Y-Component of Strain for Iteration 13 As Viewed From Below 


\section{APPENDIX XII}

SCREEN CAPTURES OF FIRST PRINCIPAL STRAINS

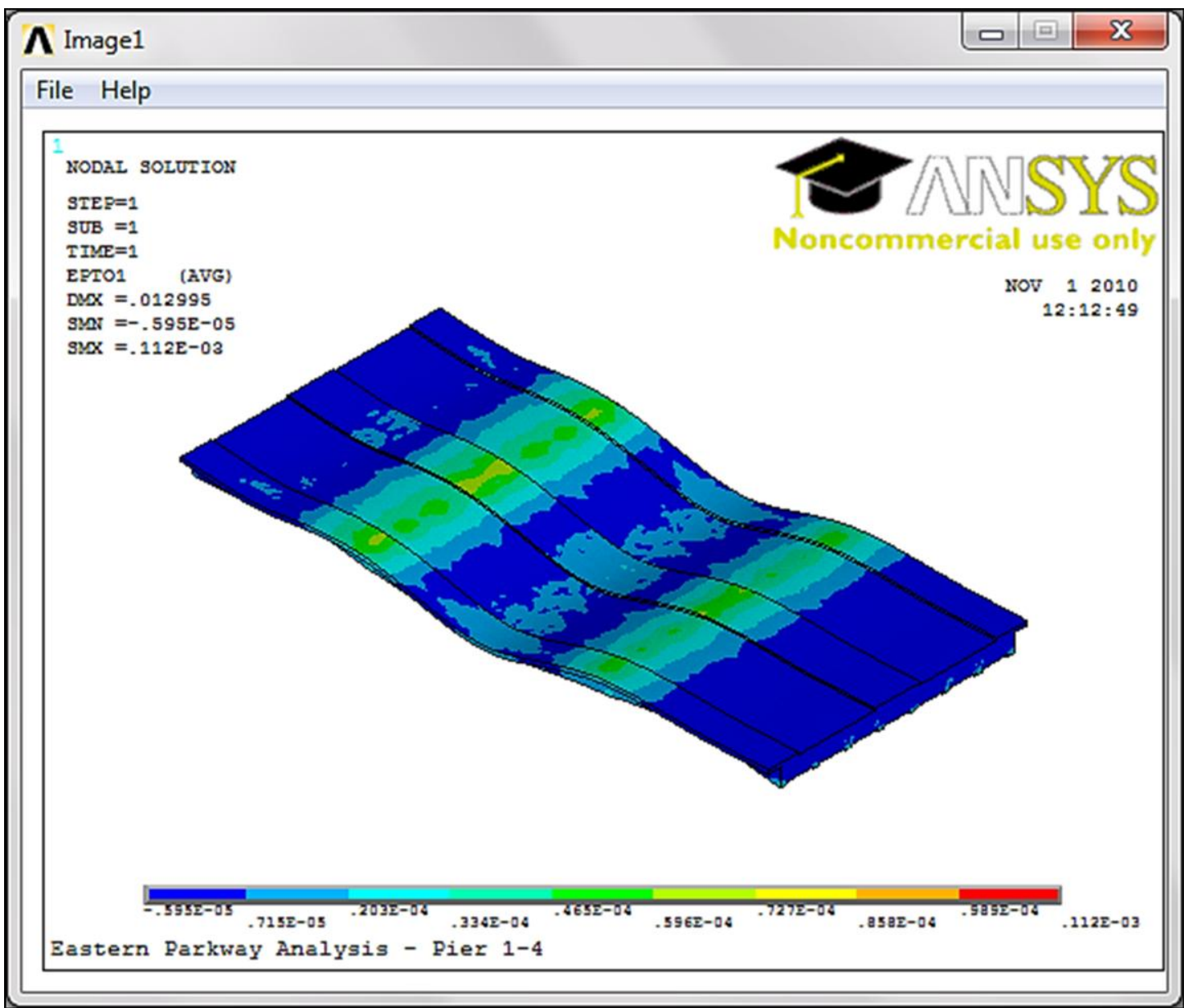

FIGURE 182 - First Principal Strain for Iteration One 


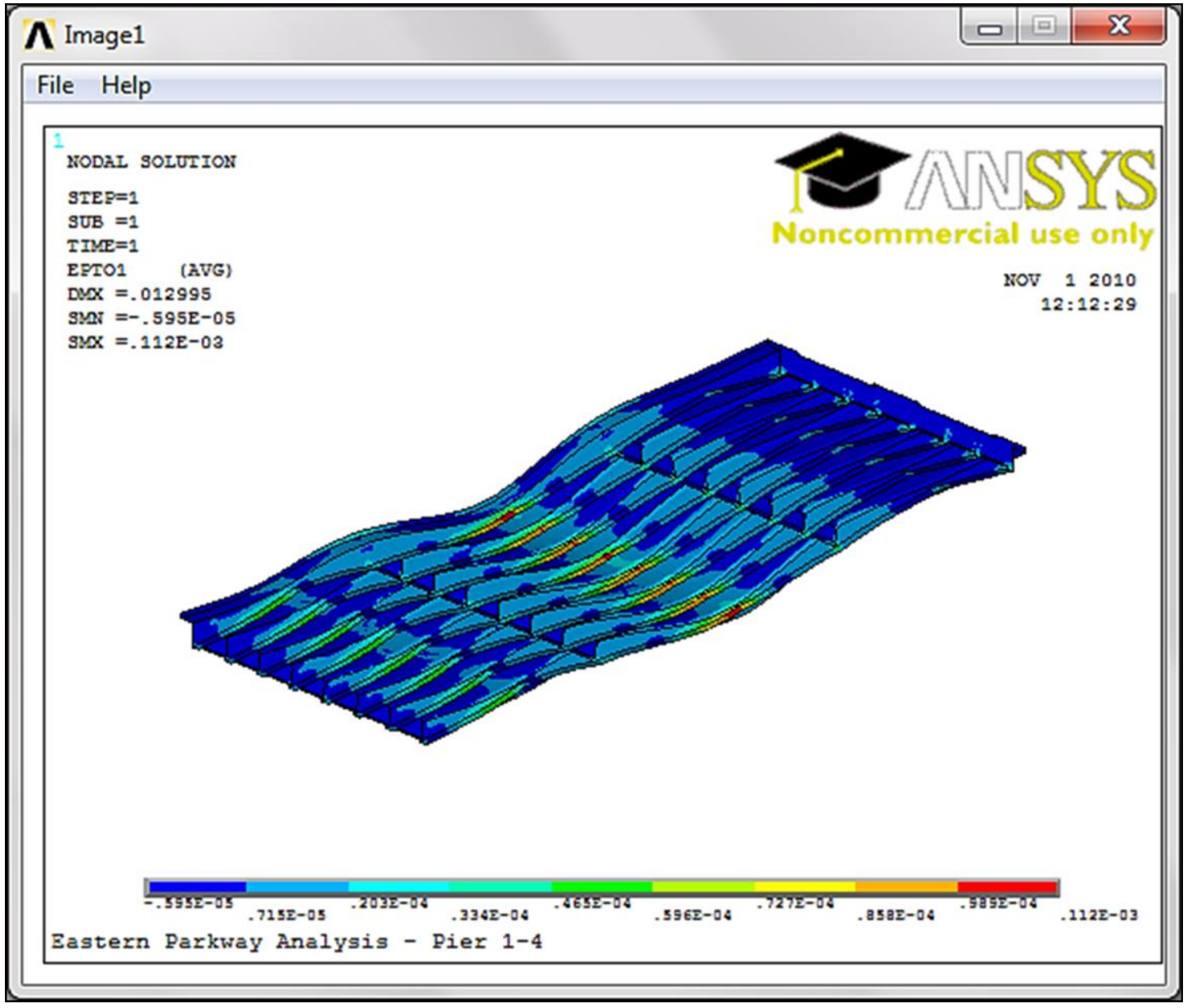

FIGURE 183 - First Principal Strain for Iteration One As Viewed From Below 


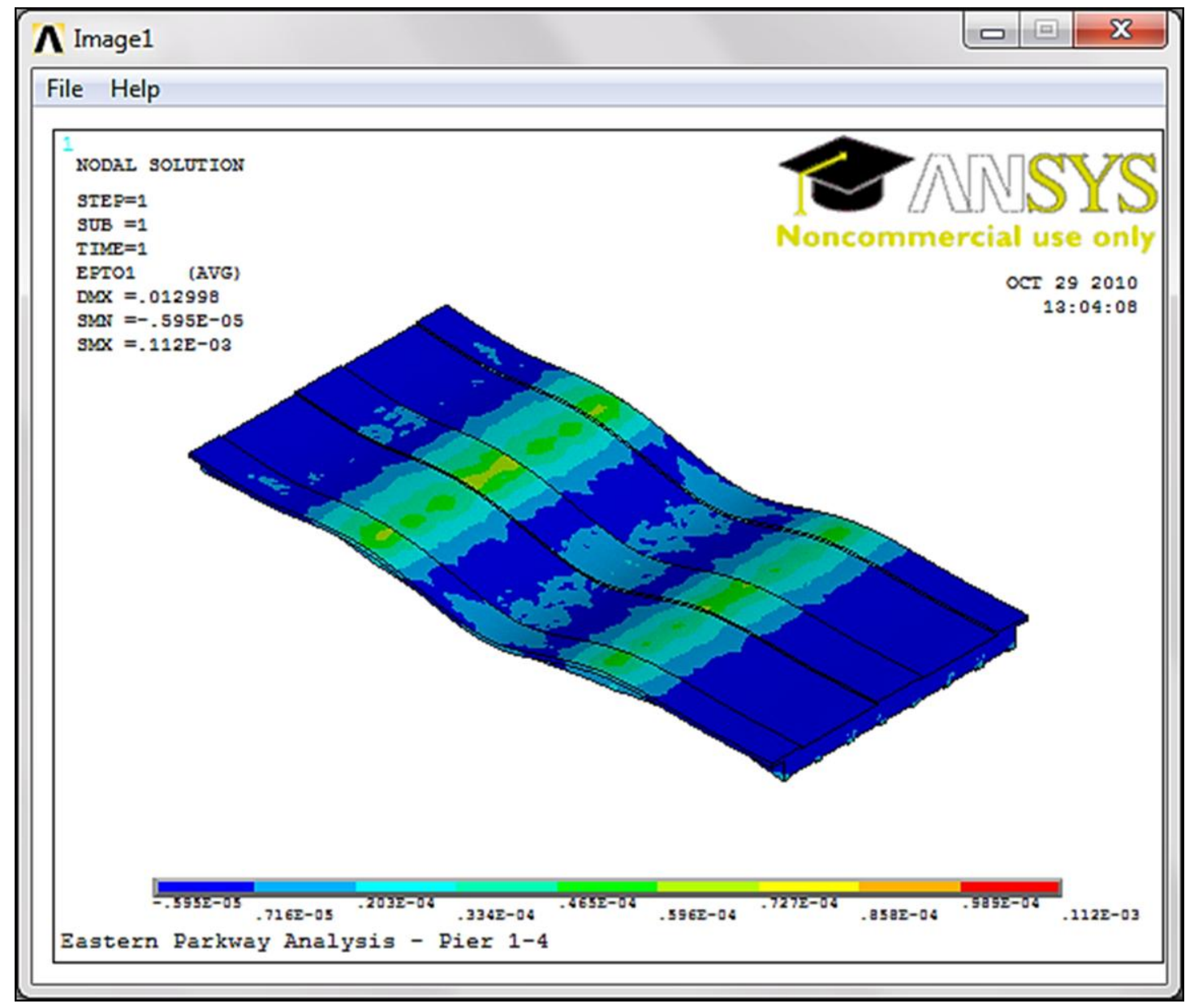

FIGURE 184 - First Principal Strain for Iteration Two 


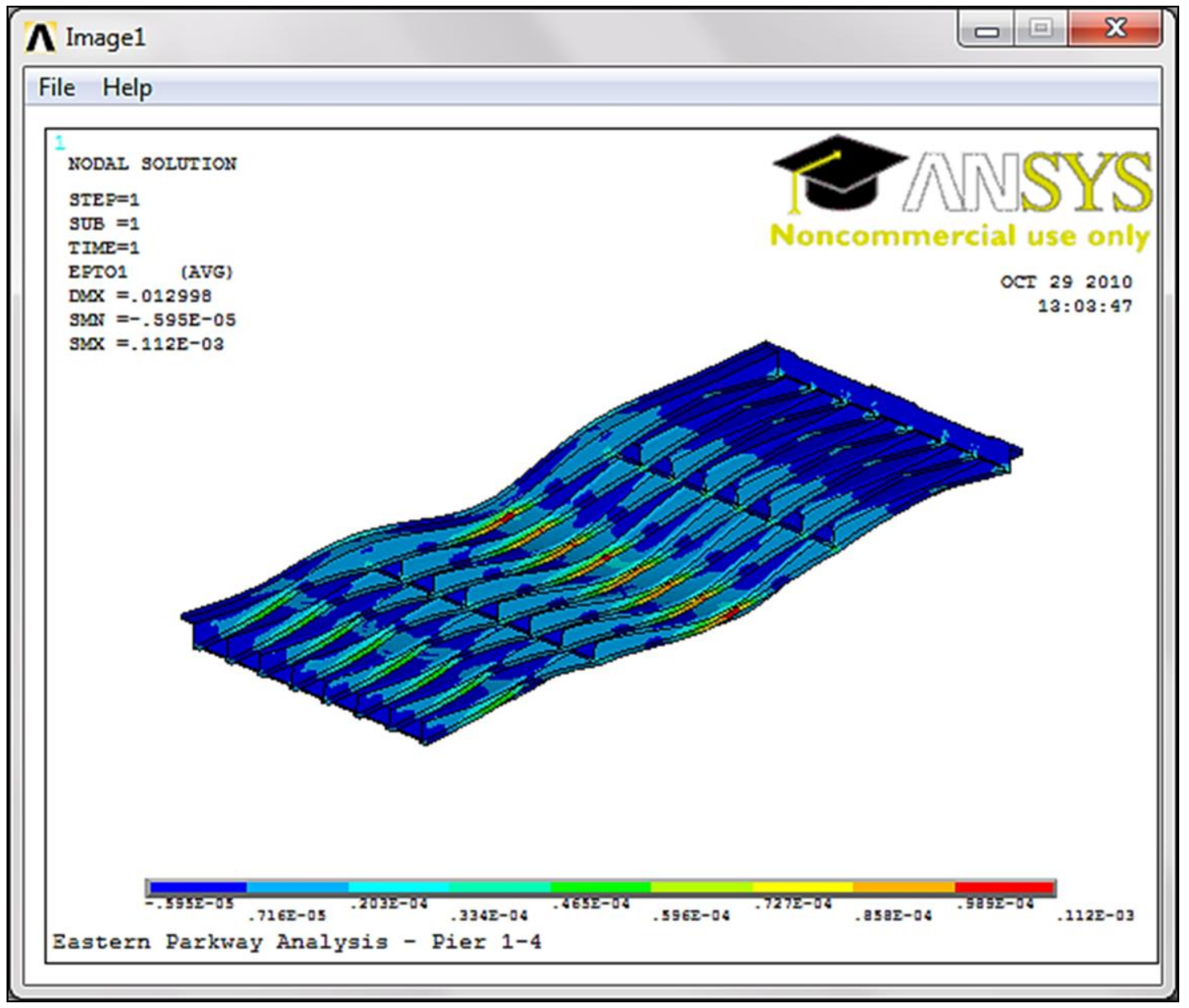

FIGURE 185 - First Principal Strain for Iteration Two As Viewed From Below 


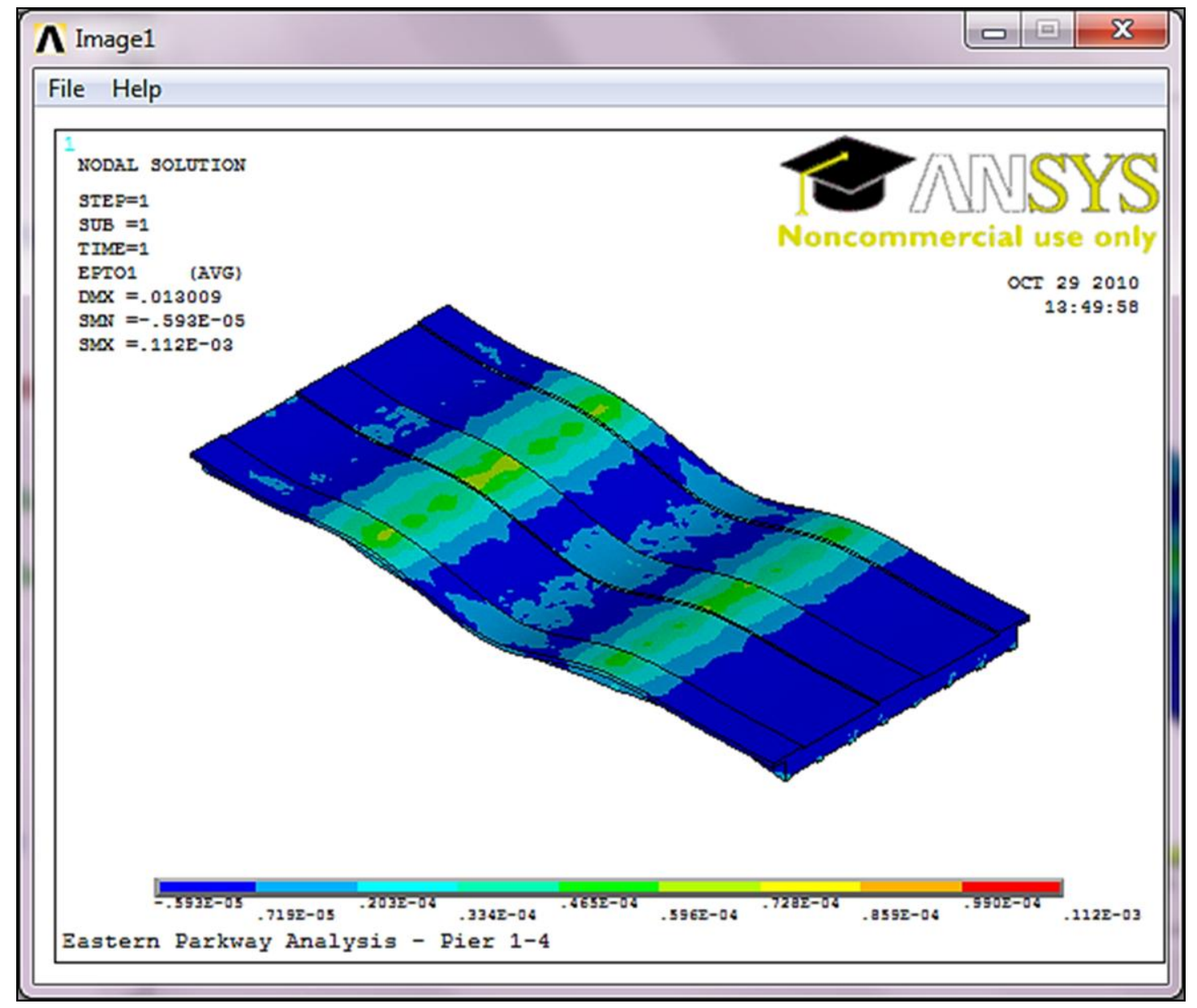

FIGURE 186 - First Principal Strain for Iteration Three 


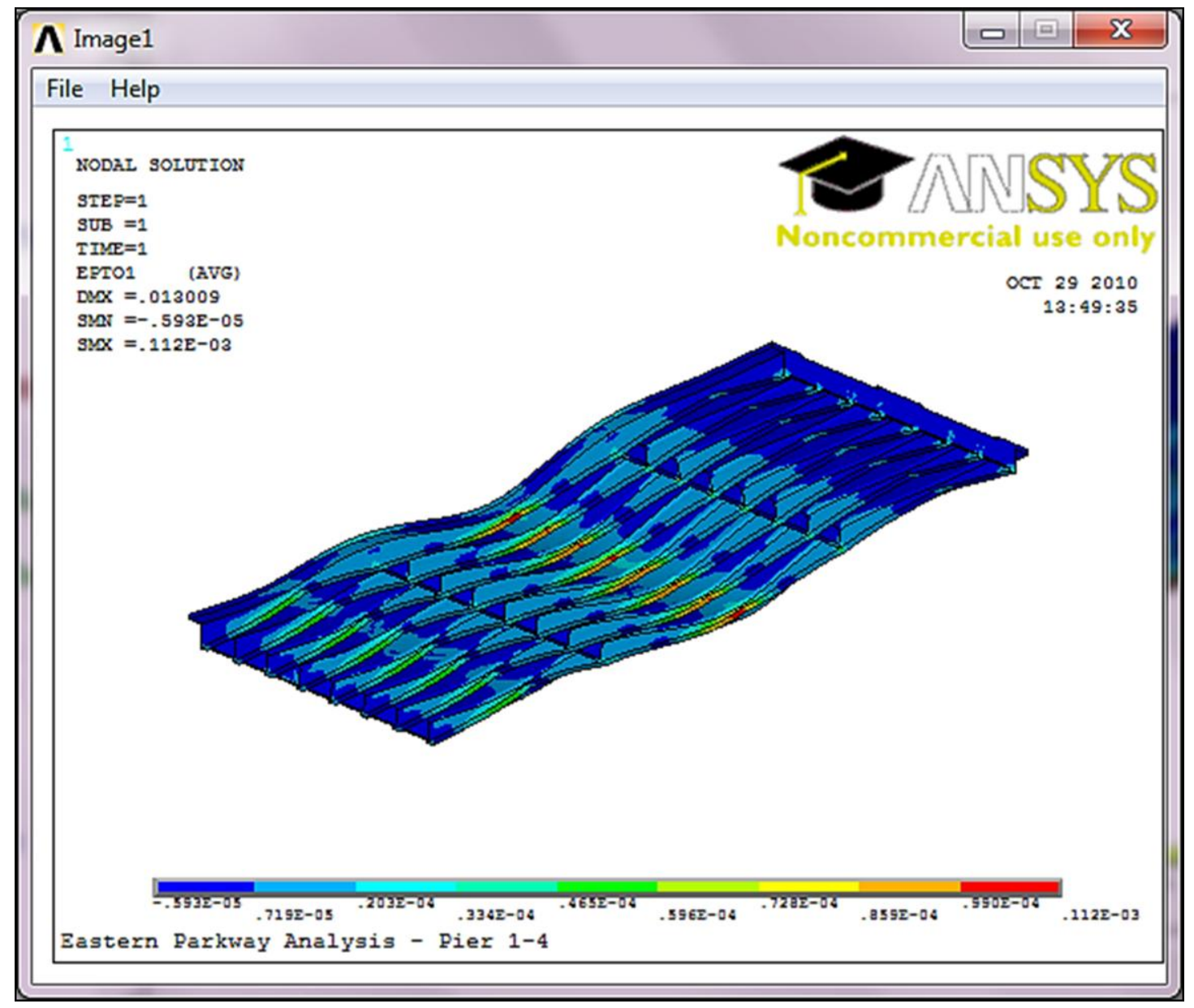

FIGURE 187 - First Principal Strain for Iteration Three As Viewed From Below 


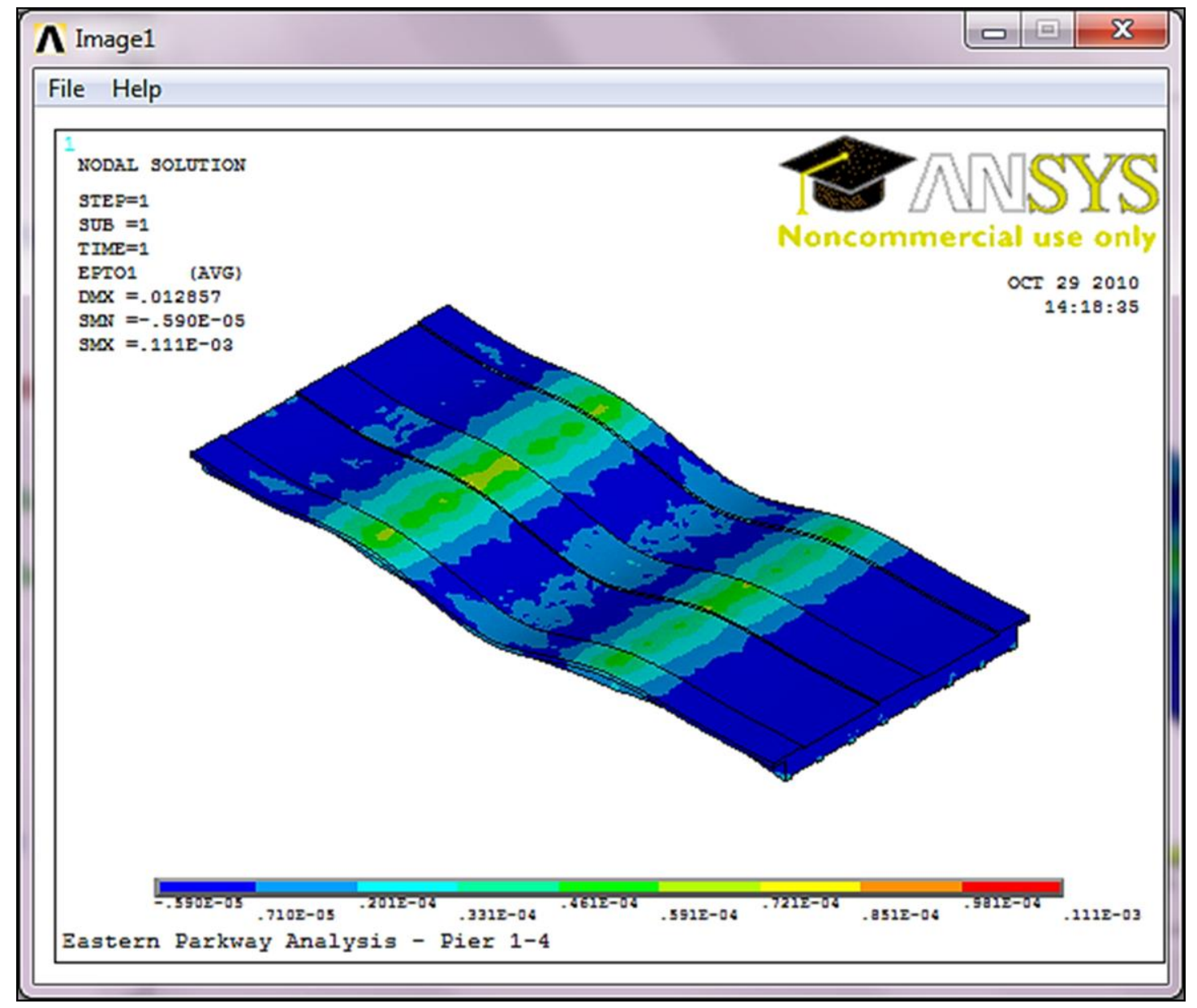

FIGURE 188 - First Principal Strain for Iteration Four 


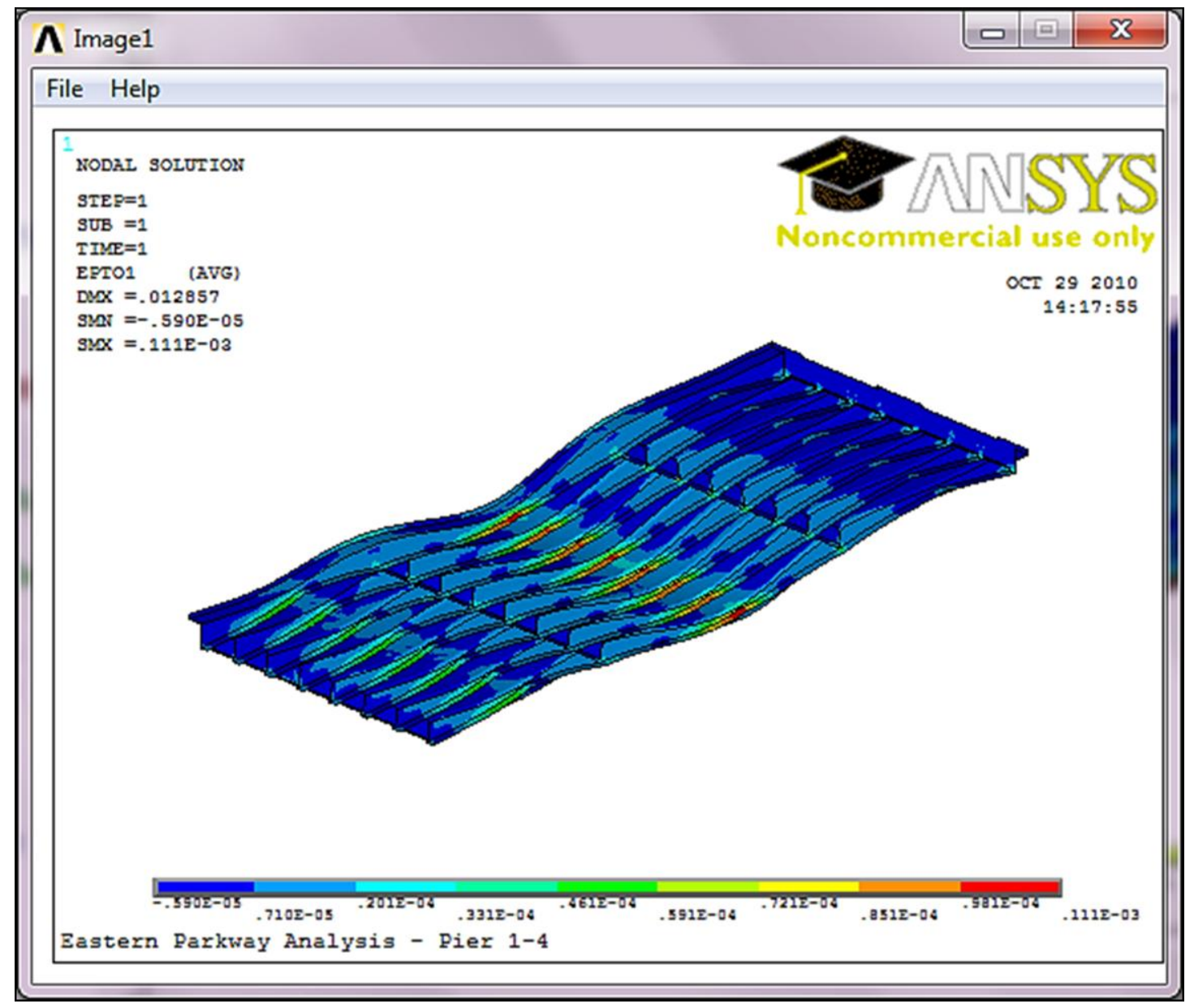

FIGURE 189 - First Principal Strain for Iteration Four As Viewed From Below 


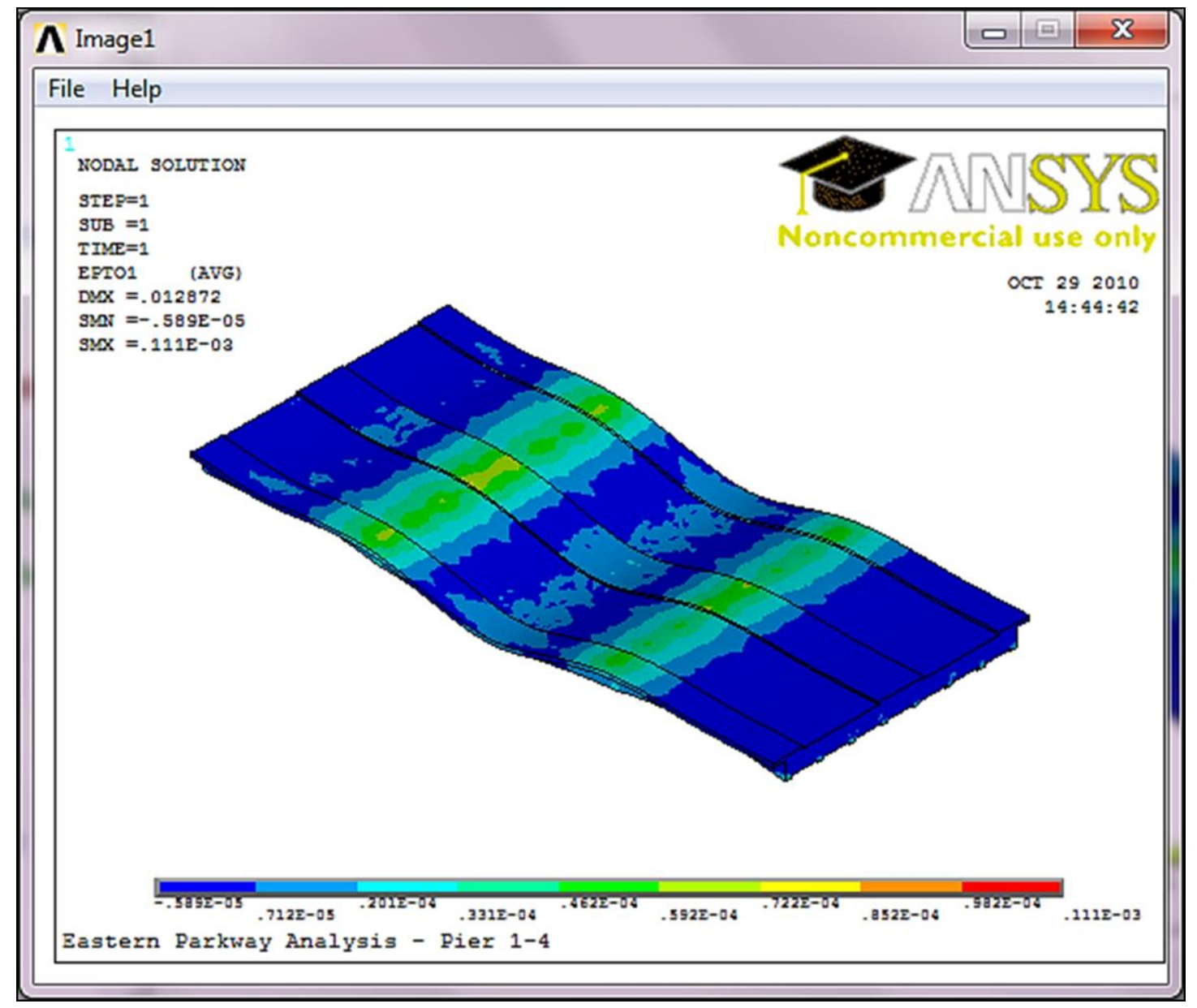

FIGURE 190 - First Principal Strain for Iteration Five 


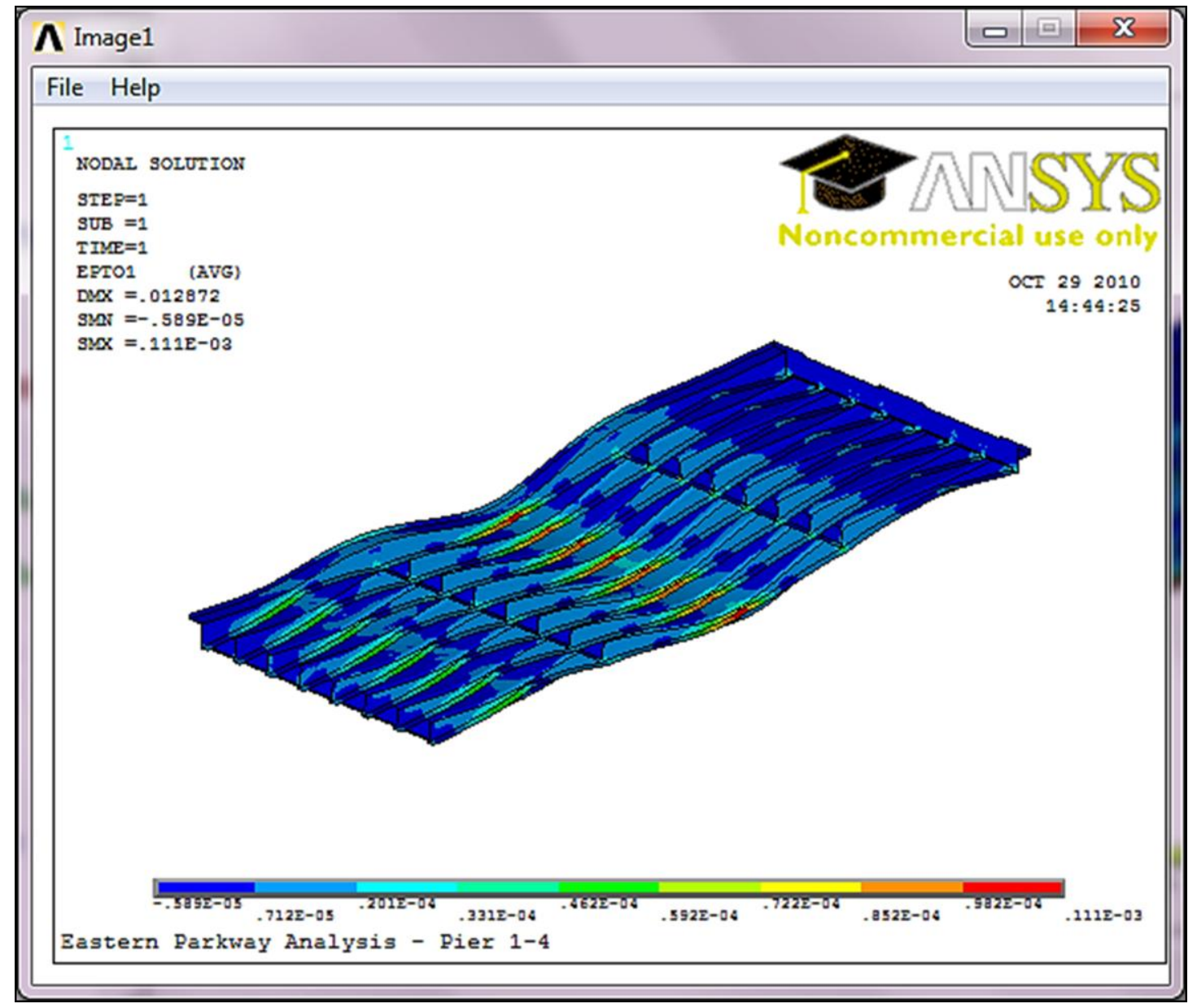

FIGURE 191 - First Principal Strain for Iteration Five As Viewed From Below 


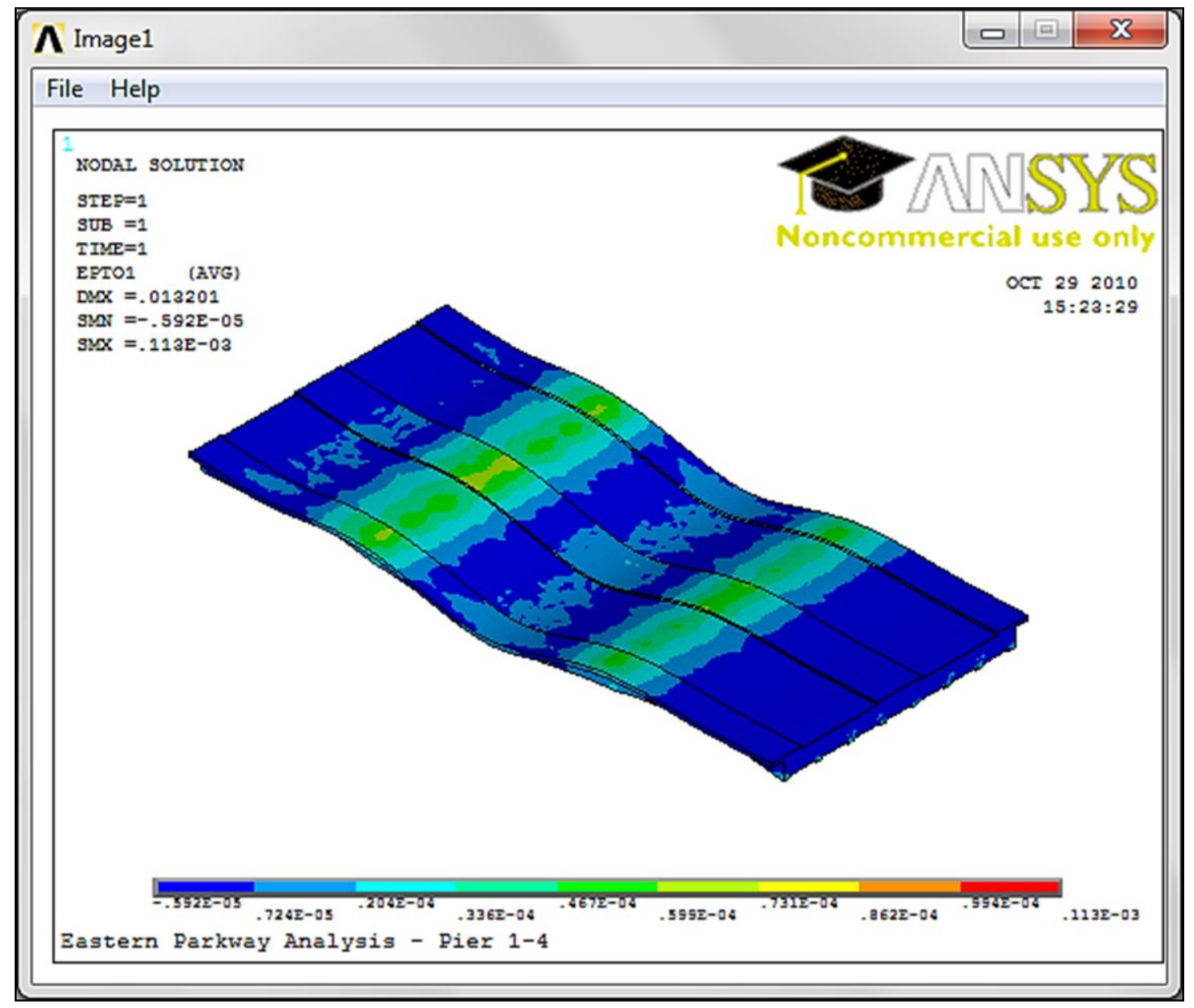

FIGURE 192 - First Principal Strain for Iteration Six 


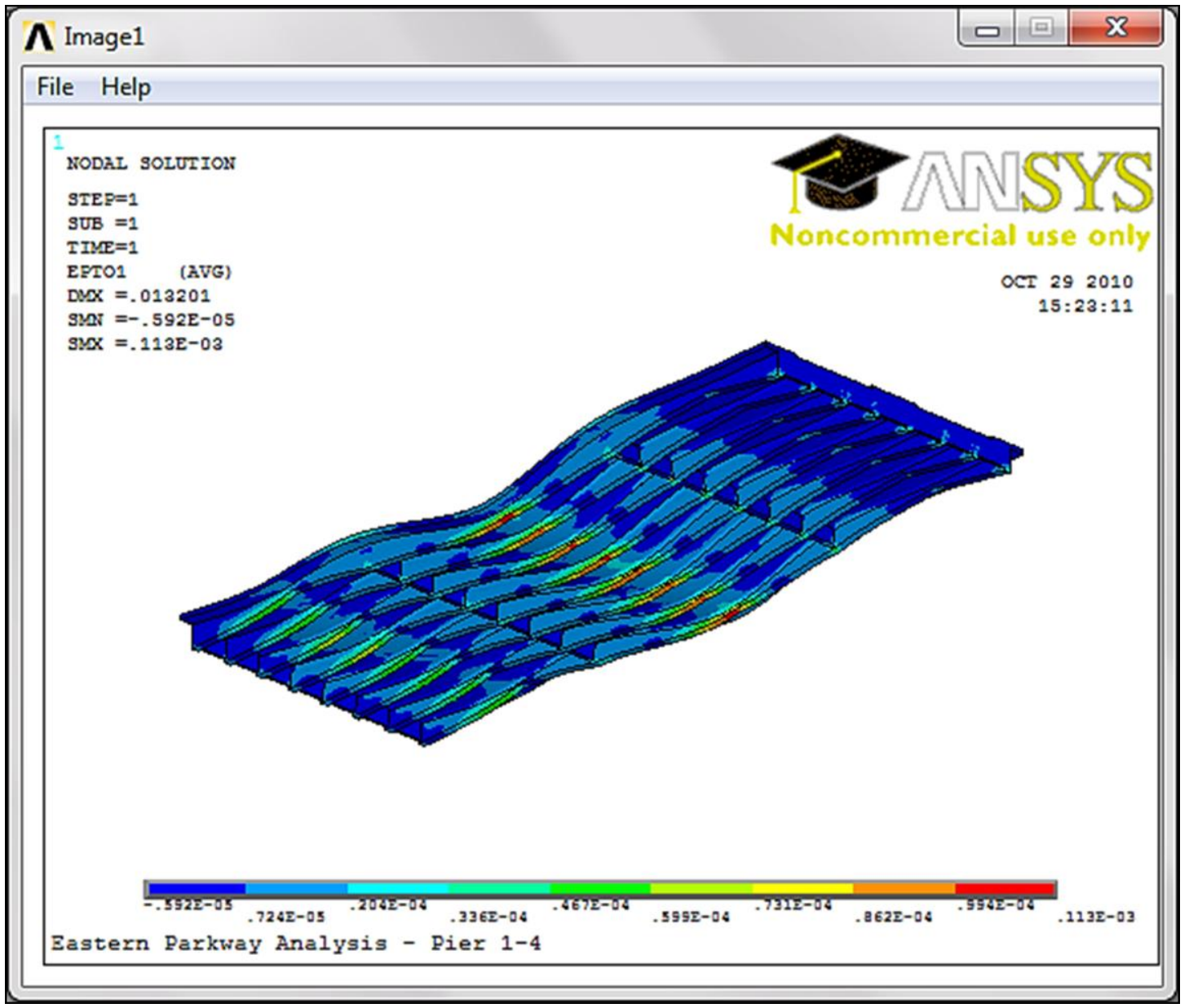

FIGURE 193 - First Principal Strain for Iteration Six As Viewed From Below 


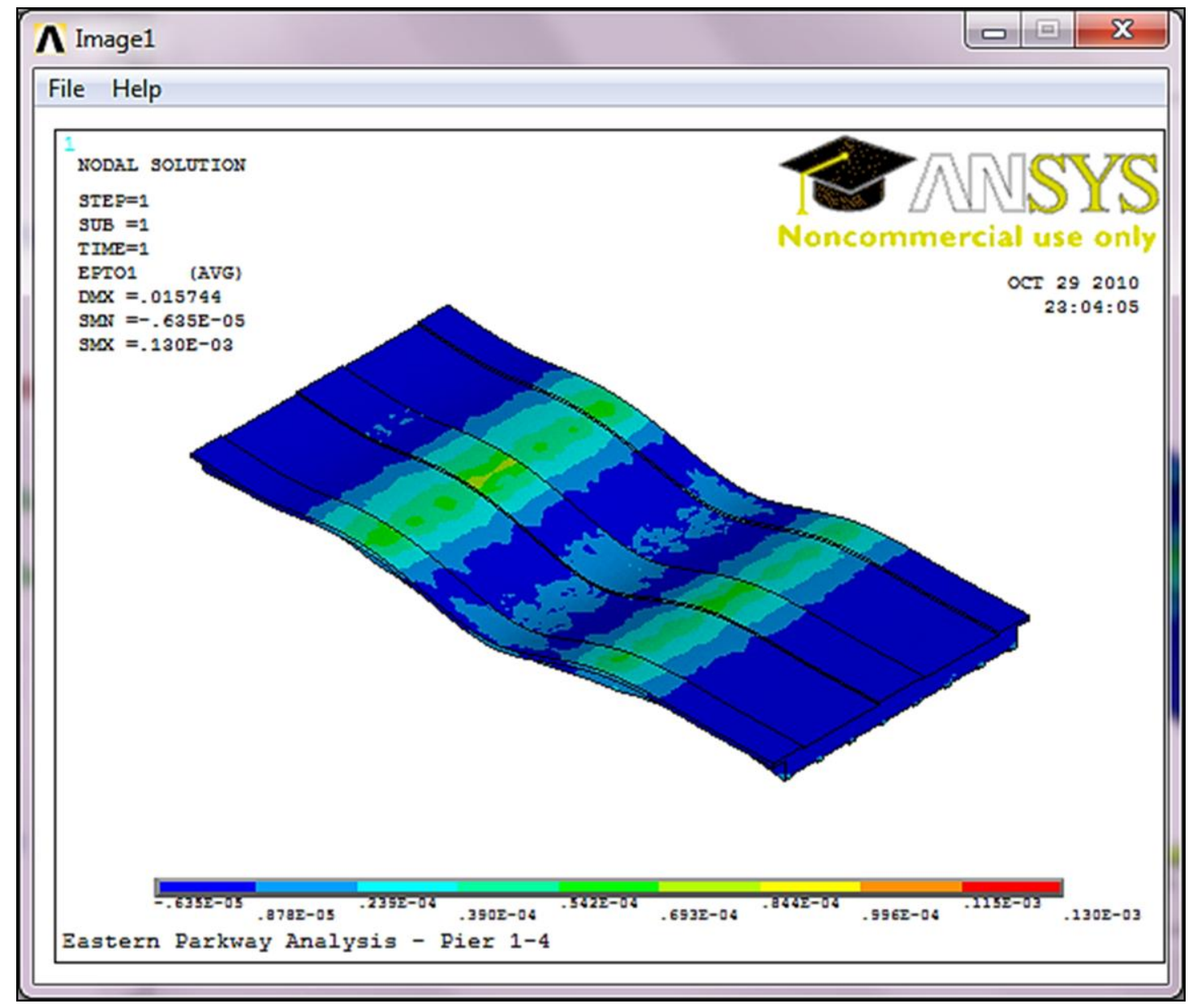

FIGURE 194 - First Principal Strain for Iteration Seven 


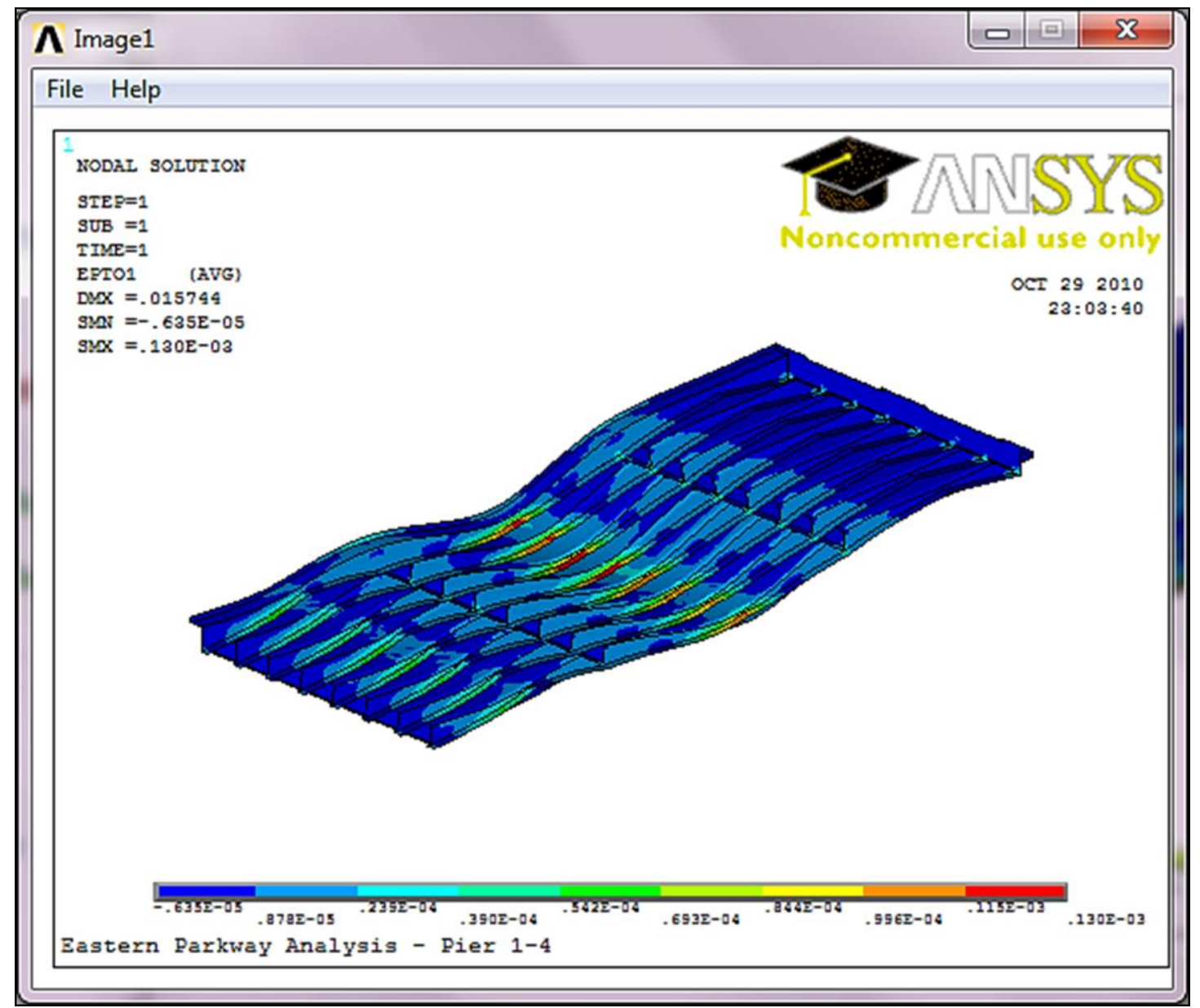

FIGURE 195 - First Principal Strain for Iteration Seven As Viewed From Below 


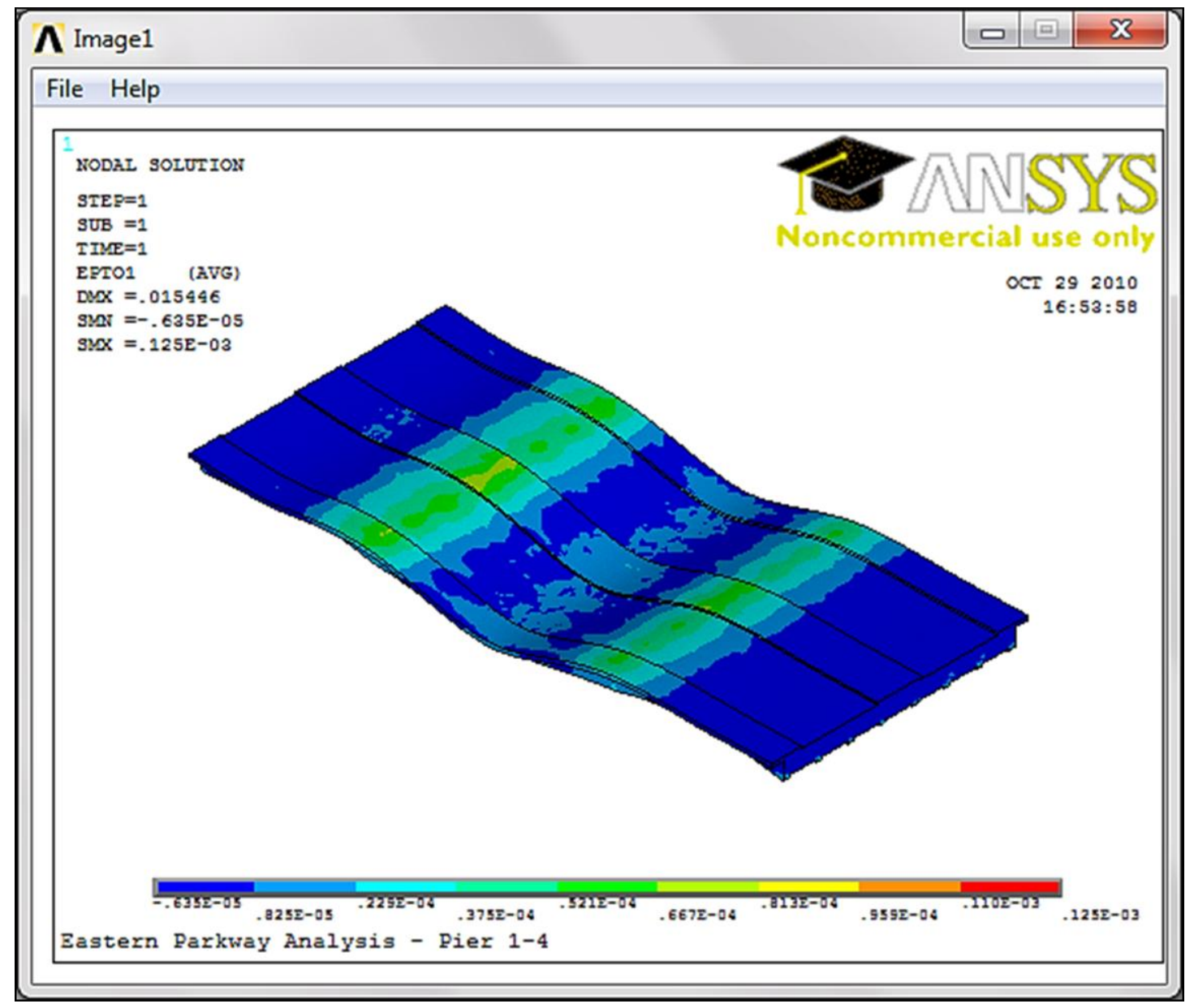

FIGURE 196 - First Principal Strain for Iteration Eight 


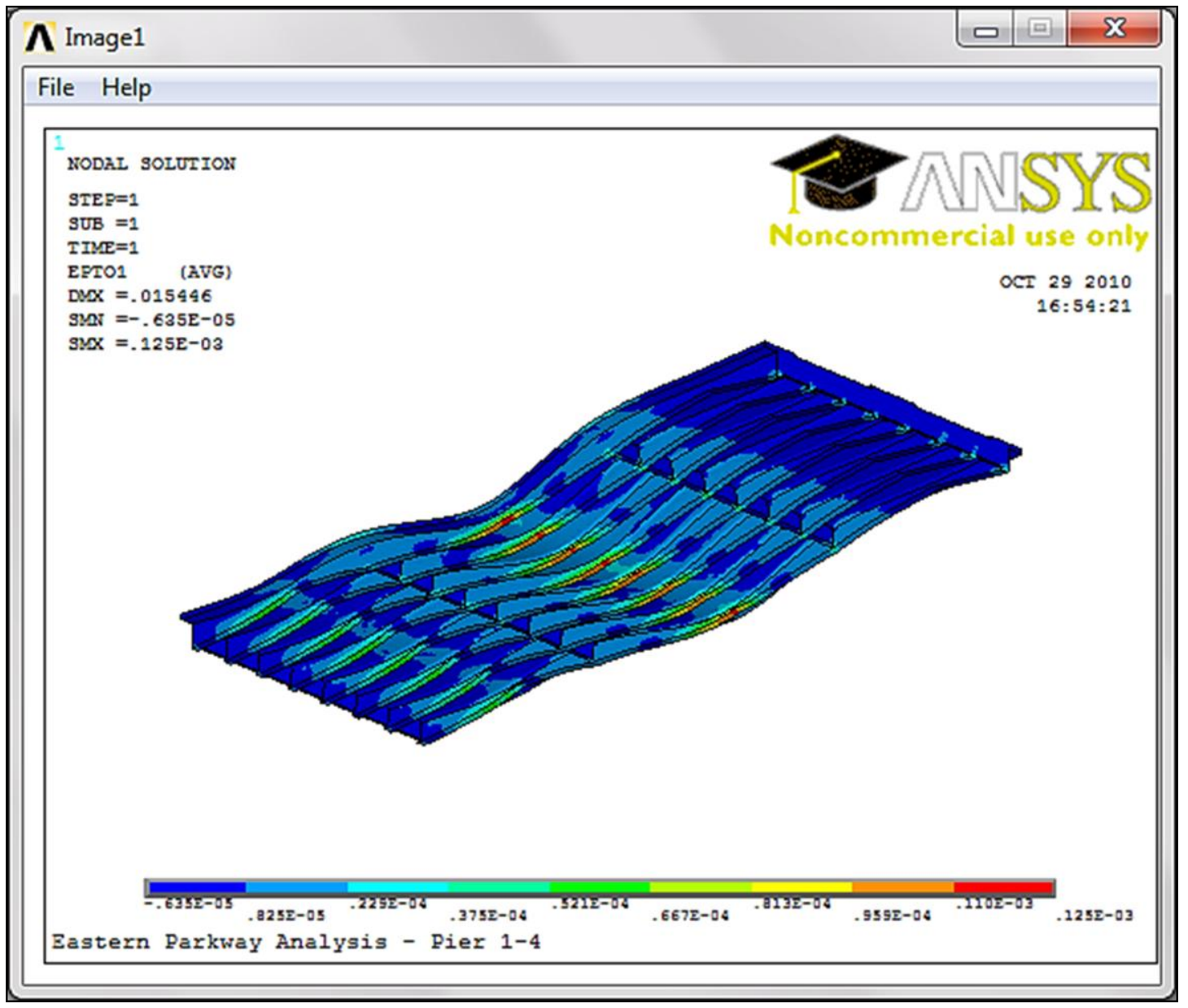

FIGURE 197 - First Principal Strain for Iteration Eight As Viewed From Below 


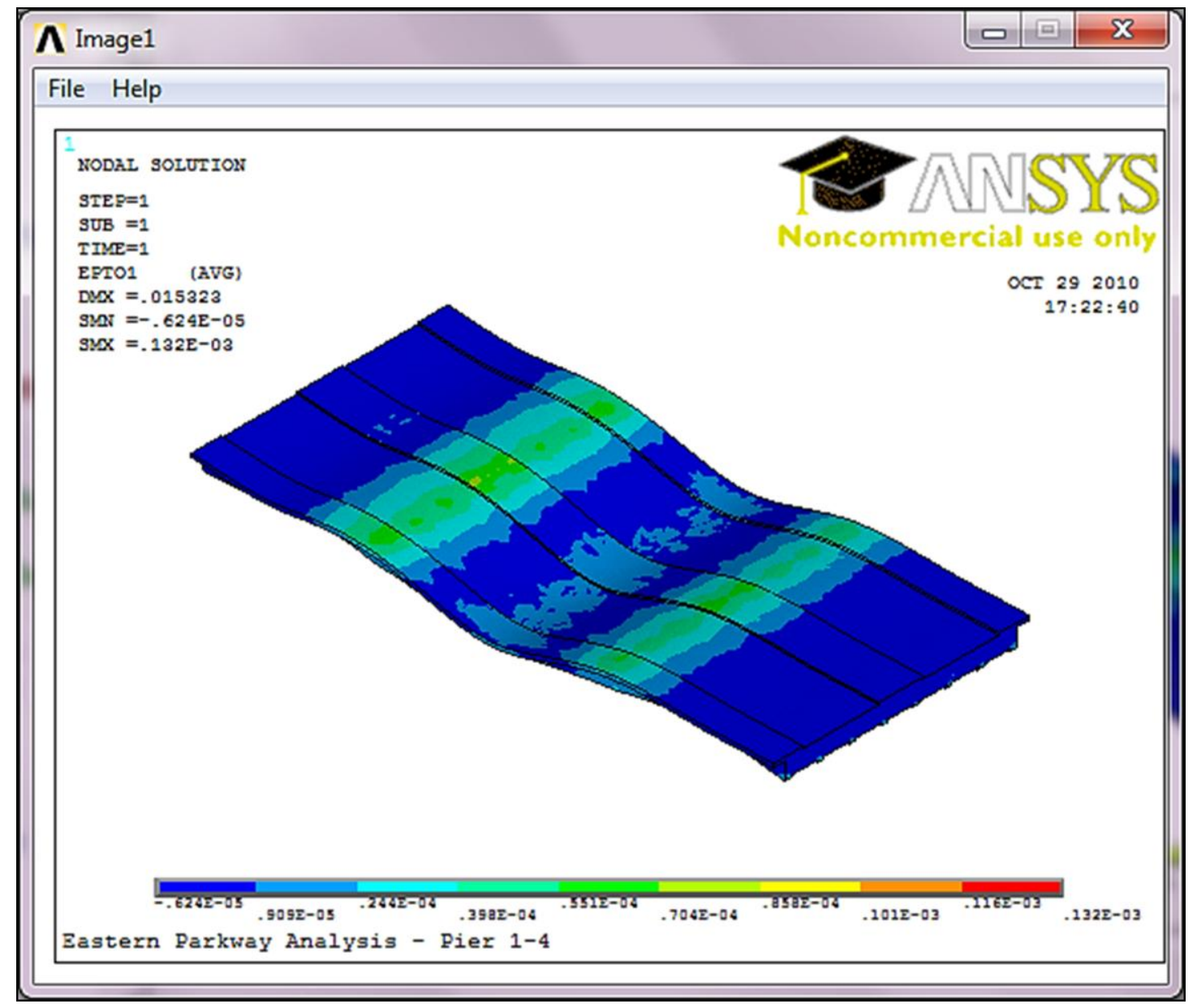

FIGURE 198 - First Principal Strain for Iteration Nine 


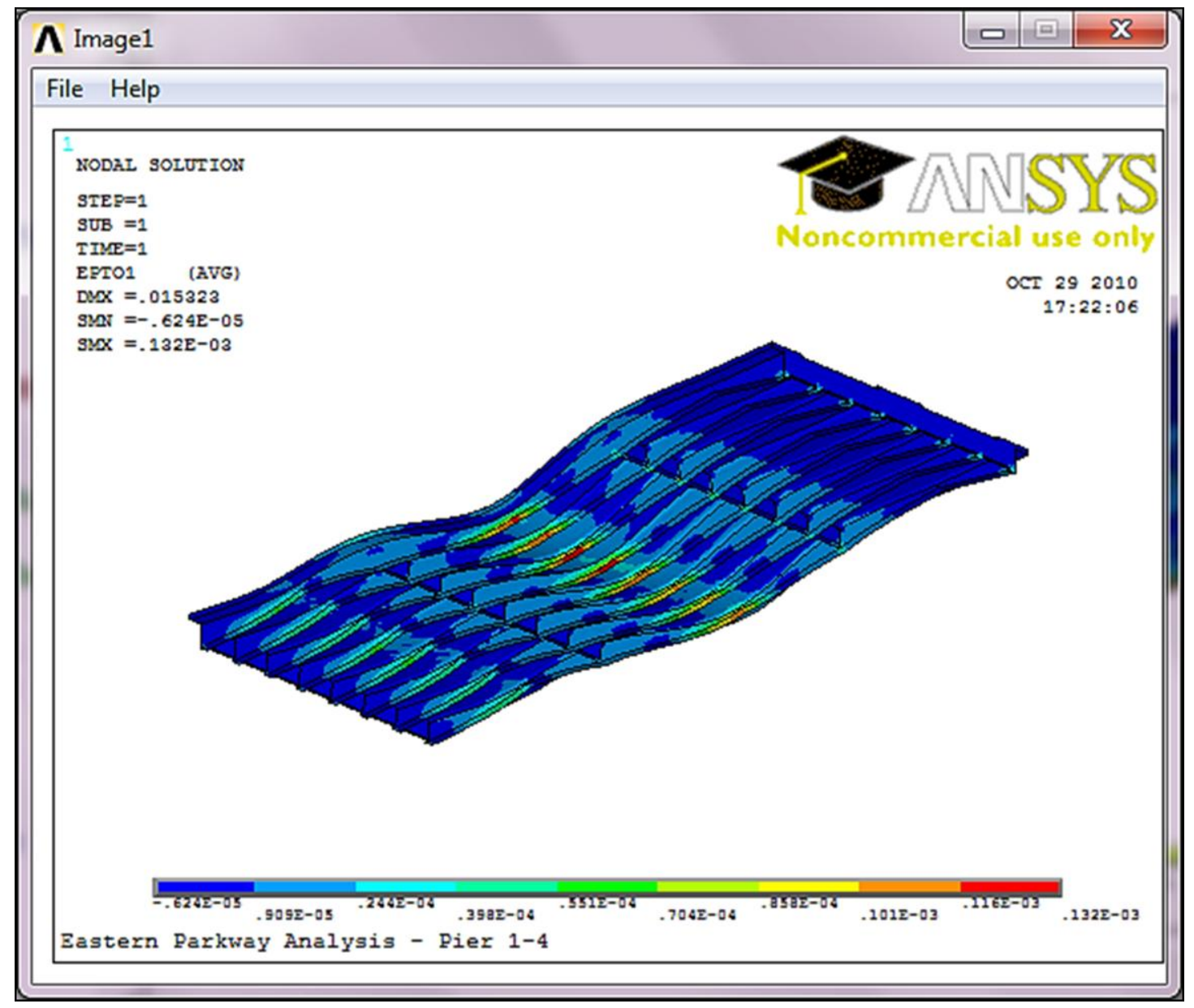

FIGURE 199 - First Principal Strain for Iteration Nine As Viewed From Below 


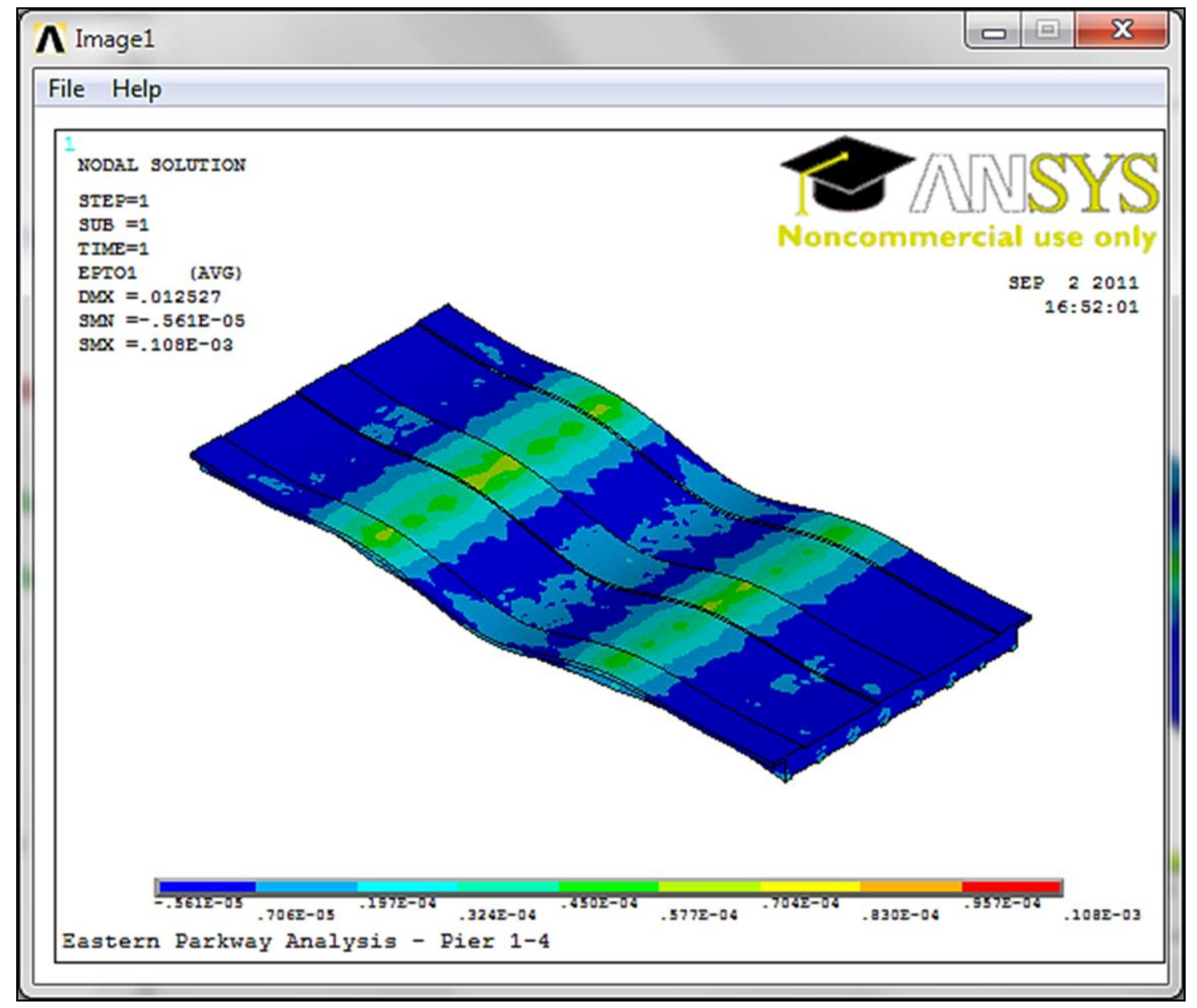

FIGURE 200 - First Principal Strain for Iteration 10 


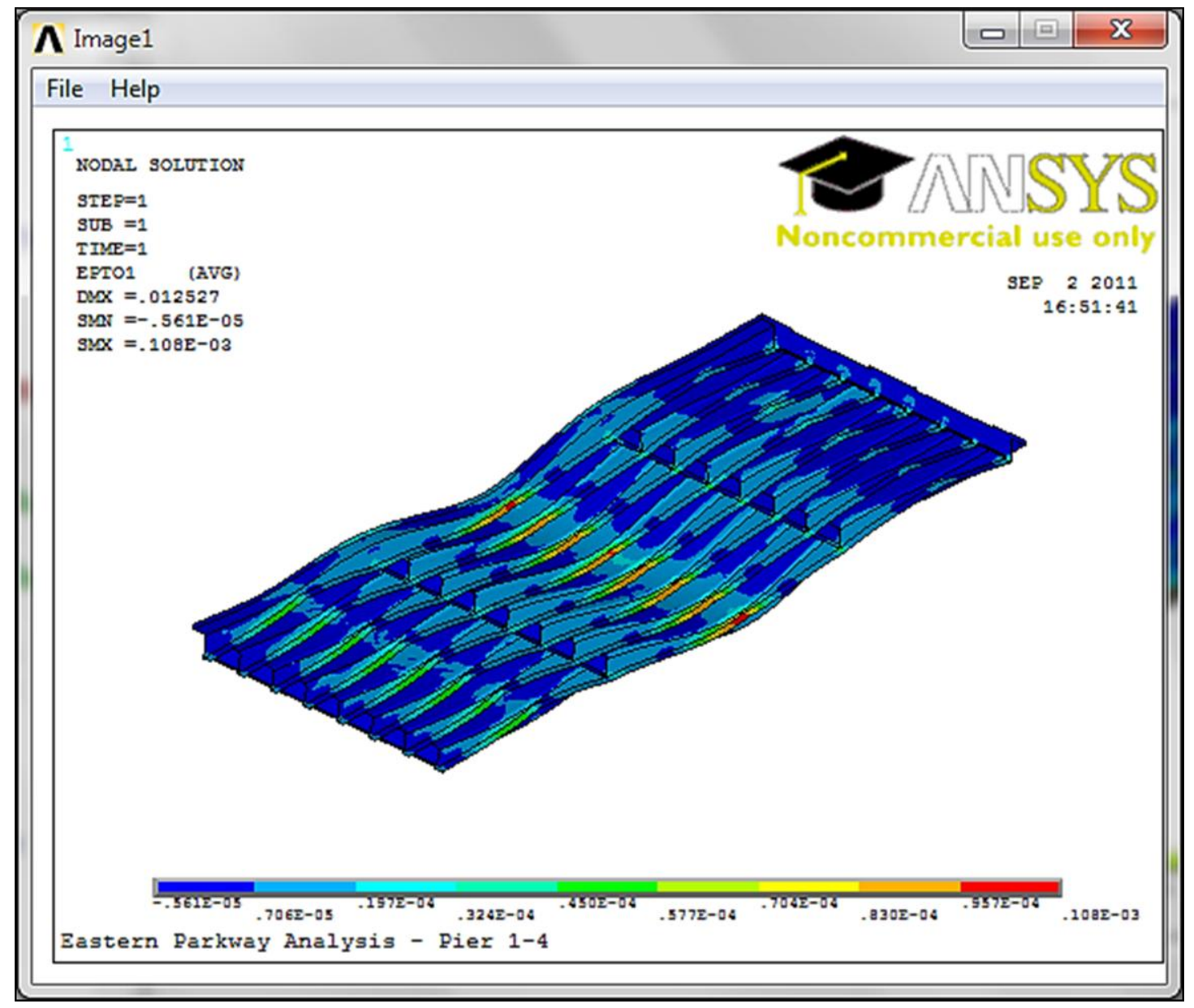

FIGURE 201 - First Principal Strain for Iteration 10 As Viewed From Below 


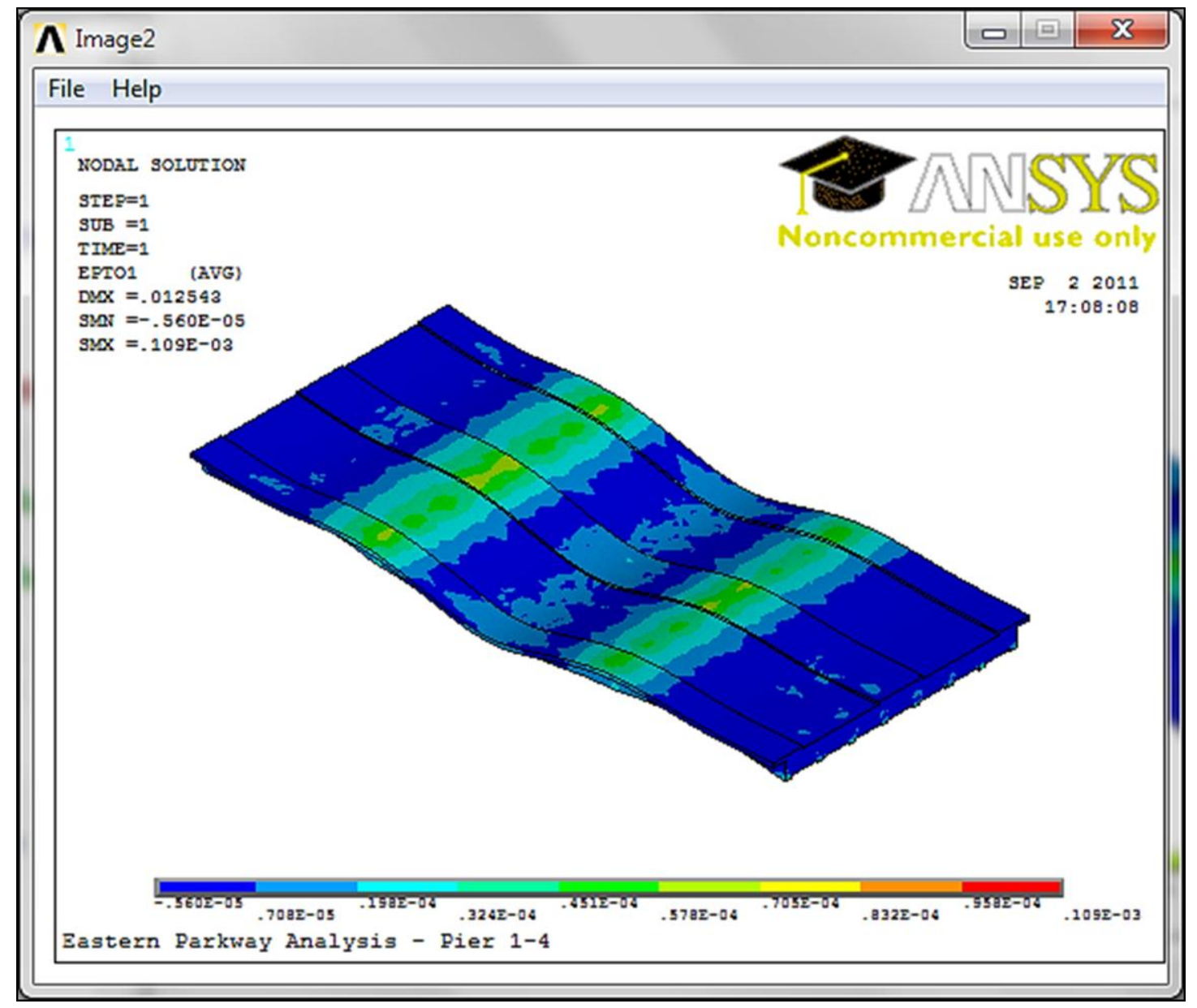

FIGURE 202 - First Principal Strain for Iteration 11 


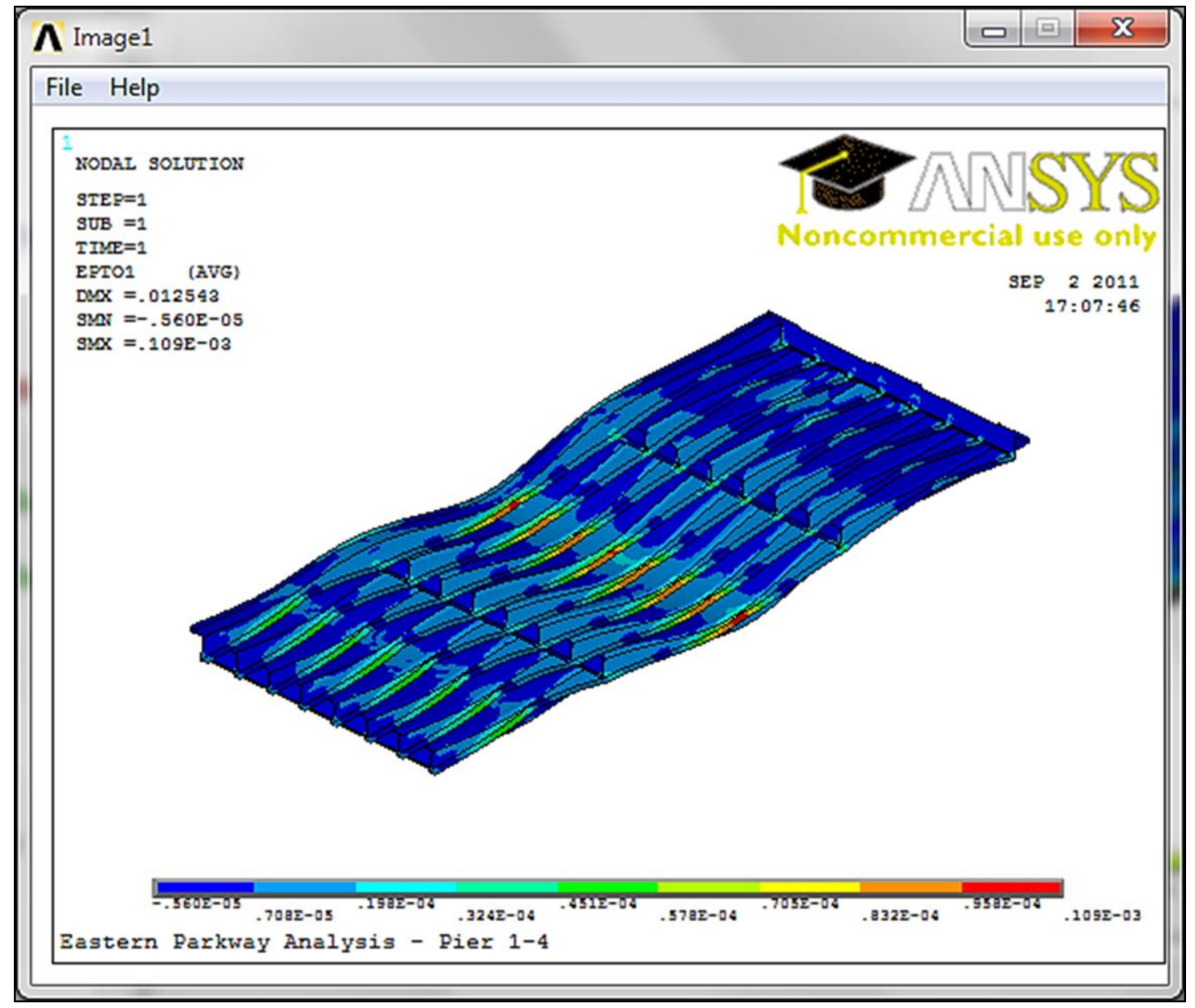

FIGURE 203 - First Principal Strain for Iteration 11 As Viewed From Below 


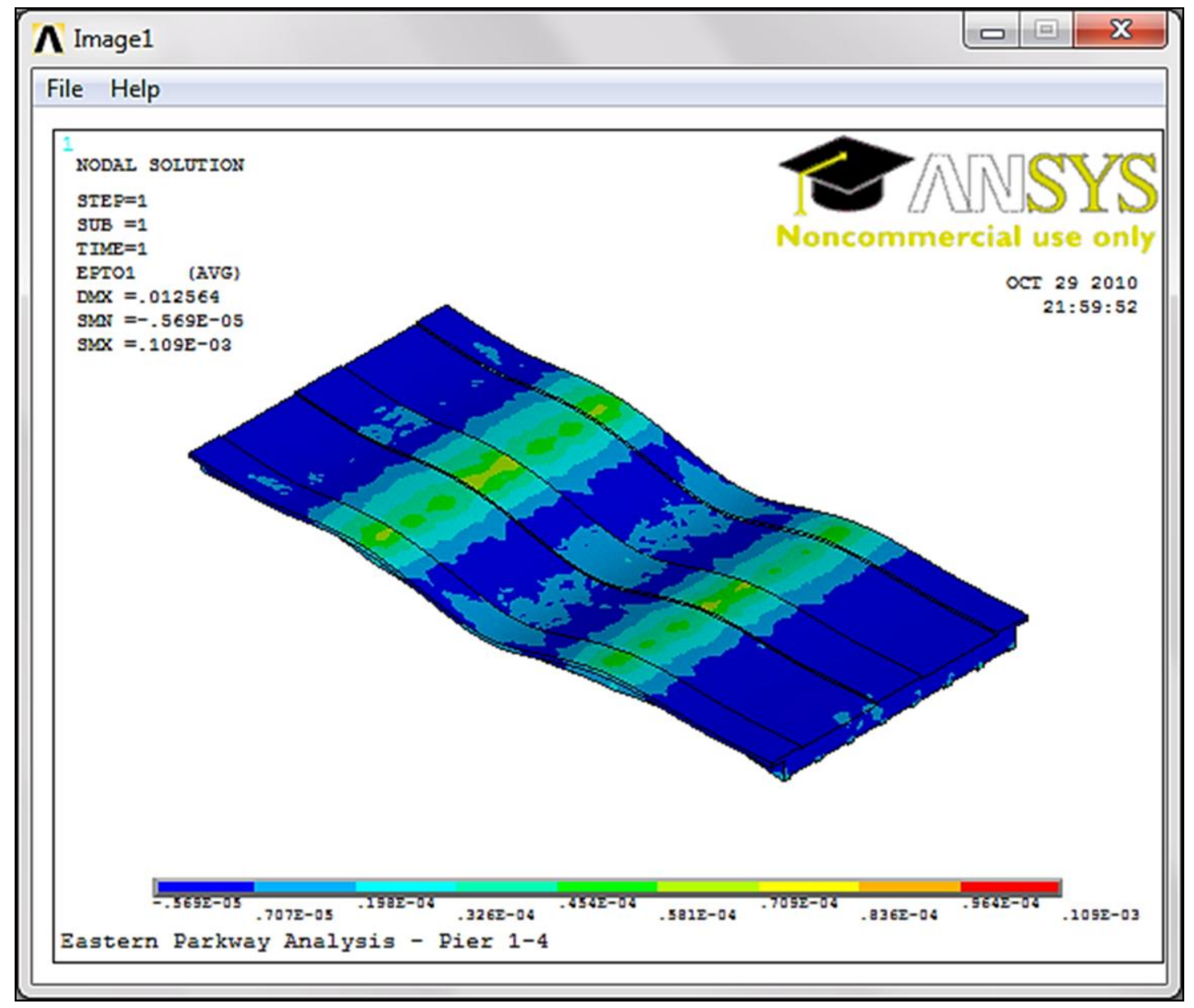

FIGURE 204 - First Principal Strain for Iteration 12 


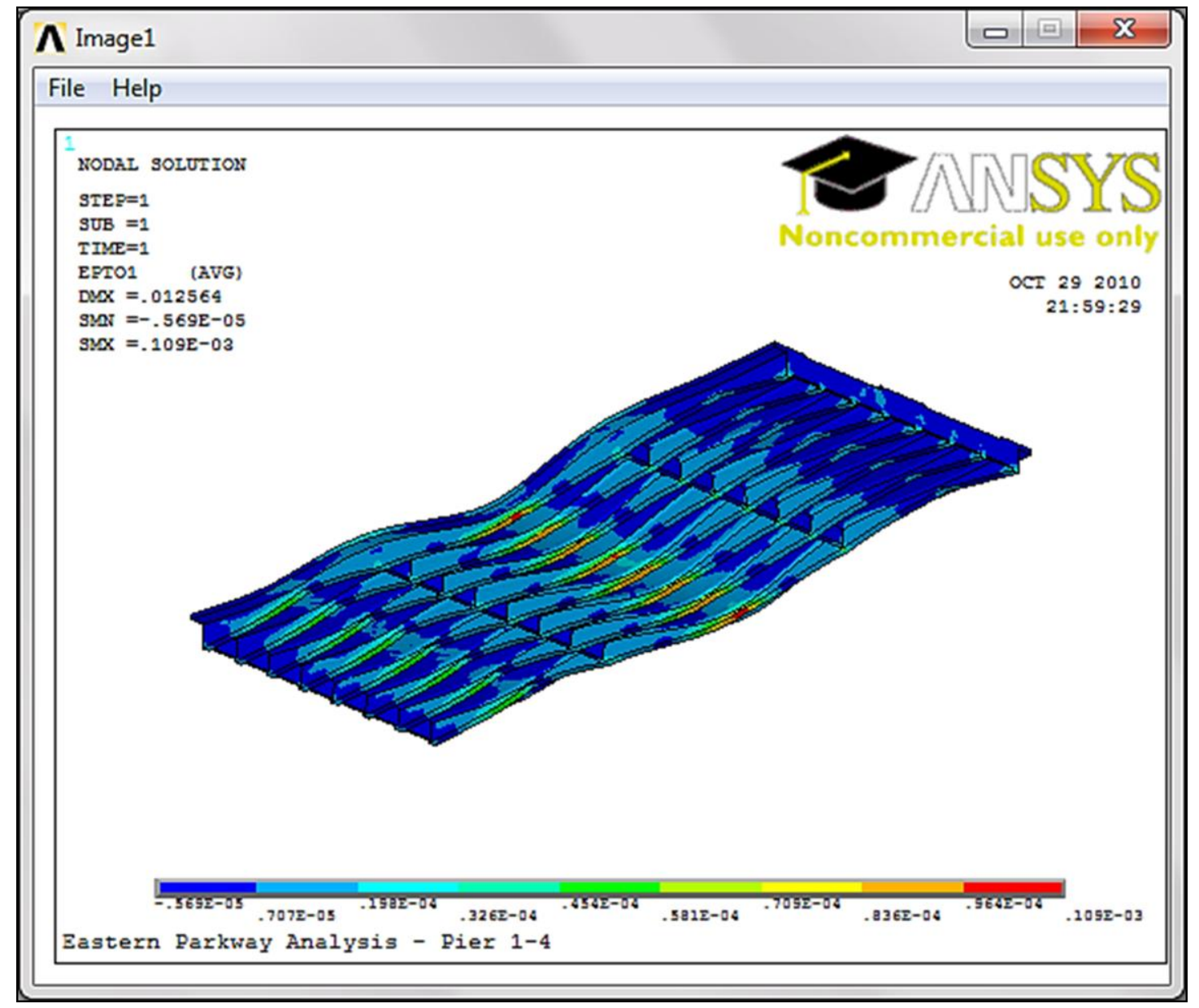

FIGURE 205 - First Principal Strain for Iteration 12 As Viewed From Below 


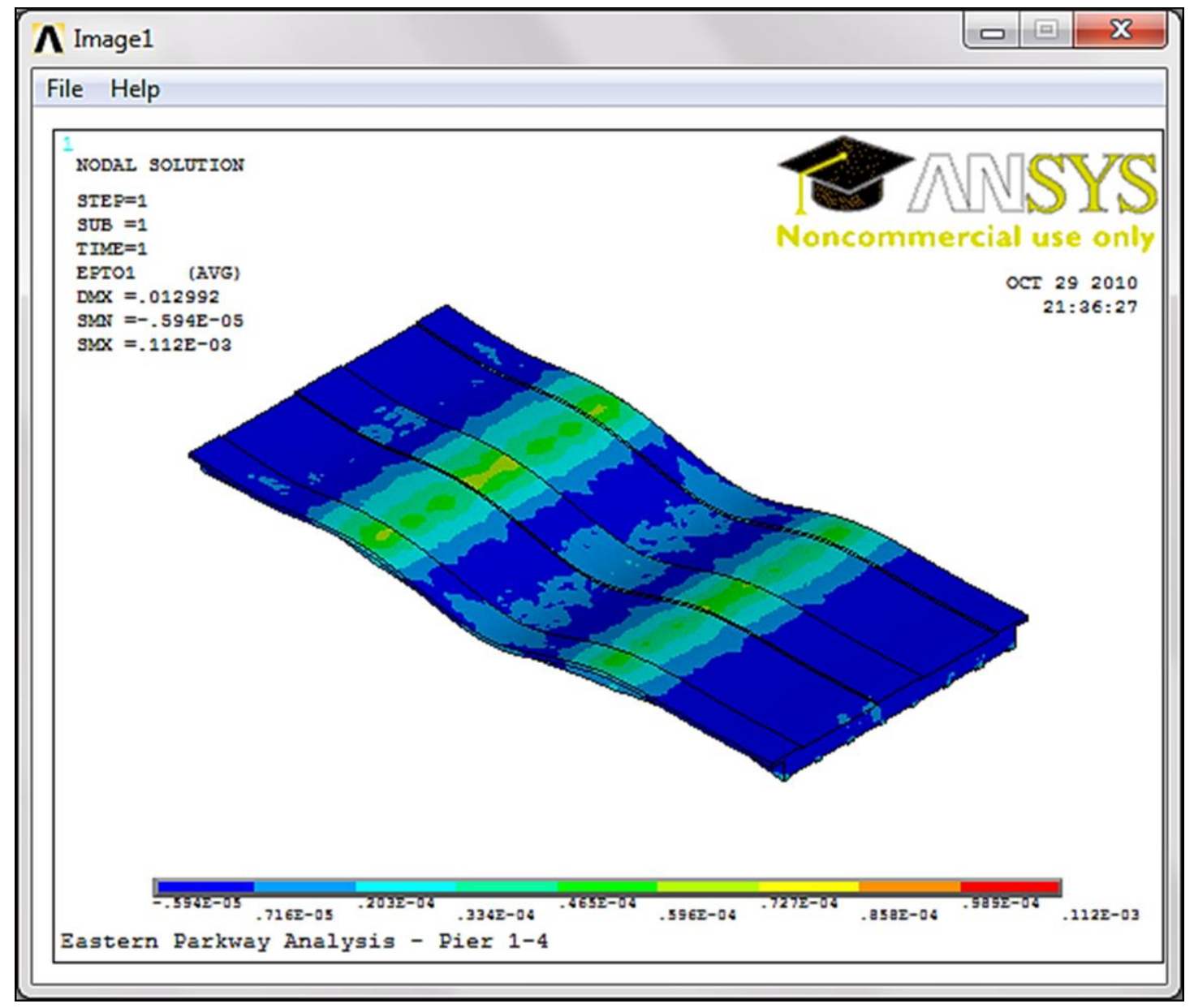

FIGURE 206 - First Principal Strain for Iteration 13 


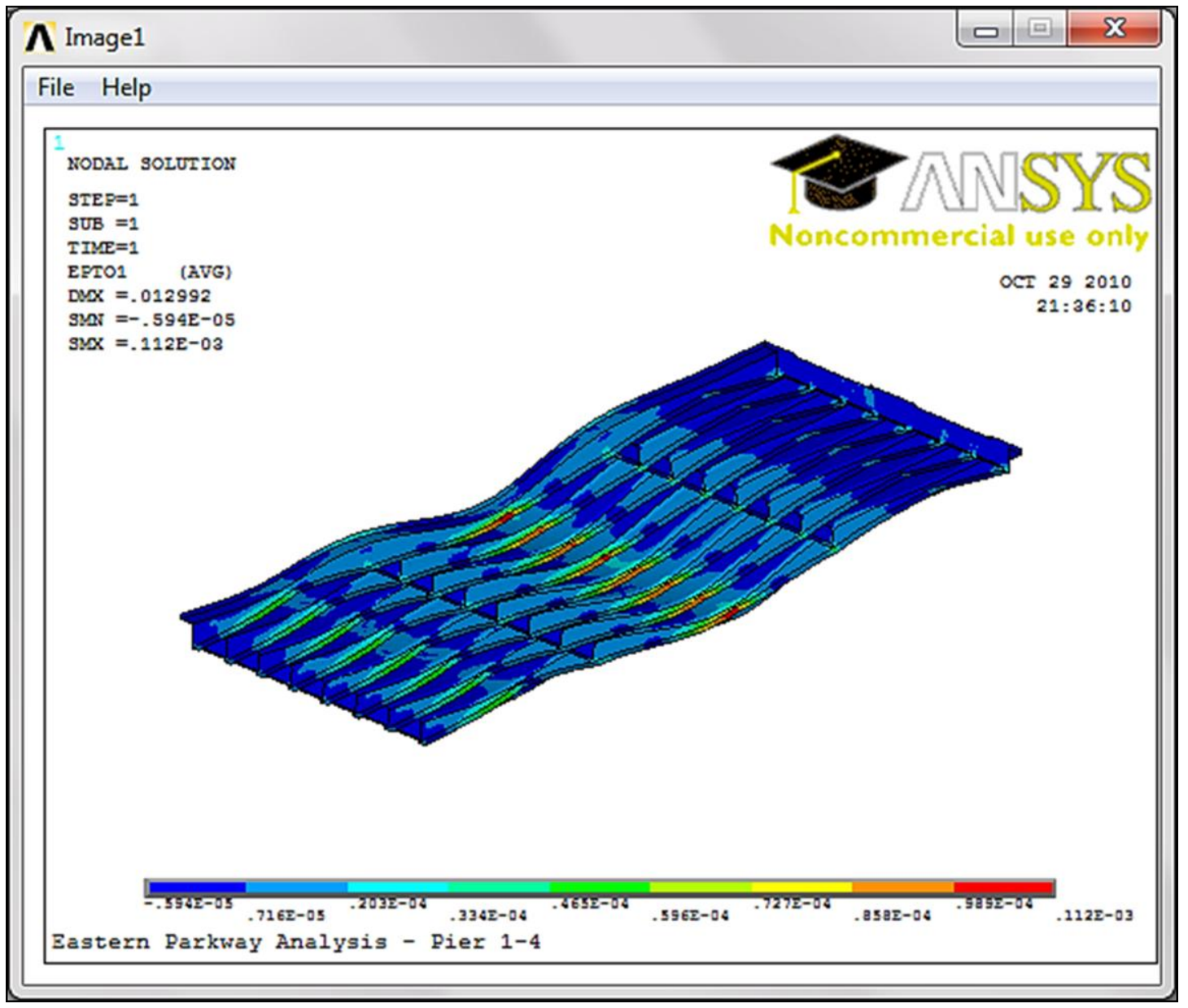

FIGURE 207 - First Principal Strain for Iteration 13 As Viewed From Below 
APPENDIX XIII

OTHER MODAL ANALYSIS METHODS

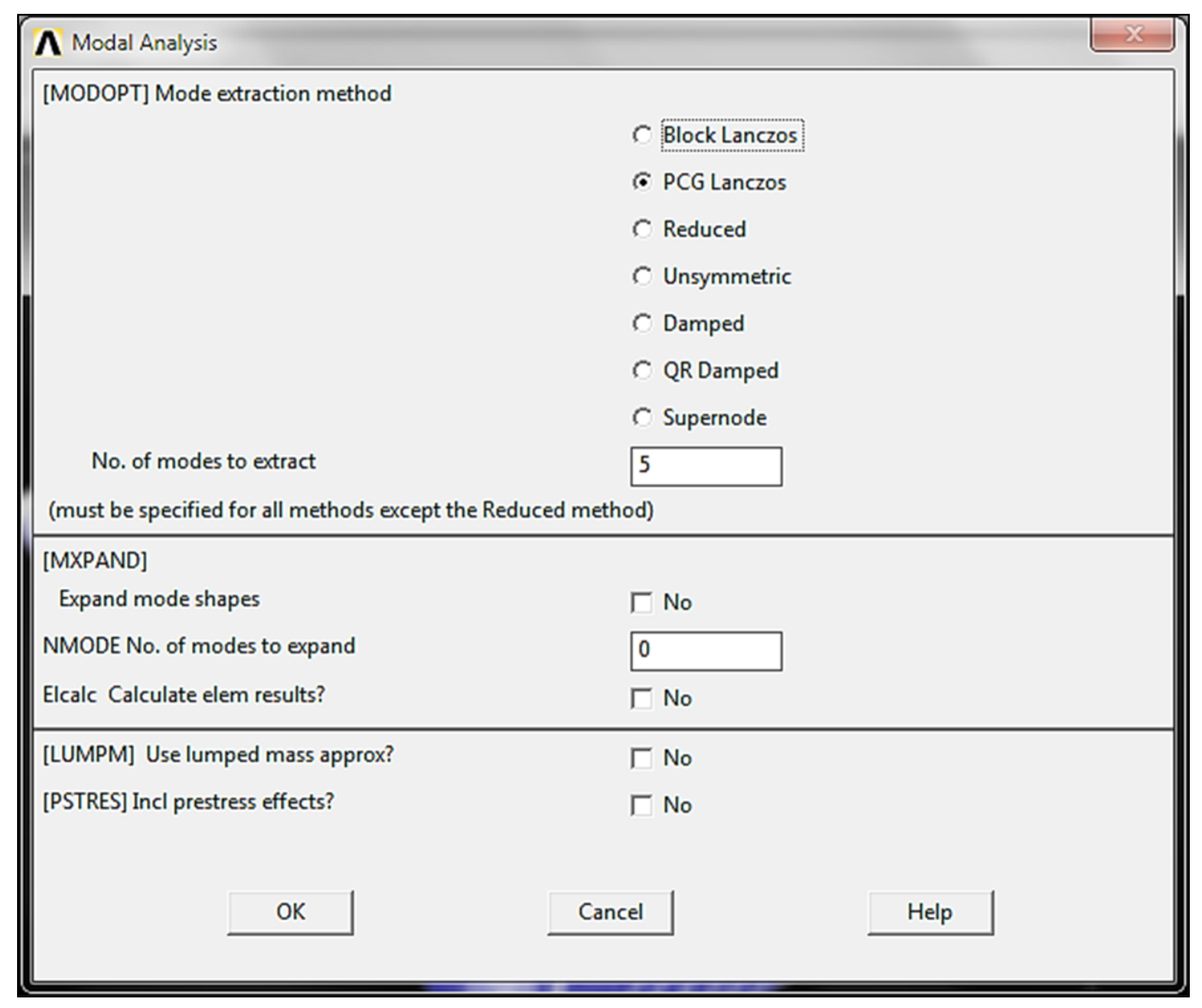

FIGURE 208 - First Page of Settings for PCG Lanczos Modal Analysis As Entered in ANSYS 


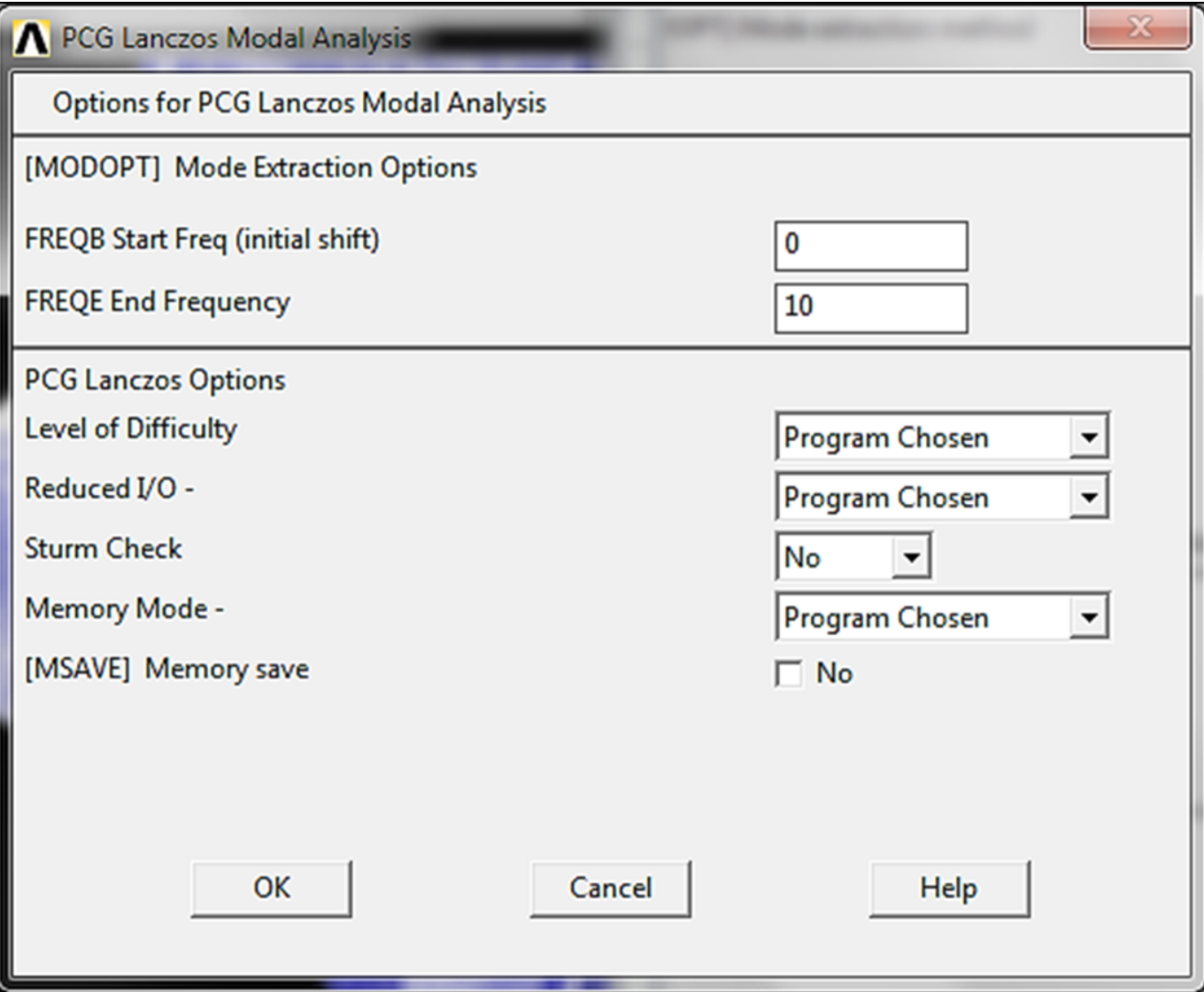

FIGURE 209 - Second Page of Settings for PCG Lanczos Modal Analysis As Entered in ANSYS 


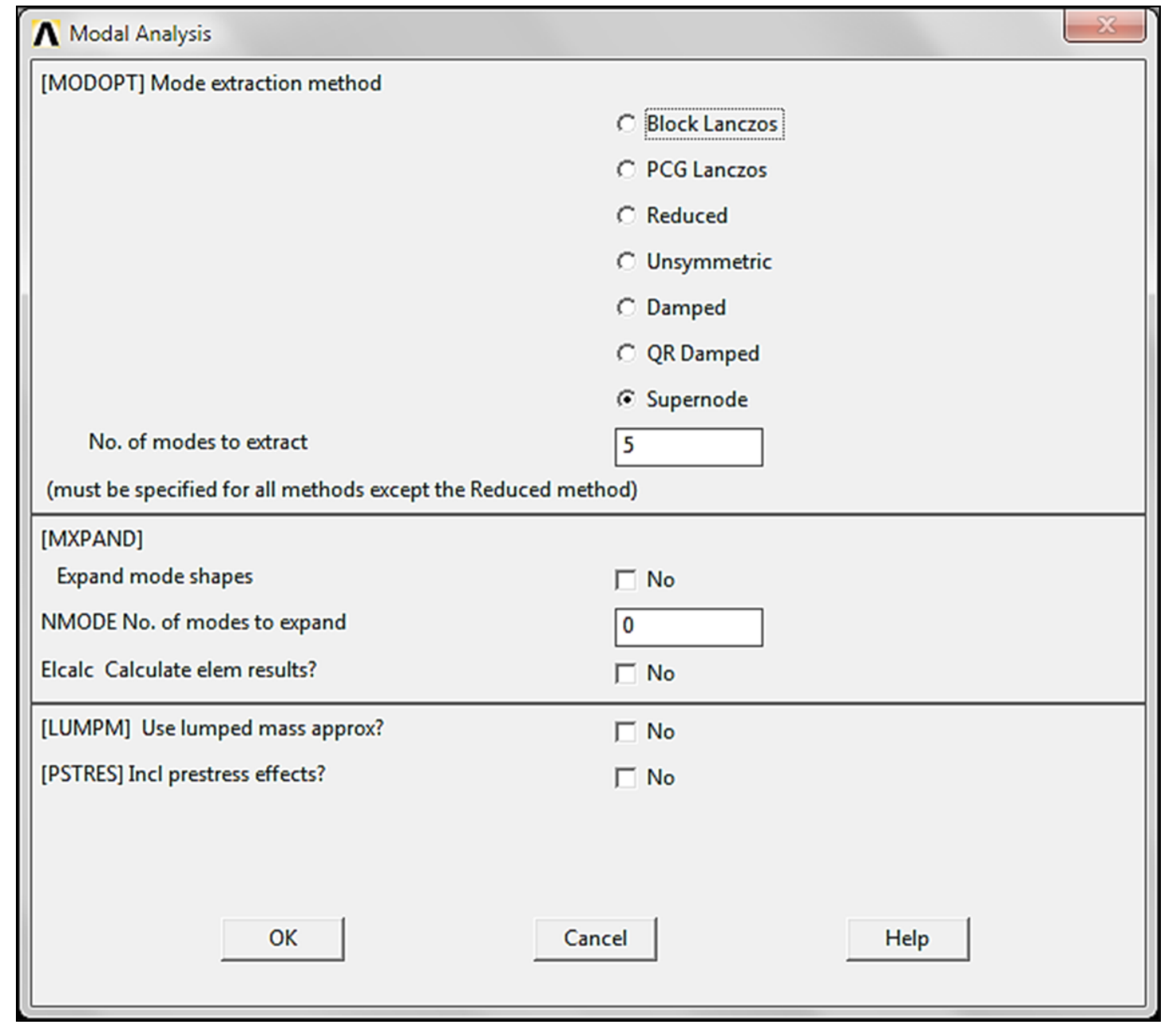

FIGURE 210 - First Page of Settings for Supernode Modal Analysis As Entered in ANSYS 


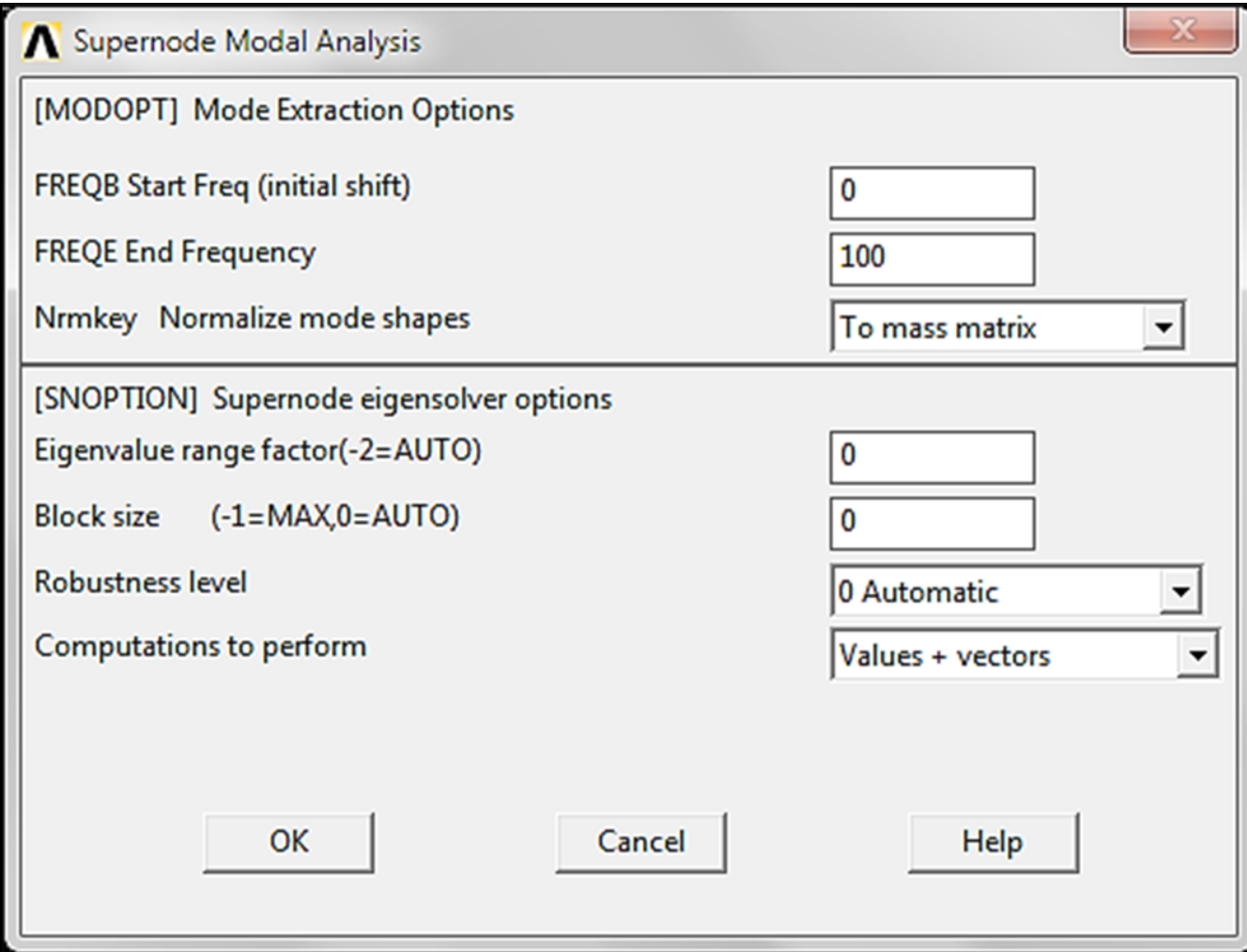

FIGURE 211 - Second Page of Settings for Supernode Modal Analysis As Entered in ANSYS 
APPENDIX XIV

SCREEN CAPTURES OF MODAL ANALYSIS RESULTS

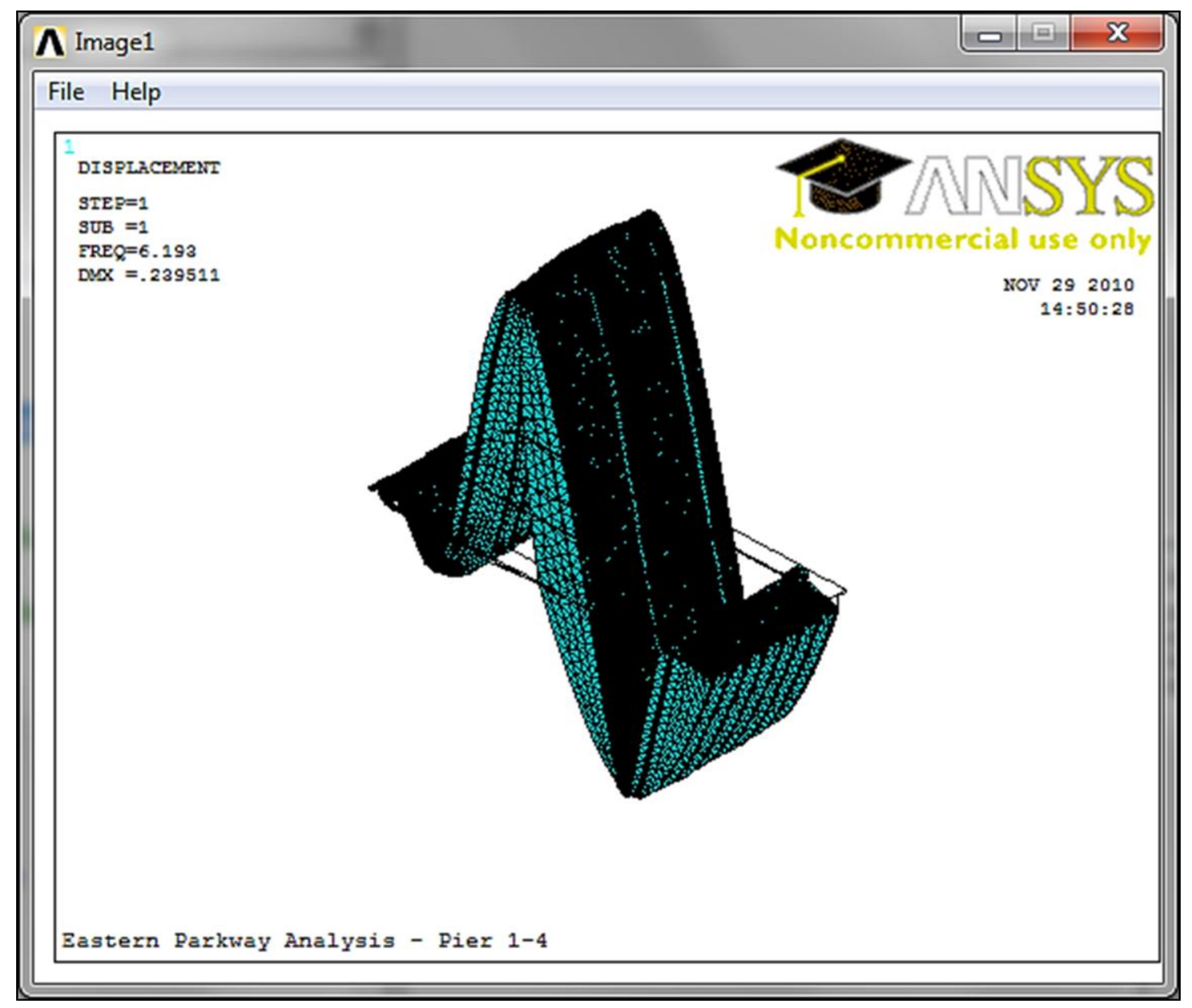

FIGURE 212 - First Mode Shape As Calculated by the Block Lanczos and PCG Lanczos Modal Analysis Methods 


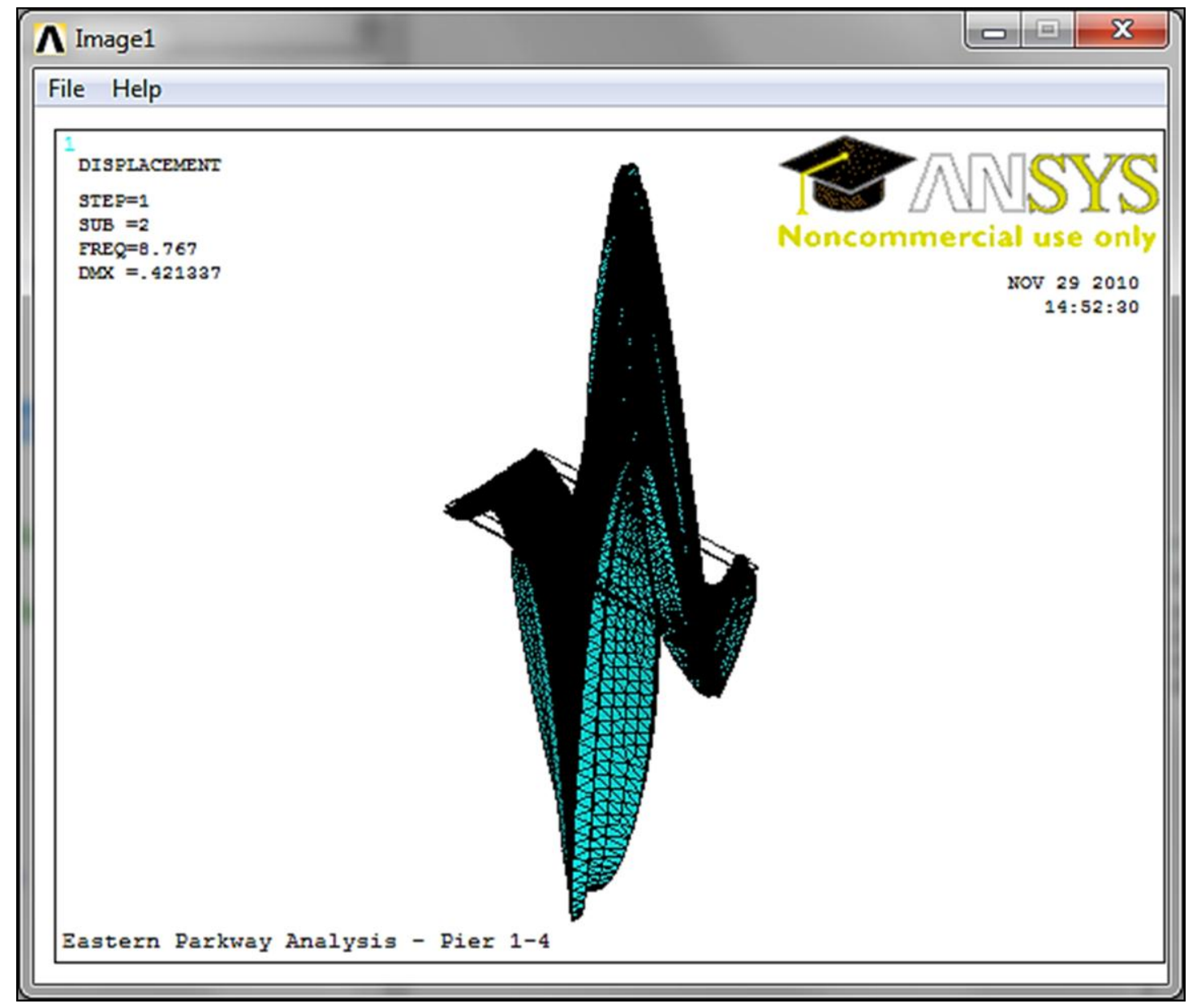

FIGURE 213 - Second Mode Shape As Calculated by the Block Lanczos and PCG Lanczos Modal Analysis Methods 


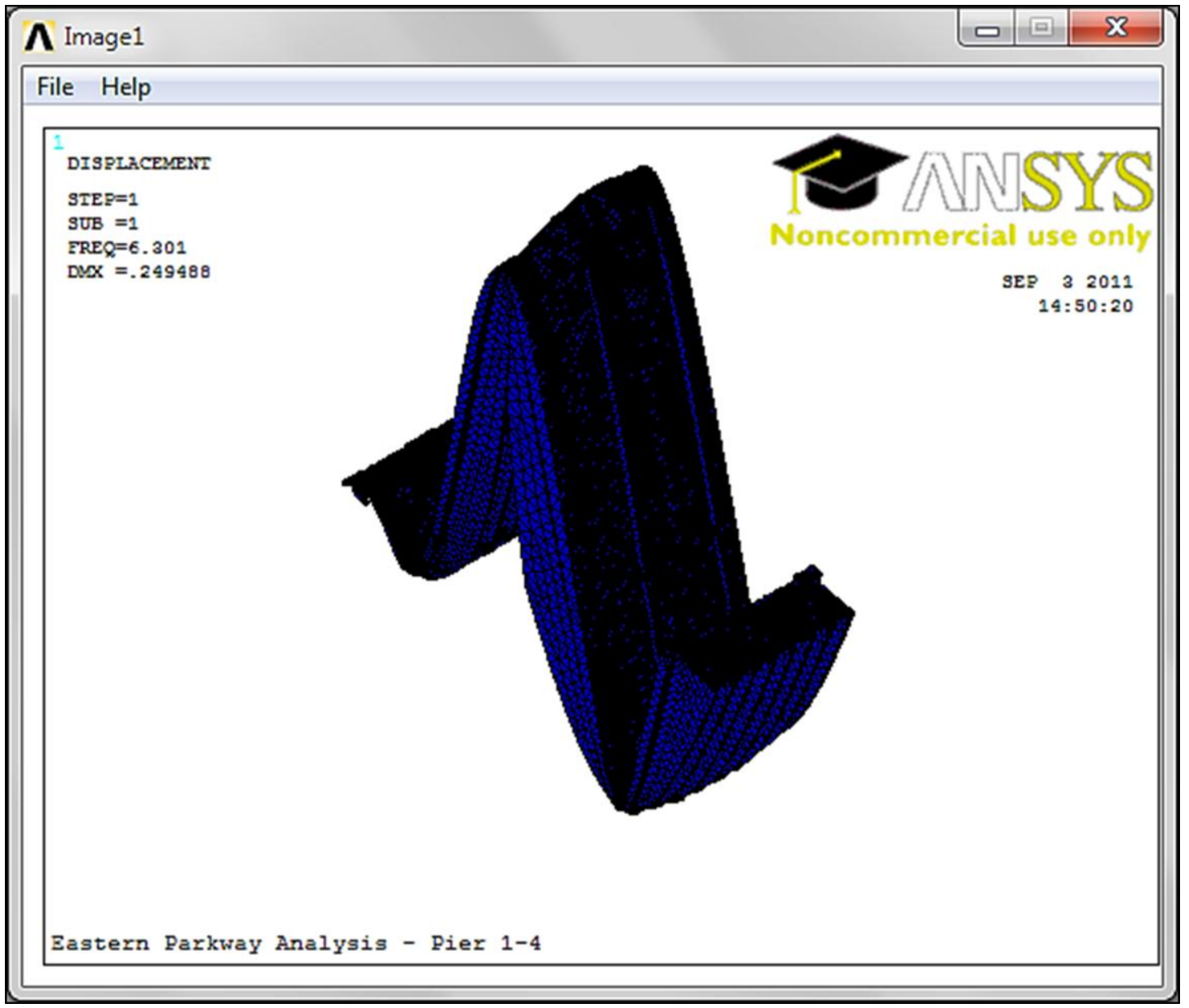

FIGURE 214 - First Mode Shape As Calculated by the Supernode Modal Analysis Method 


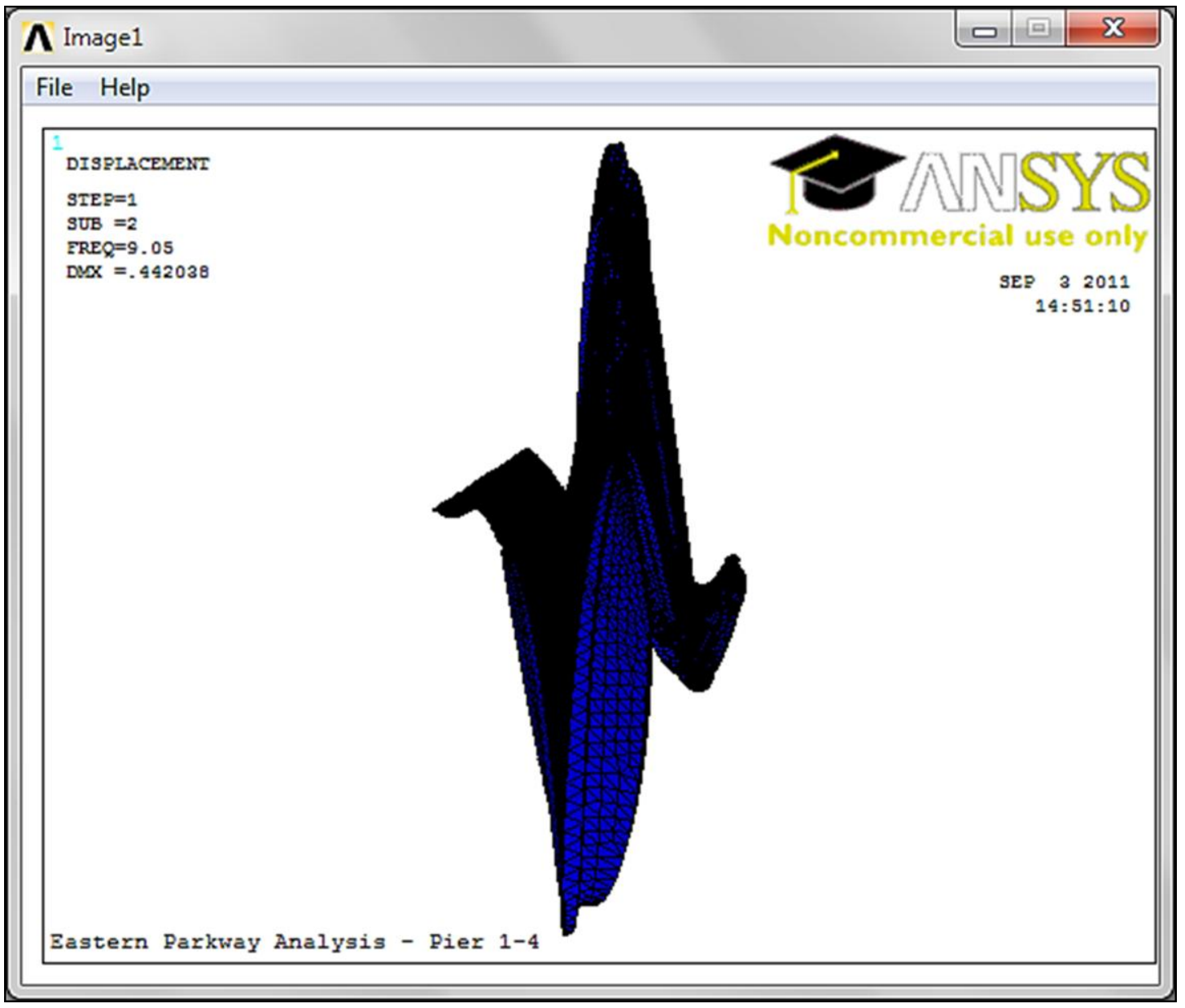

FIGURE 215 - Second Mode Shape As Calculated by the Supernode Modal Analysis Method 
VITA

Christina Allgeier Perez completed her Bachelors of Engineering degree in Civil Engineering in May 2010 at the University of Louisville. She continued on to the Masters of Engineering program at the University of Louisville upon graduation and will be earning her degree in December 2011. While completing the thesis requirements, she continued her education in the School of Business at the University of Nevada - Las Vegas. 